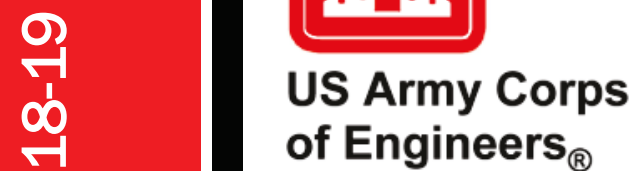

of Engineers ${ }_{\circledast}$

Engineer Research and

Development Center

Environmental Security Technology Certification Program (ESTCP)

\title{
High Efficiency Dehumidification System
}

Scot M. Duncan and Dahtzen Chu

August 2018

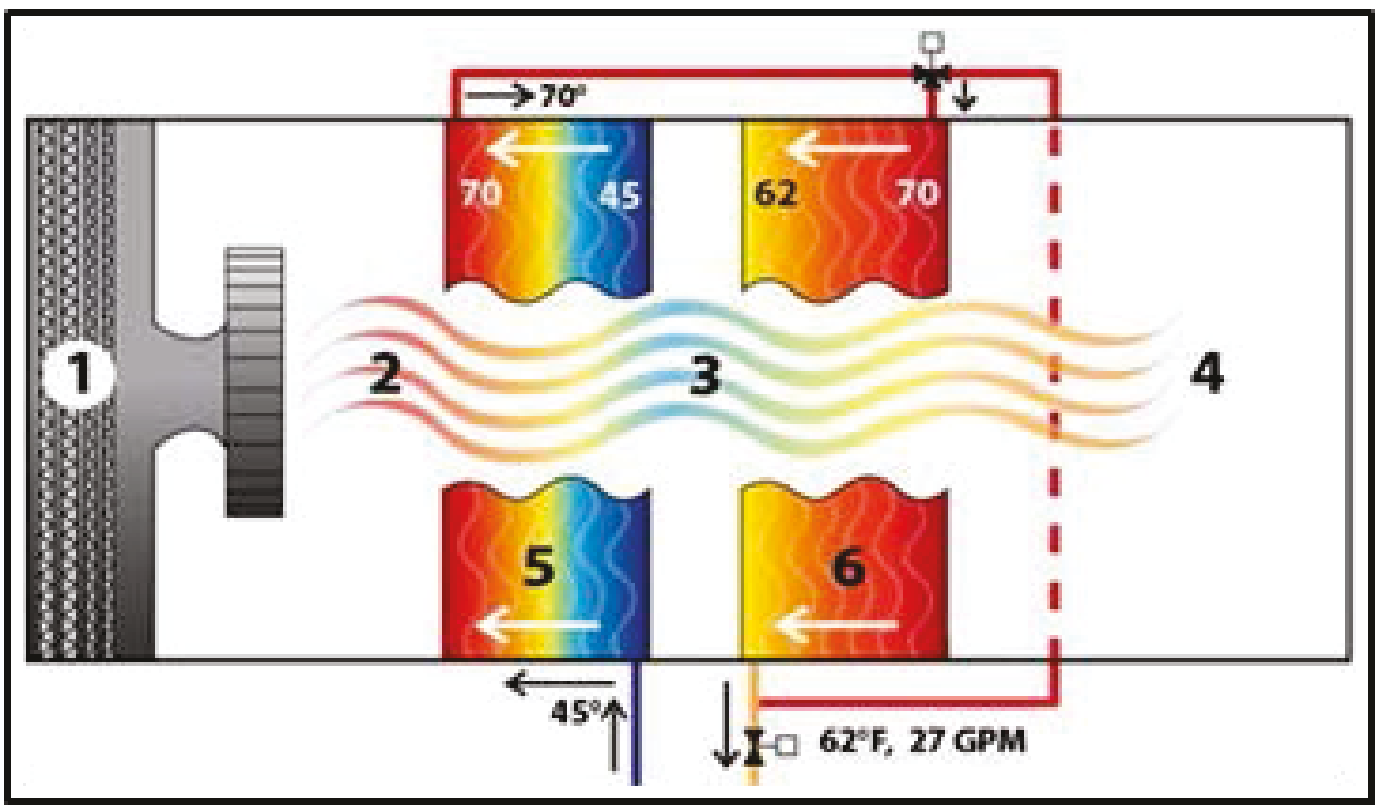


The U.S. Army Engineer Research and Development Center (ERDC) solves the nation's toughest engineering and environmental challenges. ERDC develops innovative solutions in civil and military engineering, geospatial sciences, water resources, and environmental sciences for the Army, the Department of Defense, civilian agencies, and our nation's public good. Find out more at www.erdc.usace.army.mil.

To search for other technical reports published by ERDC, visit the ERDC online library at https://erdc-library.erdc.dren.mil. 
ERDC/CERL TR-18-19

August 2018

\title{
High Efficiency Dehumidification System
}

\author{
Scot M. Duncan \\ Retrofit Originality Inc. \\ 26441 Houston Trail \\ Laguna Hills, CA 92653 \\ Dahtzen Chu \\ U.S. Army Engineer Research and Development Center (ERDC) \\ Construction Engineering Research Laboratory (CERL) \\ 2902 Newmark Dr. \\ Champaign, IL 61824
}

Final Report

Approved for public release; distribution is unlimited.

Prepared for Environmental Security Technology Certification Program (ESTCP)

Under Environmental Security Technology Certification Program (ESTCP), FY13 Energy and Water Project EW-201344, "High Efficiency Dehumidification System (HEDS)" via Military Interdepartmental Purchase Requests (MIPRs) No. W74RDV30312782 (31 January 2013), W74RDV41828281 (01 July 2014), W74RDV50785262 (24 March 2015), W74RDV61477740 (27 May 2016), W74RDV30312785 (31 January 2013), W74RDV50785263 (24 March 2015), W74RDV61477741 (27 May 2016) 


\section{Abstract}

The current "industry standard" method to control relative humidity (RH) and biological growth involves sub-cooling air to condense moisture out of the air, then reheating the same air that was just sub-cooled to reduce the $\mathrm{RH}$ of the air before it enters the space. However, the heating, ventilating, and air-conditioning (HVAC) systems at many Federal Facilities are not equipped with (or do not use) the required reheat function, so high indoor $\mathrm{RH}$ and the growth of mold are often inevitable occurrences. The High Efficiency Dehumidification System (HEDS) is a patent-protected, proprietary energy recovery method designed to save more than $50 \%$ of the dehumidification-related cooling and heating plant energy in RH controlled environments. This work validated the performance of a new HVAC dehumidification technology and investigated performance claims, installation costs, and maintenance impacts through the installation of two test units at Tinker Air Force Base (AFB), OK and Fort Bragg, NC. Based on the results of the ESTCP tests from Fort Bragg, NC and Tinker AFB, OK, HEDS significantly exceeded the energy savings targets, providing HVAC system savings related to the cooling, dehumidification and reheat process of $50 \%$ to well over 70\%. HEDS appears to be a viable, low maintenance, effective alternative to current RH control technologies, and can be a significant contributor to meeting energy savings Policies, Mandates, and Executive Orders. 


\section{Executive Summary}

Proper relative humidity (RH) control is critical to maintaining healthy and productive indoor environments in buildings. It is estimated that U.S. companies waste as much as $\$ 48$ billion annually in medical costs and $\$ 160$ billion annually in lost productivity as a result of sick building syndrome (Mumma 2006). Mold remediation costs associated with poor RH control have been observed to top $\$ 1$ million annually on some military bases. Proper RH control minimizes the potential for indoor air quality problems and related sick-building illnesses while improving thermal comfort and productivity (Vavrin 2006).

The current "industry standard" method to control RH and biological growth involves sub-cooling air to condense moisture out of the air, then reheating the same air that was just sub-cooled to reduce the $\mathrm{RH}$ of the air before it enters the space. This method has been used for over 100 years, and is known to be very energy intensive due to the need for reheat. However, the reheat process is extremely important in dehumidification applications. The cold, $100 \% \mathrm{RH}$ air leaving the air-handling units (AHUs) needs to be warmed up to eliminate the potential for surface condensation to occur in the space and to eliminate condensation in the space, which is critical to the control of mold and biological growth.

The heating, ventilating, and air-conditioning (HVAC) systems at many Federal Facilities are not even equipped with the required reheat function, so the growth of mold is an often inevitable occurrence. Many more of the facilities do not use the installed reheat function, as the energy expense is very high, and "common sense" tells people that you should not be running boilers to produce $180^{\circ} \mathrm{F}$ hot water in the middle of the summer in humid environments, even though it is needed to perform the required reheat function. As a result, many Federal facilities have the compounded problems of excessive energy use and excessive biological growth, coupled with an HVAC system design or operation that actually promotes mold growth.

The High Efficiency Dehumidification System (HEDS) is a patent-protected, proprietary energy recovery method designed to save more than $50 \%$ of the dehumidification-related cooling and heating plant energy in $\mathrm{RH}$ controlled environments while also eliminating the health, wellness, product and productivity loss risks caused by poor RH control. By design, the HEDS system is simple and easily maintained; it requires knowledge of only basic 
HVAC system operations. HEDS is designed to be scalable, from the smallest room level equipment to the largest central system equipment.

The basic concept underlying HEDS is very simple, and the need for the system is global. The HEDS process recovers 20 to $40 \%$ of the low-quality heat generated in the cooling and dehumidification process and uses that reclaimed heat for two purposes: (1) to eliminate the need for new reheat energy for RH control, and (2) to reduce the cooling load sent to the chiller plant from the HEDS AHU by the exact same amount of energy as is recovered to provide the reheat energy. The combined energy savings can exceed $60 \%$ during non-peak load conditions. The actual chiller plant and boiler plant energy savings related to the cooling, dehumidification and reheat process can exceed $80 \%$ for certain loads in humid environments.

\section{Objective of the demonstration}

The objective of this project was to validate the performance of a new HVAC dehumidification technology designed to significantly reduce energy use associated with dehumidification, while improving indoor air quality and reducing potential for mold growth. Performance claims, installation costs, and maintenance impacts were investigated through the installation of two test units at Tinker Air Force Base (AFB), OK and Fort Bragg, NC.

\section{Technology description}

The HEDS technology is very simple; a standard AHU is built with a pair of deep, low face velocity heat transfer coils: a cooling coil and a cooling recovery coil. The first coil does the cooling and dehumidifying, the second coil uses the warm water leaving the cooling coil to do the reheating for RH control and cuts the loads on the chiller and boiler plants by using the low quality recovered cooling energy to meet reheat loads. The result is a dehumidification system that is energy efficient, maintainable and resilient.

\section{Demonstration results}

Two test units were installed, a Variable Air Volume (VAV) system at Tinker AFB, OK and a Constant Air Volume (CAV) system at Fort Bragg NC. This report summarizes the observed field performance results from more than 6 months of real world testing for both sites. Performance tests were conducted across a range of supply air dew point temperatures to 
emulate the needs of various building types in the U.S. Department of Defense (DoD), General Services Administration (GSA), Veterans Administration (VA), and Federal building portfolios.

For the constant volume system at Fort Bragg, the peak day cooling load savings was $18 \%$, while the average cooling load reduction was $25 \%$. For the VAV system at Tinker AFB, the peak day cooling load savings was 29\%, while the average cooling load reduction was $28 \%$. The peak load reductions effectively expand the capacity of the existing chilled water systems, enabling the chiller plants to serve more cooling loads with the installed capacity, or to be downsized in the future for use in new construction projects. Both these benefits can help reduce capital costs.

Based on the results of the ESTCP HEDS tests from Fort Bragg, NC and Tinker $\mathrm{AFB}, \mathrm{OK}$, the energy reclamation function of HEDS is able to significantly reduce the cooling load associated with dehumidification while completely eliminating the need for additional reheat energy to provide $\mathrm{RH}$ control in a variety of facility types. Cooling load savings range from 20 to $37 \%$ depending on the application, and the dehumidification-related heating energy savings associated with the reheat function at the AHU is $100 \%$ in all cases.

Note that the actual cooling energy percentage savings that will show up at the utility meter can be a much greater figure than the cooling load savings percentage. This is due to the non-linear relationship between energy use and load on modern variable speed equipment such as pumps, fans and chillers. For example, reducing the cooling load on chilled water pumps with variable speed drives by $20 \%$ typically results in electricity savings of around $40 \%$.

The results from the two ESTCP test sites indicate that HEDS exceeded the energy savings targets by a significant amount. Chiller plant energy savings related to the dehumidification process varied between $32 \%$ for hospital-type applications with $24 / 7$ cooling loads, to $64 \%$ for administrative type VAV cooling loads that only need conditioning $12 / 5$, but that are typically run $24 / 7$ during the dehumidification season in humid climates. Reheat energy savings related to the dehumidification process were $100 \%$ for the test sites.

\section{Implementation issues}

Both demonstration sites had issues with failing chillers that led to high chilled water supply temperatures from the chiller plants. Even as chilled water supply temperatures rose as high as $60^{\circ} \mathrm{F}$, both HEDS units were 
able to continue to provide dehumidification while reducing cooling loads by 16 to $30 \%$. The cooling load saved by the HEDS unit was used by the other AHUs on the chilled water system to provide added cooling to those spaces, which will lead to improved comfort, productivity, health, and wellness, even when chiller performance was sub-optimal. A HEDS installation can improve resiliency by doing more with less.

Throughout the demonstration, HEDS was shown to have the same, or slightly lower, maintenance needs as a normal AHU. In other words, the system's needs are significantly lower than the needs of other commercial dehumidification technologies. Technology transition is occurring through ongoing presentations, white papers, and direct project analysis with Federal energy managers and vendors, all of which combine to demonstrate performance results, and to illustrate implementation strategies for HEDS.

\section{Conclusions}

The installed HEDS units met or exceeded each Performance Objective target outlined in the original study plan. HEDS was able to deliver average dehumidification season cooling load savings ranging from 25 to $29 \%$, while eliminating the need for additional reheat energy sources.

The HEDS units were able to maintain internal temperature and RH conditions 96 to $98 \%$ of the time. Internal conditions were maintained within $\mathrm{RH}$ conditions that typically do not allow biological growth to occur. When Federal facilities are required to comply with American Society of Heating, Refrigerating, and Air-Conditioning Engineers (ASHRAE) 90.1 energy codes, it is likely that HEDS will be the least first cost option and the lowest lifecycle cost option compared to currently available alternatives. HEDS has the same, or slightly lower, maintenance needs as a normal AHU, thus the needs are significantly lower than many of the alternatives.

HEDS appears to be a viable, effective alternative to current RH control technologies, and can be a significant contributor to meeting energy savings Policies, Mandates, and Executive Orders. In addition to working on land-based assets, the technology can be applied to both combatant and noncombatant ships with similar effects (ship-based applications are currently being investigated under award No0167-17-BAA-01 with Naval Surface Warfare Center [NSWC] Carderock Division). 


\section{Contents}

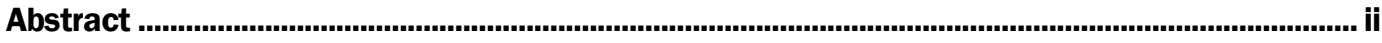

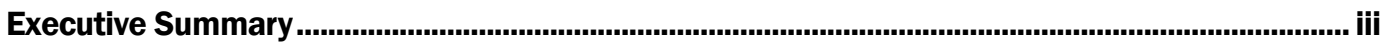

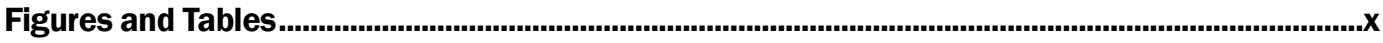

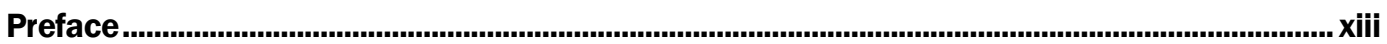

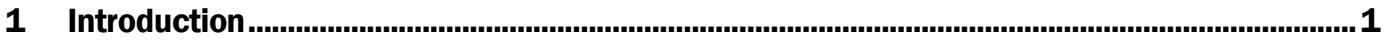

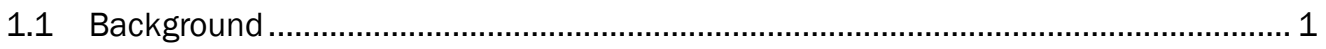

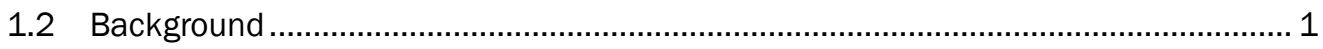

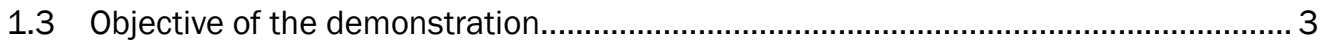

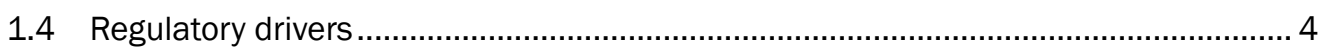

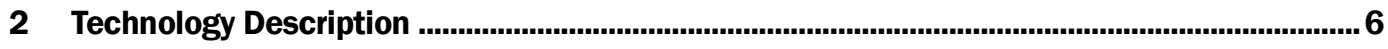

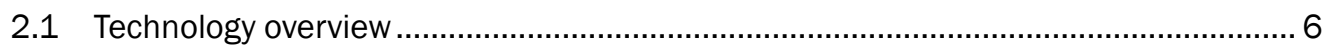

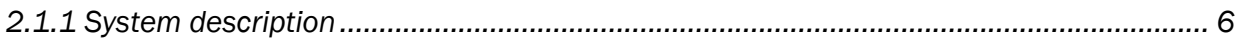

2.1.2 HEDS standalone unit controller description ........................................................ 10

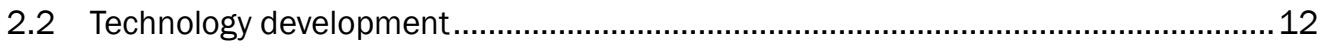

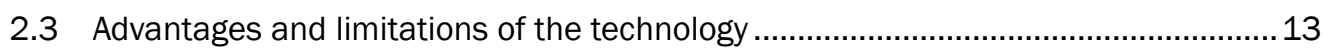

2.3.1 Comparative technologies ...................................................................................... 13

2.3.2 Chilled water/ direct expansion coils with gas or electric reheat................................. 14

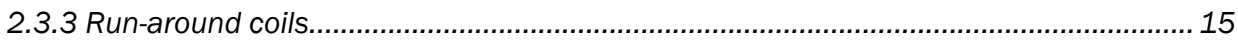

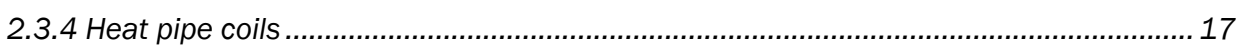

2.3.5 Rotary wheel heat exchangers ............................................................................ 18

2.3.6 Air-to-air heat exchangers ................................................................................... 19

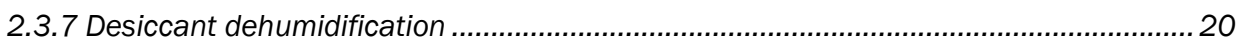

2.3.8 Performance advantages of the HEDS technology .................................................... 21

2.3.9 Cost advantages of the HEDS technology................................................................. 22

2.3.10 Performance limitations of the HEDS technology ..................................................... 23

2.3.11 Cost limitations of the HEDS technology ............................................................... 23

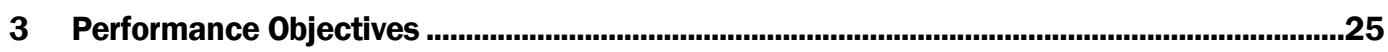

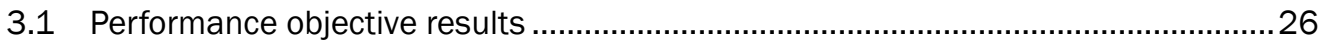

3.2 Performance objectives (POs) descriptions .......................................................... 28

3.2.1 Determine the peak cooling load reduction percent that occurs as a result of the energy recovered via the $C R C$ during the dehumidification/reheat process. ....................................28

3.2.2 Determine the greatest cooling load reduction percent that occurs as a result of the energy recovered via the CRC during the dehumidification/reheat process. ......29

3.2.3 Dehumidification/reheat coil energy reduction. Does the HEDS unit reduce reheat energy required by the downstream reheat coil at Tinker AFB by more than $90 \%$ during the dehumidification-reheat process? Fort Bragg AHU does not have a downstream reheat coil, so this PO only applies to Tinker AFB...................................... 31

3.2.4 Enhance space comfort conditions .............................................................................. 32

3.2.5 Reduce cooling ton-hours consumption. Determine the cooling load ton-hours savings percent that occurs as a result of the cooling energy recovered via the CRC during the dehumidification/reheat process. 
3.2.6 Determine if the HEDS unit can provide a chilled water system temperature differential that is higher than typical, to help solve the "Low Delta T" syndrome.......................................... 34

3.2.7 Determine the level of GHG emissions that the HEDS unit contributes to.......................... 35

3.2.8 Reduce energy cost of dehumidification/reheat process............................................. 36

3.2.9 Reduce lifecycle cost of dehumidification/ reheat process......................................... 37

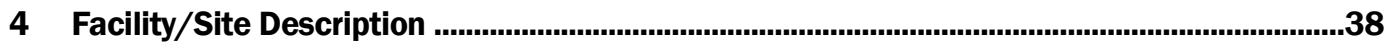

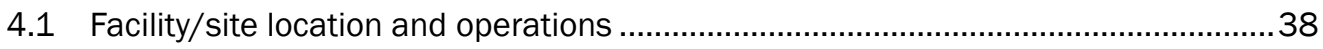

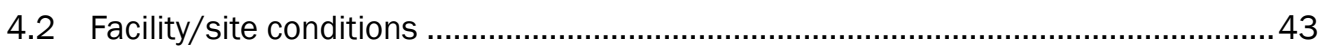

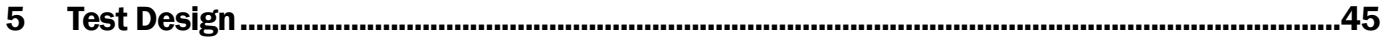

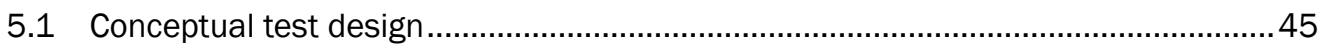

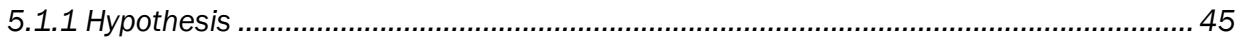

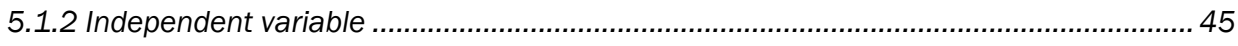

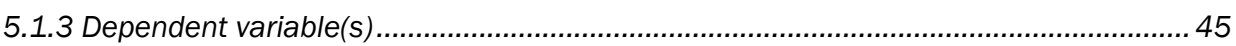

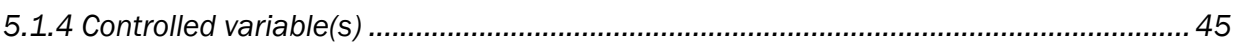

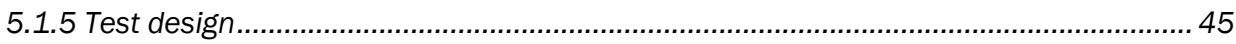

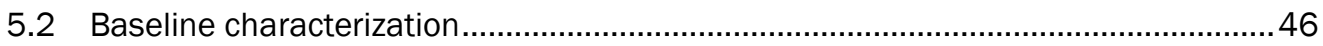

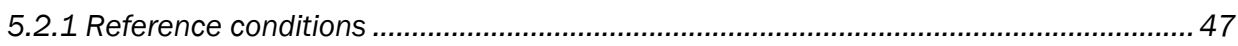

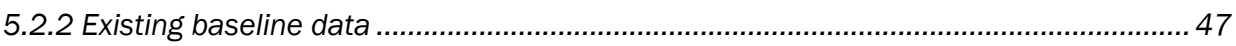

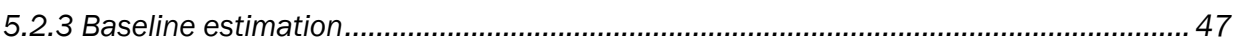

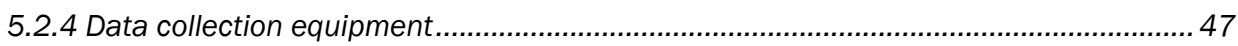

5.3 Design and layout of technology components .................................................48

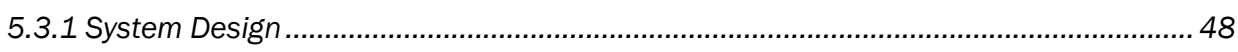

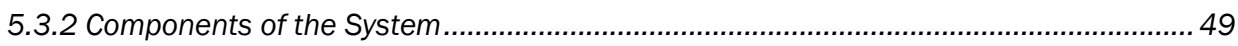

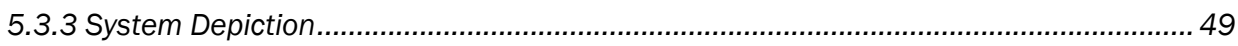

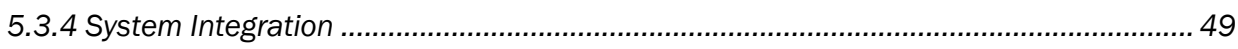

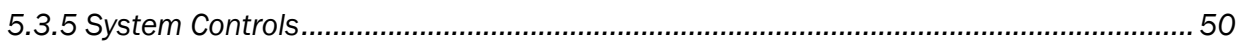

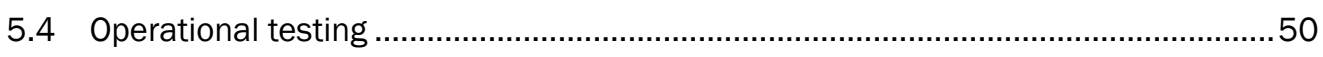

5.4.1 Operational Testing of Cost and Performance.........................................................50

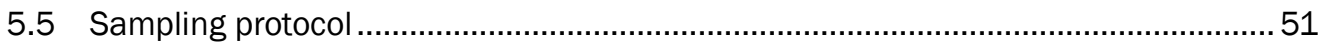

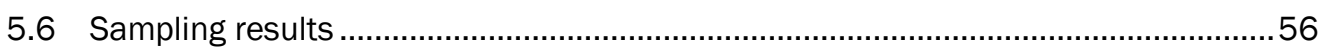

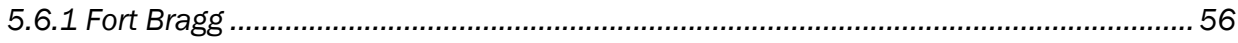

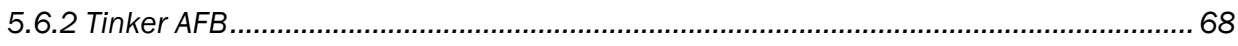

6 Performance Assessment ....................................................................................................78

6.1 Savings analysis methodology .................................................................... 78

6.2 Cooling load savings vs. cooling energy savings ................................................... 79

6.3 Data collection methodology and quality analysis................................................8 80

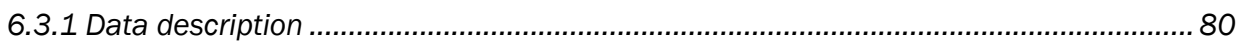

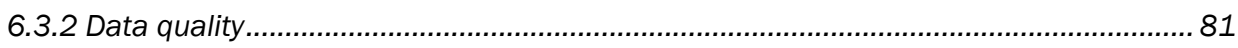

6.3.3 Fort Bragg data calibration analysis........................................................................ 82

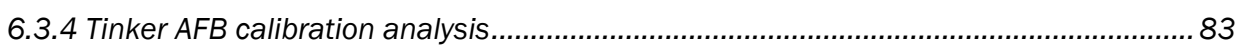

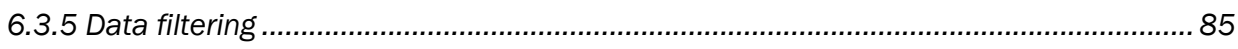

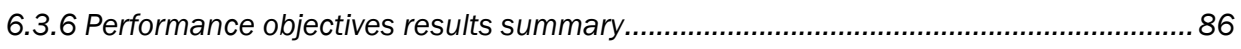


7 Cost Assessment.........................................................................................................................88

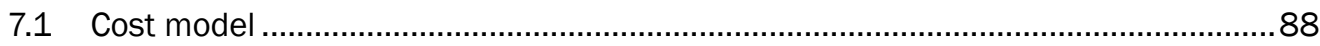

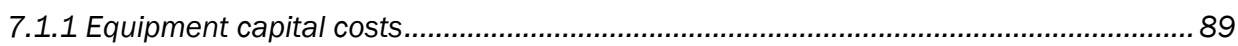

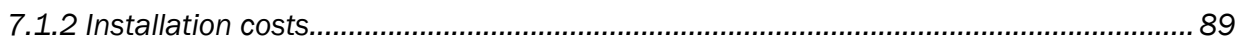

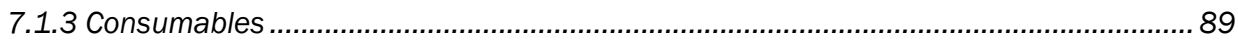

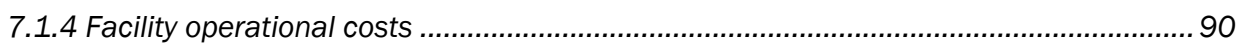

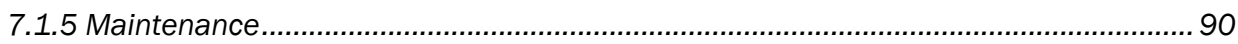

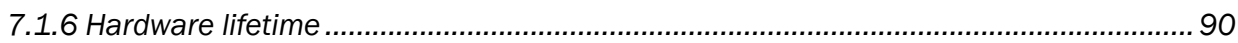

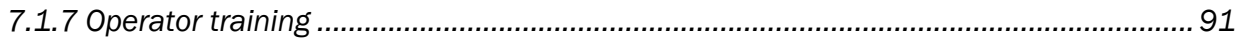

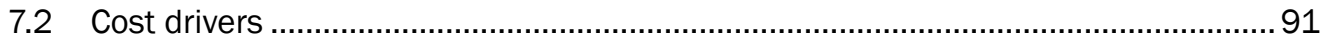

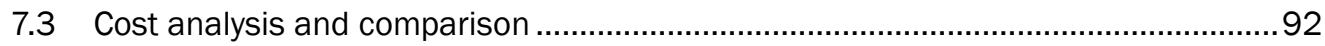

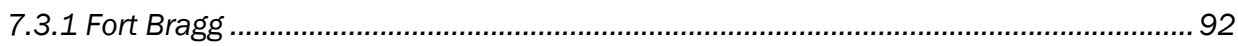

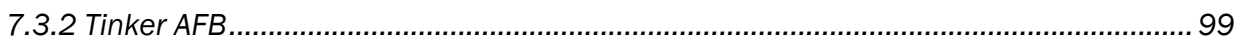

8 Implementation Issues ...................................................................................................... 104

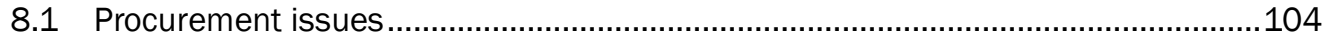

8.2 Potential barriers to acceptance........................................................................ 104

8.3 ASHRAE 90.1 Prescriptive energy code requirements ..........................................105

8.4 Lessons learned....................................................................................................106

8.5 Future potential HEDS applications for DoD ....................................................106

References .................................................................................................................................. 108

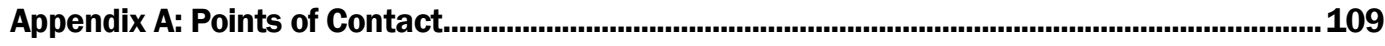

Appendix B: HEDS Frequently Asked Questions (FAQs) ........................................................110

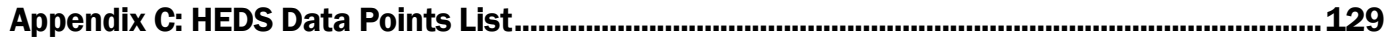

Appendix D: HEDS Instrumentation Drawings .................................................................139

Appendix E: HEDS Instrumentation Cut Sheets .............................................................................149

Report Documentation Page (SF 298) ................................................................................ 173 


\section{Figures and Tables}

\section{Figures}

1 Typical reheat dehumidification design ......................................................................

$2 \quad$ High efficiency dehumidification system ..................................................................... 8

3 Typical reheat dehumidification design ......................................................................

$4 \quad$ HEDS unit depiction highlighting the mechanism for eliminating reheat

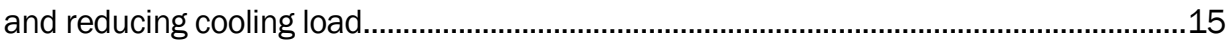

$5 \quad$ Run-around coil system example layouts ...................................................................16

$6 \quad$ Heat pipe coil design example ……….........................................................................

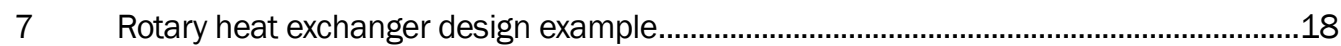

$8 \quad$ Air-to-air heat exchanger system example layouts .........................................................19

9 Desiccant wheel system placeholder layout. (Ignore airside temperatures, rough physical layout only intended as a proxy for the desiccant wheel

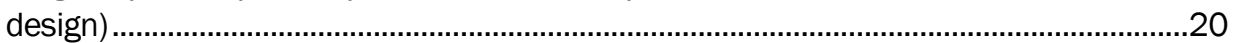

10 Existing AHU that was replaced on Bldg. 3 at Tinker AFB ..............................................39

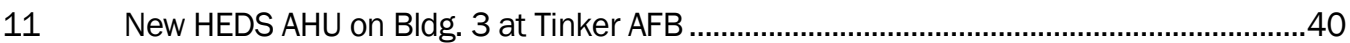

12 Existing AHU that was replaced in Bldg. A-3556 at Fort Bragg .......................................40

13 New HEDS AHU in Bldg. A-3556 at Fort Bragg ............................................................

14 Location of Bldg. 3, the Administrative Building for the demonstration on

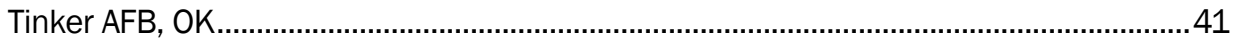

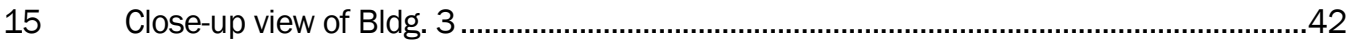

16 Location of Dining Facility (DFAC) A-3556 on Fort Bragg, NC .........................................42

17 Close-up views of DFAC location and building ..................................................................43

18 Psychrometric chart highlighting the impact of the cooling recovery coil on HEDS system performance at Fort Bragg.

19 Dynamic HEDS savings and impact analysis for the peak cooling load week of August 1, 2016

20 Dynamic HEDS savings and impact analysis for the peak cooling load day of August 5, 2016

21 HEDS savings analysis for fall part load days where the CHWST is less than $46{ }^{\circ} \mathrm{F}$ and the CC SAT is between 52 to $56^{\circ} \mathrm{F}$

22 HEDS savings analysis for fall part load peak day October 2, 2016 where the CHST is less than $46^{\circ} \mathrm{F}$ and the CC SAT is between 52 to $56^{\circ} \mathrm{F}$

23 HEDS cooling load reduction as a function of CC supply air temp (SAT) when chilled water supply temp is in control (less than $46^{\circ} \mathrm{F}$ ). Note that the higher SAT ranges have been removed due to the limited hours of operation within the bins

24 Fort Bragg HEDS cooling load reduction as a function of chilled water supply temperature across all supply air temperature ranges

25 Psychrometric analysis for Tinker AFB Highlighting the impact of the cooling recovery coil on HEDS performance 
26 Tinker AFB dynamic HEDS savings and impact analysis for the peak cooling load on June 3, 2016

27 Tinker AFB HEDS dynamic savings analysis for part load days in the fall

28 Tinker AFB HEDS dynamic savings analysis for part load day November 1, 2016

29 Tinker AFB HEDS cooling load reduction as a function of CC supply air temp when the chilled water temperature is in control (less than $46^{\circ} \mathrm{F}$ )

30 Tinker AFB HEDS cooling load reduction as a function of chilled water supply temperature from the plant.

31 Calibration period results highlighting the low error between sensors for Fort Bragg

32 Calibration period results highlighting the low error between sensors for Tinker AFB.

33 Characteristic load curves for the baseline and net HEDS cooling loads as a function of average daily outdoor air temperature for Fort Bragg .

34 Lifecycle performance across a range of scenarios.

35 Characteristic load curves for the baseline and net HEDS cooling loads as a function of average daily outdoor air temperature for Tinker AFB.

Lifecycle performance across a range of scenarios.

\section{Tables}

1 Summary of quantitative performance objectives

2 Quantitative performance objective results summary for the Fort Bragg

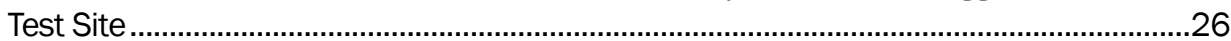

3 Performance objective summary for the Tinker AFB test site...........................................27

$4 \quad$ Project timeline for each HEDS installation and data collection period.............................51

5 Summary of hours at each temperature bin analyzed for Fort Bragg ..............................57

6 Fort Bragg HEDS savings summary with differential temperatures across all temperature bins. Note that gray rows represent transient conditions and may not be representative of steady state results

7 Fort Bragg AHU temperatures across the range of operating conditions

8 Fort Bragg HEDS peak load reduction results when CHWST is in control (less than $46^{\circ} \mathrm{F}$ ).

9 Summary of hours at each temperature bin analyzed for Tinker AFB

10 Tinker AFB HEDS savings summary with differential temperatures across all temperature bins. Note that gray rows represent transient conditions and may not be representative of steady state results

11 Tinker AFB average AHU temperatures across the range of operating conditions

12 Tinker AFB HEDS peak load reduction results when CHWST is in control (less than $46^{\circ} \mathrm{F}$ )

13 Calibration period results highlighting the low error between sensors for Fort Bragg.

14 Calibration period results highlighting the low error between sensors for

Tinker AFB . 
15 Quantitative performance objective results summary for the Fort Bragg

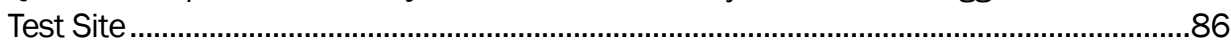

16 Performance objective summary for the Tinker AFB Test Site .......................................87

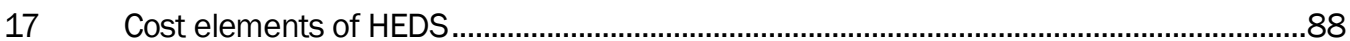

18 Energy savings results for $\mathrm{CC}$ supply air temperatures below $50^{\circ} \mathrm{F}$ (very high dehumidification loads).

19 Energy savings results for $\mathrm{CC}$ supply air temperatures between 50 and $52^{\circ} \mathrm{F}$ (moderate dehumidification loads)

20 Energy savings results for $\mathrm{CC}$ supply air temperatures between 52 and $56{ }^{\circ} \mathrm{F}$ (low dehumidification loads).

21 GHG emissions savings results for $\mathrm{CC}$ supply air temperatures below $50{ }^{\circ} \mathrm{F}$ (very high dehumidification loads)..

22 GHG emissions savings results for $\mathrm{CC}$ supply air temperatures between 50 and $52^{\circ} \mathrm{f}$ (moderate dehumidification loads).

23 GHG emissions savings results for $\mathrm{CC}$ supply air temperatures between 52 and $56^{\circ} \mathrm{f}$ (low dehumidification loads)

$24 \quad$ Low, mid, and high scenarios .............................................................................................

25 Energy savings results for $\mathrm{CC}$ supply air temperatures between 52 to $56{ }^{\circ} \mathrm{f}$ (office dehumidification loads). 101

26 GHG emissions savings results for $\mathrm{CC}$ supply air temperatures between 52 to $56^{\circ} \mathrm{f}$ (low dehumidification loads) 101

$27 \quad$ Lifecycle cost analysis 


\section{Preface}

Funding for this demonstration was provided by the Environmental Security Technology Certification Program (ESTCP) under FY13 Energy and Water Project EW-201344, "High Efficiency Dehumidification System (HEDS)" via Military Interdepartmental Purchase Requests (MIPRs) No. W74RDV30312782 (31 January 2013), W74RDV41828281 (o1 July 2014), W74RDV50785262 (24 March 2015), W74RDV61477740 (27 May 2016), W74RDV30312785 (31 January 2013), W74RDV50785263 (24 March 2015), W74RDV61477741 (27 May 2016).The ESTCP technical monitor was Sarah Medepalli.

The work was performed by the Energy Branch (CFE) of the Facilities Division (CF), of the Facilities Division (CF), of the U.S. Army Engineer Research and Development Center, Construction Engineering Research Laboratory (ERDC-CERL). At the time of publication, Giselle Rodriguez was Chief, CEERD-CFE. The Deputy Director of ERDC-CERL was Dr. Kirankumar V. Topudurti and the Director was Dr. Lance D. Hansen.

COL Ivan P. Beckman was Commander of ERDC, and Dr. David W. Pittman was the Director. 


\section{Introduction}

\subsection{Background}

The objective of this project is to validate the performance of a new heating, ventilating, and air-conditioning (HVAC) dehumidification technology designed to significantly reduce energy use associated with dehumidification, while improving indoor air quality and reducing mold growth. This work was undertaken to investigate performance claims, installation costs, and maintenance impacts through the installation of two test units, at Tinker AFB, OK and Fort Bragg, NC.

\subsection{Background}

Proper relative humidity $(\mathrm{RH})$ control is critical to maintaining healthy and productive indoor environments in buildings. It is estimated that U.S. companies waste as much as $\$ 48$ billion annually in medical costs and $\$ 160$ billion annually in lost productivity as a result of sick building syndrome (Mumma 2006). Mold remediation costs associated with poor $\mathrm{RH}$ control have been observed to exceed $\$ 1$ million annually on military bases. Proper RH control minimizes the potential for indoor air quality problems and related sick-building illnesses while improving thermal comfort and productivity (Vavrin 2006).

The current "industry standard" method to control RH and biological growth involves sub-cooling air to condense moisture out of the air, then reheating the same air that was just sub-cooled to reduce the RH of the air before it enters the space. This method has been used for over 100 years, and is known to be very energy intensive due to the need for reheat. However, the reheat process is extremely important in dehumidification applications. The cold, $100 \% \mathrm{RH}$ air leaving the air-handling units (AHUs) needs to be warmed up to eliminate the potential for surface condensation to occur in the space and to eliminate condensation in the space, which is critical to the control of mold and biological growth.

Unfortunately, the HVAC systems at many Federal Facilities are not equipped with the required reheat function. Many more of the remaining facilities do not use the installed reheat function because the energy expense is very high and because "common sense" tells people that you 
should not be running boilers to produce $180^{\circ} \mathrm{F}$ hot water in the middle of the summer in humid environments, even though it is needed to perform the required reheat function. As a result, many Federal facilities have the compounded problems of excessive energy use and excessive biological growth, coupled with an HVAC system design or operation that actually promotes mold growth.

To combat those problems, in 2006, Retrofit Originality Incorporated was approached by the U.S. Army Corps of Engineers (USACE) to develop a cost effective, energy efficient, maintainable, sustainable and scalable dehumidification and RH control solution. The solution had to work in retrofit applications as well as new construction. After substantial research, development and computer modelling, the High Efficiency Dehumidification System (HEDS) was born. The HEDS is a patent-protected, proprietary energy recovery method designed to save more than $35 \%$ of the cooling and heating energy in RH controlled environments while also eliminating the health, wellness, product and productivity loss risks caused by poor $\mathrm{RH}$ control. It is essentially a standard AHU, equipped with a very large face area and depth cooling coil designed to deliver very warm chilled water (CHW) return temperatures, and a "Cooling Recovery Coil" (CRC) designed to reclaim 20 to $40 \%$ of the wasted low quality heat that was generated in the cooling and dehumidification process. This reclaimed waste heat is used for two purposes: (1) to completely eliminate the need for new reheat energy for RH control, and (2) to reduce the cooling load sent to the chiller plant from the HEDS AHU by the exact same amount of energy as is recovered to provide the reheat energy. The combined energy savings can exceed 60\% during non-peak load conditions. The actual chiller and boiler plant energy savings related to the cooling, dehumidification and reheat process can exceed $70 \%$ for certain loads in humid environments.

The HEDS system offers many potential benefits that will impact a number of missions throughout DoD. These include saving energy; reducing condensation in AHUs, ducts, and occupied spaces; reducing lifecycle costs; and improving the health, comfort and productivity of employees-all of which are extremely important to DoD. The development of HEDS makes it possible to resolve the problems described above. Peak day peak cooling loads can be cut by approximately $20 \%$ and the reheat energy required for proper RH control on peak load days can be eliminated completely. 


\subsection{Objective of the demonstration}

The main technical objective of this project is to evaluate the HEDS unit design in two real world buildings to determine if there are technical issues that must be addressed before full scale commercialization. Additional objectives are to quantify the extent to which systems are able to be downsized to assess the level of improved efficiency of the HVAC systems, and to determine the extent to which upgrade costs can be reduced. All previous development has been undertaken via computer analysis using cooling coil and heating coil rating programs and differing design conditions varying from recirculated air type systems in barracks in the Midwest to $100 \%$ dedicated outside air systems (DOAS) in the tropics. The analysis has shown that peak day peak loads can have substantial reductions for all of the test conditions that were evaluated, and if variable volume air distribution systems are used, the part load savings can also be very substantial. This project will verify the actual performance of the HEDS.

- Validate: The ESTCP demonstration project will validate the performance, costs, and benefits of the technology in the following manner. Performance will be validated by measuring and calculating the energy saved by the HEDS units at two separate locations and facilities types. Expected energy savings will occur at the chiller plant due to reduced cooling loads and pump energy savings due to higher CHW system temperature differentials, and at the boiler plant or power plant due to reduced/eliminated need for reheat energy. Costs will be validated by using the actual costs of the equipment and installation process that would normally be required for a unit replacement, i.e., excluding the research and development (R\&D) costs and excluding instrumentation and controls costs associated with the demonstration process. Benefits will be calculated and determined based on the savings and results of the demonstration process.

- Findings and Guidelines: Once the HEDS technology has been proven to perform in hot and humid climates and any limitations have been discovered and rectified through the ESTCP demonstration process, it will be much easier to make the case for widespread adoption of the technology. The results of the ESTCP demonstration process will prove the levels of savings that the design can potentially make available. Proposed recommendations to DoD policies and standards may include: mandating proper HVAC and humidity control designs for high RH locations; mandating that no new energy be used for the reheat 
portion associated with RH control; mandating that maintenance requirements for dehumidification systems be no greater than those of a "normal" AHU; and mandating that the loads served by the cooling plant be less than the sum of the loads associated with the cooling and dehumidification process when RH control is occurring.

- Technology Transfer: After the completion of the project, the results will be published in the ASHRAE Journal and other outlets such as the U.S. Green Building Council (USGBC), Austrian Energy \& Environment (AEE), and Building Owners and Managers Association International (BOMA). The findings can also be presented at USACE, the Energy Exchange, Resource Efficiency Manager (REM) and Energy Service Co. (ESCO) conferences to educate them on how they can improve energy efficiency at their client facilities. Recommendations will be developed for revisions to relevant Unified Facilities Criteria (UFC) and Unified Facilities Guide Specifications (UFGS).

- Additionally, the participation of Trane as a team member can provide rapid and scaled deployments of the proposed technology for DoD. With over 400 offices in 100 countries worldwide, Trane has the resources to transfer the technology and to rapidly deploy HEDS at DoD facilities around the globe.

- Acceptance: The implementation of the HEDS ESTCP project at the two demonstration sites is intended to demonstrate that this new, simple to understand and operate technology will save energy, reduce capital costs to control moisture condensation in AHUs' ducts and occupied spaces repair expenditures, reduce lifecycle costs, and improve the comfort of the buildings' occupants, and that the system will have the same or fewer operational and maintenance requirements as the conventional systems it is replacing.

\subsection{Regulatory drivers}

The regulatory drivers listed below are intended reduce the energy utilization intensity (EUI) of Federal buildings on an annual basis. This requirement is dictated primarily by the Energy Policy Act of 2005. This project will directly support the cost effective attainment of these goals by reducing the amount of energy used in the HVAC system for dehumidification, heating, and cooling. In a typical DoD building, the HVAC energy is about 30 to $40 \%$ of the total energy. The component for cooling, dehumidification, and reheat for RH control expends up to $40 \%$ (even more in very humid climates) of the total energy in humid climates. Proper applications of this technology should reduce that amount by an average in the range of 
30 to $40 \%$, thereby reducing the energy total by about $5 \%$ for the total building energy use. The application of this one technology breakthrough can help DoD meet almost 2 years' worth of energy intensity reduction goals that are a $3 \%$ energy intensity annual reduction. There is also a potential water savings for systems that use hydronic cooling towers for heat rejection, but this will not be validated as part of this demonstration. The HEDS solution has a further effect of reducing capital costs for new central plant installations, and of reducing equipment maintenance costs due to reduced run time of the chiller, pumps, and boiler.

The regulatory drivers underlying this demonstration are:

- Executive Orders: Executive Order (EO) 13423, EO 13514, EO 13693: http://www.whitehouse.gov/administration/eop/ceq/sustainability; https://www.federalregister.gov/articles/2015/03/25/2015-07016/planning-for-federal-sustainability-in-the-next-decade

- Legislative Mandates: Energy Policy Act of 2005, Energy Independence and Security Act of 2007, National Defense Authorization Act (NDAA) for Fiscal Year 2015: http://www.armed-services.senate.gov/press-releases/senate-committee-on-armed-services-reach-agreement-with-house-counterparts-regarding-the-national-defense-authorization-act-for-fiscal-year-2015

- Federal Policy: Federal Leadership in High Performance and Sustainable Buildings Memorandum of Understanding (MOU) 2006

- DoD Policy: Strategic Sustainability Performance Plan, Energy Security MOU with U.S. Department of Energy (DOE)

- Service Policy: Army Sustainable Design and Development Policy Update, 16 December 2013: http://www.usace.army.mil/Portals/2/docs/Sustainability/Hydrology_LID/ASAIEE_SDD_Policy_Update_2013-12-16.pdf, Secretary of the Navy Energy Goals: http://www.navy.mil/features/Navy_EnergySecurity.pdf, Air Force Sustainable Design and Development Implementing Guidance: http://www.wbdg.org/ccb/AF/POLICY/af_sdd_impl_guidance.pdf; http://www.safie.hq.af.mil/shared/media/document/AFD-091208-027.pdf

- Guides: Whole Building Design Guide (http://www.wbdg.org/). See specifically: http://www.wbdg.org/pdfs/usace_dg_epact2005.pdf; http://www.wbdg.org/references/mou_ee.php

- Specifications: ASHRAE Standards 62.1 and 90.1, Leadership in Energy and Environmental Design [LEED], Institute of Electrical and Electronics Engineers [IEEE], International Code Council (ICC) Codes (International Mechanical Code [IMC], International Plumbing Code [IPC], International Energy Conservation Code [IECC,] etc.). 


\section{Technology Description}

\subsection{Technology overview}

The High Efficiency Dehumidification System (HEDS) reclaims some of the very low quality heat generated during the cooling and dehumidification process in the chilled water stream, and uses it to provide the reheat energy used to lower the RH of the air supplied to buildings, which reduces the potential for condensation to occur and reduces reheat requirements to ensure that spaces are not overcooled due to dehumidification processes. The energy that is reclaimed for reheat, has a compounding benefit; every British Thermal Unit (BTU) of energy that is used for reheat also reduces the cooling load on the chiller plant by the exact same amount.

\subsubsection{System description}

HEDS is a "Cooling Recovery System" designed to save lives and substantially reduce energy waste, reduce space $\mathrm{RH}$ and improve occupant safety, comfort and productivity. In hospitals, laboratories, and manufacturing facilities, the improved temperature control and RH stability can lead to better patient outcomes, and improved product quality. In administrative and other facilities, HEDS can reduce energy waste; eliminate biological growth; and improve occupant health, wellness, and productivity.

Based on DoD ESTCP test results, the HEDS unit will:

- Recover between 18 and $29 \%$ of the heat generated in the chilled water stream from the cooling and dehumidification process to maintain $\mathrm{RH}$ control during peak cooling load periods.

- Reduce total cooling loads between 25 and $37 \%$ by recovering heat generated during the cooling and dehumidification process to maintain RH control.

- Eliminate the need for new reheat energy (for example from reheat coils or electric strip elements) for RH control for all dehumidification loads encountered at both test sites.

- Cut the average summertime need for cooling and reheat energy by approximately $50 \%$ or more, while simultaneously reducing potable water usage in the cooling and heat rejection process for systems that use water cooled chiller equipment.

- Cut dehumidification-related energy use by 50 to over $80 \%$ for the chiller plant and boiler plant. 
By far the most common solution used in dehumidification AHUs is to subcool the air to remove moisture by condensation, then reheat the sub-cooled and dehumidified air to lower the $\mathrm{RH}$ of that air and provide temperature control for the spaces (Figure 1). The reheat energy can be provided by hot water coils fed from a central boiler system, on-board furnace, or electric strip heating elements.

Figure 1. Typical reheat dehumidification design.

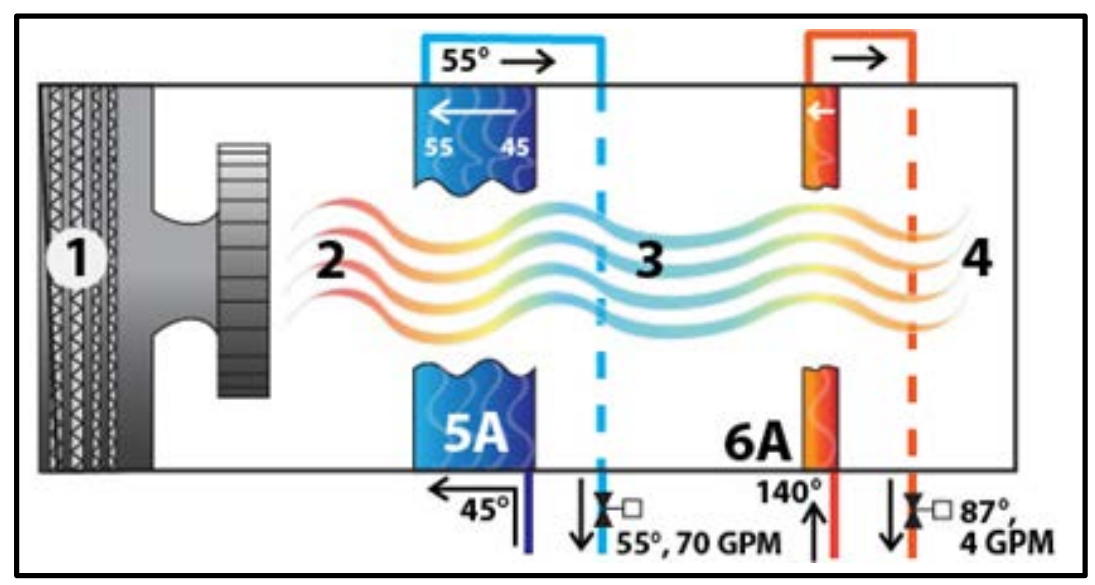

Data Points 1 through 4 in Figure 1 denote: [1] 10,000 CFM airflow [2] $78{ }^{\circ} \mathrm{F}$ dry bulb temp, $65^{\circ} \mathrm{F}$ wet bulb temp [3] $55^{\circ} \mathrm{F}$ dry bulb, $55^{\circ} \mathrm{F}$ dewpoint, essentially $100 \% \mathrm{RH}$ [4] $65.3{ }^{\circ} \mathrm{F}$ dry bulb, $55^{\circ} \mathrm{F}$ dewpoint, $55 \% \mathrm{RH}$. In the diagram, the air is moving through the system from the left to the right.

Typical AHUs providing dehumidification and reheat use relatively small, high air velocity cooling and reheat coils, high $\mathrm{CHW}$ flow rates, low $\mathrm{CHW}$ temperature differentials, and high AHU air pressure drops. In the example above, $45^{\circ} \mathrm{F}$ CHW enters the cooling coil ( $\left.5 \mathrm{~A}\right)$ at 70 gallons per minute (GPM) and leaves the cooling coil at $55^{\circ} \mathrm{F}$. A new source of $140^{\circ} \mathrm{F}$ water enters the reheat coil (6A) at $4 \mathrm{GPM}$ and leaves the reheat coil at $87^{\circ} \mathrm{F}$. The unit requires 479,319 BTUs per hour to cool, dehumidify and reheat $10,000 \mathrm{CFM}$ of air at the design conditions in this example.

Figure 2 shows how HEDS eliminates the need for new reheat energy and reduces the total cooling load of the unit, using the same design conditions shown in Figure 1. 
Figure 2. High efficiency dehumidification system.

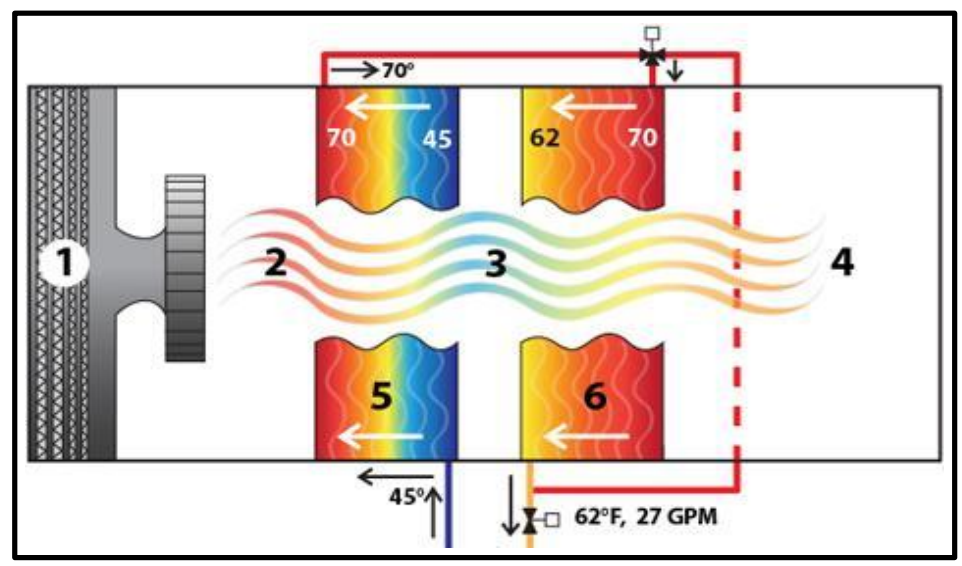

The HEDS units use very large, low air face velocity cooling and cooling recovery coils, low $\mathrm{CHW}$ flow rates, high $\mathrm{CHW}$ temperature differential, and low AHU air pressure drops. In this example, which matches the base case air conditions above, $45^{\circ} \mathrm{F} \mathrm{CHW}$ enters the cooling coil (5) at $27 \mathrm{GPM}$ and leaves the cooling coil at $70{ }^{\circ} \mathrm{F}$. This $70^{\circ} \mathrm{F}$ water then enters the $\mathrm{CRC}$ coil (6) at $27 \mathrm{GPM}$ and leaves the $\mathrm{CRC}$ coil at $62{ }^{\circ} \mathrm{F}$ while heating the air from $55^{\circ} \mathrm{F}$ up to $65^{\circ} \mathrm{F}$. The HEDS unit requires 226,187 BTU per hour to cool, dehumidify and reheat 10,000 CFM of air at the same conditions, a total British Thermal Unit per Hour (BTUH) savings of $53 \%$ and a $\mathrm{CHW}$ flow reduction of $62 \%$ in this example.

Attributes of the HEDS unit include:

- Very large face area and depth cooling and cooling recovery coils

- Low CHW flow rates and High CHW temp differential

- Increased cooling capacity at lower CHW flows

- Elimination of "Low Delta T syndrome"

- Low AHU air pressure drops due to large coil face area and low face velocity

- Ability to reduce equipment run time by thousands of hours per year on non-8,76o loads

- Delivery of cool, dry air in an energy efficient manner

- Reduction of infrastructure and operations and maintenance (O\&M) costs

- Reduction of pumping and chiller energy use

- Configuration that allows chillers to be piped in series to further improve chiller capacity and energy efficiency

- Increased CHW system infrastructure delivery capacity, saves infrastructure $\$ \$ \$$. 
- Reduction of water consumption/can generate water from condensation

- Support for ASHRAE 90.1 Prescriptive Energy Code Compliance.

A number of existing technologies currently on the market for dehumidification have significant limitations when compared with the HEDS system design, including:

- Increased maintenance costs due to complexity of additional fluid stream, pumps, heat recovery wheels, heat exchangers, motors, belts and other components

- Potentially decreased CHW system temperature differential due to smaller coils and reduced inlet air temperatures to the cooling coil, leading to the "Low Delta T Syndrome," which can increase central plant energy use and reduce cooling system usable capacity

- Poor temperature control due to uncontrolled inlet temperatures from heat recovery coils

- Added regeneration heat energy and post-wheel cooling associated with some desiccant designs

- Much longer, taller or heavier AHUs

- Higher air pressure drop and fan energy due to additional upstream and downstream coils and wheels requiring more fan energy

- Condensate re-evaporation when water is blown off the cooling coil into the fan or ductwork

- Designs that are not scalable to room or fan coil unit sizes, where many of the problems are found.

The following is an example of how the HEDS unit may operate in the field.

To serve a specific load at a specific time, the mixed air may need to be sub-cooled to $52{ }^{\circ} \mathrm{F}$ using the Cooling Coil (CC) to condense and remove moisture, and then the air must be reheated back up to $62{ }^{\circ} \mathrm{F}$ to control $\mathrm{RH}$ and prevent space over cooling. To do this, the CRC is used to warm up the supply air leaving the cooling coil with the warmer water leaving the cooling coil. This will lower the $\mathrm{RH}$ of the supply air entering the space to prevent overcooling of the space and reduce the potential for condensation to occur in the space.

Two hours later, occupancy may have reduced substantially, the HEDS AHU may have adequately removed moisture from the space, and the outside air (OSA) may have a dewpoint below $53^{\circ} \mathrm{F}$. Therefore, the unit 
only needs to cool the air to $60^{\circ} \mathrm{F}$ to meet the load. Supply air can be supplied without any sub-cooling or reheat, because the space or return air dewpoint is at $52{ }^{\circ} \mathrm{F}$, so the supply air $\mathrm{RH}$ is around $75 \%$ and it is going into a relatively dry space.

If the space is very hot and muggy, the AHU may need to provide $48^{\circ} \mathrm{F}$ supply air off the cooling coil to remove moisture, and provide $58^{\circ} \mathrm{F}$ drybulb temperature coming off the CRC to dry the space out quickly, and reduce the potential for condensation to occur.

The cooling/ dehumidification/ reheat loads change constantly, and the control strategies will take the changing loads into account on a continuous basis. The HEDS unit is equipped with a standalone control system capable of performing all required functions (described below).

\subsubsection{HEDS standalone unit controller description}

The HEDS units are equipped with factory programmed standalone controllers. The HEDS controller hardware for these two test sites consists of the Trane UC 600 hardware platform, which is configured to receive inputs from all of the HEDS sensors and alarms, including water temperatures, water differential pressures, Belimo Energy Valve data, airside drybulb and dewpoint temperature sensors, airside RH sensors, airside airflow rates, filter alarms, low pressure cutout alarms, and low temperature cutout alarms. In addition, the HEDS controller will accept data from the variable speed drive network connection.

The HEDS standalone controller is configured to control the valve positions for the preheat coil, the cooling coil, the cooling recovery coil, and the reheat coil (RHC is at Tinker AFB only) to maintain space conditions within Unified Facilities Criteria (UFC) requirements. The outside air, mixed air, and exhaust air dampers are controlled in addition to the speed of the fan motor in response to logic commands contained in the HEDS controller software. The HEDS controller receives inputs from the Building Automation System (BAS) to start and stop the HEDS unit; it also sends requests to start the chiller plant and boiler plant if the HEDS unit determines the need for after-hours RH or temperature control.

The HEDS controller feeds operational data to the HEDS trending system, the Tracer SC system. The HEDS trending system stored data for the monitored and calculated variables at 5 -minute intervals for retrieval and evaluation. 
There are three basic operational modes for the HEDS unit contained in the HEDS standalone controller, with underlying mode specific sequences that describe the detail of how the system will be operated when in those modes

1. The first and simplest main mode is the heating mode. In this mode, the unit will operate the supply fan and the heating coil(s) as required to maintain the space conditions as needed.

2. The second main mode is the cooling-dehumidification-reheat mode of operation. This mode is where the majority of the energy savings occur. When in this mode, the cooling coil is operated to cool the air and to remove moisture from the air to reduce the RH in the space. In this mode, the cooling recovery coil is operated to increase the supply air temperature of the supply air, which will lower the RH of the supply air and the space conditions. Operation of the CRC will also reduce the potential for overcooling of the spaces and reduce the potential for condensation to occur in the HVAC ductwork and the occupied spaces.

3. The last main mode is the cooling-only mode. When the space temperatures and dewpoint are under control, and the outside air and mixed air temperature dewpoint temperatures are low enough to reduce the potential for condensation to occur, the CRC logic will be disabled and the cooling coil will still provide cooling and possibly dehumidification, but with no need to operate the CRC.

Other operational modes include:

- Startup mode. During initial system startup the system is enabled with a 5- to 10-minute delay to reduce the potential for unneeded system spikes.

- Overnight batch dehumidification mode. The overnight batch dehumidification mode can be selected by the operating staff if they feel the need to operate the HEDS unit to keep the facility dried out during hot muggy conditions when the facility is normally shut down. The batch mode would be used when conditions are bad but not terrible, and the HEDS unit may need to be started once or twice a night to prevent the facility from becoming humidity saturated. Due to chiller plant operational issues at both sites, it was not possible to test this sequence.

- Overnight continuous dehumidification mode. The overnight continuous dehumidification mode can be selected by the operating staff if they feel the need to operate the HEDS unit to keep the facility dried out during hot muggy conditions when the facility is normally shut 
down. The continuous mode would be used when conditions are very moist, and the HEDS unit may need to be run continuously overnight to prevent the facility from becoming humidity saturated. Due to chiller plant operational issues at both sites, this sequence was unable to be tested.

- DOAS Mode. To simulate being a 100\% outside air Dedicated Outdoor Air System unit. Due to chiller plant operational issues at both sites, this sequence could not be tested.

- Economizer mode. The economizer mode would be enabled when conditions show that use of the economizer would provide benefits to the facility. The economizer mode would have three triggers that would keep it off, or shut it off if it is operational: comparative enthalpy, outdoor dewpoint temperature and outdoor drybulb can all be used to limit the use of the economizer when it may impact humidity control.

These sequences should be operated seamlessly; facility occupants should feel no discernible changes. All these operating modes can occur daily during transitional weather patterns.

\subsection{Technology development}

The background design work for the HEDS technology dates back to 1985 . The experience gained designing, implementing and testing cooling coils with extremely high chilled water system temperature differentials between 1985 and 2007 was critical to the development of the HEDS technology; therefore, the technology development timeline below includes representative work in those time frames. Some of the high points of the experience that has supported the technology development are:

- 1985 - Large Temperature Differential (LTD) cooling system designs, with systems designed to deliver $76^{\circ} \mathrm{F}$ chilled water return temperatures when the cooling coils were provided with $39^{\circ} \mathrm{F}$ chilled water from a chilled water thermal energy storage system.

- 1985 to 2007 - Installation of hundreds of LTD cooling coils at dozens of facilities prove the ability to reliably obtain cooling coil leaving chilled water temperatures in excess of $70^{\circ} \mathrm{F}$ in the summer.

- 1992 to 2005 - University of Southern California (USC) campus converts the majority of their cooling coils to LTD design. Campus chilled water system temperature differential (TD) increases from $8{ }^{\circ} \mathrm{F}$ to $9^{\circ} \mathrm{F}$ in the summer ("Low Delta T Syndrome") to $25^{\circ} \mathrm{F}$ to $27^{\circ} \mathrm{F}$. This enables a $300 \%$ increase in cooling capacity through the existing CHW 
piping distribution system, saving millions of dollars for USC. This also enables a proposed 9MMG Thermal Energy Storage (TES) tank to be downsized to a 3MMG TES tank, saving additional millions of dollars.

- 2006/7 - Site visits to multiple DoD facilities to evaluate hundreds of buildings shows biological growth in human-occupied spaces is still a large problem. This further proves the need for a dehumidification system that is cost effective, efficient, reliable, maintainable, and sustainable, and that can be used with either two-pipe or four-pipe water distribution systems.

- 2007 - The USACE Challenge to Principal Investigator while on a base in a room full of biological growth was stated as a directive to "figure out a way to solve the biological growth problem with a system that our guys can understand and that can be maintained with very low maintenance budgets." The HEDS unit was developed to address this challenge.

- 2007 - Development of HEDS design, which reclaims very low quality cooling energy as a reheat energy source to eliminate the need for new reheat energy for RH control, and to save chiller plant energy at the same time.

- 2007 - 2011 - HEDS patents applied for and awarded.

- Technology Maturity for Commercialization: The results from the two ESTCP test sites indicates that the savings potential is on par with the estimated, modeled savings potential. Additionally, the HEDS units' maintenance is no different than that of a standard chilled water AHU.

\subsection{Advantages and limitations of the technology}

\subsubsection{Comparative technologies}

HEDS AHUs have a number of advantages over existing dehumidification systems solutions. Some of the most common dehumidification designs applicable to chilled water systems are:

- Chilled water/ direct expansion coils with gas or electric reheat

- Run-around coils

- Heat pipe coils

- Rotary wheel heat exchangers

- Air-to-air heat exchangers

- Desiccant dehumidification wheels.

The following sections briefly discuss each system. 


\subsubsection{Chilled water/ direct expansion coils with gas or electric reheat}

By far the most common and energy intensive solution used in dehumidification AHUs is the sub-cooling of the air to remove moisture by condensation, then to add heat to reheat the sub cooled and dehumidified air back up to lower the $\mathrm{RH}$ of that air and provide temperature control for the spaces (Figure 3). The reheat energy can be provided by hot water coils fed from a central boiler system, on-board furnace, or electric strip heating elements. Cooling energy can be provided by chilled water coils or direct expansion (DX) coils.

Figure 3. Typical reheat dehumidification design.

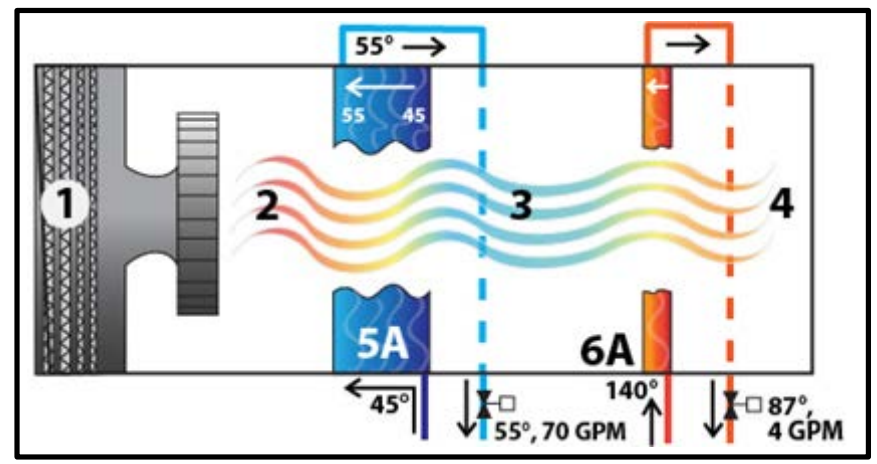

Data Points 1 through 4 in Figure 3 denote: [1] 10,00o CFM airflow [2] $78^{\circ} \mathrm{F}$ dry bulb temp, $65^{\circ} \mathrm{F}$ wet bulb temp [3] $55^{\circ} \mathrm{F}$ dry bulb, $55^{\circ} \mathrm{F}$ dewpoint, essentially $100 \% \mathrm{RH}$ [4] $65.3{ }^{\circ} \mathrm{F}$ dry bulb, $55^{\circ} \mathrm{F}$ dewpoint, $55 \% \mathrm{RH}$

Typical AHUs providing dehumidification and reheat use relatively small, high air face velocity cooling and reheat coils, high CHW flow rates, low CHW temperature differential and high AHU air pressure drops. In this example, $45^{\circ} \mathrm{F}$ CHW enters the cooling coil (5A) at $70 \mathrm{GPM}$ and leaves the cooling coil at $55^{\circ} \mathrm{F}$. A new source of $140^{\circ} \mathrm{F}$ water enters the reheat coil (6A) at $4 \mathrm{GPM}$ and leaves the reheat coil at $87^{\circ} \mathrm{F}$. The unit requires 479,319 BTUs per hour to cool, dehumidify and reheat 10,000 CFM of air at the design conditions in this example.

Figure 4 shows how HEDS eliminates the need for new reheat energy and reduces the total cooling load of the unit, using the same airside design conditions as shown in Figure 3 above. 
Figure 4. HEDS unit depiction highlighting the mechanism for eliminating reheat and reducing cooling load.

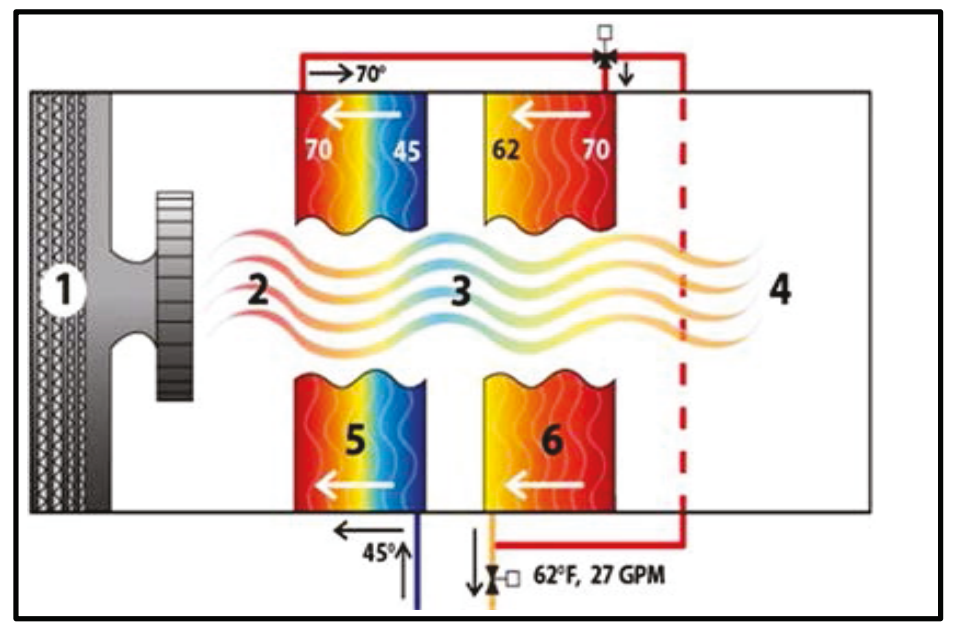

The HEDS units use very large face area and depth cooling and cooling recovery coils, low $\mathrm{CHW}$ flow rates, high $\mathrm{CHW}$ temperature differential, and low AHU air pressure drops. In this example, which matches the conditions above, $45^{\circ} \mathrm{F} \mathrm{CHW}$ enters the cooling coil (5) at $27 \mathrm{GPM}$ and leaves the cooling coil at $70{ }^{\circ} \mathrm{F}$. This $70^{\circ} \mathrm{F}$ water then enters the $\mathrm{CRC}$ coil (6) at $27 \mathrm{GPM}$ and leaves the $\mathrm{CRC}$ coil at $62{ }^{\circ} \mathrm{F}$ while heating the air to $65^{\circ} \mathrm{F}$. The HEDS unit requires 226,187 BTU per hour to cool, dehumidify and reheat 10,000 CFM of air at the same conditions, a BTUH savings of $53 \%$ and a CHW flow reduction of $62 \%$ in this example.

\subsubsection{Run-around coils}

Run-around coil designs use a set of coils to accomplish reheat with reduced energy consumption (Figure 5). The coils can be placed in the return/ exhaust air streams or in the upstream outside air stream or mixed air plenum before the cooling coil to provide the reheat energy. The runaround coil examples below show the pre-cool coil upstream of the cooling coil to act as a heat source for the downstream reheat coil to provide some heat for reheating in dehumidification units. 
Figure 5. Run-around coil system example layouts.

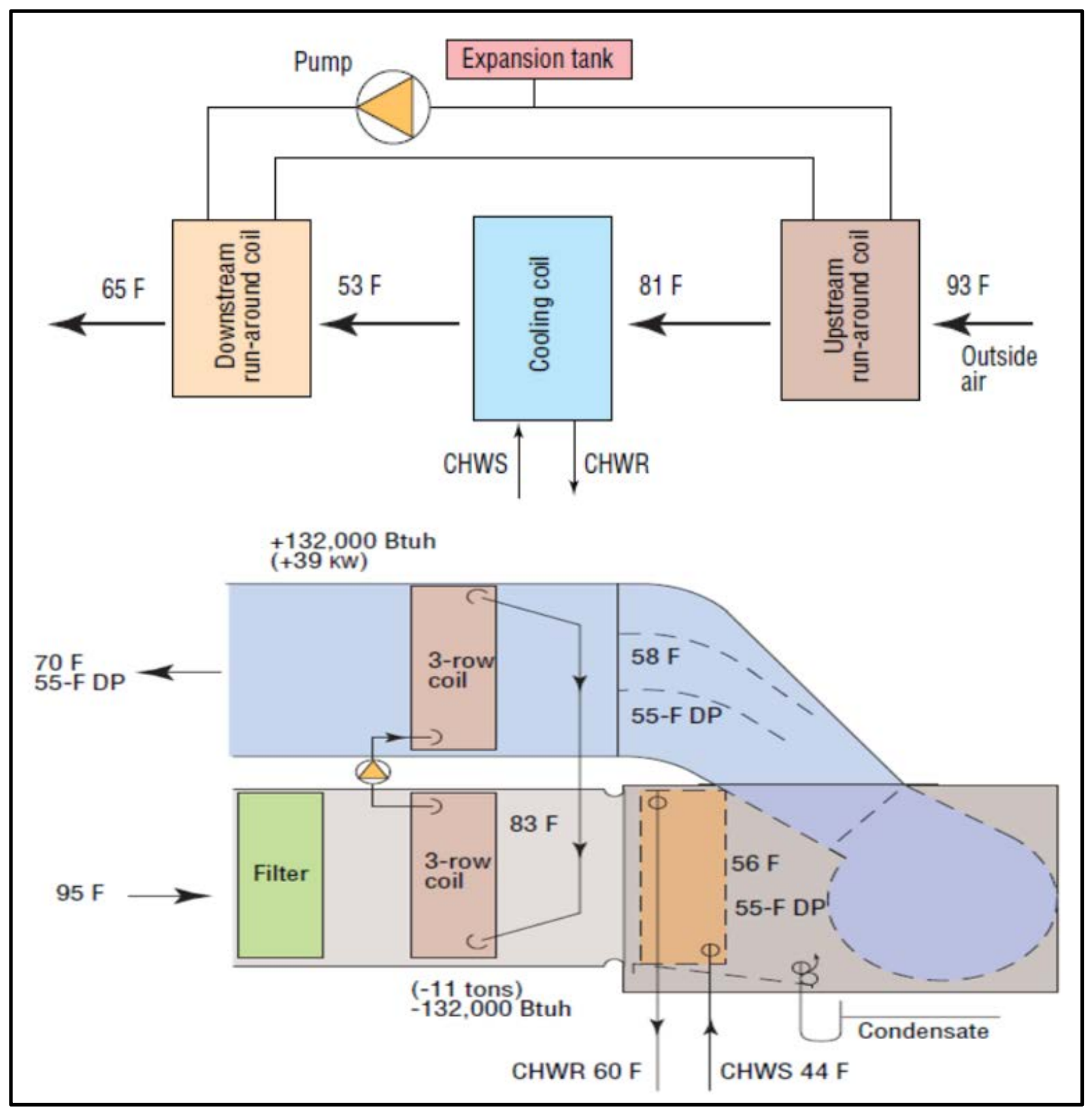

Source: Donald P. Gatley, P.E. President, Gatley and Associates, for HPAC Engineering Magazine in 2000

Compared with HEDS technology, run-around coils have a number of disadvantages, including:

- Increased maintenance costs due to complexity of additional fluid stream, pumps, and components.

- Potentially decreased CHW system Delta T due to smaller coils and reduced inlet air temperatures to the cooling coil, leading to the "Low 
Delta T Syndrome.” This can increase central plant energy use and reduce cooling system capacity.

- Poor temperature control due to uncontrolled inlet temperatures of the run-around coil.

- Much longer or taller AHU.

- Higher air pressure drop due to additional upstream and downstream coils requiring more fan energy.

- Condensate re-evaporation when blown off cooling coil.

- A design that is not scalable to Fan-Coil Unit (FCU) sizes.

\subsubsection{Heat pipe coils}

Heat pipes are very similar to run-around coils, but are refrigerant based, which eliminates the need for additional pumps, expansion tanks, and other ancillary equipment (Figure 6).

Figure 6. Heat pipe coil design example.

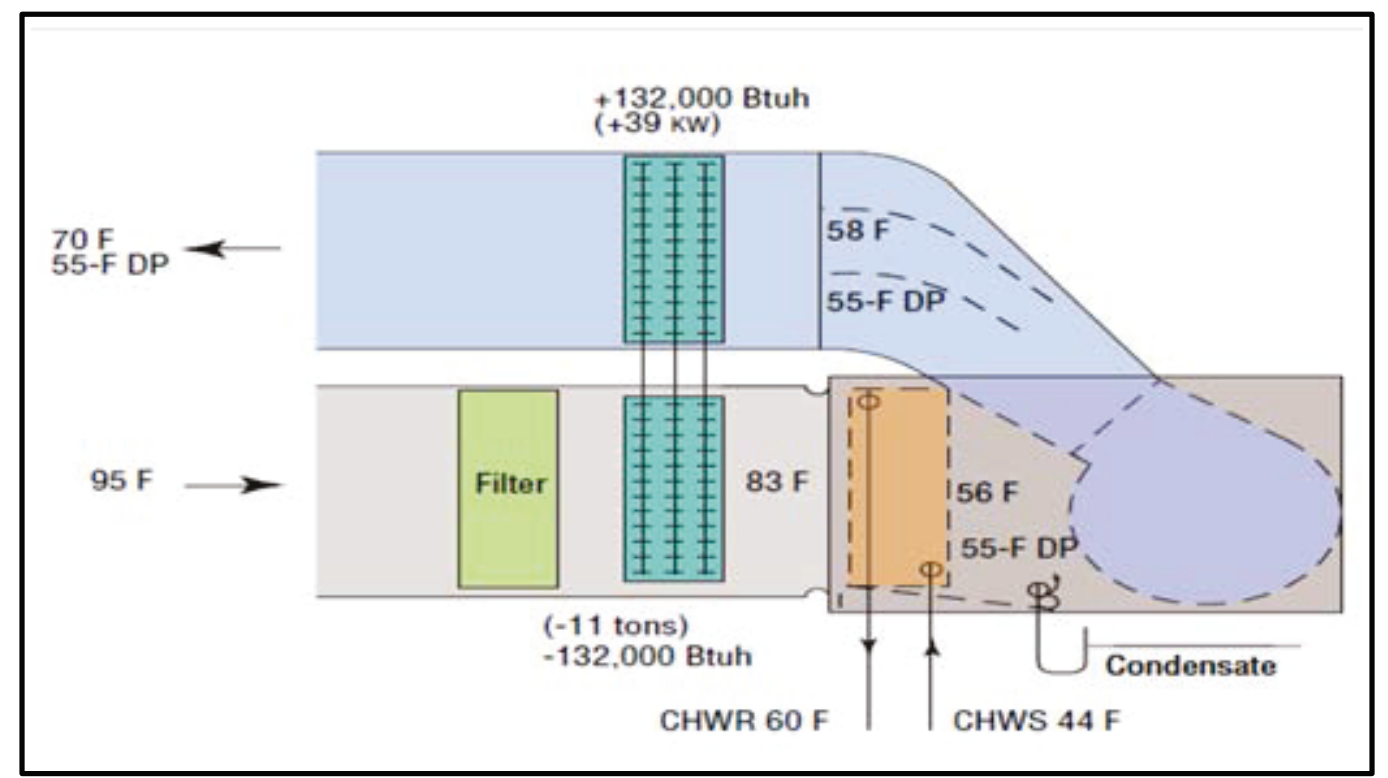

Source: Donald P. Gatley, P.E. President, Gatley and Associates, for HPAC Engineering Magazine in 2000

Compared with HEDS technology, heat pipe coils have a number of disadvantages, including:

- Increased maintenance costs due to complexity of refrigerant transfer coils.

- Potentially decreased CHW system Delta T due to smaller coils and reduced inlet air temperatures to the cooling coil, leading to the "Low 
Delta T Syndrome.” This can increase central plant energy use and reduce cooling system capacity.

- Poor temperature control due to uncontrolled or minimally controlled inlet temperatures of the heat pipe coil.

- Much longer or taller AHU.

- Higher air pressure drop due to additional upstream/downstream coils requiring more fan energy.

- Condensate re-evaporation when blown off cooling coil.

- Design is not scalable to FCU sizes.

\subsubsection{Rotary wheel heat exchangers}

Rotary wheel heat exchangers such as sensible energy recovery wheels can also be used to provide the reheat energy associated with dehumidification (Figure 7). Enthalpy (or total energy) wheels can also be used to reduce the humidity of incoming air streams. Rotary wheels capture energy from an exhaust or return air stream and transfer it directly to the supply air stream downstream of the cooling coil, providing the reheat to raise the temperature of the subcooled air off the cooling coil.

Figure 7. Rotary heat exchanger design example.

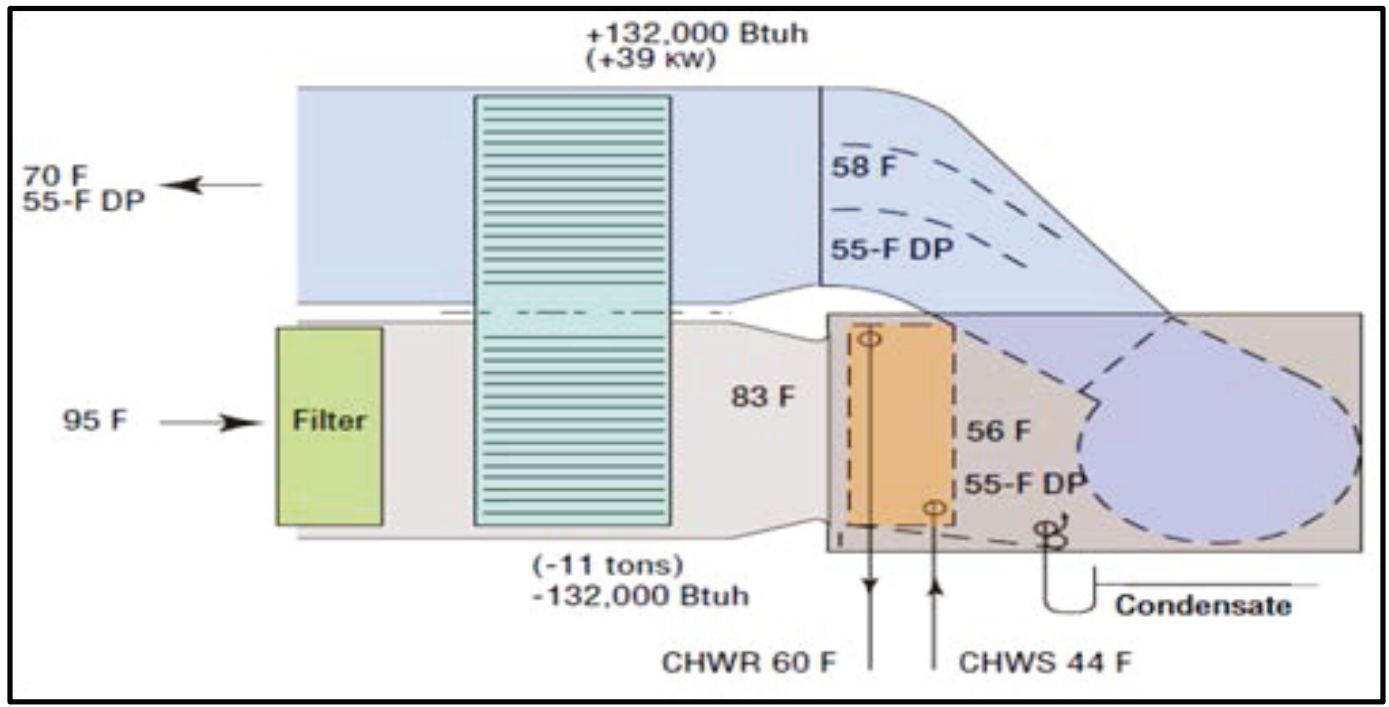

Source: Donald P. Gatley, P.E. President, Gatley and Associates, for HPAC Engineering Magazine in 2000

Compared with HEDS technology, rotary heat exchangers have a number of disadvantages, including:

- Increased maintenance costs due to complexity of heat transfer wheels and motors. 
- Plugging or contamination of heat exchanger wheels caused by imperfect air filtration, which can significantly decrease performance.

- Potentially decreased CHW system Delta T due to smaller coils and reduced inlet air temperatures to the cooling coil, leading to the "Low Delta T Syndrome." This can increase central plant energy use and reduce cooling system capacity.

- Much longer or taller AHU.

- Higher air pressure drop due to added losses in both supply and exhaust streams for the rotary wheel requiring more fan energy.

- Condensate re-evaporation when blown off cooling coil.

- A design that is not scalable to FCU sizes.

\subsubsection{Air-to-air heat exchangers}

Air-to-air heat exchangers use a set of plate heat exchangers to accomplish reheat without additional energy by recovering energy from the outside air or return air streams to provide reheat (Figure 8).

Figure 8. Air-to-air heat exchanger system example layouts.

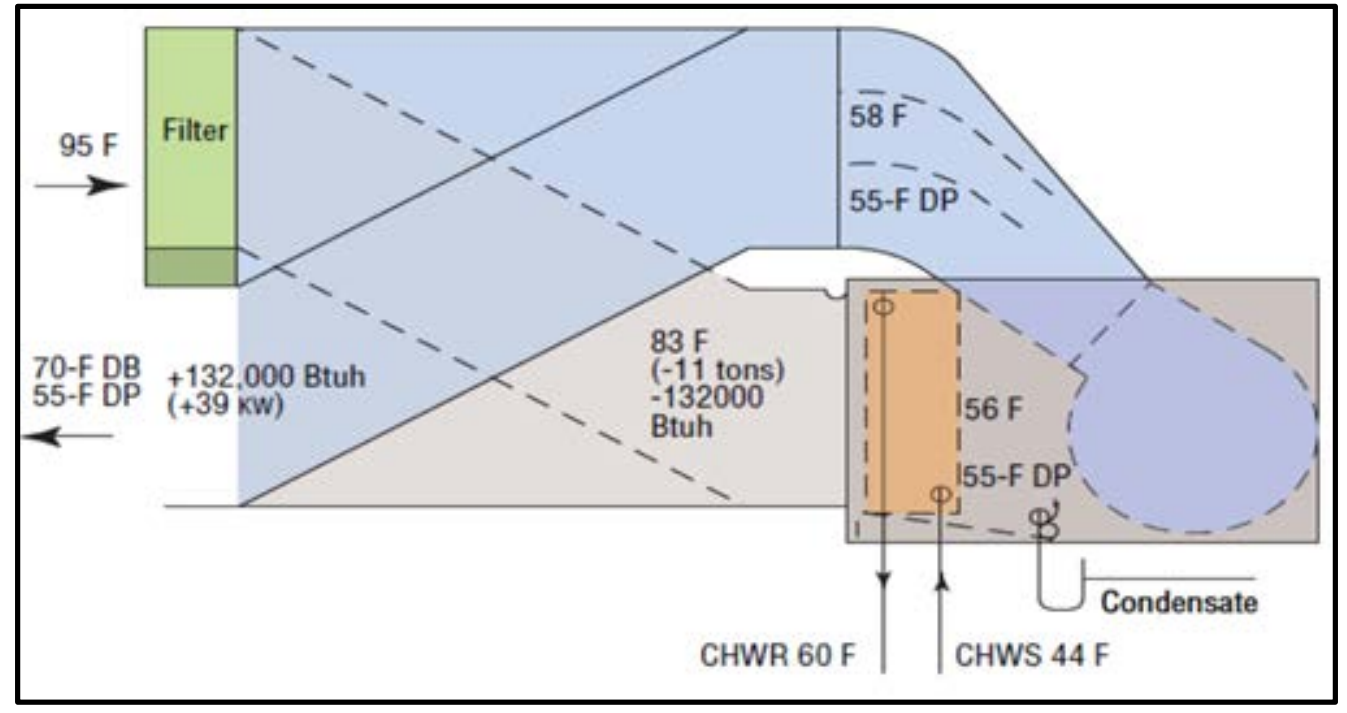

Source: Donald P. Gatley, P.E. President, Gatley and Associates, for HPAC Engineering Magazine in 2000

Compared with HEDS technology, air-to-air heat exchangers have a number of disadvantages, including:

- A potentially decreased CHW system Delta T due to smaller coils and reduced inlet air temperatures to the cooling coil, leading to the "Low Delta T Syndrome." This can increase central plant energy use and reduce cooling system capacity. 
- Poor temperature control due to uncontrolled inlet temperatures of the air-to-air heat exchanger.

- Much longer or taller AHU.

- Significantly higher ductwork costs.

- Higher air pressure drop due to additional air coils requiring more fan energy.

- Condensation may form inside the Heat Exchanger (HX).

- Condensate re-evaporation when blown off cooling coil.

- Design is not scalable to FCU sizes.

\subsubsection{Desiccant dehumidification}

At this time, a correct thermodynamic or physical diagram for the desiccant wheel design is not available, but it is vaguely similar to the rotary wheel diagram shown in Figure 9 if the temperature points are ignored. Desiccantbased systems use a regenerative desiccant wheel to accomplish dehumidification while eliminating required reheat energy, but adding post-unit cooling energy to reduce the supply air temperature to a reasonable level. The desiccant wheel is placed in the return/exhaust air streams or in the upstream outside air stream before the cooling coil to provide the required dehumidification while reducing cooling and reheat energy. Many desiccant wheel designs require an additional heat source of $200^{\circ} \mathrm{F}$ or higher air to regenerate the desiccant to provide sufficient dehumidification.

Figure 9. Desiccant wheel system placeholder layout. (Ignore airside temperatures, rough physical layout only intended as a proxy for the desiccant wheel design)

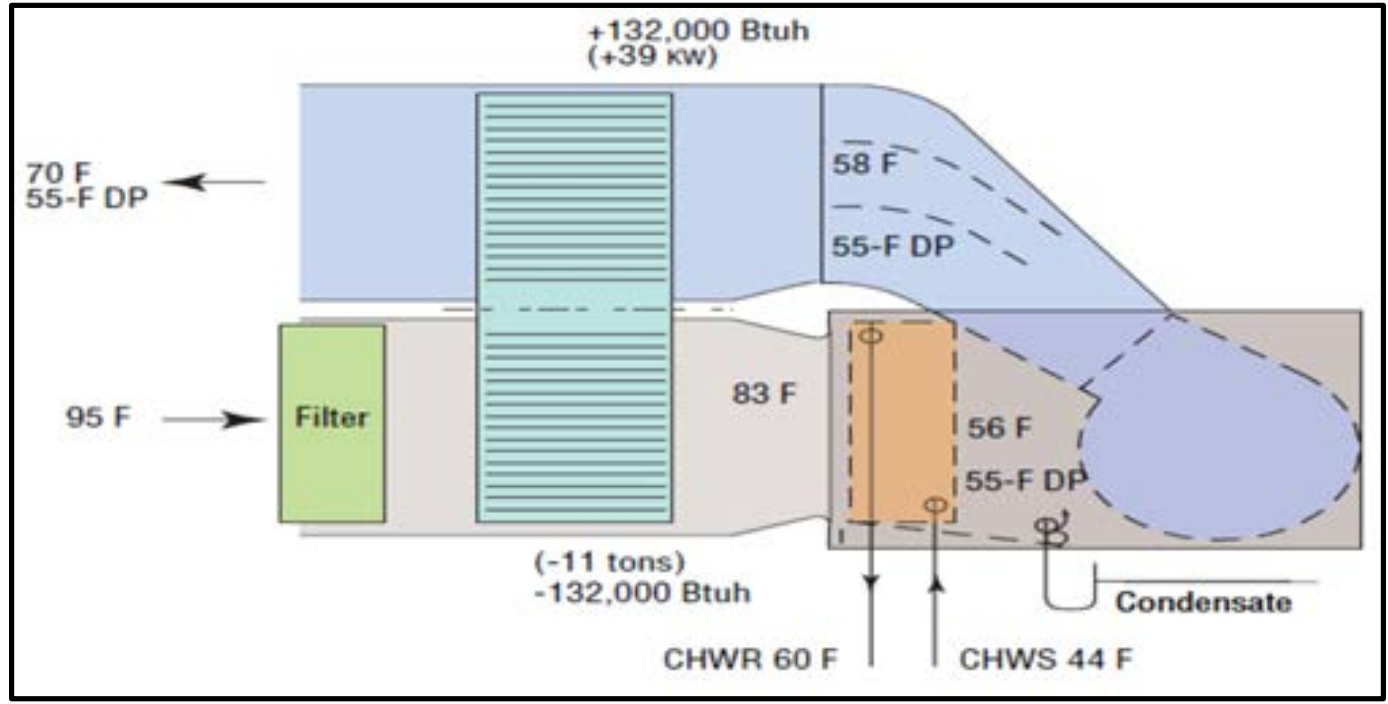

Source: Donald P. Gatley, P.E. President, Gatley and Associates, for HPAC Engineering Magazine in 2000 
Compared with HEDS technology, desiccant wheels have a number of disadvantages, including:

- Much longer or taller AHU.

- Significantly higher air pressure drop, such that desiccant wheel requires more fan energy.

- Added regeneration heat energy with some desiccant designs.

- A need for post wheel cooling (for most desiccants)

- Typically much larger and heavier units.

- A need for post cooling coil to drop supply air temperature off some wheel types from over $90^{\circ} \mathrm{F}$ to a usable level.

- Significant increased complexity and maintenance costs.

- A design that is not scalable to FCU sizes.

\subsubsection{Performance advantages of the HEDS technology}

The HEDS unit uses the very low quality heat that is generated during the cooling and dehumidification process to provide the necessary reheat energy to lower the RH of the supply air. This in turn reduces the potential for moisture condensation in AHUs' ducts and occupied spaces, and reduces the cooling load on the chiller plant. This cooling load reduction in BTUs is equal to the amount of recovered energy that is used to provide reheat. For $\mathrm{RH}$ control processes, this eliminates the need for a supplemental reheat source in many climates, thereby substantially reducing both chiller plant and heating plant energy consumption. HEDS can work with two-pipe water distribution systems where other systems may not work.

The HEDS unit is designed exactly as a "normal" AHU would be built, but with two major changes

1. The cooling coil in a HEDS unit has approximately $300 \%$ more heat transfer surface area than a normal cooling coil to obtain a very warm water temperature leaving the coil. As a result, this warm water can be used as a reheating energy source by the CRC.

2. The use of a CRC, which has more than $1000 \%$ greater heat transfer surface area than a normal reheat coil, which enables the use of the low quality heat leaving the cooling coil. This enables the warm chilled water leaving the cooling coil to raise the temperature of the chilled air leaving the cooling coil so that the building spaces are kept comfortable and the supply air is delivered at a much lower RH. 
The act of warming the sub-cooled air leaving the cooling coil using the $\mathrm{CRC}$ draws heat from the chilled water and reduces the temperature of the return chilled water, minimizing the load on the chiller. The CRC "looks" like an upstream series chiller to the chilled water system in that it reduces the water temperature returning to the chiller plant by $6^{\circ} \mathrm{F}$ to $12^{\circ} \mathrm{F}$. The $\mathrm{CRC}$ also looks like a heating coil to the airstream, in that it raises the supply air temperature by $6^{\circ} \mathrm{F}$ to $15^{\circ} \mathrm{F}$.

The large face area coil design reduces the air velocity through the AHU, which provides a $>50 \%$ reduction in air filter and coil air pressure drop; the lower required cooling water flow rate results in $>70 \%$ pumping energy reduction for the loads served by HEDS units. The combined air pressure drop of the CC and CRC is approximately 50\% lower than that of a typical cooling coil and reheat coil combination due to the very large face area of the HEDS coils and the associated very low air velocities through the coils.

\subsubsection{Cost advantages of the HEDS technology}

A benefit of HEDS is that the chilled water flow rate required to meet peak day cooling/dehumidification needs will be reduced by approximately 50 to $60 \%$ compared to typically installed AHU systems. This results from a combination of reduced cooling plant loads and increased chilled water system temperature differentials provided by the very large cooling coils and the CRC. On sites that may be at the capacity limits of their piping infrastructure, the ability to meet the same cooling loads with a 50 to $60 \%$ reduction in the chilled water flow rate can mean that the avoided costs from not having to replace or augment the piping infrastructure can cover most or all of the costs of HEDS retrofit projects.

For many installations, if HEDS is not used, to provide code mandated RH control to facilities equipped with two-pipe water distribution systems, reheat energy for RH control must be provided by electric strip heaters, which, ironically, will not comply with new energy codes. The electrical infrastructure of most facilities is inadequate to provide this added power requirement to the buildings and down to the AHU level, so the facilities that need RH control typically go without RH control. This has led to the current situation with widespread biological growth and high biological remediation costs. Health, wellness, productivity and morale all suffer in a facility affected by biological growth. 
Since the HEDS unit is a normal AHU built with very large cooling and cooling recovery coils, it is no more complex or costly to operate and maintain than a conventional AHU. A basis of its design is that it is intended to be maintained by HVAC mechanics with a basic level of maintenance training to reduce the lifecycle cost on the unit. Other systems, such as desiccant driven or direct expansion (DX) type dehumidifiers, require operators to have specialized maintenance and operations knowledge, and require additional energy use to perform $\mathrm{RH}$ and temperature control in comparison to the HEDS unit.

\subsubsection{Performance limitations of the HEDS technology}

Adequate physical space will need to be allocated for the HEDS units, which cannot be located in very tight mechanical spaces as they can be physically larger than a "normal" AHU. Where there is a lack of space in a very tight mechanical room, it may be possible to locate the HEDS unit next to the loads and cut it into the required point of connection. Note however that HEDS units will typically be smaller than a desiccant wheelbased system that delivers the same conditions.

The lowest reasonable dewpoint temperature that a HEDS unit can provide without requiring defrost cycles is approximately $35^{\circ} \mathrm{F}$, so many industrial processes can use HEDS. For process loads that need to be provided with ultra-low dewpoint air, some form of a desiccant-based system will most likely be the most effective option, as long as there are adequately trained mechanics and an appropriate maintenance budget allocated for this system.

Because a major intent of the HEDS technology is to cool and dehumidify conditioned air in a more efficient and lifecycle cost effective way, the HEDS units will work best at geographic locations that have a hot and humid climate for at least 4 months of the year, or that are in milder climates, but need to provide 48 to $50^{\circ} \mathrm{F}$ dewpoint air to their cooling loads, such as hospitals and clean room environments located in the U.S. Southwest or precision semiconductor and pharmaceutical manufacturing facilities across much of the United States.

\subsubsection{Cost limitations of the HEDS technology}

The cost effectiveness of the HEDS units may be very site specific. On standalone implementations of an HVAC unit that is not currently 
equipped to provide the "reheat" part of the dehumidification-reheat process, it may be less costly to employ the HEDS unit than to try to create and implement a new reheat energy source, or to convert the unit to one of the other dehumidification/reheat strategies, especially if the installation must comply with energy codes that forbid simultaneous heating and cooling for RH control.

Conversely, if a facility has a 4 pipe water distribution system, and runs the boilers all summer long in addition to running the chillers, and the AHUs are already equipped with reheat coils (not just pre-heat coils), the HEDS unit may have a higher first cost, but the lower operating expenses or other cost offsets, such as reduced capital expenditures for chillers, pipes, pumps, cooling towers, and chiller plant physical room expansions may make it cost effective.

For facilities operating under a mandate to reduce energy and water consumption, the efficiency benefits of the HEDS unit may make it a lifecycle cost effective solution, even if it has a higher first cost.

A top-level analysis was performed to determine potential Savings to Investment Ratios (SIRs) for various HEDS applications. The SIRs ranged from a low of 2 to a high of over 300. Some implementations would have an infinitely high SIR, as the first cost of the HEDS may be lower than the base case alternative system, so there is no "investment"; the system evaluation starts with a cost reduction vs. a cost.

Non-energy benefits such as improved health and wellness, energy resiliency, improved use of renewable energy, and saving lives through the reduction of Healthcare Acquired Infections (HAIs) are non-trivial, and may be the driving forces behind HEDS implementations. The energy benefits are important, but may not be the main reason for the implementations. 


\section{Performance Objectives}

Table 1. Summary of quantitative performance objectives.

\begin{tabular}{|c|c|c|c|}
\hline Performance Objective & Metric & Data Requirements & Success Criteria \\
\hline $\begin{array}{l}\text { 1. Peak Cooling Load } \\
\text { Reduction } \%\end{array}$ & \begin{tabular}{|l|} 
Thermal Energy \\
(Tons \\
Refrigeration, kW, \\
mmBTU)
\end{tabular} & $\begin{array}{l}\text { Refrigeration tonnage, CC load, CRC } \\
\text { load, supply and return water } \\
\text { temperatures, chilled water flow } \\
\text { rate through CC and CRC }\end{array}$ & $\begin{array}{l}\text { Reduce } 15-\text { minute peak } \\
\text { cooling load by } 15 \% \text { on a } \\
\text { peak cooling load day } \\
\text { during the demonstration } \\
\text { period }\end{array}$ \\
\hline $\begin{array}{l}\text { 2. Greatest Cooling } \\
\text { Load Reduction \% }\end{array}$ & $\begin{array}{l}\text { Thermal Energy } \\
\text { (Tons } \\
\text { Refrigeration, kW, } \\
\text { mmBTU) }\end{array}$ & $\begin{array}{l}\text { Refrigeration tonnage, CC load, CRC } \\
\text { load, supply and return water } \\
\text { temperatures, chilled water flow } \\
\text { rate through CC and CRC }\end{array}$ & $\begin{array}{l}\text { Highest cooling load } \% \\
\text { reduction exceeds } 20 \% \\
\text { during the demonstration } \\
\text { period }\end{array}$ \\
\hline $\begin{array}{l}\text { 3. Dehumidification } \\
\text { /Reheat Coil Energy } \\
\text { Reduction }\end{array}$ & $\begin{array}{l}\text { Thermal Energy } \\
\text { (Tons } \\
\text { Refrigeration, kW, } \\
\text { mmBTU) }\end{array}$ & $\begin{array}{l}\text { CC load, CRC load, chilled water } \\
\text { supply and return temperatures, } \\
\text { chilled water flow rate through CC } \\
\text { and CRC, reheat coil (RHC) load, hot } \\
\text { water supply and return } \\
\text { temperatures, RHC flow }\end{array}$ & $\begin{array}{l}\text { CRC coil eliminates the } \\
\text { need for at least } 90 \% \text { of the } \\
\text { RH-control -related reheat } \\
\text { energy required from the } \\
\text { reheat coil when the system } \\
\text { is in dehumidification- } \\
\text { reheat mode during the } \\
\text { demonstration period }\end{array}$ \\
\hline $\begin{array}{l}\text { 4. Enhance Space } \\
\text { Comfort Conditions }\end{array}$ & $\begin{array}{l}\text { Space and return } \\
\text { air conditions } \\
\text { compared to UFC } \\
\text { comfort zone for } \\
\text { summer }\end{array}$ & $\begin{array}{l}\text { Space drybulb and dewpoint } \\
\text { temperatures, space } \mathrm{RH} \% \text {, return } \\
\text { air drybulb and dewpoint } \\
\text { temperatures, return air } \mathrm{RH} \%\end{array}$ & $\begin{array}{l}\text { Space conditions fall within } \\
\text { UFC comfort guidelines } \\
\text { more than } 90 \% \text { of the time } \\
\text { during occupied hours }\end{array}$ \\
\hline $\begin{array}{l}\text { 5. Reduce Cooling Ton- } \\
\text { Hours Consumption }\end{array}$ & $\begin{array}{l}\text { Thermal Energy } \\
\text { (Tons } \\
\text { Refrigeration, kW, } \\
\text { mmBTU) }\end{array}$ & $\begin{array}{l}\text { CC load, CRC load, supply and } \\
\text { return water temperatures, chilled } \\
\text { water flow rate through CC and CRC }\end{array}$ & $\begin{array}{l}\text { Cooling ton-hours } \\
\text { associated with the HEDS } \\
\text { unit are reduced by the } \\
\text { cooling recovery coil by } \\
7.5 \% \text { compared to the ton- } \\
\text { hours consumed by the } \\
\text { cooling coil during the time } \\
\text { that the HEDS is in } \\
\text { dehumidification-reheat } \\
\text { mode during the } \\
\text { demonstration period }\end{array}$ \\
\hline $\begin{array}{l}\text { 6. Improve "Low Delta } \\
\text { T" Syndrome }\end{array}$ & $\begin{array}{l}\text { Temperature and } \\
\text { flow } \\
\text { measurements } \\
\text { and/or } \\
\text { calculations }\end{array}$ & $\begin{array}{l}\text { HEDS CC CHW TD and flow, HEDS } \\
\text { CRC CHW TD and flow, HEDS unit } \\
\text { CHW TD and flow }\end{array}$ & $\begin{array}{l}\text { HEDS average CHW system } \\
\text { TD exceeds } 14 \mathrm{~F} \text { during the } \\
\text { time that the HEDS is in the } \\
\text { cooling or dehumidification- } \\
\text { reheat modes during the } \\
\text { demonstration period }\end{array}$ \\
\hline $\begin{array}{l}\text { 7. Reduce Greenhouse } \\
\text { Gas (GHG) } \\
\text { Emissions }\end{array}$ & $\begin{array}{l}\text { Fossil fuel GHG } \\
\text { emissions (metric } \\
\text { tons) }\end{array}$ & $\begin{array}{l}\text { Information in \#8 and estimated } \\
\text { source energy GHG production for } \\
\text { cooling and reheat energy sources }\end{array}$ & $\begin{array}{l}\text { GHG emission reductions } \\
\text { exceed 3\% (annual } \\
\text { comparison) }\end{array}$ \\
\hline
\end{tabular}




\begin{tabular}{|c|c|c|c|}
\hline Performance Objective & Metric & Data Requirements & Success Criteria \\
\hline $\begin{array}{l}\text { 8. Reduce Energy cost } \\
\text { of Dehumidification/ } \\
\text { Reheat process }\end{array}$ & $\%, \$$ & $\begin{array}{l}\text { HEDS estimated kWh/ton-hour for } \\
\text { chiller plant, HEDS cooling ton- } \\
\text { hours for dehumidification, HEDS } \\
\text { CRC tons/MMBTU, calculated RHC } \\
\text { energy use, estimated chiller and } \\
\text { boiler plant system efficiency, kWh } \\
\text { and therms } \\
\text { Average cost/kWh and cost/therm } \\
\text { for Natural Gas (NG) }\end{array}$ & $\begin{array}{l}\text { Cost of Dehumidification } \\
\text { and reheat with HEDS vs. } \\
\text { CV subcool/ terminal reheat } \\
\text { is reduced by } 10 \% \text { during } \\
\text { dehumidification-reheat } \\
\text { modes of operation. }\end{array}$ \\
\hline $\begin{array}{l}\text { 9. System Economics } \\
\text { Reduce Lifecycle } \\
\text { cost of } \\
\text { Dehumidification/ } \\
\text { Reheat process }\end{array}$ & $\%$, \$, years & $\begin{array}{l}\text { Estimated and calculated dollar } \\
\text { costs and savings, discount rate, } \\
\text { usable life }\end{array}$ & $\begin{array}{l}5 \% \text { reduction in lifecycle } \\
\text { costs. }\end{array}$ \\
\hline
\end{tabular}

\subsection{Performance objective results}

Tables 2 and 3 summarize the results of each objective for the test sites. All success criteria were met, and often substantially exceeded, across all objectives at both test sites.

Table 2. Quantitative performance objective results summary for the Fort Bragg Test Site.

\begin{tabular}{|c|c|c|}
\hline Performance Objective & Success Criterion & $\begin{array}{l}\text { Results } \\
\left(\mathrm{CHWST}<46^{\circ} \mathrm{F}\right)\end{array}$ \\
\hline $\begin{array}{l}\text { 1. Peak Cooling Load } \\
\text { Reduction \% }\end{array}$ & $\begin{array}{l}\text { Reduce } 15-\text { minute cooling load by } 15 \% \text { on a peak } \\
\text { cooling load day during the demonstration period }\end{array}$ & $18.3 \%$ \\
\hline $\begin{array}{l}\text { 2.Greatest Cooling Load } \\
\text { Reduction \% }\end{array}$ & $\begin{array}{l}\text { Highest average cooling load \% reduction exceeds 20\% } \\
\text { during the demonstration period }\end{array}$ & $37.4 \%$ \\
\hline $\begin{array}{l}\text { 3. Dehumidification /Reheat } \\
\text { Coil Energy Reduction }\end{array}$ & $\begin{array}{l}\text { CRC coil eliminates the need for at least } 90 \% \text { of the } \\
\text { RH-control-related reheat energy required from the } \\
\text { reheat coil during the time the system is in } \\
\text { dehumidification-reheat mode during the } \\
\text { demonstration period }\end{array}$ & $100.0 \%$ \\
\hline $\begin{array}{l}\text { 4. Enhance Space Comfort } \\
\text { Conditions }\end{array}$ & $\begin{array}{l}\text { Space conditions fall within UFC comfort guidelines } \\
\text { more than } 90 \% \text { of the time during operating hours }\end{array}$ & $96.0 \%$ \\
\hline $\begin{array}{l}\text { 5. Reduce Cooling Ton-Hours } \\
\text { Consumption }\end{array}$ & $\begin{array}{l}\text { Cooling ton-hours associated with the HEDS unit are } \\
\text { reduced by the CRC by } 7.5 \% \text { compared to the ton-hours } \\
\text { consumed by the cooling coil during the time that the } \\
\text { HEDS is in dehumidification-reheat modes during the } \\
\text { demonstration period }\end{array}$ & $24.7 \%$ \\
\hline $\begin{array}{l}\text { 6. Improve "Low Delta T" } \\
\text { Syndrome }\end{array}$ & $\begin{array}{l}\text { HEDS average cooling coil CHW system TD exceeds } \\
14^{\circ} \mathrm{F} \text { during the time that the HEDS is in } \\
\text { dehumidification-reheat modes during the } \\
\text { demonstration period }\end{array}$ & $17.1 \%$ \\
\hline $\begin{array}{l}\text { 7. Reduce Greenhouse Gas } \\
\text { (GHG) Emissions }\end{array}$ & $\begin{array}{l}\text { GHG emission reductions associated with the } \\
\text { dehumidification/reheat process exceed 3\% (annual } \\
\text { comparison) }\end{array}$ & $45-79 \%$ \\
\hline
\end{tabular}




\begin{tabular}{|c|c|c|}
\hline Performance Objective & Success Criterion & $\begin{array}{l}\text { Results } \\
\left(\mathrm{CHWST}<46^{\circ} \mathrm{F}\right)\end{array}$ \\
\hline $\begin{array}{l}\text { 8. Reduce Energy cost of } \\
\text { Dehumidification/ Reheat } \\
\text { process }\end{array}$ & $\begin{array}{l}\text { Cost of dehumidification and reheat with HEDS vs. CV } \\
\text { subcool/terminal reheat is reduced by } 10 \% \text { during } \\
\text { dehumidification -reheat modes of operation }\end{array}$ & $41-51 \%+$ \\
\hline $\begin{array}{l}\text { 9. System Economics Reduce } \\
\text { Lifecycle cost of } \\
\text { Dehumidification/ Reheat } \\
\text { process }\end{array}$ & $5 \%$ reduction in lifecycle costs & $\begin{array}{l}\text { Retrofit: } 26-29 \%+ \\
\text { New construction/ } \\
\text { end of useful life } \\
\text { (EUL): } 38-44 \%+\end{array}$ \\
\hline
\end{tabular}

10. Savings vary based on central plant chiller and heating system efficiencies; uses eGrid national average electricity emissions factors.

Table 3. Performance objective summary for the Tinker AFB test site.

\begin{tabular}{|c|c|c|}
\hline Performance Objective & Success Criterion & $\begin{array}{l}\text { Results } \\
\left(\mathrm{CHWST}<46^{\circ} \mathrm{F}\right)\end{array}$ \\
\hline $\begin{array}{l}\text { 1. Peak Cooling Load } \\
\text { Reduction \% }\end{array}$ & $\begin{array}{l}\text { Reduce } 15-\text { minute cooling load by } 15 \% \text { on a peak } \\
\text { cooling load day during the demonstration period }\end{array}$ & $28.9 \%$ \\
\hline $\begin{array}{l}\text { 2.Greatest Cooling Load } \\
\quad \text { Reduction \% }\end{array}$ & $\begin{array}{l}\text { Highest average cooling load \% reduction exceeds 20\% } \\
\text { during the demonstration period }\end{array}$ & $28.7 \%$ \\
\hline $\begin{array}{l}\text { 3. Dehumidification /Reheat } \\
\text { Coil Energy Reduction }\end{array}$ & $\begin{array}{l}\text { CRC coil eliminates the need for at least } 90 \% \text { of the } \\
\text { RH-control-related reheat energy required from the } \\
\text { reheat coil during the time the system is in } \\
\text { dehumidification-reheat mode during the } \\
\text { demonstration period }\end{array}$ & $100.0 \%$ \\
\hline $\begin{array}{l}\text { 4. Enhance Space Comfort } \\
\text { Conditions }\end{array}$ & $\begin{array}{l}\text { Space conditions fall within UFC comfort guidelines } \\
\text { more than } 90 \% \text { of the time during operating hours }\end{array}$ & $98.0 \%$ \\
\hline $\begin{array}{l}\text { 5. Reduce Cooling Ton-Hours } \\
\text { Consumption }\end{array}$ & $\begin{array}{l}\text { Cooling ton-hours associated with the HEDS unit are } \\
\text { reduced by the CRC by } 7.5 \% \text { compared to the ton-hours } \\
\text { consumed by the cooling coil during the time that the } \\
\text { HEDS is in dehumidification-reheat modes during the } \\
\text { demonstration period }\end{array}$ & $27.6 \%$ \\
\hline $\begin{array}{l}\text { 6. Improve "Low Delta T" } \\
\text { Syndrome }\end{array}$ & $\begin{array}{l}\text { HEDS average cooling coil CHW system TD exceeds } \\
14^{\circ} \mathrm{F} \text { during the time that the HEDS is in } \\
\text { dehumidification-reheat modes during the } \\
\text { demonstration period }\end{array}$ & $24 \%$ \\
\hline $\begin{array}{l}\text { 7. Reduce Greenhouse Gas } \\
\text { (GHG) Emissions }\end{array}$ & $\begin{array}{l}\text { GHG emission reductions associated with the } \\
\text { dehumidification/reheat process exceed 3\% (annual } \\
\text { comparison) }\end{array}$ & $70-86 \%$ \\
\hline $\begin{array}{l}\text { 8. Reduce Energy cost of } \\
\text { Dehumidification/ Reheat } \\
\text { process }\end{array}$ & $\begin{array}{l}\text { Cost of dehumidification and reheat with HEDS vs. CV } \\
\text { subcool/terminal reheat is reduced by } 10 \% \text { during } \\
\text { dehumidification - reheat modes of operation }\end{array}$ & $68-75 \%+$ \\
\hline $\begin{array}{l}\text { 9. System Economics Reduce } \\
\text { Lifecycle cost of } \\
\text { Dehumidification/ Reheat } \\
\text { process }\end{array}$ & $5 \%$ reduction in lifecycle costs & $\begin{array}{l}\text { Retrofit: } 13-41 \%+ \\
\text { New construction/ } \\
\text { EUL: } 43-61 \%+\end{array}$ \\
\hline \multicolumn{3}{|c|}{$\begin{array}{l}\text { 12. Savings vary based on central plant chiller and heating system efficiencies; uses eGrid national average } \\
\text { electricity emissions factors. } \\
\text { 13. Savings vary based on central plant chiller and heating system efficiencies, as well as electricity and gas } \\
\text { commodity rates. Average potential savings over a range of potential cost, efficiency, and reheat source } \\
\text { scenarios is shown. }\end{array}$} \\
\hline
\end{tabular}




\subsection{Performance objectives (POs) descriptions}

\subsubsection{Determine the peak cooling load reduction percent that occurs as a result of the energy recovered via the CRC during the dehumidification/reheat process.}

\subsubsection{Purpose}

The purpose of this PO is to determine the amount of the peak cooling load that can be reduced by using internally reclaimed heating energy for $\mathrm{RH}$ control, vs. introducing externally generated heat into the airstream/facility for RH control.

A substantial amount of cooling and heating energy is used in the dehumidification/reheat process. During the cooling season, most HVAC systems use a substantial amount of recirculated air with a small fraction of fresh outside air brought into the facility, usually 10 to $15 \%$. Since up to $90 \%$ of the air is being recirculated, up to $90 \%$ of the newly introduced reheat energy that is being used for RH control ends up being recirculated by the air distribution system and brought back to the cooling coil in the form of higher return air temperatures and higher cooling loads.

The ability to reduce the peak cooling load can lead to substantially lower operating costs, and can potentially help eliminate the need to expand chiller plants and increase the size of chilled water distribution piping infrastructure.

\subsubsection{Metric}

Tons of cooling required to cool/dry the air via the cooling coil, minus tons of cooling energy reclaimed by the CRC. Tons of cooling required, and subtract the cooling loads that are reduced due to the use of the cooling recovery coil, i.e., if it takes 50 tons to condition the supply air to a $55^{\circ} \mathrm{F}$ dew point temperature, and 120,000 BTUs (10 tons) of reheat energy provided by the cooling recovery coil to raise the supply air temperature to lower the $\mathrm{RH}$, a reduction in the cooling load at the chiller plant of 10 tons would be seen, so the peak load reduction in this case would be $10 / 50=20 \%$. The expected range of peak cooling load reduction is between $10 \%$ and $20 \%$.

The peak load will be determined as follows:

Determine Peak Day 15-minute Peak Load Reduction \% at the Chiller Plant. During dehumidification-reheat operation, reduce the peak-day 15minute peak cooling load served by the chiller plant for the HEDS AHU by 
$15 \%$ compared to the cooling load served by the cooling coil at the HEDS AHU. This assumes that the chiller plant is delivering the design chilled water supply temperature of approximately 44 to $45^{\circ} \mathrm{F}$.

Determine peak day cooling load by summing up the individual day cooling coil tons measurements from $4 \mathrm{AM}$ to $10 \mathrm{PM}$ and comparing all the days that the system is in the dehumidification-reheat mode. The day with the highest cooling coil ton-hours will be considered the peak load day. Use data from this day for the calculations associated with this PO.

\subsubsection{Data}

The following data are required to evaluate the metric:

CC load, CRC load, chilled water supply temperature.

\subsubsection{Analytical Methodology}

Please refer to Section 6.1, "Savings analysis methodology."

\subsubsection{Success criteria}

Reduce 15 -minute peak cooling load by $15 \%$ on a peak cooling load day during the demonstration period.

\subsubsection{Determine the greatest cooling load reduction percent that occurs as a result of the energy recovered via the CRC during the dehumidification/reheat process.}

\subsubsection{Purpose}

The purpose of this PO is to determine the greatest cooling load reduction percent that can be obtained by recovering cooling energy via the CRC.

The CRC performs two main functions, the first is to provide a recovered source of heat energy to perform RH control and temperature control for the supply air and occupied spaces, and the second function is to reduce the cooling load on the chiller plant by the amount of reheat energy that was used for RH control duties. 
Being able to determine the greatest cooling load reduction percent delivers another metric to help determine cost effectiveness and the extent to which cooling plant sizes may be able to be reduced.

\subsubsection{Metric}

Tons of cooling required to cool/dry the air via the cooling coil, minus tons of cooling energy reclaimed by the Cooling Recovery Coil. Tons of cooling required, then subtract the cooling loads that are reduced due to the use of the cooling recovery coil. This is very similar to the first PO, but the project is looking to determine the maximum percent reduction, not the maximum peak load percent reduction. The expected range of greatest cooling load reduction percent is between 15 and $40 \%$.

The greatest load percent reduction will be determined as follows:

Determine greatest load percent reduction at the Chiller Plant by comparing the cooling load served by the cooling coil, to the cooling energy recovered by the CRC. Calculate the percent load reduction for each 5 -minute period that the system is in the dehumidification-reheat mode. From this data, calculate the maximum percent load reduction at the chiller plant. Does the maximum percent cooling load reduction load served by the chiller plant for the HEDS AHU exceed 20\%? This assumes that the chiller plant is delivering the design chilled water supply temperature of approximately 44 to $45^{\circ} \mathrm{F}$.

\subsubsection{Data}

The following data are required to evaluate the metric:

CC load, CRC load, chilled water supply temperature.

\subsubsection{Analytical Methodology}

Please refer to the Section 6.1, "Savings analysis methodology."

\subsubsection{Success criteria}

Reduce the cooling load by $20 \%$ or more for any 5 -minute period that the system is in the dehumidification-reheat mode. 


\subsubsection{Dehumidification / reheat coil energy reduction. Does the HEDS unit reduce reheat energy required by the downstream reheat coil at Tinker AFB by more than $\mathbf{9 0 \%}$ during the dehumidification-reheat process? Fort Bragg AHU does not have a downstream reheat coil, so this PO only applies to Tinker AFB.}

\subsubsection{Purpose}

The purpose of this $\mathrm{PO}$ is to determine if the CRC can eliminate more than $90 \%$ of the reheat-related energy needed for $\mathrm{RH}$ control during the dehumidification-reheat process. Ideally, the HEDS CRC would eliminate all reheat energy required for the $\mathrm{RH}$ control process.

Does the HEDS unit eliminate the need for more than $90 \%$ of the supplemental reheat energy from the downstream reheating coil for RH control at the Tinker AFB test site? This assumes that the chiller plant is delivering the design chilled water supply temperature of approximately 44 to $45^{\circ} \mathrm{F}$ during the cooling season.

\subsubsection{Metric}

Total MBTU of heat/cool energy recovered by the CRC and MBTU of heating thermal energy used for reheat in the reheat coil during the dehumidification/reheat process.

The total amount of reheat energy added by the downstream reheat coil during the dehumidification/reheat coil will be compared to the total amount of reheat energy added by the CRC.

The expected range of avoided reheat coil provided reheat energy during the dehumidification/reheat process is between 90 and $100 \%$.

\subsubsection{Data}

The following data are required to evaluate the metric: CRC load, downstream Reheat Coil (RHC) load, chilled water supply temperature.

\subsubsection{Analytical methodology}

Please refer to the Section 6.1, "Savings analysis methodology." 


\subsubsection{Success criteria}

Reduce the amount of reheat energy required to be provided by the downstream RHC at Tinker AFB by $90 \%$ or more when the system is in dehumidification-reheat mode. $(\mathrm{CRC}$ BTUH/(CRC BTUH + $($ RHC BTUH $))>0.9$

\subsubsection{Enhance space comfort conditions}

\subsubsection{Purpose}

The purpose of this PO is to determine if the HEDS unit can deliver comfort conditions that fall within UFC comfort guidelines more than $90 \%$ of the time during occupied hours, on an annual basis.

\subsubsection{Metric:}

Space conditions and return air conditions will be compared to UFC comfort guidelines during occupied hours. Because it may be difficult to find one sensor location in the space that represents the entire space, sensor have been included in the return air in the projects. These will be the sensors that are more representative of the entire space being served. The expected annual range of compliance with UFC comfort guidelines is between 90 and 95\% during occupied hours.

\subsubsection{Data}

Space conditions and return air conditions - dry bulb temperature, dewpoint temperature and $\mathrm{RH}$ will be used to determine whether the system is operating within UFC guidelines during occupied hours. This assumes that the chiller plant is delivering the design chilled water supply temperature of approximately 44 to $45^{\circ} \mathrm{F}$ during the cooling season.

\subsubsection{Analytical methodology}

The total hours of space conditions within the UFC guidelines will be determined, compared to the total hours of operations (with chilled water systems delivering approximately design chilled water to the AHUs).

\subsubsection{Success criteria}

Does the HEDS unit deliver comfort conditions that fall within UFC comfort guidelines more than $90 \%$ of the time during occupied hours, on an annual basis? 


\subsubsection{Reduce cooling ton-hours consumption. Determine the cooling load ton-hours savings percent that occurs as a result of the cooling energy recovered via the $\mathrm{CRC}$ during the dehumidification/reheat process.}

\subsubsection{Purpose}

The purpose of this PO is to determine the amount of the cooling load in ton-hours that can be reduced by using internally reclaimed heating energy via the $\mathrm{CRC}$ for $\mathrm{RH}$ control, vs. introducing externally generated heat into the airstream/facility for RH control during the cooling season.

A substantial amount of cooling and heating energy is used in the dehumidification/reheat process. The cooling recovery coil has the ability to reduce the annual cooling load that must be served, since it uses reclaimed heat from the cooling process for RH control of the supply air and spaces, rather than introducing a new source of heat into the facility/airstream. The amount of reheat energy saved in BTUH translates exactly into the amount of cooling energy saved (BTUH converted to ton-hours).

Being able to reduce the annual cooling load (ton-hours) can lead to substantially lower operating costs.

\subsubsection{Metric}

Tons of cooling required to cool/dry the air via the cooling coil, compared to tons of cooling energy reclaimed by the CRC.

Tons of cooling delivered by the cooling coil when the system is in the dehumidification-reheat mode of operation, and subtract the cooling loads that are reduced due to the use of the cooling recovery coil. This assumes that the chiller plant is delivering the design chilled water supply temperature of approximately 44 to $45^{\circ} \mathrm{F}$ during the cooling season.

The expected range of cooling load reduction during the dehumidificationreheat mode of operation is between 5 and $10 \%$ for the systems being tested.

\subsubsection{Data}

The following data are required to evaluate the metric:

CC load, CRC load, chilled water supply temperature. 


\subsubsection{Analytical methodology}

Please refer to the Section 6.1, "Savings analysis methodology."

\subsubsection{Success criteria}

Reduce cooling load ton-hours by $7.5 \%$ when the system is in a dehumidification-reheat mode of operation.

\subsubsection{Determine if the HEDS unit can provide a chilled water system temperature differential that is higher than typical, to help solve the "Low Delta T" syndrome}

\subsubsection{Purpose}

The purpose of this PO is to determine if the HEDS unit can provide a chilled water system temperature differential that is higher than typical, to help solve the "Low Delta T" syndrome.

A substantial amount of chiller plant energy waste occurs due to the "Low Delta T Syndrome." This problem occurs due to undersized/improperly sized cooling coils that require substantially greater CHW flow at a much lower chilled water system temperature differential to meet the typically occurring cooling loads.

This problem creates the need to move a substantial amount of flow through the system at relatively low loads, which can mean that a facility needs to run multiple chillers, when the load may only equate to $50 \%$ of one chiller.

Being able to increase the chilled water system temperature differential can lead to substantially lower operating costs, and can potentially help eliminate the need to expand chiller plants and increase the size of chilled water distribution piping infrastructure.

\subsubsection{Metric}

HEDS unit chilled water temperature differential when in the cooling mode.

The expected range of the HEDS unit chilled water temperature differential for the cooling coil when in the cooling mode is between 15 and $30^{\circ} \mathrm{F}$. 
When the system is in the dehumidification-reheat mode of operation, the expected range is between 10 and $20^{\circ} \mathrm{F}$. This assumes that the chiller plant is delivering the design chilled water supply temperature of approximately 44 to $45^{\circ} \mathrm{F}$ during the cooling season.

\subsubsection{Data}

The following data are required to evaluate the metric:

CC chilled water temperature differential, CRC chilled water temperature differential, overall HEDS unit chilled water temperature differential, chilled water supply temperature entering the cooling coil.

The cooling coil TD and flow are being taken such that the tons of cooling required for the cooling/dehumidification process can be calculated. The cooling recovery coil TD and flow are being taken such that the BTUs of heating required for the reheat process can be calculated. This data enables simulation of a "normal" cooling/reheat AHU for comparative purposes.

\subsubsection{Analytical methodology}

Please refer to the Section 6.1, "Savings analysis methodology."

\subsubsection{Success criteria}

HEDS average CHW cooling coil TD exceeds $14{ }^{\circ} \mathrm{F}$ during the time that the HEDS is in the cooling or dehumidification-reheat modes during the demonstration period.

\subsubsection{Determine the level of GHG emissions that the HEDS unit contributes to}

\subsubsection{Purpose}

The purpose of this PO is to determine the level of reduction of Green House Gases (GHG) that the HEDS unit contributes to.

\subsubsection{Metric}

Tons or lbs. of GHG reduction made possible by the HEDS system converted to a percent of the baseline GHG emissions. 
The expected range of GHG reductions made possible by the HEDS system is between 1 and $5 \%$.

\subsubsection{Data}

Energy saved at the AHU, chiller plant, boiler plant as calculated in other POs. Conversion factors to electrical generation sources.

\subsubsection{Analytical methodology}

Please refer to the Section 6.1, "Savings analysis methodology," along with detailed GHG emissions factors.

\subsubsection{Success criteria}

Are GHG reductions equivalent to an approximate 3\% savings comparing HEDS operation to Non-HEDS operation?

\subsubsection{Reduce energy cost of dehumidification/reheat process}

\subsubsection{Purpose}

To determine if the savings cost and percent cost savings are greater than $10 \%$ for the dehumidification-reheat process due to the energy savings associated with the HEDS system.

\subsubsection{Metric}

Fan, chiller plant and boiler plant energy savings associated with the energy for reheat in the dehumidification-reheat process being provided by the CRC vs. being provided by a new source of reheat energy, i.e., boilers/thermal or electric strip reheat.

The expected range of the dehumidification-reheat process cost savings is between 5 and $20 \%$ for the systems being tested.

\subsubsection{Data}

Thermal and electrical energy savings as calculated in other POs. Average cost $/ \mathrm{kWh}$ and cost/therm for Natural Gas (NG) at each of the facilities seasonal if available 


\subsubsection{Analytical methodology}

Please refer to the Section 6.1, "Savings analysis methodology."

\subsubsection{Success criteria}

Does the savings cost and percent cost savings exceed $10 \%$ for the dehumidification-reheat process due to the energy savings associated with the HEDS system?

\subsubsection{Reduce lifecycle cost of dehumidification/ reheat process}

\subsubsection{Purpose}

To determine if the HEDS system can reduce lifecycle costs of the HVAC process for facilities that need RH control by at least $5 \%$.

\subsubsection{Metric}

Energy costs as determined in other POs. Equipment expected useful life. Lifecycle cost analysis tools.

The expected range of the lifecycle cost savings is between o (zero) and $10 \%$ for the systems being tested.

\subsubsection{Data}

Energy cost savings as determined in other POs. Equipment expected lifecycles as determined by DoD or ASHRAE publications in the absence of DoD lifecycles.

\subsubsection{Analytical methodology}

Please refer to the Section 6.1, "Savings analysis methodology."

\subsubsection{Success criteria}

To determine if the HEDS system can reduce lifecycle costs of the HVAC process for facilities that need RH control by at least $5 \%$. 


\section{Facility/Site Description}

\subsection{Facility/site location and operations}

Two locations were selected for the pilot demonstration. The first is at Tinker AFB, OK in Bldg. 3, an administrative building, and the second is at Fort Bragg, NC in Bldg. A-3556, a Dining Facility (DFAC). Both Fort Bragg and Tinker AFB are in Department of Energy Climate Zone 3A, which is defined as Warm - Humid.

The selected installations are representative of those located in climates that have at least 4 months each year of dehumidification. This represents a large percentage of military installations worldwide. The two types of buildings chosen were an administrative building and a dining facility, which represent a large portion of building stock across DoD and General Services Administration (GSA). For the demonstration, the intent was to select facilities that would have stable occupancies during the test period. A barracks facility was originally targeted, but with deployments and empty barracks being a possibility, the two installations worked to select facilities that were felt to provide the greatest potential for stability over the test period. The administrative/office facility is supposed to operate with a 5 day per week, 12 hour per day HVAC schedule, and is representative of office types of facilities. The DFAC has variable occupancy and relatively long operating hours, and is representative of many other DoD facilities, even barracks to some extent. Both sites have ongoing problems with biological growth, odors and a "musty feel" associated with high internal RH and biological growth.

Tinker AFB's Bldg. 3 had a Variable Air Volume AHU that serves office spaces. The unit was supposed to run to match the occupancy schedule of the building. As with many facilities encountered in humid climates, the HVAC system in this facility was undersized. The AHUs did not have adequate cooling capacity and the chiller as unable to allow the building to shut down at night or over the weekends. When the HVAC system was shut down at night, it was unable to regain control of the facility until late in the following day. If the HVAC system was shut down over the weekend and at night, the facility would be hot and muggy inside until Tuesday or Wednesday. For this reason, many administrative type facilities that are supposed to have 5 day per week, 12 hour per day (5/12) operating schedules run their HVAC systems continuously, 24/7, during the peak summer 
cooling months, and also during the peak winter heating months. Bldg. A3556, the DFAC at Fort Bragg, had a Constant Air Volume (CAV) AHU that serves a kitchen. The unit ran continuously due to the existing AHUs that serve the building being undersized, for similar reasons as discussed above for Tinker AFB.

Neither of the demonstration buildings contain or are located near critical military operations that would have impacted the demonstration. The occupants, however, are subject to discomfort if the respective buildings' HVAC does not function properly and is unable to maintain reasonable interior environmental conditions. If the HEDS were not functioning properly in Bldg. 3 of Tinker AFB, the people in that area would have decreased productivity due to poor comfort levels until the HEDS unit was restored to proper operation. If the HEDS unit were not functioning properly in Bldg. A-3556 of Fort Bragg, the people dining would be uncomfortable until the HEDS unit was restored to proper operation. Figures 10 to 13 show the respective AHUs that were replaced with new HEDS units. Figures 14 and 15 show site maps for Tinker AFB, and Figures 16 and 17 show site maps for Fort Bragg.

Figure 10. Existing AHU that was replaced on BIdg. 3 at Tinker AFB.

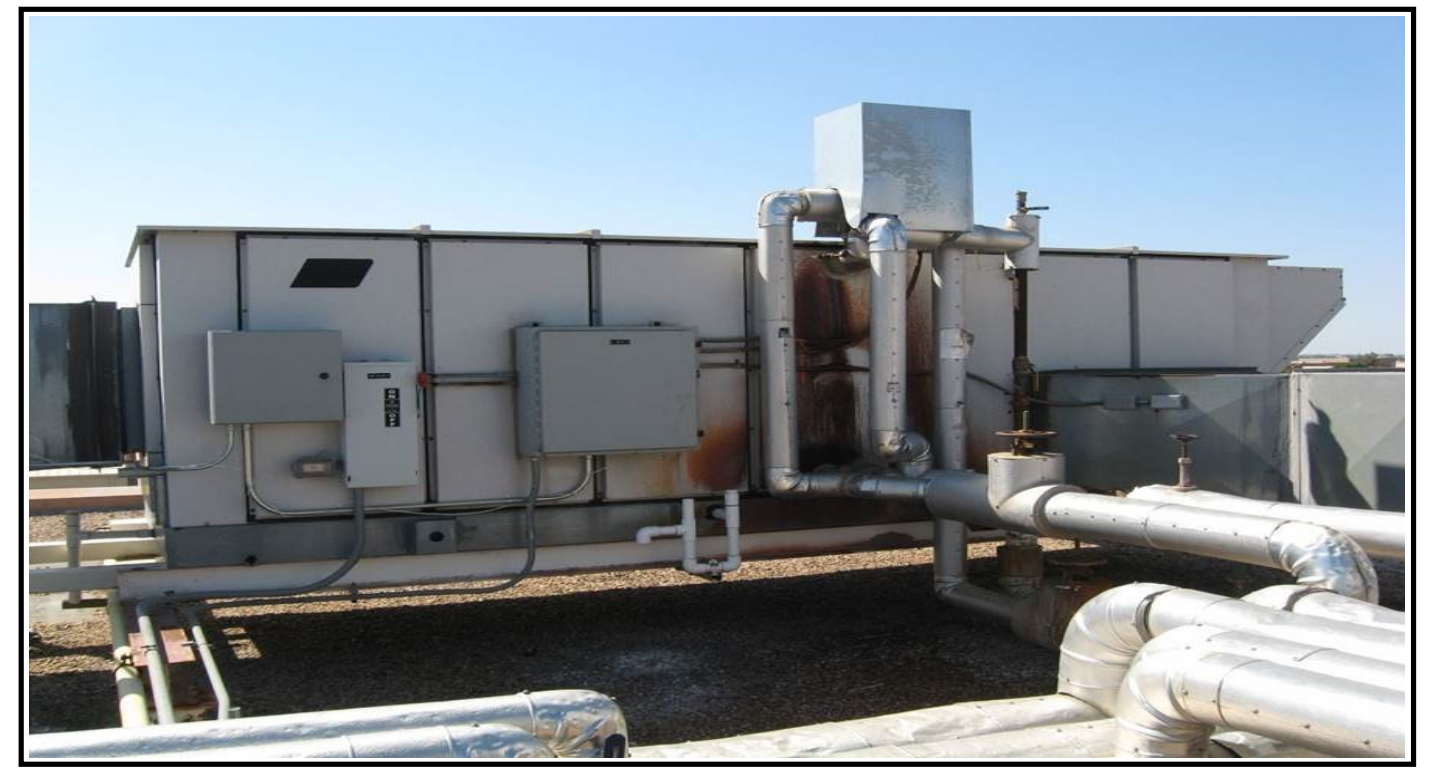


Figure 11. New HEDS AHU on Bldg. 3 at Tinker AFB.

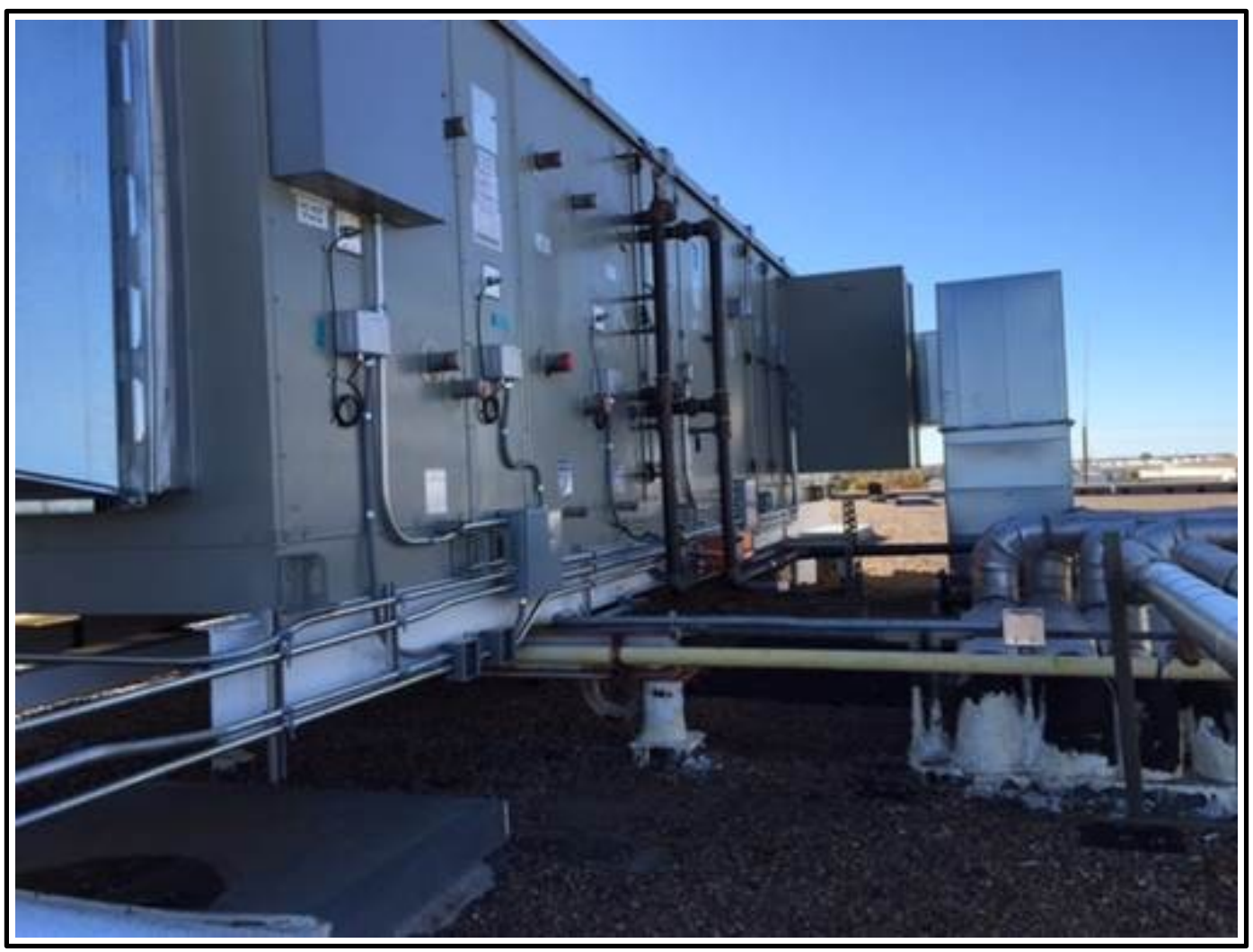

Figure 12. Existing AHU that was replaced in Bldg. A-3556 at Fort Bragg.

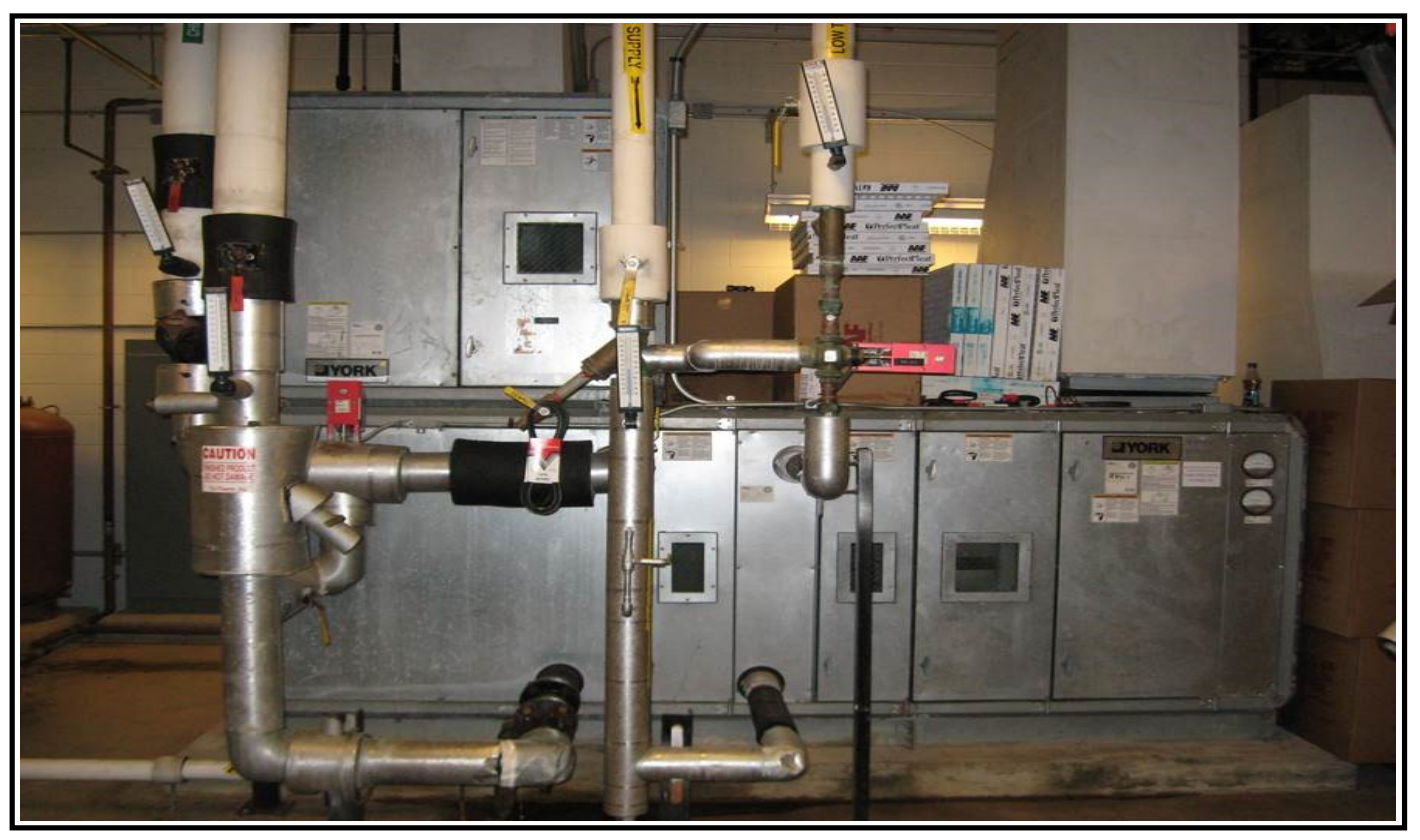


Figure 13. New HEDS AHU in Bldg. A-3556 at Fort Bragg.

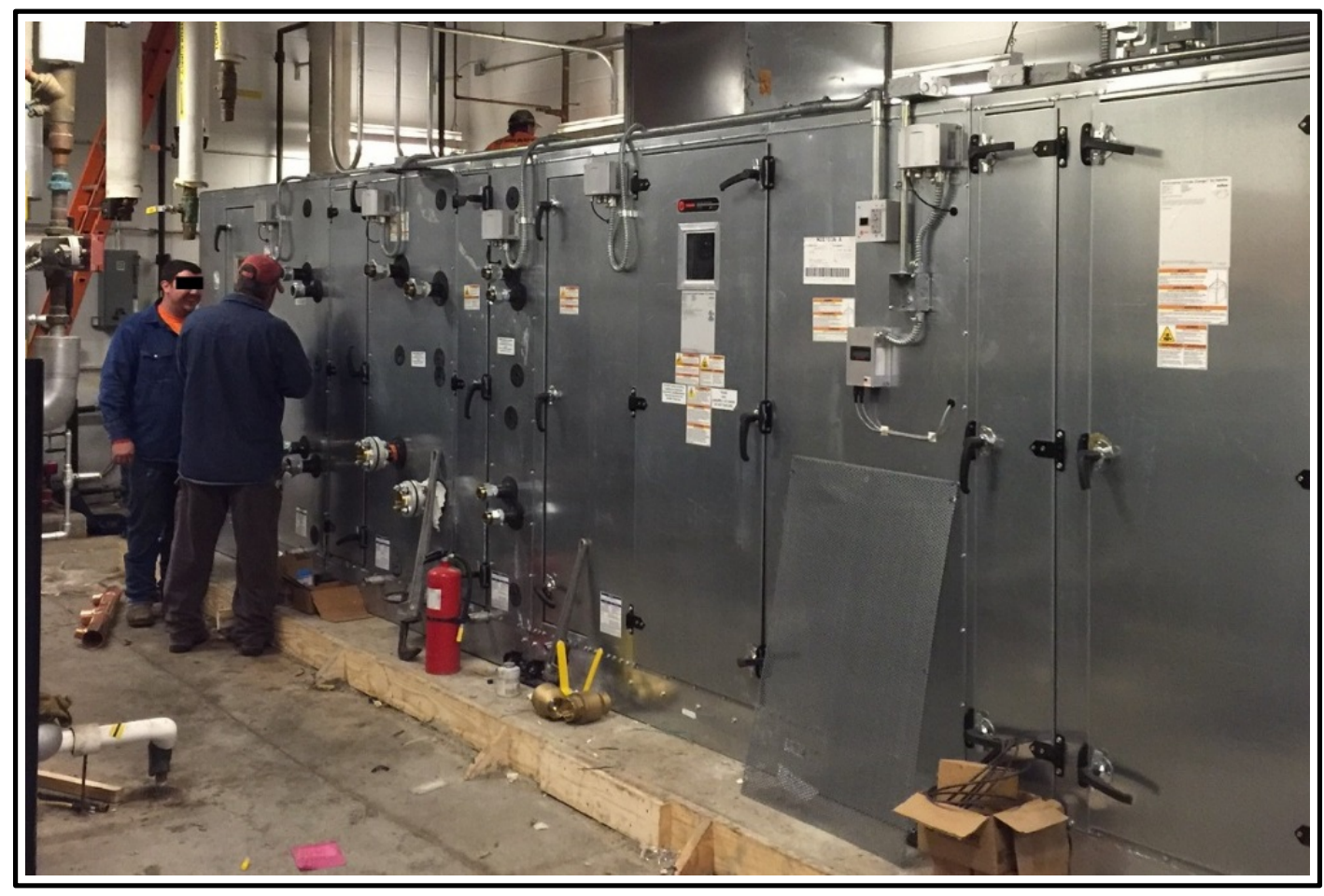

Figure 14. Location of Bldg. 3, the Administrative Building for the demonstration on Tinker AFB, OK.

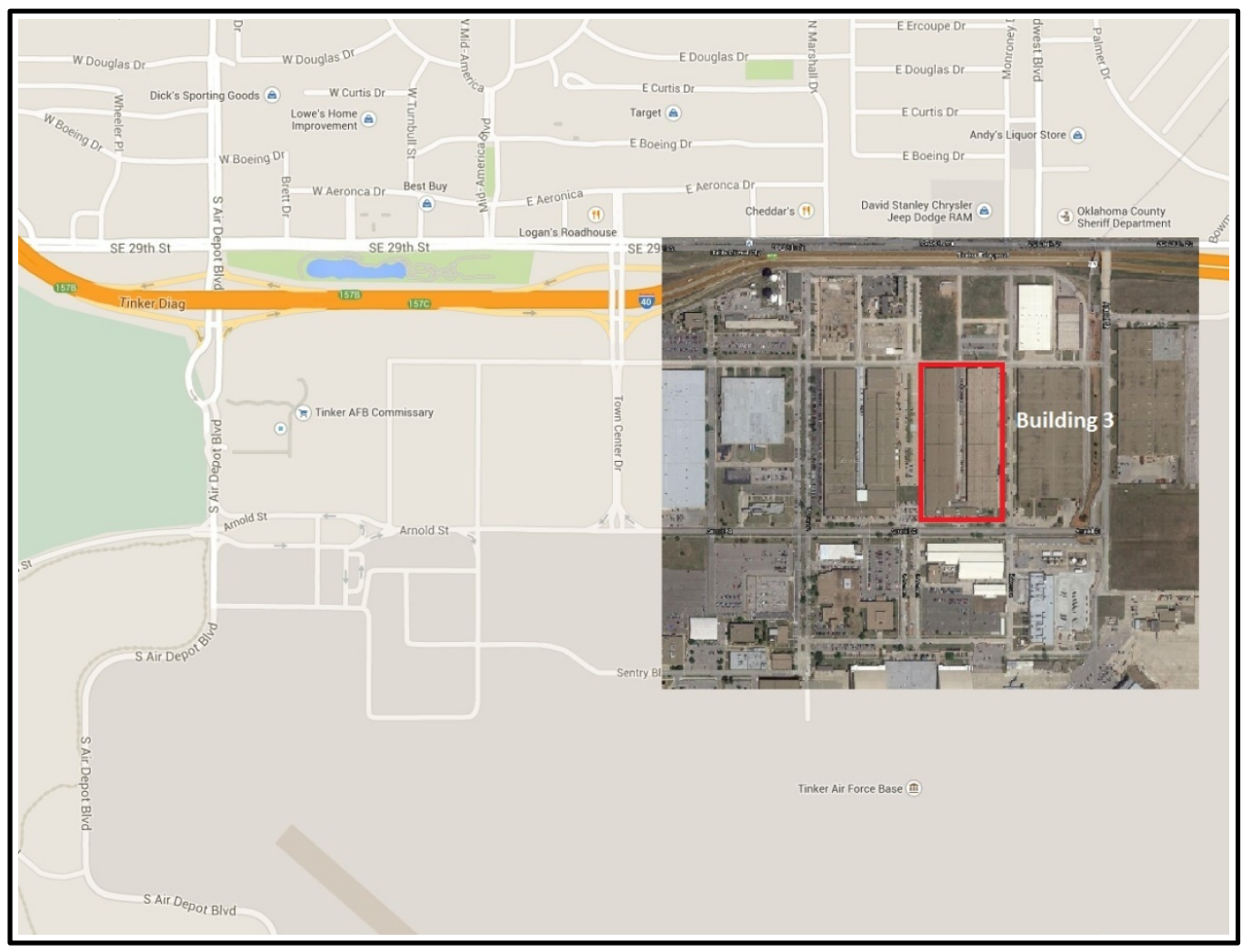


Figure 15. Close-up view of Bldg. 3.

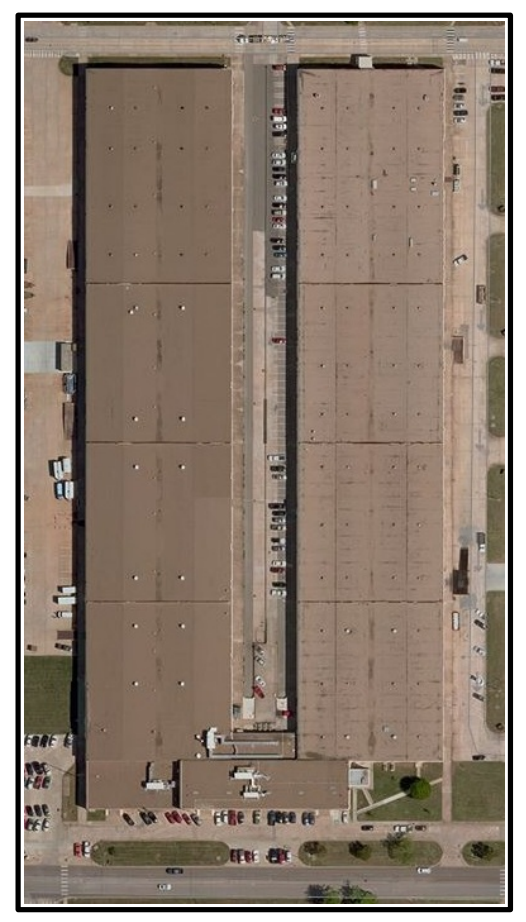

Figure 16. Location of Dining Facility (DFAC) A-3556 on Fort Bragg, NC.

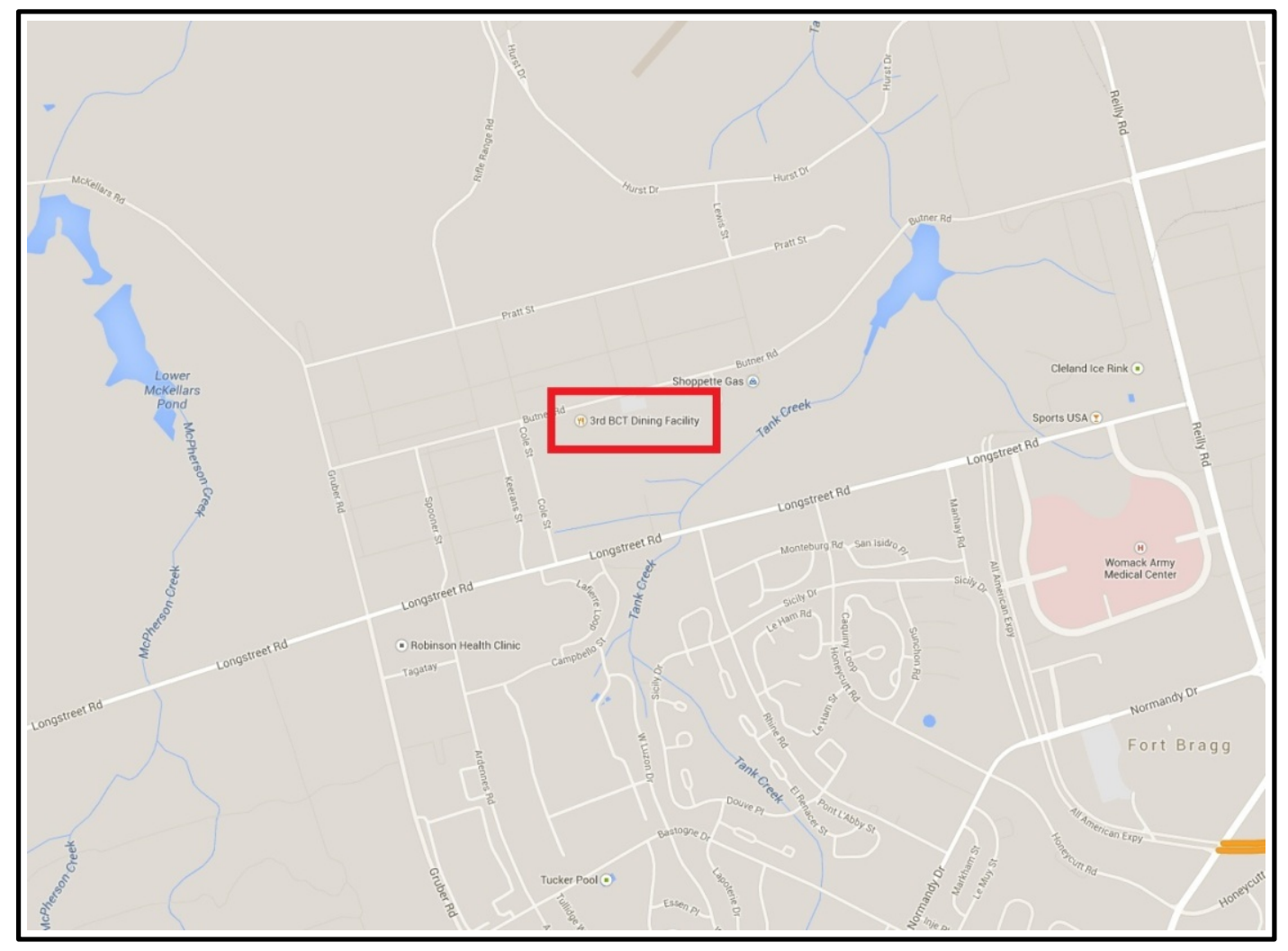


Figure 17. Close-up views of DFAC location and building.

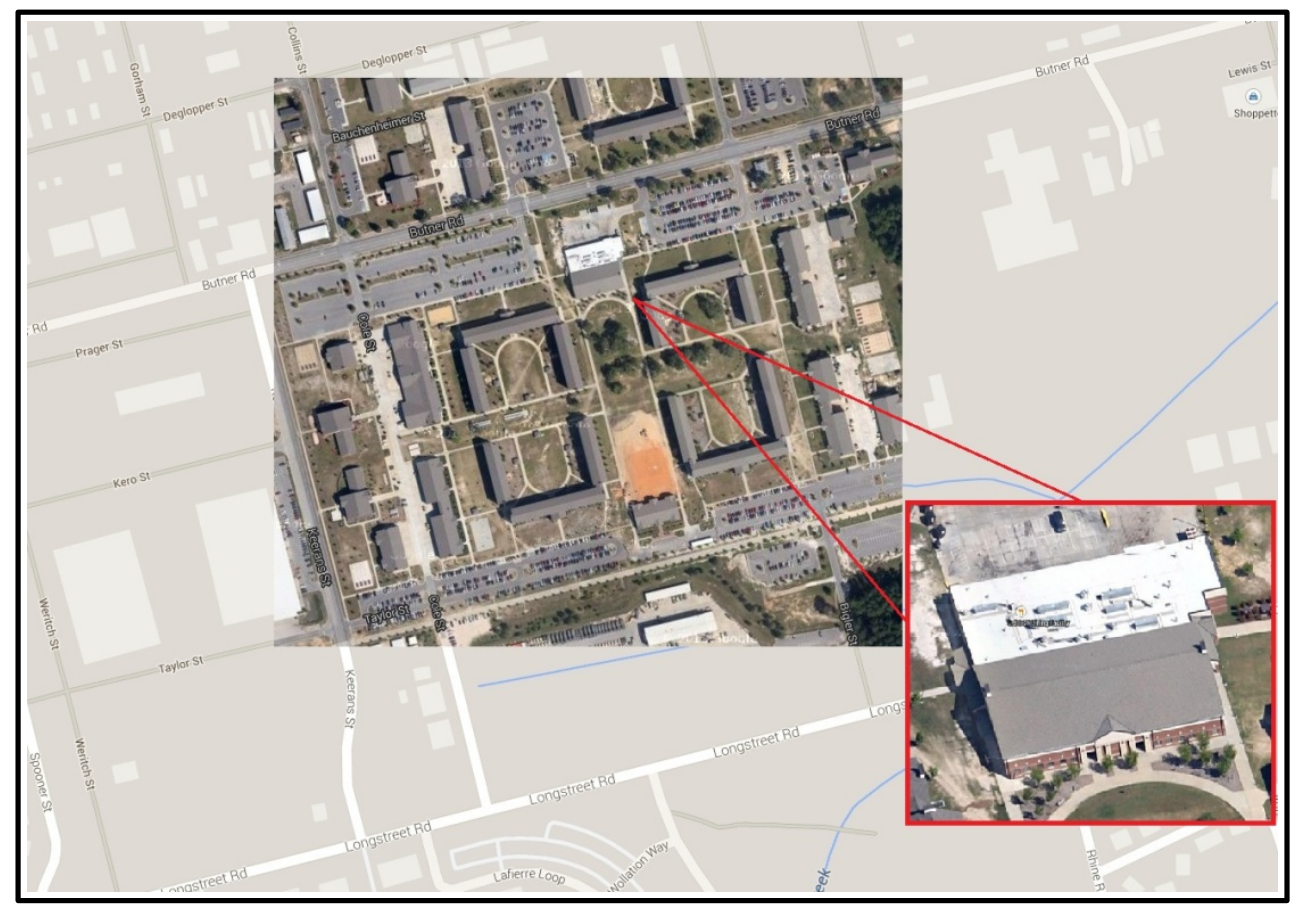

\subsection{Facility/site conditions}

As described above, both project locations currently have significant operating constraints due to undersized equipment and failing chilled water systems. Before the project, even when the chiller systems were operating properly, they had to be run $24 / 7$ during the summer to try (unsuccessfully) to maintain temperature and $\mathrm{RH}$ control.

The existing HVAC unit on Tinker AFB's Bldg. 3 was a Variable Air Volume (VAV) AHU that serves office spaces, which ran continuously due to lack of adequate cooling capacity and undersized AHUs. Throughout the majority of the monitoring period, the building's chiller had heavily fouled condenser tubes and nearly plugged fill in the cooling towers due to sediment in the condenser system. These issues combined to reduce the chiller output to approximately $60 \%$ of rated capacity. To keep the chiller operational, the HEDS onsite team instituted a 60\% demand limit setpoint reset routine. The chiller would only allow the demand limit to remain functional for a 4-hour period. If the reset time were missed, the chiller would load up, then fail on high surge count in very short order. This resulted in pervasive, higher than design chilled water supply temperatures. In fact, the chilled water supply temperature was below $46^{\circ} \mathrm{F}$, or "in control," less than $10 \%$ of the monitoring period. Due to the severity of the issue, a temporary chiller was installed at the base to ensure chilled water temperature 
control in the fall of 2016. Due to the issues observed in the chilled water systems at both locations, the performance data had to be "binned" into chilled water supply temperature ranges to explore the impact of HEDS across a range of chilled water supply conditions, from "in control" design conditions (Chilled Water Supply [CHWS] temperature less than $46^{\circ} \mathrm{F}$ ) to out of control failing systems with chilled water supply temperatures above $62{ }^{\circ} \mathrm{F}$.

At Fort Bragg, there are a total of four AHUs serving the facility, three existing AHUs in addition to the new HEDS AHU that replaced the original CAV AHU serving the kitchen. All are fed from the same chilled water plant. The existing AHUs serving the facility are currently undersized, requiring that they be run $24 / 7$ in an attempt to maintain comfortable and dehumidified operations for the kitchen, serving area, and the two dining halls. Additionally, throughout the monitoring period, the chiller experienced significant capacity constraints due to failed sensors that limited the compressor staging, effectively limiting the chiller output to roughly $50 \%$ of rated capacity. As a result of this decreased capacity, chilled water supply temperatures from the plant were routinely above the design range of 42 to $46^{\circ} \mathrm{F}$. In fact, the chilled water supply temperature was below $46^{\circ} \mathrm{F}$, or "in control," less than $50 \%$ of the monitoring period. Increased chilled water supply temperatures from the plant lead to decreased cooling and dehumidification capacities in the AHUs, and to reduced potential energy for the HEDS unit to use for RH control. 


\section{Test Design}

This chapter provides the detailed description of the system design and testing conducted during the demonstration.

\subsection{Conceptual test design}

\subsubsection{Hypothesis}

The HEDS system will reduce the energy consumed by an HVAC system while simultaneously providing RH and space dewpoint control without the use of additional equipment.

\subsubsection{Independent variable}

The independent variable in this case is the installation of the HEDS AHU and the related controls, instrumentation, piping, valves, and control valves.

\subsubsection{Dependent variable(s)}

The dependent variables are: AHU cooling coil load in tons and ton-hours, avoided cooling coil load in tons and ton-hours, avoided reheat energy in tons and BTU/BTUH, interior space temperature, interior space RH, interior space dewpoint temperature.

\subsubsection{Controlled variable(s)}

The controlled variables are: the cooling coil leaving dewpoint temperature, the AHU leaving drybulb temperature after the cooling recovery coil, the size of the building, the area being served by the HEDS AHUs. They also include the mission of the building, and occupancy hours and levels (to the extent practical), and the other central plant equipment serving the buildings.

\subsubsection{Test design}

The test design is to serve the cooling/dehumidification loads of a facility with the HEDS unit, and to compare the HEDS unit energy consumption and performance to a hypothetical "normal" AHU that performs cooling, dehumidification, and reheat duties, which serve the identical loads.

In the test case, the loads and other variables are being measured at 5-minute intervals. The space temperature, dewpoint and $\mathrm{RH}$ conditions must 
be maintained within the UFC comfort zone, so cooling needs to be provided to dry the air out and re-heating to lower the RH of the supply air so that $100 \%$ saturated, cold wet air is not being delivered into a space. The total load being served by the AHU - associated with fresh air, solar and internal loads - will not be altered as part of this demonstration, only the method of serving the loads changes.

Since "the load is the load," the amount of BTUs required to cool the air down and how many BTUs are required to reheat the air back up to meet comfort conditions and control space RH will be measured. From this data, the avoided BTUs of reheat energy that the CRC airside temperature increase provides will be measured, and will be equated to the decreased cooling load that has to be served by the chiller plant. The cooling load on the chiller plant is reduced due to the reduced CHW return temperature associated with the cold supply air coming off the $\mathrm{CC}$ and entering the CRC. The cold air coming off the CC being blown through the CRC cools the CHW return going back to the chiller plant, removing the same amount of load from the chiller plant that was added to the supply air in the reheat process by the CRC. By measuring only the chilled water flow rate entering $\mathrm{CHW}$ temp to the cooling coil, leaving CHW temp from the cooling coil, and leaving CHW temp from the HEDS unit, the baseline case cooling load and reheat loads can be calculated.

In this manner, the HEDS unit serves as both the baseline and the test case. Since the cooling load is known (and is not impacted by the installation of the HEDS unit), and the reheat loads needed to meet comfort and $\mathrm{RH}$ control conditions in the space are known, a separate AHU is not needed for baseline comparison.

Test phases included:

- HEDS Unit commissioning and startup

- Initial data collection and evaluation

- HEDS unit operation and ongoing data collection and evaluation

- Required report development.

\subsection{Baseline characterization}

The baseline energy use will be measured continually as a part of the test as described elsewhere in the demonstration plan. The baseline consists of 
the cooling energy in ton-hours that is consumed in the cooling and dehumidification process, and the reheat energy that is used to warm up the supply air to reduce the RH of the supply air and the spaces being conditioned. This is the same load as for the HEDS case. The fan energy $(\mathrm{kW})$ is being monitored and trended. However, fan energy savings as a PO have been removed. Fan energy savings may occur, but presently, saving fan energy is not considered to be a critical part of the lifecycle cost reductions. This opinion may change during the testing process, and the data will be available to calculate any potential savings that occur.

One cooling season of data was collected, as were shoulder season data from one fall and one spring. More details on the precise data ranges and amount of data collected can be found further in this report.

\subsubsection{Reference conditions}

Although more than 300 physical and calculated variables are being monitored at each test site, the six main data points that will be obtained to determine compliance with comfort and $\mathrm{RH}$ control conditions, which drive all other variables, are: Space and return air dry bulb temperatures, space and return air dewpoint temperatures, and space and return air RH conditions are being measured. Maintaining these comfort conditions drives the cooling load and reheat loads will be measured and used for the basis of the savings calculations.

\subsubsection{Existing baseline data}

The loads that are being served on a continuous basis are the baseline data and the HEDS data. As noted elsewhere, the main difference will be the calculations for the reheat energy source, be they CRC-sourced or new energy-sourced.

\subsubsection{Baseline estimation}

Since all critical data points are being measured, baseline estimation is not required.

\subsubsection{Data collection equipment}

Section 5.5 describes the data collection and calculated points. Appendices $\mathrm{D}$ and $\mathrm{E}$ include the instrumentation diagrams for Tinker AFB and Fort Bragg. From a data collection perspective, the two systems are very similar to each other. 


\subsection{Design and layout of technology components}

\subsubsection{System Design}

- Other sections of the Report (especially Section 2.1) and the diagrams in the Appendix D describe the HEDS unit.

- Appendices D and E contain the Trane HEDS unit drawings for Fort Bragg and Tinker AFB, including the physical layouts for the instrumentation within the HEDS units.

- The units will be connected into the existing ductwork and piping systems in close proximity to the current piping and ductwork points of contact (POCs). The piping and ductwork sizes are not being changed past the POCs. There are no changes to any interior ductwork.

- For the Fort Bragg DFAC unit, the motor horsepower (HP) was upgraded from a 10- to a 15-HP system, and now include a variable frequency drive (VFD) instead of using a two-speed motor for volume control when the exhaust fan 39 is on or off. The Fort Bragg HVAC system was described as problematic in terms of total capacity; consequently, a lack of CFM as a driver of the success or failure of the test was eliminated.

- For the Tinker AFB Roof Top Unit 4 (RTU-4), the motor HP was upgraded from 7.5- to a 10-HP system, and now includes a VFD for static pressure control. As with the DFAC unit at Fort Bragg, the RTU-4 HVAC system was described as problematic in terms of total capacity; consequently, a lack of CFM as a driver of the success or failure of the test was eliminated.

- The Tinker AFB HEDS unit is roof mounted and exposed to the weather, so extra precautions are being taken to make the unit reliable in the OK environment.

- The HEDS units were delivered complete with all instrumentation, valves, unit controls and trending equipment required for the test and to operate the systems. Factory testing was conducted to ensure proper operation of the components before shipment to the site.

- Each unit is being equipped with a full airside economizer damper section.

- For the two test sites, the HEDS units were built with a preheat coil to match existing construction of the AHUs that were replaced as a part of this project. The pre-heat coils are used in cold weather climates to reduce the potential for cooling coil freeze-ups. Downstream from the preheat coil are the cooling coil and the cooling recovery coil. 
- The AHU replaced at Tinker AFB had a ductwork-mounted reheat coil located downstream from the cooling recovery coil that was added to the discharge ductwork after the initial project construction. It is not known why this reheat coil was installed, but it was left in place and incorporated as a part of the system. Note that this coil was never required for use during the demonstration period.

- The main portion of the HEDS that is being tested is the relationship between the cooling coil and the cooling recovery coil that is located downstream of the cooling coil.

- There are no "custom" components used in the system. The HEDS unit uses standard Trane AHU construction, fans, VFDs and coils. The instrumentation is off the shelf, but high accuracy equipment from Vaisala or Setra; the coil control valves are the Energy valve and ball valves from Belimo.

\subsubsection{Components of the System}

- The major system components include the Trane HEDS unit, the airside and waterside instrumentation and controls and the Belimo Energy Valves.

- Appendices D and E contain data sheets for the major equipment, including the sensor locations on the Trane shop drawings.

\subsubsection{System Depiction}

- Appendix D includes schematics of the HEDS units.

\subsubsection{System Integration}

- The HEDS units replaced the existing under-performing AHUs. Everything between the supply and return ductwork points of connections was replaced. At Tinker AFB, the downstream ductwork mounted reheat coil was left in place.

- The failure modes are the same for the HEDS unit as for a typical AHU, and the recovery processes are also the same. The main difference is that, if there is a failure of some sort when the unit is brought back on line, the larger cooling coils and larger heating coils will allow the spaces to come back into comfort conditions more rapidly than the baseline units with smaller coils could accomplish. 


\subsubsection{System Controls}

- Appendix E contains schematics of the HEDS units, including the controls hardware diagrams. Section 2.1 of this report describes detailed controls sequences.

\subsection{Operational testing}

\subsubsection{Operational Testing of Cost and Performance}

- The data collection process is the same for all modes of operation and all times of the day. Physical data and calculated values, as described elsewhere in this document, will be trended at 5-minute intervals, continuously throughout the process.

- Standalone trending equipment is provided for both facilities.

- At Tinker AFB, several control points are hardwired between the HEDS controller and the base BAS system. These points include: HEDS start/stop, space temperature drybulb reading, space temperature dewpoint temperature reading, fan speed command, unit discharge static pressure, and unit supply air temperature.

- At Fort Bragg, at the request of the base personnel, the HEDS controller is controlling the unit and trending data locally.

- During the commissioning process, data were downloaded at 7- to 10day intervals, to validate the data and address any potential operational or data discrepancies before operations.

- The systems were started up and commissioned by trained Trane personnel in the field, with data validation throughout the start-up and commissioning process by ROI.

Modeling and Simulation: Given the testing setup and available data, no simulations were required to support the analysis. Modeling has been conducted in Microsoft Excel to annualize the results to typical meteorological year (TMY3) weather.

Timeline: Table 4 lists the project overall timeline for the test sites. 
Table 4. Project timeline for each HEDS installation and data collection period.

\begin{tabular}{|c|c|c|c|c|c|c|c|c|}
\hline Fort Bragg & $\begin{array}{c}2 Q \\
2015\end{array}$ & $\begin{array}{c}3 Q \\
2015\end{array}$ & $\begin{array}{c}4 Q \\
2015\end{array}$ & $\begin{array}{c}1 Q \\
2016\end{array}$ & $\begin{array}{c}2 Q \\
2016\end{array}$ & $\begin{array}{c}3 Q \\
2016\end{array}$ & $\begin{array}{c}4 Q \\
2016\end{array}$ & $\begin{array}{c}1 Q \\
2017\end{array}$ \\
\hline HEDS Unit Ordered from Trane & & $x$ & & & & & & \\
\hline HEDS Installation & & & $x$ & & & & & \\
\hline HEDS Start-up and Commissioning & & & & $X X X$ & $\mathrm{x}$ & & & \\
\hline $\begin{array}{l}\text { HEDS Data Collection for } \\
\text { Dehumidification Performance Data }\end{array}$ & & & & & $\mathrm{XXX}$ & $X X X$ & $x$ & \\
\hline $\begin{array}{l}\text { Data Analysis and Report } \\
\text { Development }\end{array}$ & & & & & & & $x$ & $X X X$ \\
\hline \multicolumn{9}{|c|}{$\begin{array}{l}\text { The number of "Xs" in the column indicate the number of months in that quarter that the work was } \\
\text { conducted }\end{array}$} \\
\hline Tinker AFB & $\begin{array}{c}2 Q \\
2015\end{array}$ & $\begin{array}{c}3 Q \\
2015\end{array}$ & $\begin{array}{c}4 Q \\
2015\end{array}$ & $\begin{array}{c}1 Q \\
2016\end{array}$ & $\begin{array}{c}2 Q \\
2016\end{array}$ & $\begin{array}{c}3 Q \\
2016\end{array}$ & $\begin{array}{c}4 Q \\
2016\end{array}$ & $\begin{array}{c}1 Q \\
2017\end{array}$ \\
\hline HEDS Unit Ordered from Trane & & $x$ & & & & & & \\
\hline HEDS Installation & & & $x$ & & & & & \\
\hline HEDS Start-up and Commissioning & & & & $x X X$ & $\mathrm{x}$ & & & \\
\hline $\begin{array}{l}\text { HEDS Data Collection for } \\
\text { Dehumidification Performance Data }\end{array}$ & & & & & $\mathrm{XXX}$ & $X X X$ & $x$ & \\
\hline $\begin{array}{l}\text { Data Analysis and Report } \\
\text { Development }\end{array}$ & & & & & & & $x$ & $x x x$ \\
\hline \multicolumn{8}{|c|}{$\begin{array}{l}\text { The number of "Xs" in the column indicate the number of months in that quarter that the work was } \\
\text { conducted }\end{array}$} & \\
\hline
\end{tabular}

\subsection{Sampling protocol}

Data Collector(s) and Data Recording: The data are being automatically collected by the HEDS unit control system at 5 -minute intervals. The HEDS unit archives the data locally so it can be retrieved periodically by Trane staff for archive and analysis.

Data Description: There are approximately 300 points that are being trended or calculated as described in this document for each site. The trend interval is 5-minutes per point, and data were collected from April to November 2016.

Appendix $\mathrm{C}$ contains the entire list of calculated points that are being trended, numbering approximately 200 additional points. The points that 
are either physical points or commanded points (approximately 100 points total) in trend are:

- Measured or Commanded Values Trended

i. Differential pressure (DP) across each coil:

1. Preheat coil (PHC) DP

2. CC DP

3. cooling recovery coil (CRC) DP

4. reheat coil (RHC) DP.

ii. Water flow as provided by the Belimo Energy Valves:

1. Preheat coil (PHC) flow

2. cooling coil (CC) flow

3. reheat coil (RHC) hot water flow.

iii. Coil tons or BTU as provided by the Belimo Energy Valves:

1. Preheat coil (PHC) Btu

2. CC Tons

3. reheat coil (RHC) Btu.

iv. Supply fan CFM

v. Supply fan speed command

vi. Supply fan $\mathrm{kW}$

vii. Preheat coil control valve command percent open

viii. Cooling coil control valve command percent open

ix. Cooling recovery coil control valve command percent open

$\mathrm{x}$. Reheat coil control valve command percent open

xi. Return air dewpoint temperature @ return air temperature (RAT) sensors

xii. Space dewpoint temperature @ space sensors

xiii. Mixed air dewpoint temperature upstream of supply fan

xiv. Mixed air dewpoint temperature downstream of supply fan

xv. Outside air dewpoint temperature

xvi. PHC leaving dewpoint temperature

xvii. CC leaving dewpoint temperature

xviii. CRC leaving dewpoint temperature

xix. RHC leaving dewpoint temperature

xx. Return air drybulb temperature @ RAT sensors

xxi. Space drybulb temperature @ space sensors

xxii. Mixed air drybulb temperature upstream of supply fan

xxiii. Mixed air drybulb temperature downstream of supply fan

xxiv. Outside air drybulb temperature

xxv. PHC leaving drybulb temperature 
xxvi. CC leaving drybulb temperature

xxvii. CRC leaving drybulb temperature

xxviii. RHC leaving drybulb temperature

xxix. Return air RH\% @ RAT sensors

xxx. Space RH\% @ space sensors

xxxi. Mixed air RH\% upstream of supply fan

xxxii. Mixed air RH\% downstream of supply fan

xxxiii. Outside air RH\%

xxxiv. PHC leaving RH\%

xxxv. CC leaving RH\%

xxxvi. CRC leaving RH\%

xxxvii. RHC leaving RH \%

xxxviii. OSA economizer damper position command percent

open

xxxix. Mixed and Return air economizer damper position com-

mand percent open

xl. Air filter, air pressure drop

xli. HEDS discharge static pressure, actual

xlii. HEDS discharge static pressure, setpoint

xliii. Coil and HEDS water temperatures

1. PHC inlet hot water temperature, DDC

2. PHC leaving hot water temperature, DDC

3. CC inlet chilled water temperature, DDC (HEDS Inlet CHWS temp)

4. CC leaving chilled water temperature, DDC

5. CRC leaving chilled water temperature, DDC

6. HEDS leaving CHWR temp chilled water temperature, DDC (Mixed - common HEDS CHWR temp)

7. RHC inlet hot water temperature, DDC

8. RHC leaving hot water temperature, DDC

9. HEDS unit inlet hot water temperature, DDC

10. HEDS unit leaving hot water temperature, DDC

11. PHC inlet hot water temperature, Belimo Energy Valve

12. PHC leaving hot water temperature, Belimo Energy Valve

13. CC inlet chilled water temperature, Belimo Energy Valve

14. CC leaving chilled water temperature, Belimo Energy Valve

15. RHC inlet hot water temperature, Belimo Energy Valve

16. RHC leaving hot water temperature, Belimo Energy Valve

xliv. Space drybulb temperature setpoint, cooling and dehumidification modes 
xlv. Space dewpoint temperature setpoint, cooling and dehumidification modes

xlvi. Space drybulb temperature setpoint, heating mode

xlvii. Return air drybulb temperature setpoint, cooling and dehumidification modes

xlviii. Return air dewpoint temperature setpoint, cooling and dehumidification modes

xlix. Return air drybulb temperature setpoint, heating mode

1. Economizer enable setpoint, drybulb logic

li. Economizer disable setpoint, drybulb logic

lii. Economizer enable setpoint, enthalpy logic

liii.Economizer disable setpoint, enthalpy logic

liv. The status of each mode of operation will be trended both in COV (Change of Value) and at 5-minute intervals. Samples of modes are:

1. Startup mode

2. Heating mode

3. Cooling mode

4. Dehumidification-reheat mode

5. Overnight batch dehumidification mode

6. Overnight continuous dehumidification mode

7. Economizer mode, enthalpy on/off command

8. Economizer mode, drybulb on/off command

9. Economizer mode, dewpoint on/off command

10. Economizer mode, actual on/off command

11. AHU Start command

12. Facility occupied mode

13. Other distinct operating modes, to be determined (TBD)

14. etc.

lv. The status of each alarm will be trended both in COV (Change of

Value) and at 5-minute intervals. Samples of alarms are:

1. Economizer failure

2. PHC enabled when should be off

3. RHC enabled when should be off

4. Low pressure cutout

5. Freeze stat

6. Fire/life safety alarms

7. Air filter, air pressure drop

8. Other alarms TBD. 
Data Storage and Backup: Trend data are stored locally in the HEDS unit controller and retrieved monthly via jobsite visits. The data are sent to ROI, Trane, and CERL, and are archived in at least three locations for redundancy.

Data Collection Diagram: Appendices D and E includes the instrumentation diagrams for the HEDS units. The points list described above also describes calculated values used in the test.

Non-standard Data: All data are collected and retrieved in a standard format.

Data Binning for Analysis: As mentioned earlier in the report, the data analysis results where binned into chilled water supply temperature ranges to examine the HEDS performance across a range of plant operating conditions as shown below. These bin descriptions should be used for reference when reviewing results figures throughout the report, as needed.

1. All Data (average performance across all chilled water supply temperature ranges).

2. Chilled Water Supply Temperature (CHWST) less than (LT) $46^{\circ} \mathrm{F}$, (which indicates a chilled water plant in control and providing adequate capacity).

3. CHWST greater than (GT) 46 and less than $50^{\circ} \mathrm{F}$ (which indicates of a chilled water plant with mild chiller and capacity issues).

4. CHWST GT 50 and LT $54^{\circ} \mathrm{F}$ (which indicates of a chilled water plant with moderate chiller and capacity issues).

5. CHWST GT 54 and LT $58^{\circ} \mathrm{F}$ (which indicates of a chilled water plant with significant chiller and capacity issues).

6. CHWST GT 58 and LT $62{ }^{\circ} \mathrm{F}$ (which indicates of a chilled water plant with significant chiller and capacity issues).

7. CHWST GT 62 and LT $66^{\circ} \mathrm{F}$ (which indicates a chilled water plant with significant chiller and capacity issues).

8. CHWST GT $66^{\circ} \mathrm{F}$ (which indicates a chilled water plant that has failed and is completely out of control).

Additionally, the results were binned into supply air temperature ranges within each chilled water supply temperature bin to analyze the impact of varying levels of dehumidification as evidenced by the cooling coil supply air temperature. The bins are described as:

1. CC Supply Air Temperature (SAT) less than (LT) $50^{\circ} \mathrm{F}$ (which indicates a very high dehumidification requirements associated with critical environ- 
ments such as hospital operating rooms, clean rooms, and precision manufacturing or indicative of leaky envelopes in humid areas).

2. CC SAT greater than 50 and LT $52^{\circ} \mathrm{F}$ (which indicates moderate dehumidification requirements associated with general hospital areas, pharmaceutical manufacturing, general manufacturing, and Navy ships or Military Sealift Command ships or indicative of lower loads in the critical environments referenced above).

3. CC SAT GT 52 and LT $56^{\circ} \mathrm{F}$ (which indicates lower dehumidification requirements associated with office areas, barracks, DFACs, etc. or indicative of lower loads in the environments referenced above).

4. CC SAT GT 56 and LT $62^{\circ} \mathrm{F}$ (which indicates light dehumidification loads at any of the above referenced environments).

5. CC SAT GT $62{ }^{\circ} \mathrm{F}$ (which indicates very light dehumidification loads at any of the above referenced environments).

For the presentation of the results, bins with less than 20 total hours of operation were removed as these low hour bins represent primarily dynamic conditions that are not representative of steady state operating performance. These dynamic conditions were included in the savings results reported for each overall CHWS temperature bin.

\subsection{Sampling results}

The following sections detail the results for each test site.

\subsubsection{Fort Bragg}

For a large portion of the analysis period, the chiller plant at Fort Bragg was experiencing significant performance issues associated with a failed pressure sensor on the chiller that limited capacity to around $50 \%$ of rated output. As a result, there are significant periods of time where the plant was unable to meet the leaving chilled water temperature setpoint due to inadequate capacity, resulting in chilled water supply temperatures to the AHU ranging from $42^{\circ} \mathrm{F}$ to over $65^{\circ} \mathrm{F}$ (compared with a design leaving temperature of $45^{\circ} \mathrm{F}$ ). Table 5 lists the resulting run hours in each temperature bin for the analysis period. Note that the rows highlighted in gray represent transient conditions for which there is insufficient data to draw significant conclusions, and therefore have been removed from presentation of savings in subsequent analyses. 
Table 5. Summary of hours at each temperature bin analyzed for Fort Bragg.

\begin{tabular}{|c|r|r|}
\hline & Hours at Condition & $\begin{array}{c}\text { \% of Hours at } \\
\text { Condition }\end{array}$ \\
\hline All Included (Filtered) Data & $4,454.3$ & $100.0 \%$ \\
\hline CHWST LT 46F (All Data) & $2,143.3$ & $48.1 \%$ \\
\hline CC SAT LT 50F & $1,251.1$ & $28.1 \%$ \\
\hline CC SAT GT 50F and LT 52F & 160.2 & $3.6 \%$ \\
\hline CC SAT GT 52F and LT 56F & 717.6 & $16.1 \%$ \\
\hline CC SAT GT 56F and LT 62F & 8.8 & $0.2 \%$ \\
\hline CC SAT GT 62F & 5.6 & $0.1 \%$ \\
\hline CHWST GT 46F and LT 50F & $1,345.8$ & $30.2 \%$ \\
\hline CC SAT LT 50F & 185.4 & $4.2 \%$ \\
\hline CC SAT GT 50F and LT 52F & 592.3 & $13.3 \%$ \\
\hline CC SAT GT 52F and LT 56F & 567.2 & $12.7 \%$ \\
\hline CC SAT GT 56F and LT 62F & 0.5 & $0.0 \%$ \\
\hline CC SAT GT 62F & 0.4 & $0.0 \%$ \\
\hline CHWST GT 50F and LT 54F & 524.3 & $11.8 \%$ \\
\hline CC SAT GT 50F and LT 52F & 1.0 & $0.0 \%$ \\
\hline CC SAT GT 52F and LT 56F & 377.3 & $8.5 \%$ \\
\hline CC SAT GT 56F and LT 62F & 145.8 & $3.3 \%$ \\
\hline CC SAT GT 62F & 0.3 & $0.0 \%$ \\
\hline CHWST GT 54F and LT 58F & 169.0 & $3.8 \%$ \\
\hline CC SAT GT 52F and LT 56F & 1.0 & $0.0 \%$ \\
\hline CC SAT GT 56F and LT 62F & 167.8 & $3.8 \%$ \\
\hline CC SAT GT 62F & 0.2 & $0.0 \%$ \\
\hline CHWST GT 58F and LT 62F & 90.8 & $2.0 \%$ \\
\hline CC SAT GT 56F and LT 62F & 49.3 & $1.1 \%$ \\
\hline CC SAT GT 62F & 41.5 & $0.9 \%$ \\
\hline CHWST GT 62F and LT 66F & 105.0 & $2.4 \%$ \\
\hline CC SAT GT 62F & 104.9 & $2.4 \%$ \\
\hline CHWST GT 66F & 76.1 & $1.7 \%$ \\
\hline CC SAT GT 62F & & \\
\hline
\end{tabular}

The results of the analysis show that the HEDS AHU significantly reduces the cooling loads and reheat energy associated with dehumidification across all operating conditions, even considering the failing chiller conditions. Additionally, due to the large cooling coil design, HEDS was able to provide dehumidification and reheat even when the chilled water supply temperature from the failing plants approached $60^{\circ} \mathrm{F}$, as indicated in the table below by the reduced CC dewpoint temperatures compared with outdoor and return air dewpoints. Visual HVAC system inspections of all of the AHUs during these warm CHWS water conditions showed that the only AHU that was producing meaningful levels of condensate into the drains was the HEDS unit. The other units were producing zero to insignificant amounts of condensate, while the HEDS unit was pouring condensate down the drain. 
The data in Table 6 confirm that the HEDS system demonstrated a net 21.5\% cooling load reduction across all operating conditions, including times when the chiller was in a failure or capacity constraint mode of some sort.

Table 6. Fort Bragg HEDS savings summary with differential temperatures across all temperature bins. Note that gray rows represent transient conditions and may not be representative of steady state results.

\begin{tabular}{|c|c|c|c|c|c|c|}
\hline & $\begin{array}{l}\text { Total Cooling } \\
\text { Coil Ton-hrs }\end{array}$ & $\begin{array}{l}\text { Net AHU Total } \\
\text { Ton-hrs DDC }\end{array}$ & $\begin{array}{c}\text { Total Ton-hrs } \\
\text { Savings from } \\
\text { HEDS }\end{array}$ & $\begin{array}{l}\text { Total HEDS Savings } \\
\% \text { (saved ton-hrs / } \\
\text { CC ton-hrs) }\end{array}$ & $\begin{array}{l}\text { Cooling Coil } \\
\text { CHW Delta T }\end{array}$ & $\begin{array}{c}\text { Net AHU } \\
\text { CHW Delta T }\end{array}$ \\
\hline All Included (Filtered) Data & 150,081 & 117,874 & 32,207 & $21.5 \%$ & 14.38 & 10.61 \\
\hline CHWST LT 46F (All Data) & 68,276 & 51,410 & 16,866 & $24.7 \%$ & 17.08 & 11.80 \\
\hline CC SAT LT 5OF & 47,189 & 37,929 & 9,260 & $19.6 \%$ & 13.47 & 10.63 \\
\hline CC SAT GT $50 \mathrm{~F}$ and LT 52F & 4,899 & 3,354 & 1,545 & $31.5 \%$ & 20.99 & 13.22 \\
\hline CC SAT GT $52 \mathrm{~F}$ and LT 56F & 15,725 & 9,843 & 5,882 & $37.4 \%$ & 22.10 & 13.29 \\
\hline CC SAT GT 56F and LT 62F & 293 & 178 & 116 & $39.5 \%$ & 37.01 & 21.94 \\
\hline CC SAT GT $62 \mathrm{~F}$ & 170 & 106 & 63 & $37.4 \%$ & 38.40 & 26.04 \\
\hline CHWST GT 46F and LT 50F & 51,626 & 41,645 & 9,981 & $19.3 \%$ & 13.15 & 10.41 \\
\hline CC SAT LT 5OF & 6,676 & 5,413 & 1,263 & $18.9 \%$ & 11.93 & 9.57 \\
\hline CC SAT GT $50 \mathrm{~F}$ and LT 52F & 23,382 & 18,988 & 4,394 & $18.8 \%$ & 12.93 & 10.45 \\
\hline CC SAT GT $52 \mathrm{~F}$ and LT 56F & 21,545 & 17,230 & 4,315 & $20.0 \%$ & 13.77 & 10.64 \\
\hline CC SAT GT $56 \mathrm{~F}$ and LT $62 \mathrm{~F}$ & 14 & 10 & 4 & $28.5 \%$ & 18.72 & 13.23 \\
\hline CC SAT GT $62 \mathrm{~F}$ & 9 & 4 & 5 & 58.49 & 20.55 & 13.10 \\
\hline CHWST GT 50F and LT 54F & 19,854 & 16,266 & 3,587 & $18.1 \%$ & 12.18 & 9.95 \\
\hline CC SAT GT 50F and LT 52F & 18 & 15 & 4 & $19.7 \%$ & 7.73 & 5.87 \\
\hline CC SAT GT 52F and LT 56F & 14,130 & 11,590 & 2,540 & $18.0 \%$ & 12.07 & 9.87 \\
\hline CC SAT GT $56 \mathrm{~F}$ and LT $62 \mathrm{~F}$ & 5,693 & 4,656 & 1,037 & $18.2 \%$ & 12.49 & 10.20 \\
\hline CC SAT GT 62F & 12 & & & $55.8 \%$ & 21.63 & 1215 \\
\hline CHWST GT 54F and LT 58F & 5,678 & 4,658 & 1,020 & $18.0 \%$ & 10.81 & 8.84 \\
\hline CC SAT GT 52F and LT 56F & 16 & 13 & & $19.8 \%$ & 5.01 & 3.98 \\
\hline CC SAT GT 56F and LT 62F & 5,656 & 4,640 & 1,015 & $18.0 \%$ & 10.84 & 8.87 \\
\hline CC SAT GT $62 \mathrm{~F}$ & 6 & 5 & 1 & $22.0 \%$ & 12.82 & 10,64 \\
\hline CHWST GT 58F and LT 62F & 1,610 & 1,356 & 254 & $15.8 \%$ & 6.09 & 5.03 \\
\hline CC SAT GT 56F and LT 62F & 847 & 736 & 111 & $13.1 \%$ & 5.62 & 4.83 \\
\hline CC SAT GT $62 \mathrm{~F}$ & 762 & 619 & 143 & $18.7 \%$ & 6.65 & 5.27 \\
\hline CHWST GT $62 \mathrm{~F}$ and LT 66F & 1,798 & 1,495 & 303 & $16.9 \%$ & 5.53 & 4.59 \\
\hline CC SAT GT $62 \mathrm{~F}$ & 1,797 & 1,494 & 303 & $16.9 \%$ & 5.53 & 4.59 \\
\hline CHWST GT 66F & 1,239 & 1,044 & 196 & $15.8 \%$ & 5.22 & 4.37 \\
\hline CC SAT GT $62 \mathrm{~F}$ & 1,239 & 1,044 & 196 & $15.8 \%$ & 5.22 & 4.37 \\
\hline
\end{tabular}

When considering only those times when the chiller plant was meeting setpoint (chilled water supply temperatures were less than $46^{\circ} \mathrm{F}$ ), the net cooling load reduction is $24.7 \%$.

The peak observed savings for the operating bins shown below is $37.4 \%$ when bins with less than 20 hours of operation were removed. Fortunately, this highest savings range corresponded to the most typical conditions that will be found in DoD and GSA facilities.

Extrapolating these results to VA Hospital type loads, with cooling coil supply air temperatures of less than $50^{\circ} \mathrm{F}$, the savings of $19.6 \%$ when multiplied by the 24 hour per day operating periods and significant cooling loads equate to a significant financial benefit, in addition to the life-saving 
aspects of the technology when it comes to RH control and the reduction of Hospital Acquired Infections (HAIs).

The chilled water differential temperatures for each performance bin are also shown. Under the heaviest dehumidification loads with cooling coil supply air temperatures less than $50^{\circ} \mathrm{F}$, the cooling coil chilled water system temperature differential (TD) is still above $13{ }^{\circ} \mathrm{F}$, with a net AHU waterside TD of nearly $11^{\circ} \mathrm{F}$. Under lighter loads with cooling coil supply air temperature between 52 to $56^{\circ} \mathrm{F}$, the cooling coil chilled water system TD increases to over $22{ }^{\circ} \mathrm{F}$, with a net AHU waterside TD of over $13^{\circ} \mathrm{F}$.

Figure 18 shows the results of a psychometric analysis that highlights the impact of the cooling recovery coil on the system performance. As shown, the subcooled air leaving the cooling coil at $52.5^{\circ} \mathrm{F}$ is heated to $61.5{ }^{\circ} \mathrm{F}$ using recovered energy from the chilled water in the cooling recovery coil, completely eliminating the need for additional reheat energy.

Figures 19 and 20 highlight the dynamic impact of the cooling recovery coil on the net AHU cooling load for a peak cooling week and peak cooling load day in August followed by part load days in October. The impact on total load, AHU cooling coil and net differential CHW temperatures, and total energy savings percentage are shown.

For the peak load week in August shown, the cooling coil supply air temperature is less than $50^{\circ} \mathrm{F}$ due to the high dehumidification loads required. At this condition, the average savings from HEDS is approximately 18\%. The peak cooling load day, August 5, 2016, is also shown, highlighting the savings at the time of coincident peak cooling load of $18.3 \%$.

Figures 21 and 22 highlight the impact of increased cooling coil supply air temperatures from part load conditions on overall HEDS system performance. The observed CHW temperature differentials (TD) are higher than the peak load data presented for August (where the cooling coil SAT was less than $50^{\circ} \mathrm{F}$ ). TD ranges from 15 to $22{ }^{\circ} \mathrm{F}$ for the cooling coil and 10 to $15^{\circ} \mathrm{F}$ for the entire AHU net of the cooling recovery coil (compared with 12 to $17^{\circ} \mathrm{F}$ for the cooling coil and 10 to $14{ }^{\circ} \mathrm{F}$ for the entire AHU net of the cooling recovery coil in the August peak data). This increased temperature differential results in an average cooling load reduction of over $27 \%$ for the data presented. 
As expected, the results shown in Figure 23 indicate a significant dependency of the savings on the cooling coil supply air temperature when the chiller plant is meeting the leaving setpoint (less than $46^{\circ} \mathrm{F}$ ). As the cooling coil supply air temperature increases due to lower dehumidification loads, the leaving water temperature of the coil increases, enabling more heat recovery in the cooling recovery coil.

Figure 18. Psychrometric chart highlighting the impact of the cooling recovery coil on HEDS system performance at Fort Bragg.

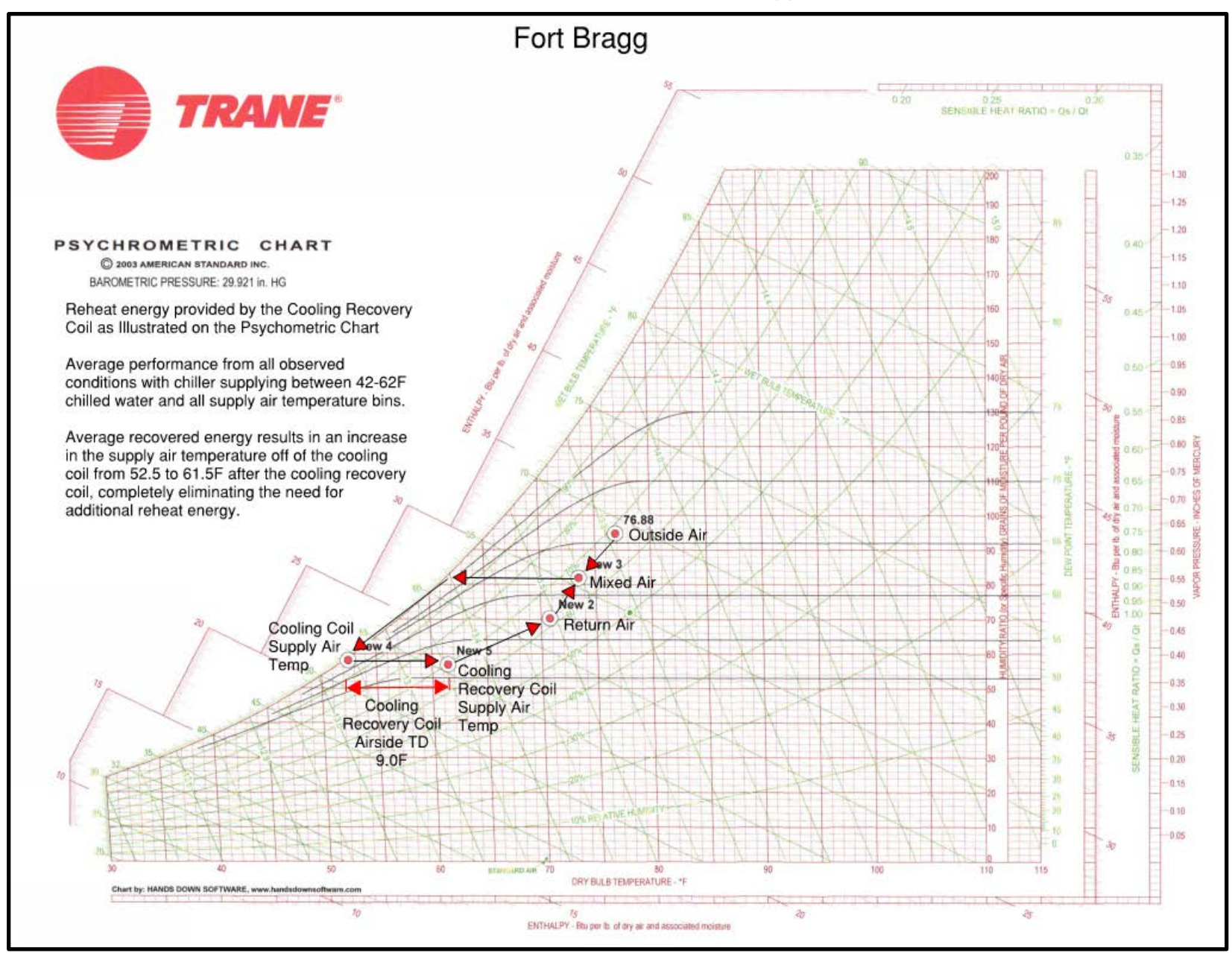


Figure 19. Dynamic HEDS savings and impact analysis for the peak cooling load week of August 1, 2016.

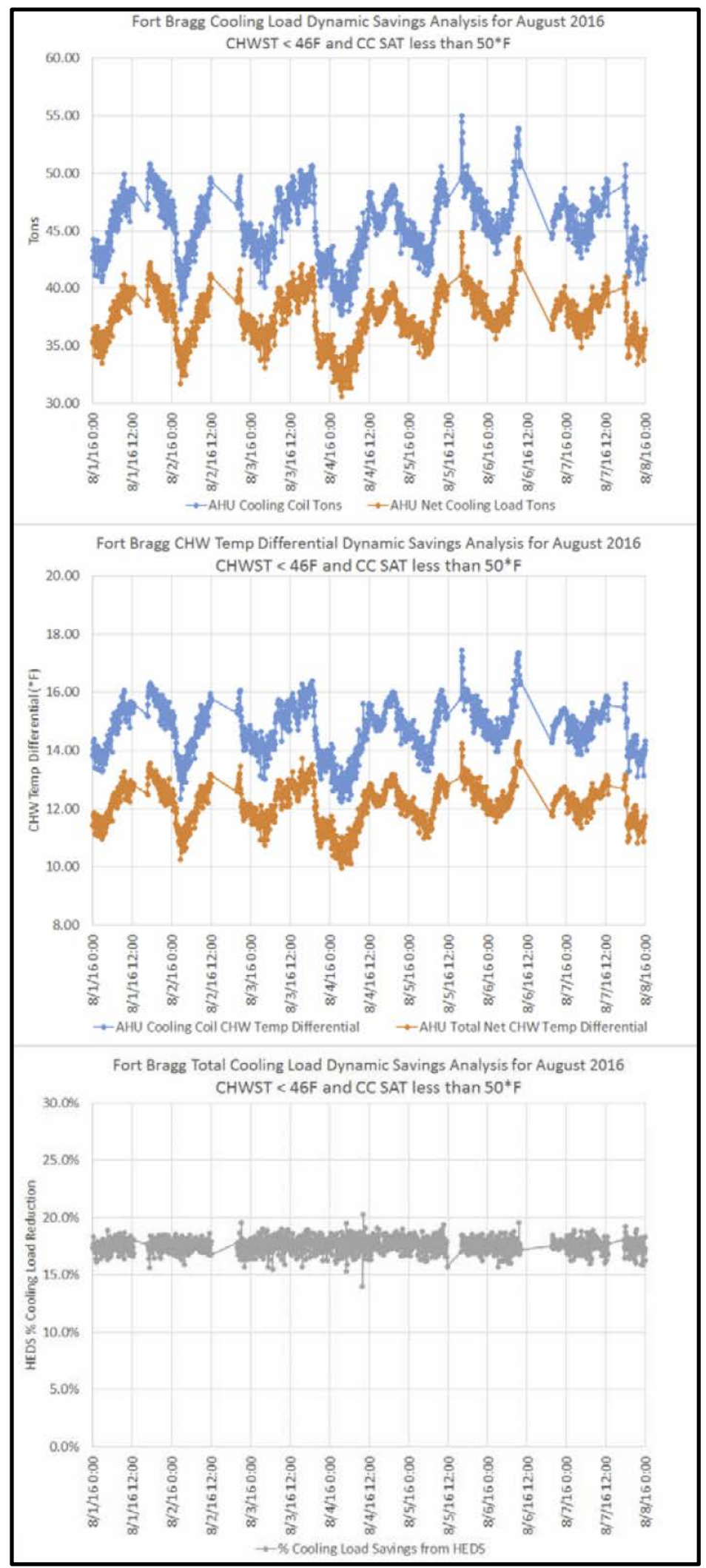


Figure 20. Dynamic HEDS savings and impact analysis for the peak cooling load day of August 5, 2016.

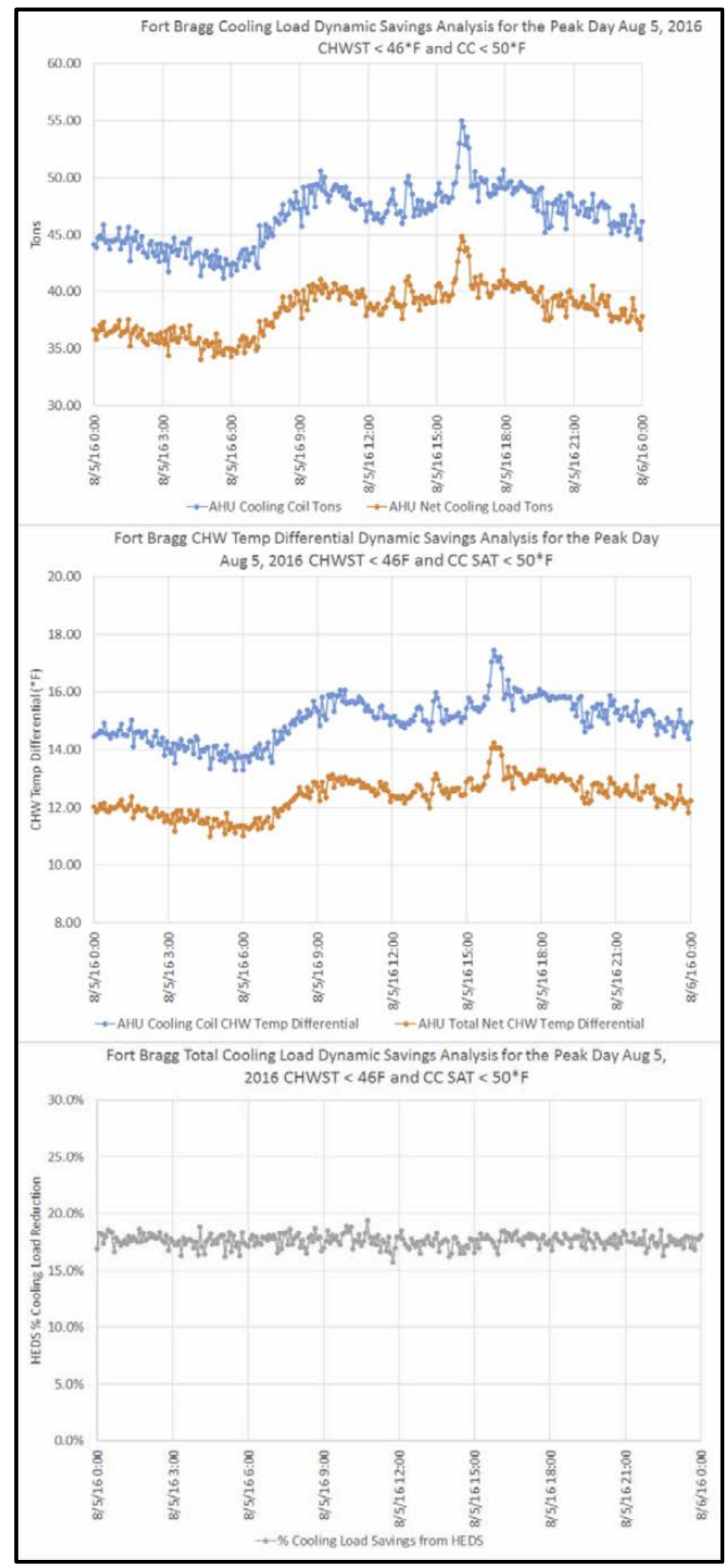


Figure 21. HEDS savings analysis for fall part load days where the CHWST is less than $46^{\circ} \mathrm{F}$ and the CC SAT is between 52 to $56^{\circ} \mathrm{F}$.

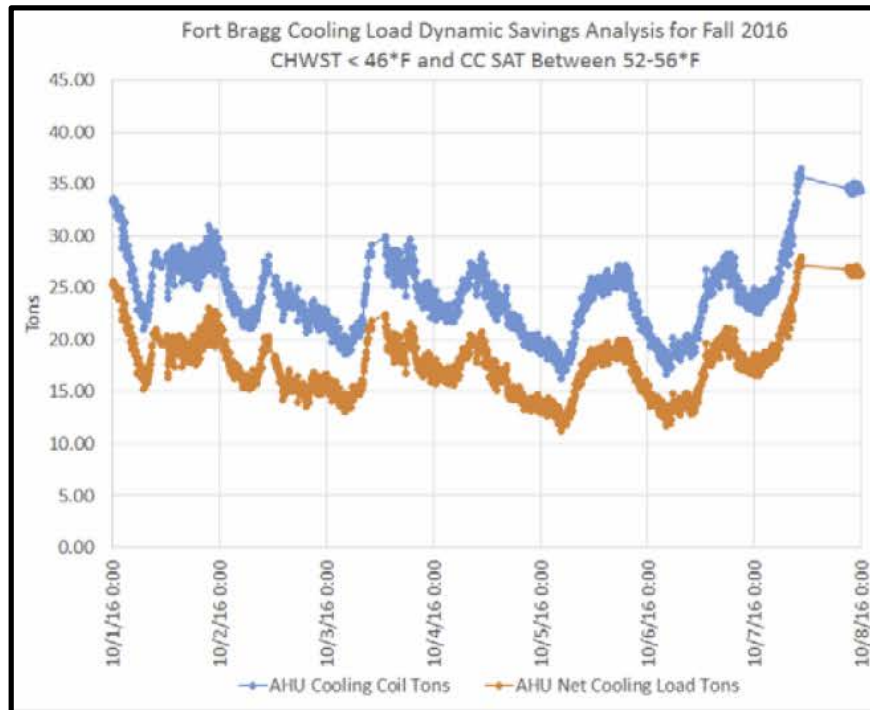

Fort Bragg CHW Temp Differential Dynamic Savings Analysis for Fall 2016 $25.00 \quad$ CHWST $\angle 46^{\circ} \mathrm{F}$ and CC SAT Between $52-56^{*} \mathrm{~F}$
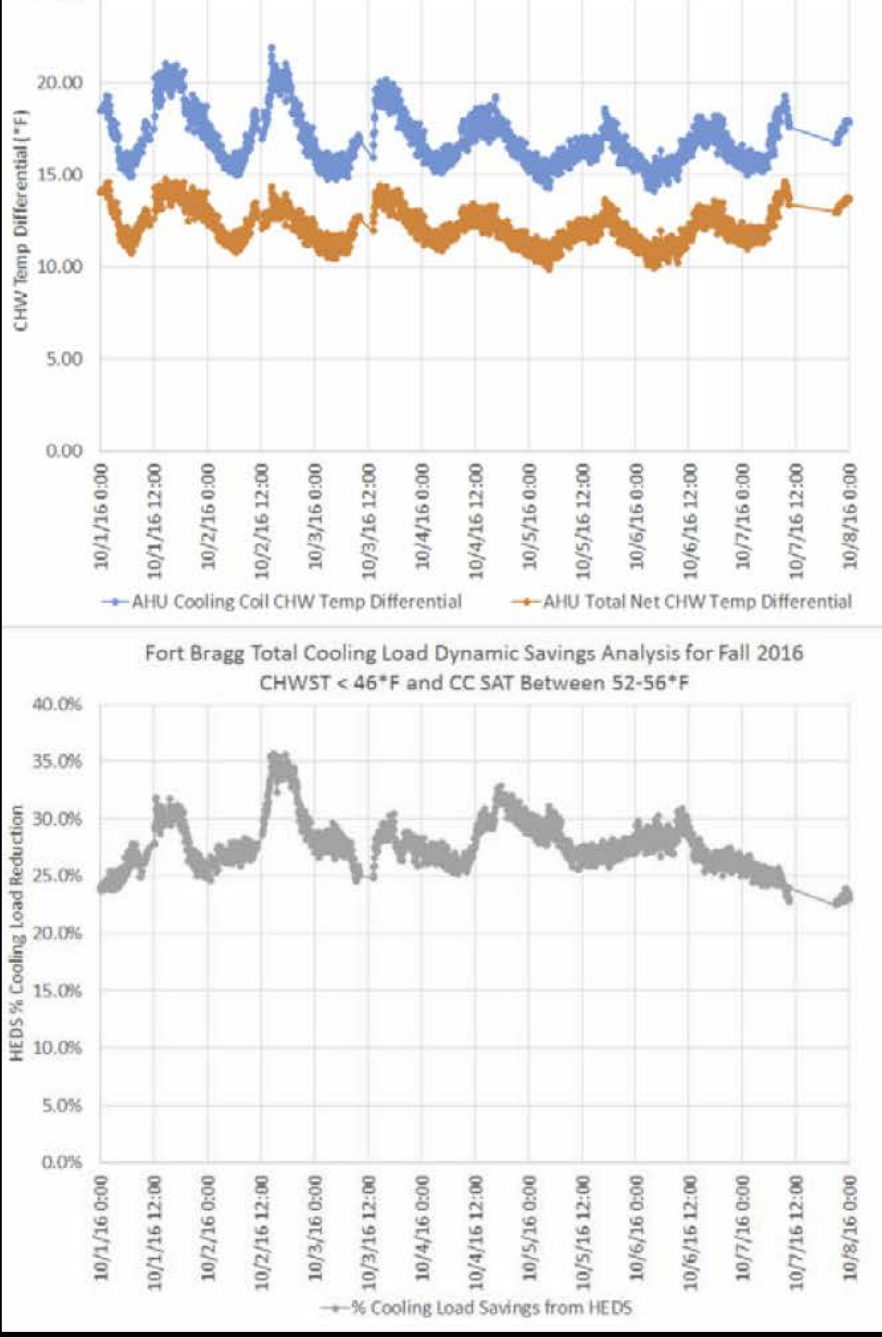
Figure 22. HEDS savings analysis for fall part load peak day October 2, 2016 where the CHST is less than $46^{\circ} \mathrm{F}$ and the CC SAT is between 52 to $56^{\circ} \mathrm{F}$.

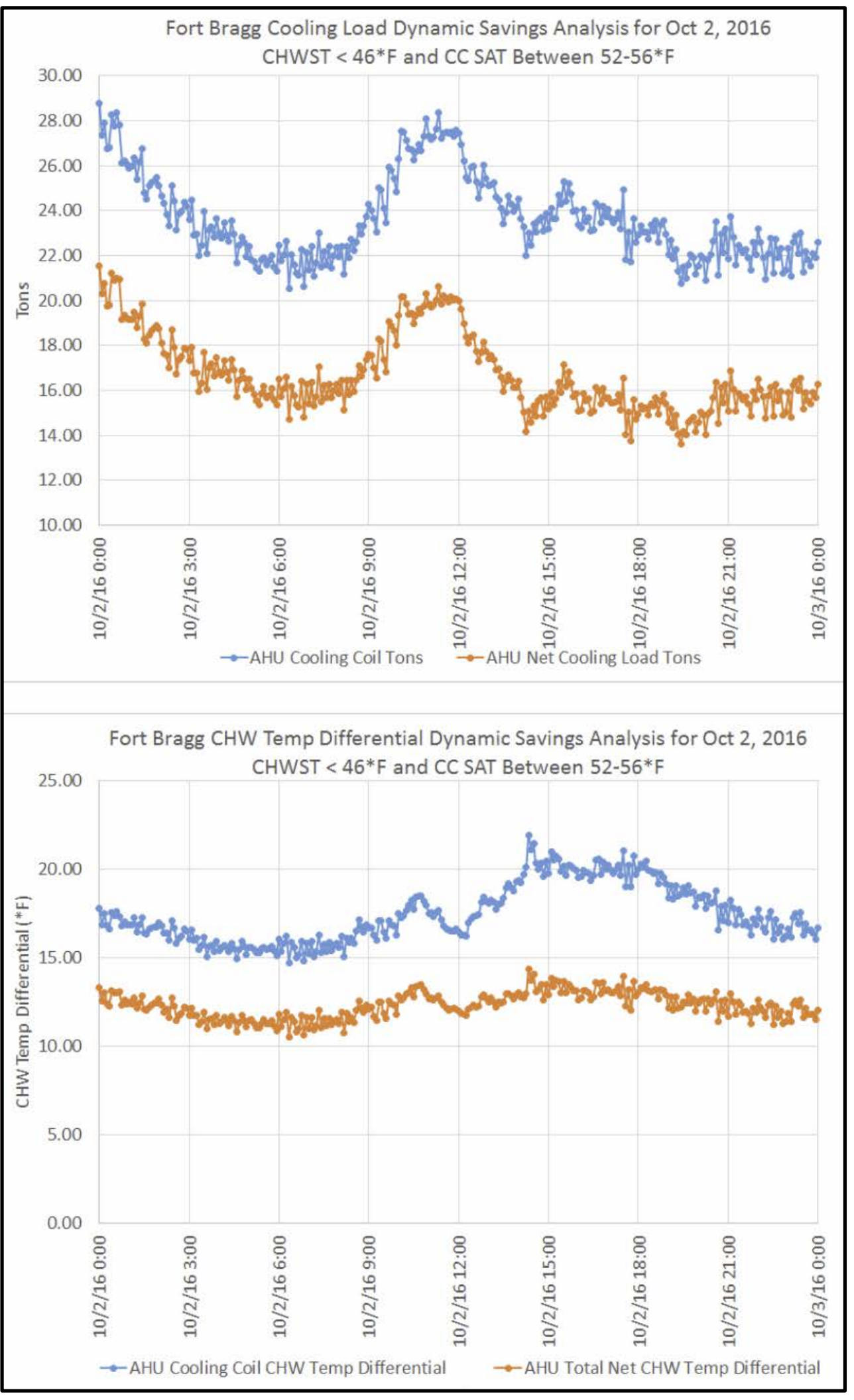


Figure 23. HEDS cooling load reduction as a function of CC supply air temp (SAT) when chilled water supply temp is in control (less than $46^{\circ} \mathrm{F}$ ). Note that the higher SAT ranges have been removed due to the limited hours of operation within the bins.

Fort Bragg HEDS Cooling Energy Savings as a Function of Cooling Coil Supply Air Temperature (CHWST < 46F)

$40.0 \%$

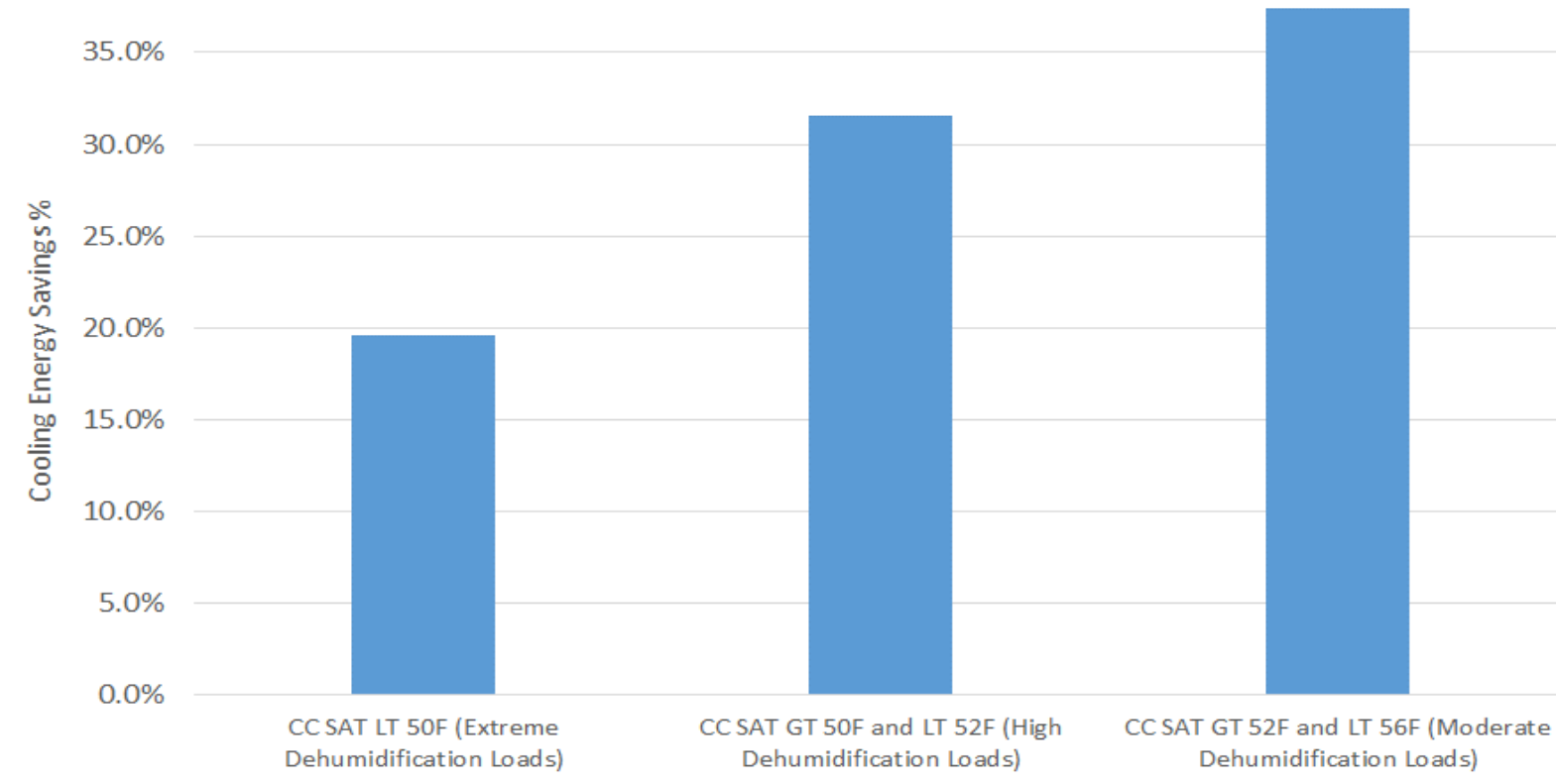

Cooling Coil Supply Air Temperature Bins

HEDS performance was tested across a range of conditions to determine a savings envelope. Very low supply air temperatures (and thus dewpoint temperatures) of less than $50^{\circ} \mathrm{F}$ off the cooling coil indicate of extreme dehumidification conditions typical of hospital operating rooms and clean room conditions (or extremely leaky envelopes in humid environments), while supply air temperatures off the cooling coil in the low $5 \mathrm{OS}\left({ }^{\circ} \mathrm{F}\right)$ are more typical of actual field conditions.

Table 7 lists the temperature conditions across the AHU for all temperature bins. When the CHWST is in control (less than $46^{\circ} \mathrm{F}$ ), the results show that, even at an average cooling coil leaving dewpoint of $52^{\circ} \mathrm{F}$, which provides significant dehumidification to the space, HEDS cooling load savings increase to over $37 \%$. In the most extreme dehumidification conditions, delivering $48^{\circ} \mathrm{F}$ dewpoint air off the cooling coil, HEDS still reduced the cooling load by nearly $20 \%$. This points to the importance of cooling coil supply air temperature resets based on space dewpoint conditions to achieve maximum energy savings. 
Table 7. Fort Bragg AHU temperatures across the range of operating conditions.

\begin{tabular}{|c|c|c|c|c|c|c|c|c|}
\hline & $\begin{array}{l}\text { Avg Outside Air } \\
\text { Dewpoint Temp }\end{array}$ & $\begin{array}{c}\text { Avg Space } \\
\text { Dewpoint Temp }\end{array}$ & $\begin{array}{l}\text { Avg Return Air } \\
\text { Dewpoint Temp }\end{array}$ & $\begin{array}{l}\text { Avg Mixed Air } \\
\text { Dewpoint Temp }\end{array}$ & $\begin{array}{l}\text { Avg CC Supply } \\
\text { Dewpoint Temp }\end{array}$ & $\begin{array}{l}\text { Avg CC Supply } \\
\text { Drybulb Temp }\end{array}$ & $\begin{array}{l}\text { AHU CRC Supply } \\
\text { Drybulb Temp }\end{array}$ & $\begin{array}{l}\text { AHU CRC Supply } \\
\text { Dewpoint Temp }\end{array}$ \\
\hline All Included (Filtered) Data & 65.56 & 58.44 & 57.27 & 61.49 & 52.13 & 52.49 & 61.46 & 51.56 \\
\hline CHWST LT 46F (All Data) & 61.51 & 54.87 & 54.19 & 57.88 & 49.67 & 50.18 & 59.97 & 49.06 \\
\hline CC SAT LT 5OF & 65.82 & 56.27 & 55.27 & 60.14 & 48.16 & 48.35 & 57.81 & 47.72 \\
\hline CC SAT GT 5OF and LT 52F & 58.39 & 53.39 & 53.35 & 56.35 & 50.66 & 50.99 & 62.83 & 49.77 \\
\hline CC SAT GT 52F and LT 56F & 55.07 & 52.98 & 52.67 & 54.57 & 52.21 & 52.99 & 62.89 & 51.33 \\
\hline CC SAT GT 56F and LT 62F & 43.17 & 4492 & 45.43 & 45,36 & 44.82 & 5872 & 6998 & 44.61 \\
\hline CC SAT GT 62F & 41.06 & 42.27 & 42.69 & 42.62 & 40.80 & 64.74 & 72.07 & 42.26 \\
\hline CHWST GT 46F and LT 50F & 68.75 & 60.07 & 58.27 & 63.32 & 51.45 & 51.60 & 60.76 & 50.94 \\
\hline CC SAT LT 5OF & 66.33 & 58.13 & 56.11 & 61.31 & 49.20 & 49.36 & 58.32 & 48.96 \\
\hline CC SAT GT 5OF and LT 52F & 69.20 & 59.92 & 58.19 & 63.35 & 50.99 & 51.05 & 60.20 & 50.53 \\
\hline CC SAT GT 52F and LT 56F & 69.07 & 60.87 & 59.07 & 63.96 & 52.68 & 52.89 & 62.14 & 52.02 \\
\hline CC SAT GT 56F and LT 62F & 62.78 & 57.33 & 56.24 & 60.57 & 51.19 & 57.17 & 63.98 & 52.05 \\
\hline CC SAT GT $62 \mathrm{~F}$ & 58.67 & 55.24 & 54.47 & 52.27 & 52.62 & 64.08 & 64.79 & 49.68 \\
\hline CHWST GT 50F and LT 54F & 71.29 & 63.76 & 61.46 & 66.65 & 55.21 & 55.23 & 63.58 & 54.69 \\
\hline CC SAT GT 5OF and LT 52F & 56.51 & 54.66 & 54.41 & 55.97 & 53.33 & 53.47 & 58.89 & 52.28 \\
\hline CC SAT GT 52F and LT 56F & 70.46 & 63.15 & 60.79 & 65.82 & 54.55 & 54.58 & 62.91 & 54.07 \\
\hline CC SAT GT 56F and LT 62F & 73.56 & 65.41 & 63.26 & 68.89 & 56.93 & 56.92 & 65.33 & 56.31 \\
\hline CC SAT GT $62 \mathrm{~F}$ & 48.73 & 49.42 & 50.61 & 52.09 & 51.22 & 53.37 & 65.94 & 46.81 \\
\hline CHWST GT 54F and LT 58F & 71.21 & 64.79 & 63.39 & 68.17 & 58.87 & 58.93 & 66.20 & 58.37 \\
\hline CC SAT GT 52F and LT 56F & 50.28 & 58.77 & 53.05 & 52.77 & 55.62 & 56.33 & 60.40 & 53.12 \\
\hline CC SAT GT 56F and LT 62F & 71.33 & 64.83 & 63.45 & 68.26 & 58.89 & 58.95 & 66.24 & 58.40 \\
\hline CC SAT GT $62 \mathrm{~F}$ & 69.93 & 57.87 & 60.15 & 67.85 & 54.57 & 54.72 & 63.43 & 58.47 \\
\hline CHWST GT 58F and LT 62F & 62.85 & 60.47 & 61.12 & 62.66 & 60.44 & 61.78 & 65.67 & 60.11 \\
\hline CC SAT GT 56F and LT 62F & 61.52 & 59.18 & 59.79 & 61.51 & 59.21 & 60.82 & 64.05 & 59.01 \\
\hline CC SAT GT $62 \mathrm{~F}$ & 64.43 & 62.00 & 62.71 & 64.02 & 61.91 & 62.92 & 67.60 & 61.42 \\
\hline CHWST GT $62 \mathrm{~F}$ and LT 66F & 68.15 & 64.72 & 64.90 & 67.13 & 64.87 & 66.08 & 69.97 & 64.39 \\
\hline CC SAT GT 62F & 68.15 & 64.72 & 64.90 & 67.15 & 64.87 & 66.08 & 69.97 & 64.40 \\
\hline CHWST GT 66F & 71.56 & 68.37 & 68.72 & 71.08 & 68.92 & 69.56 & 73.04 & 68.58 \\
\hline CC SAT GT $62 \mathrm{~F}$ & 71.56 & 68.37 & 68.72 & 71.08 & 68.92 & 69.56 & 73.04 & 68.58 \\
\hline
\end{tabular}

The elimination of the need for new reheat energy can be seen in the AHU CRC drybulb temperatures listed in Table 7 . When the cooling coil leaving dewpoint temp averages $48^{\circ} \mathrm{F}$, the HEDS units is able to deliver $58^{\circ} \mathrm{F}$ drybulb air to the space, reducing mold potential from surface condensation and ensuring a comfortable indoor environment. As loads decrease, HEDS is able to provide additional reheat to the supply air stream to both eliminate condensation potential and track the reduced cooling loads to prevent overcooling in the space. At an average cooling coil dewpoint temperature of $52{ }^{\circ} \mathrm{F}$ and drybulb temperature of $53{ }^{\circ} \mathrm{F}$, HEDS is able to provide $63{ }^{\circ} \mathrm{F}$ drybulb air to the space.

Figure 24 shows that, even under the failing chiller conditions, the HEDS system is able to reduce cooling loads significantly, reserving capacity for other equipment in the system. Even with the chiller plant delivering chilled water above $60^{\circ} \mathrm{F}$, HEDS is able to reduce the cooling load required by the unit by nearly $16 \%$, delivering added capacity to the other AHUs when the chiller is not performing. 
Figure 24. Fort Bragg HEDS cooling load reduction as a function of chilled water supply temperature across all supply air temperature ranges.

Fort Bragg HEDS Cooling Energy Savings as a Function of Chilled Water Supply

Temperature (all Supply Air Temperatures)

$30.0 \%$

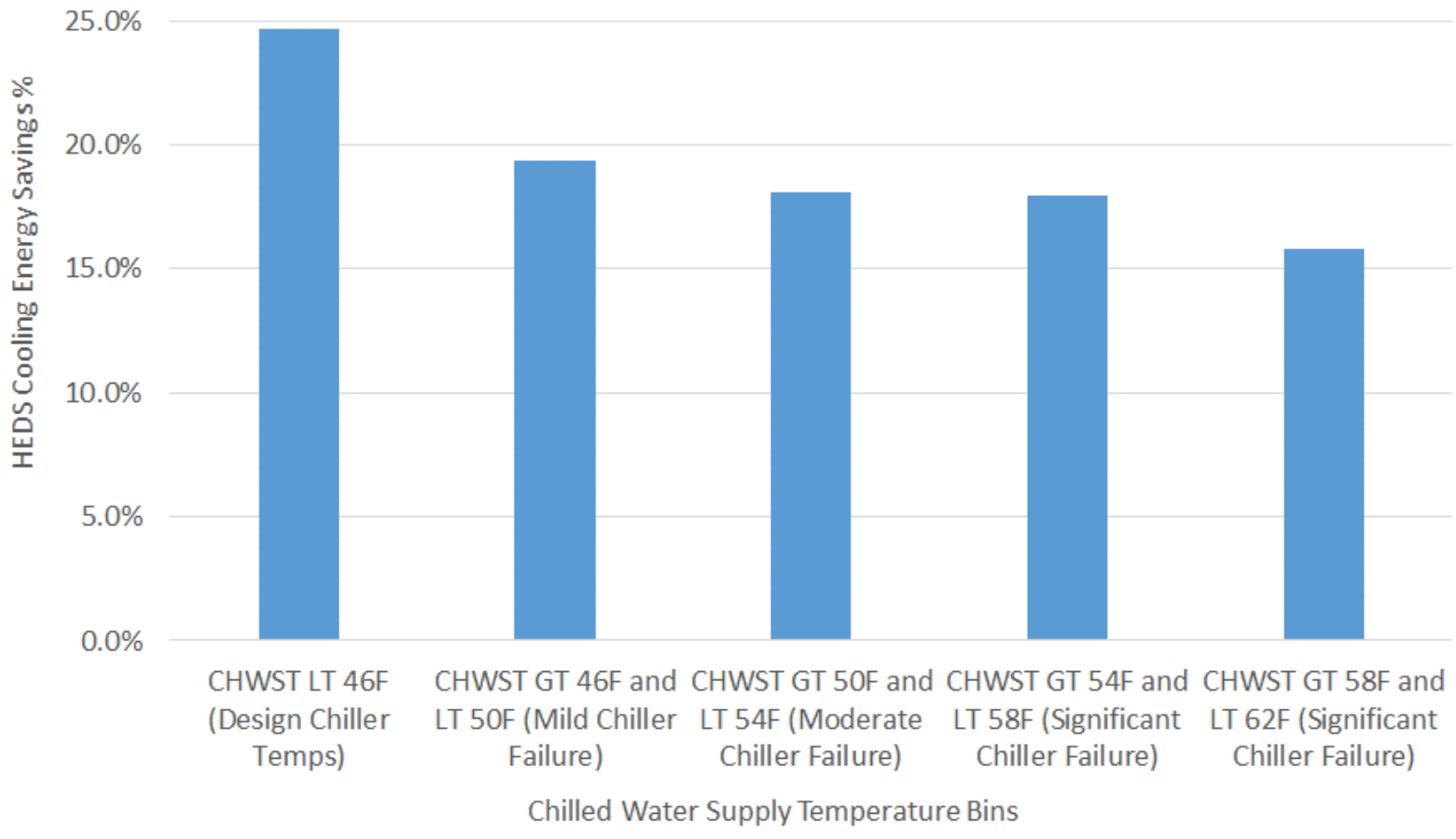

Peak cooling load is also reduced across the operating conditions. Peak loads were only analyzed for the steady state conditions where the chilled water supply temperature from the chiller plant was in control. The results (listed in Table 8) show an $18 \%$ peak demand reduction across all operating conditions. The peak is reduced by nearly $24 \%$ when the cooling coil supply air temperature is above $52^{\circ} \mathrm{F}$.

Table 8. Fort Bragg HEDS peak load reduction results when CHWST is in control (less than $\left.46^{\circ} \mathrm{F}\right)$.

\begin{tabular}{|c|c|c|c|c|}
\hline & $\begin{array}{c}\text { Peak Cooling Coil } \\
\text { Load (tons) }\end{array}$ & $\begin{array}{c}\text { Peak Net AHU Load } \\
\text { (tons) }\end{array}$ & $\begin{array}{c}\text { Peak Load Savings } \\
\text { (tons) }\end{array}$ & Peak Load Savings \% \\
\hline All Included (Filtered) Data & $\mathbf{5 5 . 5 2}$ & $\mathbf{4 5 . 3 7}$ & $\mathbf{1 0 . 1 4}$ & $\mathbf{1 8 . 3 \%}$ \\
\hline CHWST LT 46F (All Data) & $\mathbf{5 5 . 5 2}$ & $\mathbf{4 5 . 3 7}$ & $\mathbf{1 0 . 1 4}$ & $\mathbf{1 8 . 3 \%}$ \\
\hline CC SAT LT 5OF & 55.52 & 45.37 & 10.14 & $18.3 \%$ \\
\hline CC SAT GT 5OF and LT 52F & 53.52 & 44.21 & 9.31 & $17.4 \%$ \\
\hline CC SAT GT 52F and LT 56F & 36.25 & 27.64 & 8.61 & $23.7 \%$ \\
\hline CC SAT GT 56F and LT 62F & \multicolumn{4}{|c|}{ no steady state operations } \\
\hline
\end{tabular}




\subsubsection{Tinker AFB}

For a large portion of the analysis period, the chiller plant at Tinker AFB was experiencing significant performance issues associated with plugged condenser tubes in the chiller and plugged fill in the cooling tower, effectively limiting chiller output to around $60 \%$ of rated capacity when the chiller was not failed due to high surge count, which was a significant portion of the time. As a result, there were long periods of time where the plant was unable to meet the leaving chilled water temperature setpoint due to inadequate capacity or the chiller being failed off due to high surge count. This resulted in chilled water supply temperatures to the AHU ranging from $42{ }^{\circ} \mathrm{F}$ to over $80^{\circ} \mathrm{F}$. Table 9 lists the resulting run hours in each temperature bin for the analysis period. Note that the rows highlighted in gray represent transient conditions for which there was insufficient data to draw significant conclusions; these were therefore removed from discussion of savings in subsequent analyses.

Table 9. Summary of hours at each temperature bin analyzed for Tinker AFB.

\begin{tabular}{|c|c|c|}
\hline & Hours at Condition & $\begin{array}{c}\% \text { of Hours at } \\
\text { Condition }\end{array}$ \\
\hline All Included (Filtered) Data & 987.4 & $100.0 \%$ \\
\hline CHWST LT 46F (All Data) & 326.5 & $33.1 \%$ \\
\hline CC SAT LT 50F & 5.9 & $0.6 \%$ \\
\hline CC SAT GT 5OF and LT 52F & 54.8 & $5.5 \%$ \\
\hline CC SAT GT 52F and LT 56F & 262.3 & $26.6 \%$ \\
\hline CC SAT GT 56F and LT 62F & 1.9 & $0.2 \%$ \\
\hline CC SAT GT 62 F & 1.6 & 0.20 \\
\hline CHWST GT 46F and LT 5OF & 280.0 & $28.4 \%$ \\
\hline CCSATLT S0F = & 4.6 & $0.5 \%$ \\
\hline CC SAT GT 50F and LT 52F & 79.1 & $8.0 \%$ \\
\hline CC SAT GT 52F and LT 56F & 187.0 & $18.9 \%$ \\
\hline CC SAT GT 56F and LT 62F & 8.2 & $0.8 \%$ \\
\hline CC SAT GT 62F & 1.2 & $0.1 \%$ \\
\hline CHWST GT 50F and LT 54F & 227.0 & $23.0 \%$ \\
\hline CC SAT GI 50F and LT 52F & 3.5 & $0.4 \%$ \\
\hline CC SAT GT 52F and LT 56F & 153.7 & $15.6 \%$ \\
\hline CC SAT GT 56F and LT 62F & 67.6 & $6.8 \%$ \\
\hline CCSAT GT 62F & 1.9 & $0.2 \%$ \\
\hline CHWST GT 54F and LT 58F & 95.3 & $9.7 \%$ \\
\hline CCSAT CI 52Fand HT 56F & 2.9 & $0.3 \%$ \\
\hline CC SAT GT $56 \mathrm{~F}$ and LT $62 \mathrm{~F}$ & 85.8 & $8.7 \%$ \\
\hline \begin{tabular}{|l|l|l|} 
CC SAT GT $62 F=2$ \\
\end{tabular} & 6.3 & $0,6 \%$ \\
\hline CHWST GT 58F and LT 62F & 42.2 & $4.3 \%$ \\
\hline \begin{tabular}{|l} 
CCSAT GT S6F and LT 62F \\
\end{tabular} & 11.0 & $1.1 \%$ \\
\hline CC SAT GT 62F & 31.2 & $3.2 \%$ \\
\hline CHWWST GT 62F and LT 66F & 11.6 & $1.2 \%$ \\
\hline CC SAT GT 62F & 11.2 & $1.1 \%$ \\
\hline CHWNST CI 66F" & 4.8 & $0.5 \%$ \\
\hline 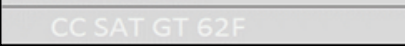 & 4.8 & 0,50 \\
\hline
\end{tabular}


The results of the analysis show that the HEDS AHU significantly reduces the cooling loads and reheat energy associated with dehumidification across all operating conditions, even considering the failing chiller conditions. Additionally, HEDS was able to provide dehumidification and reheat even when the chilled water supply temperature from the failing plants approached $60^{\circ} \mathrm{F}$.

The data in Table 10 confirm that the HEDS system demonstrated a net 29.0\% cooling load reduction across all operating conditions. When considering only those times when the chiller plant was meeting setpoint (when chilled water supply temperatures were less than $46^{\circ} \mathrm{F}$ ), the net cooling load reduction is $\mathbf{2 7 . 6 \%}$. The peak observed savings for the operating bins shown below is $33.7 \%$ when bins with less than 20 hours of total operation are removed.

The differential temperatures for each performance bin are also shown. Under the heaviest dehumidification loads with cooling coil supply air temperatures between 50 and $52^{\circ} \mathrm{F}$ and the chilled water supply temperature less than $46^{\circ} \mathrm{F}$, the cooling coil temperature differential (TD) is more than $24^{\circ} \mathrm{F}$, with a net AHU TD of nearly $18^{\circ} \mathrm{F}$. Under lighter loads with cooling coil supply air temperature between 52 to $56^{\circ} \mathrm{F}$ and the chilled water supply temperature less than $46^{\circ} \mathrm{F}$, the cooling coil TD remains over $24^{\circ} \mathrm{F}$, with a net AHU TD of nearly $17^{\circ} \mathrm{F}$.

Figure 25 shows the results of a psychometric analysis that highlights the impact of the cooling recovery coil on the system performance. As shown, the subcooled air leaving the cooling coil at $54.8^{\circ} \mathrm{F}$ is heated to $66.4^{\circ} \mathrm{F}$ using recovered energy from the chilled water in the cooling recovery coil, completely eliminating the need for additional reheat energy.

The impact of the variable air volume system can be seen in the data compared to the Fort Bragg constant air volume results. The cooling coil and AHU net TD is higher across all ranges due to the lower volume of air across the coils. This results in relatively flat cooling load savings $(\sim 30 \%)$ across all ranges of chilled water supply and supply air temperatures.

Figure 26 highlights the impact of the cooling recovery coil on the net AHU cooling load for a peak cooling day in June followed by a part load week in the Fall. The impact on total load, AHU cooling coil and net differential CHW temperatures, and total energy savings percentage are shown. 
During the peak load day in June, the average savings from HEDS is approximately $30 \%$, with a savings at the time of coincident peak cooling load of $28.9 \%$.

Figures 27 and 28 highlight the impact of the variable air volume control with the HEDS system. The resulting savings in the part load conditions stay relatively consistent with the peak load days, with average cooling load savings of just over $30 \%$.

Table 10. Tinker AFB HEDS savings summary with differential temperatures across all temperature bins. Note that gray rows represent transient conditions and may not be representative of steady state results.

\begin{tabular}{|c|c|c|c|c|c|c|}
\hline & $\begin{array}{l}\text { Total Cooling } \\
\text { Coil Ton-hrs }\end{array}$ & $\begin{array}{l}\text { Net AHU Total } \\
\text { Ton-hrs DDC }\end{array}$ & $\begin{array}{c}\text { Total Ton-hrs } \\
\text { Savings from } \\
\text { HEDS }\end{array}$ & $\begin{array}{l}\text { Total HEDS Savings } \\
\text { \% (saved ton-hrs / } \\
\text { CC ton-hrs) }\end{array}$ & $\begin{array}{l}\text { Cooling Coil } \\
\text { CHW Delta T }\end{array}$ & $\begin{array}{l}\text { Net AHU CHW } \\
\text { Delta T }\end{array}$ \\
\hline All Included (Filtered) Data & 11,658 & 8,282 & 3,376 & $29.0 \%$ & 19.91 & 13.84 \\
\hline CHWST LT 46F (All Data) & 2,837 & 2,053 & 783 & $27.6 \%$ & 24.37 & 17.07 \\
\hline & & & & & 13,31 & 9.55 \\
\hline CC SAT GT 50F and LT 52F & 689 & 505 & 184 & $26.7 \%$ & 24.69 & 18.07 \\
\hline CC SAT GT 52F and LT 56F & 1,978 & 1,408 & 570 & $28.8 \%$ & 24.51 & 16.96 \\
\hline CC SAT GT $56 F$ and LT $62 F$ & 34 & 27 & 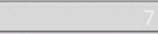 & $209 \%$ & 25,34 & 18.58 \\
\hline Ce 5 An का $62=2$ & & 48 & & 10.0 & 32.75 & 28.25 \\
\hline CHWST GT 46F and LT 5OF & 3,908 & 2,725 & 1,183 & $30.3 \%$ & 19.30 & 13.24 \\
\hline $\cos ^{2}$ & 65 & 51 & 14 & $21.1 \%$ & 11.31 & 8.24 \\
\hline CC SAT GT 50F and LT 52F & 1,497 & 993 & 504 & $33.7 \%$ & 19.76 & 13.08 \\
\hline CC SAT GT 52F and LT 56F & 2,190 & 1,557 & 633 & $28.9 \%$ & 19.20 & 13.34 \\
\hline CC SAT GI 56 F and LT $62 \mathrm{~F}$ & 108 & 78 & 30 & 27.79 & 20.64 & 13,57 \\
\hline 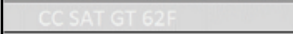 & 49 & 46 & & 598 & 2630 & 2040 \\
\hline CHWST GT 50F and LT 54F & 2,853 & 2,078 & 775 & $27.2 \%$ & 19.01 & 13.39 \\
\hline 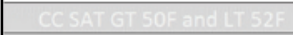 & 32 & 23 & & $28.5 \%$ & 14.43 & 9.33 \\
\hline CC SAT GT 52F and LT 56F & 1,955 & 1,430 & 526 & $26.9 \%$ & 19.78 & 14.11 \\
\hline CC SAT GT $56 \mathrm{~F}$ and LT $62 \mathrm{~F}$ & 807 & 572 & 235 & $29.1 \%$ & 17.54 & 11.98 \\
\hline & & & & & & \\
\hline CHWST GT 54F and LT 58F & 1,361 & 926 & 435 & $31.9 \%$ & 17.02 & 11.42 \\
\hline CC SAT GI $52 \mathrm{~F}$ and LT 56F & & & & $283.3 \%$ & 13,14 & 9.52 \\
\hline CC SAT GT 56F and LT 62F & 1,234 & 830 & 404 & $32.8 \%$ & 17.14 & 11.44 \\
\hline & & & & & $16: 82$ & 1189 \\
\hline CHWST GT 58F and LT 62F & 509 & 355 & 154 & $30.3 \%$ & 14.96 & 9.76 \\
\hline 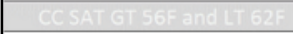 & 1113 & 82 & & & 10.25 & 6.87 \\
\hline CC SAT GT $62 \mathrm{~F}$ & 396 & 273 & 123 & $31.0 \%$ & 16.27 & 10.56 \\
\hline CHWWST GT 62 F and LT $66 \mathrm{~F}$ & 133 & 97 & 36 & $27.0 \%$ & 1296 & 8.05 \\
\hline CC SAT GI 62 F & 130 & 95 & 35 & $269 \%$ & 1290 & 8.03 \\
\hline CHWST GT $66 F$ & 57 & 48 & 9 & $16.3 \%$ & 12.76 & 8.10 \\
\hline Cesatche & 57 & 68 & & 1632 & 1278 & 210 \\
\hline
\end{tabular}


Figure 25. Psychrometric analysis for Tinker AFB Highlighting the impact of the cooling recovery coil on HEDS performance.

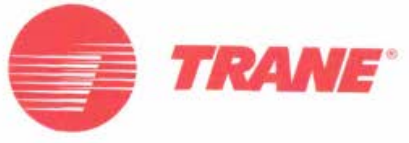

\section{Tinker AFB}

PSYCHROMETRIC CHART

O 2003 aMERICAN STANDARD INC.

BAROMETRIC PRESSURE: 29.921 in. HG

Reheat energy provided by the Cooling Recovery Coil as Illustrated on the Psychometric Chart

Average performance from all observed conditions with chiller supplying between $42-62 \mathrm{~F}$ chilled water and all supply air temperature bins.

Average recovered energy results in an increase in the supply air temperature off of the cooling coil from 54.8 to $66.4 \mathrm{~F}$ after the cooling recovery coil, completely eliminating the need for additional reheat energy.
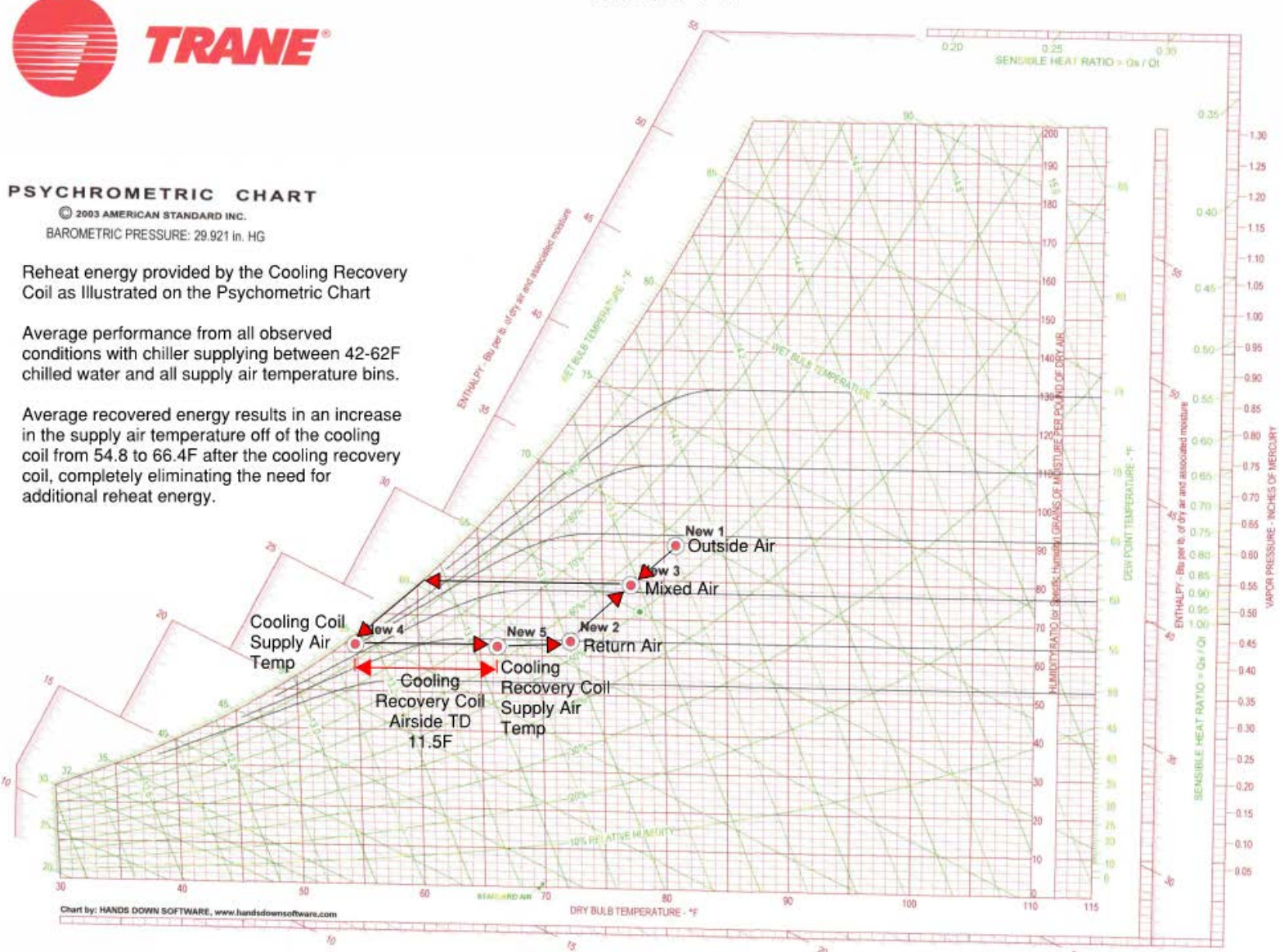
Figure 26. Tinker AFB dynamic HEDS savings and impact analysis for the peak cooling load on June 3, 2016.

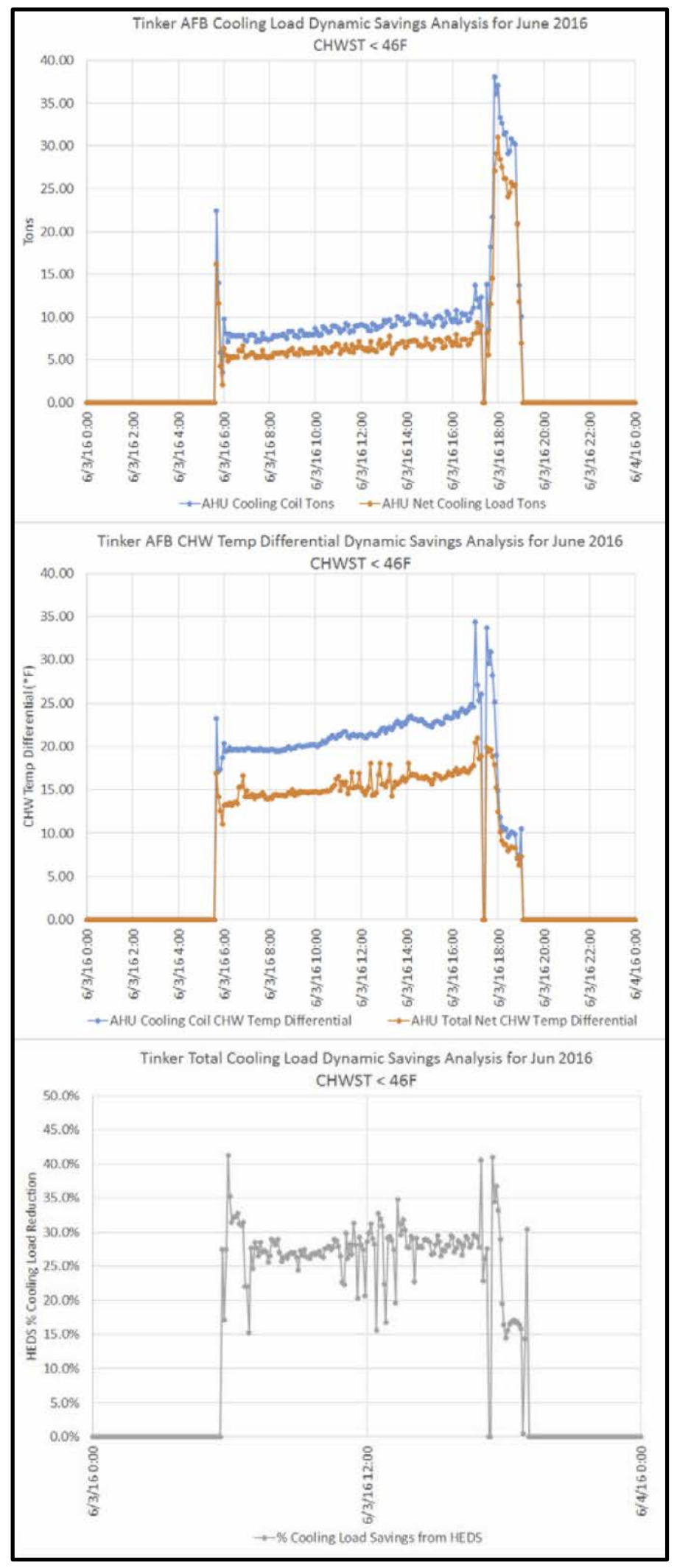


Figure 27. Tinker AFB HEDS dynamic savings analysis for part load days in the fall.

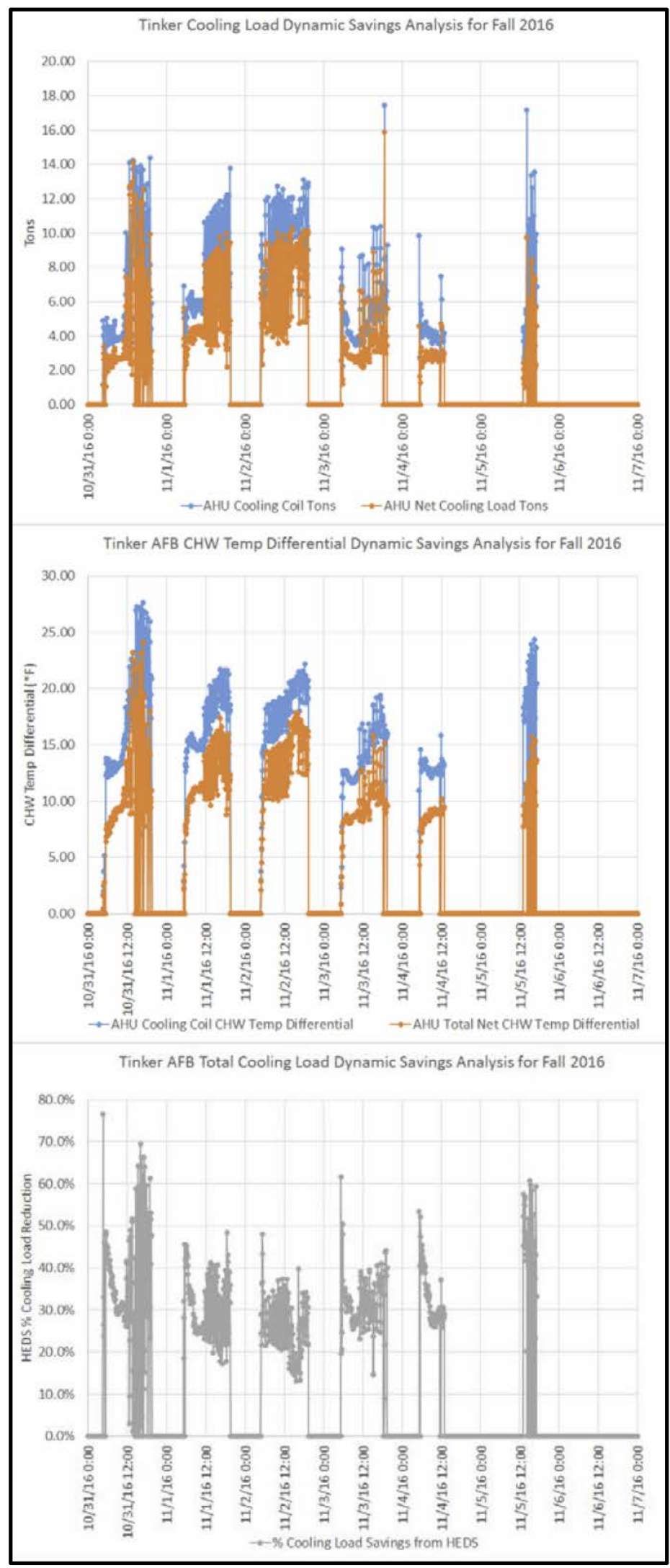


Figure 28. Tinker AFB HEDS dynamic savings analysis for part load day November 1, 2016.

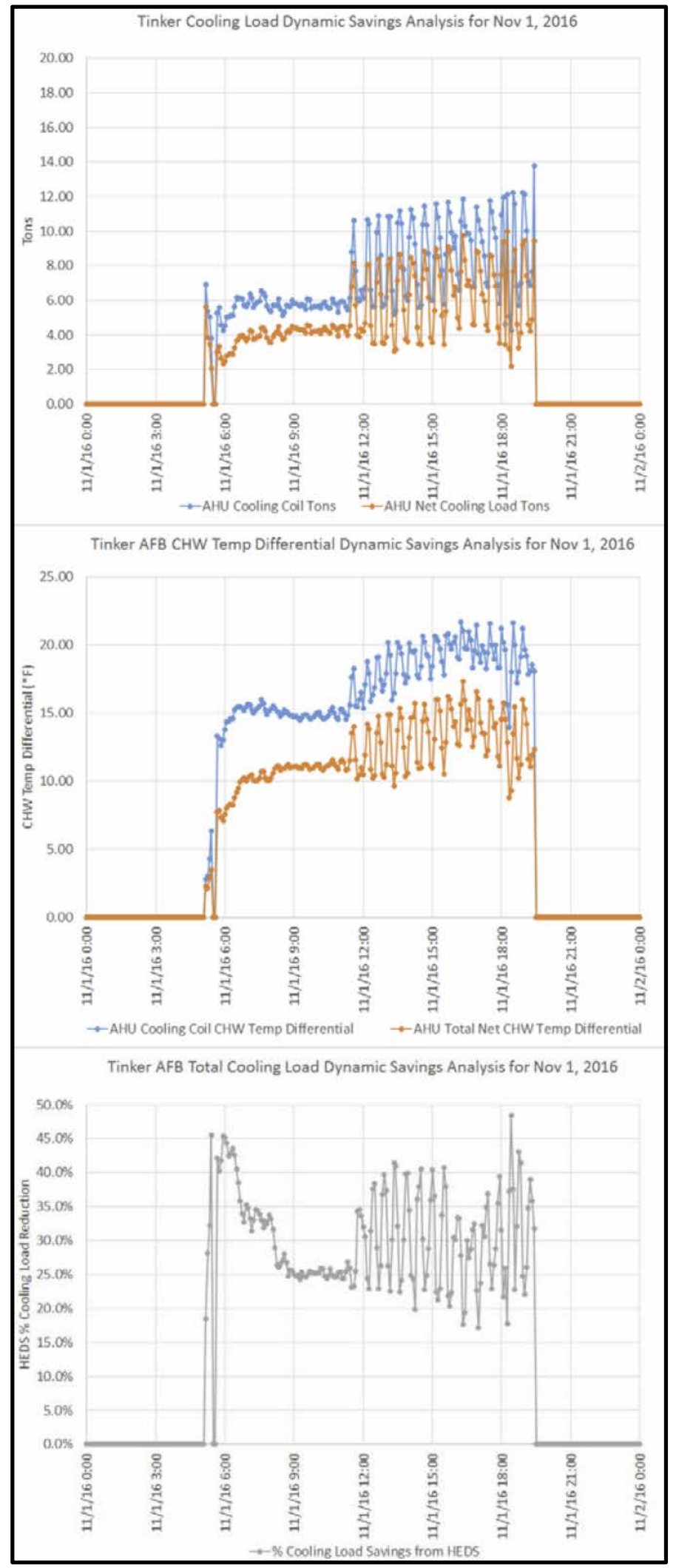


As discussed previously (and shown in Figure 29), the HEDS-VAV results also indicate only a modest dependency of the savings on the cooling coil supply air temperature when the chiller plant is meeting the leaving chilled water supply temperature setpoint (less than $46^{\circ} \mathrm{F}$ ). As the cooling coil supply air temperature increases due to lower dehumidification loads, the leaving water temperature of the coil increases, enabling more heat recovery in the cooling recovery coil. The warmer supply air temperatures are well matched with the reduced cooling loads.

Figure 29. Tinker AFB HEDS cooling load reduction as a function of CC supply air temp when the chilled water temperature is in control (less than $46^{\circ} \mathrm{F}$ ).

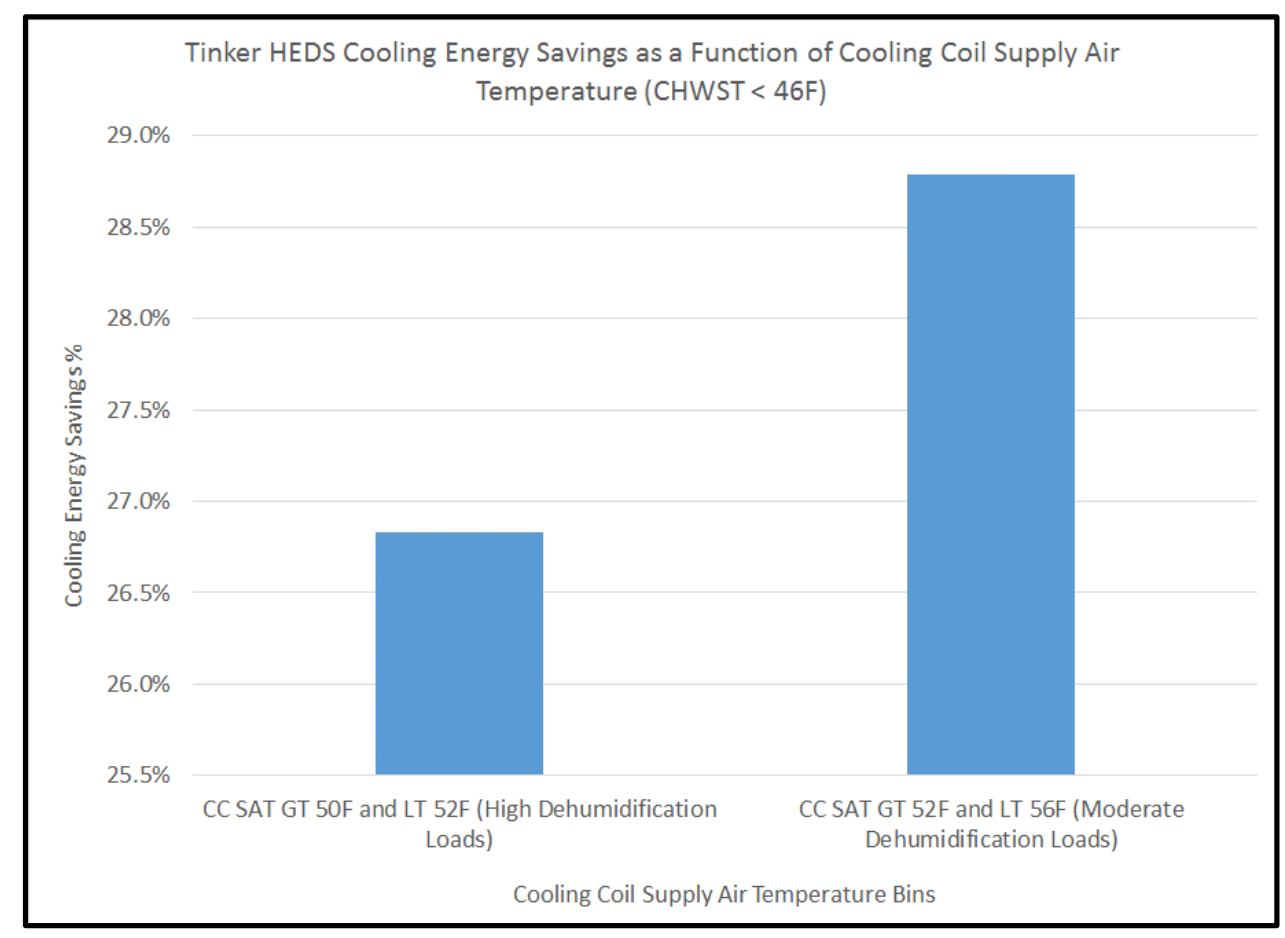

HEDS performance was tested across a range of conditions to determine a savings envelope. Very low supply air temperatures (and thus dewpoint temperatures) less than $52^{\circ} \mathrm{F}$ off the cooling coil are indicative of high dehumidification conditions typical of critical environments, while supply air temperatures off the cooling coil in the low to mid $50 \mathrm{Os}\left({ }^{\circ} \mathrm{F}\right)$ are more typical of actual field conditions for office spaces like those served at Tinker AFB with the HEDS unit.

Table 11 lists the temperatures across the AHU for all temperature bins. With the chilled water supply temperature in control (less than $46^{\circ} \mathrm{F}$ ), the results show that, even at an average cooling coil leaving dewpoint of $52{ }^{\circ} \mathrm{F}$, which provides significant dehumidification to the space, HEDS 
cooling load savings increase to nearly $29 \%$, very similar to the Fort Bragg savings at the same conditions. In the higher dehumidification conditions, which delivered $50^{\circ} \mathrm{F}$ dewpoint air off the cooling coil, HEDS still reduced the cooling load by nearly $27 \%$.

Table 11. Tinker AFB average AHU temperatures across the range of operating conditions.

\begin{tabular}{|c|c|c|c|c|c|c|c|c|}
\hline & $\begin{array}{l}\text { Total HEDS Savings } \\
\% \text { (saved ton-hrs / } \\
\text { CC ton-hrs) }\end{array}$ & $\begin{array}{l}\text { Avg Outside Air } \\
\text { Dewpoint Temp }\end{array}$ & $\begin{array}{l}\text { Avg Return Air } \\
\text { Dewpoint Temp }\end{array}$ & $\begin{array}{l}\text { Avg Mixed Air } \\
\text { Dewpoint Temp }\end{array}$ & $\begin{array}{l}\text { Avg CC Supply } \\
\text { Drybulb Temp }\end{array}$ & $\begin{array}{c}\text { Avg CC Supply } \\
\text { Dewpoint Temp }\end{array}$ & $\begin{array}{c}\text { AHU CRC } \\
\text { Supply Drybulb } \\
\text { Temp }\end{array}$ & $\begin{array}{c}\text { AHU CRC } \\
\text { Supply } \\
\text { Dewpoint Temp }\end{array}$ \\
\hline All Included (Filtered) Data & $29.0 \%$ & 63.88 & 54.62 & 60.41 & 54.85 & 53.87 & 66.39 & 53.91 \\
\hline CHWST LT 46F (All Data) & $27.6 \%$ & 61.33 & 51.57 & 56.88 & 52.65 & 51.76 & 63.73 & 51.76 \\
\hline 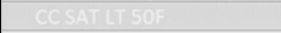 & $20,5 \%$ & 61.80 & 51.03 & 58.79 & 47.19 & 44.71 & 56.16 & 4.4 .74 \\
\hline CC SAT GT $50 \mathrm{~F}$ and LT $52 \mathrm{~F}$ & $26.7 \%$ & 62.47 & 52.10 & 59.86 & 51.32 & 50.48 & 64.76 & 50.61 \\
\hline CC SAT GT $52 \mathrm{~F}$ and LT $56 \mathrm{~F}$ & $28.8 \%$ & 61.15 & 51.44 & 56.23 & 52.90 & 52.15 & 63.64 & 52.12 \\
\hline CCSAT GI 56 F and LT $62 \mathrm{~F}$ & $20,9 \%$ & 57.55 & 53.56 & 56.86 & 57.52 & 52.41 & 63.39 & 52.43 \\
\hline CCSAT GI 62F & 10,998 & 56.96 & 54.37 & 57,32 & 7112 & 55.77 & 73.37 & 55.49 \\
\hline CHWST GT 46F and LT 50F & $30.3 \%$ & 63.74 & 53.28 & 60.00 & 52.75 & 52.09 & 65.59 & 52.00 \\
\hline 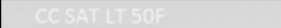 & $21.1 \%$ & 65.15 & 53.62 & 60.32 & 49.41 & 51.88 & 57.93 & 48.13 \\
\hline CC SAT GT $50 \mathrm{~F}$ and LT $52 \mathrm{~F}$ & $33.7 \%$ & 65.46 & 52.83 & 60.33 & 51.44 & 51.26 & 65.49 & 50.97 \\
\hline CC SAT GT $52 \mathrm{~F}$ and LT $56 \mathrm{~F}$ & $28.9 \%$ & 63.13 & 53.43 & 59.89 & 53.13 & 52.37 & 65.75 & 52.35 \\
\hline CC SAT GT 56 F and LT 62 F & $27.7 \%$ & 59.17 & 54.10 & 58.12 & 56,88 & 53.95 & 66,12 & 5552 \\
\hline CCSAT GT $62 \mathrm{~F}$ & $5.9 \%$ & 66,36 & 54,48 & 65.30 & 68.48 & 52.82 & 72.98 & 59.47 \\
\hline CHWST GT 50F and LT 54F & $27.2 \%$ & 65.30 & 55.79 & 62.99 & 55.62 & 54.83 & 68.58 & 54.90 \\
\hline CCSAT GT 50 F and LT 52 F & $28.5 \%$ & 61.05 & 55.71 & 59.08 & 55.26 & 54.85 & 63,34 & 50.66 \\
\hline CC SAT GT 52F and LT 56F & $26.9 \%$ & 65.60 & 55.53 & 63.32 & 55.37 & 54.54 & 69.11 & 54.35 \\
\hline CC SAT GT 56F and LT 62F & $29.1 \%$ & 64.84 & 56.41 & 62.41 & 56.21 & 55.49 & 67.68 & 56.27 \\
\hline CCSAT GI $62 \mathrm{~F}$ & 7986 & 64.98 & 56.42 & 64.44 & 56.09 & 55.52 & 66.70 & 61.92 \\
\hline CHWST GT 54F and LT 58F & $31.9 \%$ & 67.73 & 59.55 & 64.61 & 59.38 & 58.64 & 70.19 & 59.19 \\
\hline 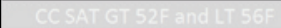 & $23.3 \%$ & 68.50 & 58.74 & 64.52 & 56.45 & 55.93 & 65,60 & 54,68 \\
\hline CC SAT GT $56 \mathrm{~F}$ and LT $62 \mathrm{~F}$ & $32.8 \%$ & 67.75 & 59.54 & 64.62 & 59.49 & 58.74 & 70.42 & 59.25 \\
\hline CCSAT GI $62 \mathrm{~F}$ & $23.5 \%$ & 67.04 & 60.15 & 64.70 & 58.95 & 58.23 & 68.54 & 6131 \\
\hline CHWST GT 58F and LT 62F & $30.3 \%$ & 66.53 & 61.54 & 64.13 & 61.98 & 60.77 & 70.31 & 61.33 \\
\hline 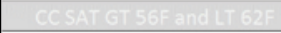 & 27.79 & 63.82 & 59.33 & 61.94 & 61.04 & 58.82 & 6725 & 58,60 \\
\hline CC SAT GT 62F & $31.0 \%$ & 67.55 & 62.15 & 64.96 & 62.24 & 61.31 & 71.16 & 62.37 \\
\hline 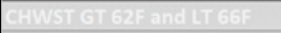 & $27.0 \%$ & 66.49 & 61.96 & 64.91 & 62.90 & 61.14 & 711.13 & 63,22 \\
\hline CCSAT GI 62F & $26.9 \%$ & 66.46 & 62.01 & 65.04 & 62.96 & 61.19 & 71.15 & 63.30 \\
\hline ctrinst ar $63=$ & $16.3 \%$ & 66.44 & 61.55 & 66.74 & 60.83 & 59.44 & 69.25 & 66.33 \\
\hline 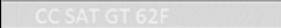 & 16525 & 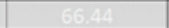 & 6455 & 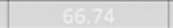 & 60028 & 5924 & 18925 & $68=3$ \\
\hline
\end{tabular}

The AHU CRC drybulb temperatures at Tinker AFB listed in Table 11 indicate that the need for new reheat energy has been eliminated, which is similar to the Fort Bragg results.

When the cooling coil leaving dewpoint temp averages $50^{\circ} \mathrm{F}$, the HEDS units is able to deliver $65^{\circ} \mathrm{F}$ drybulb air to the space, reducing mold potential from surface condensation and ensuring a comfortable indoor environment. At an average cooling coil dewpoint temperature of $52{ }^{\circ} \mathrm{F}$ and drybulb temperature of $53{ }^{\circ} \mathrm{F}$, HEDS is able to provide $64^{\circ} \mathrm{F}$ drybulb air to the space.

Even under the failing chiller conditions, the HEDS system is able to reduce cooling loads significantly, reserving capacity for other equipment in the system (Figure 30). Even when the chiller plant delivers chilled water above $55^{\circ} \mathrm{F}$, HEDS is able to provide significant dehumidification, and reduce the 
cooling load of the unit by more than $30 \%$, effectively increasing the capacity of the system and delivering added capacity to the other AHUs when the chiller is not performing, thereby enhancing system resiliency.

Peak cooling load is also reduced across the operating conditions. Peak loads were only analyzed for the steady state conditions where the chilled water supply temperature from the chiller plant was in control. The results (listed in Table 12) show a 29\% peak demand reduction during the peak cooling period on June 3, 2016.

Figure 30. Tinker AFB HEDS cooling load reduction as a function of chilled water supply temperature from the plant.

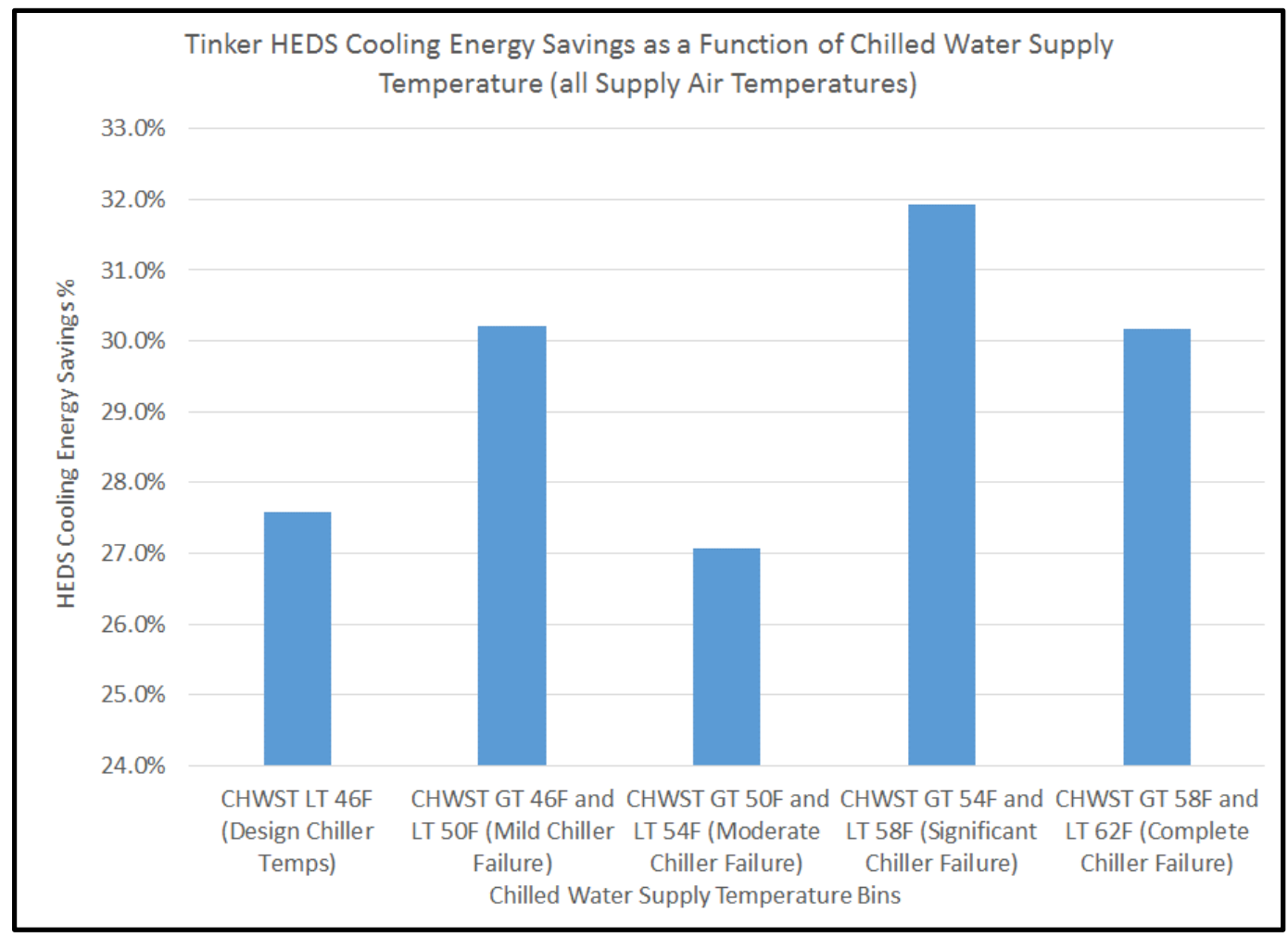

Table 12. Tinker AFB HEDS peak load reduction results when CHWST is in control (less than $\left.46^{\circ} \mathrm{F}\right)$.

\begin{tabular}{|c|c|c|c|c|}
\hline & $\begin{array}{c}\text { Peak Cooling Coil } \\
\text { Load (tons) }\end{array}$ & $\begin{array}{c}\text { Peak Net AHU Load } \\
\text { (tons) }\end{array}$ & $\begin{array}{c}\text { Peak Load Savings } \\
\text { (tons) }\end{array}$ & Peak Load Savings \% \\
\hline All Included (Filtered) Data & $\mathbf{3 8 . 1 3}$ & $\mathbf{2 7 . 1 1}$ & $\mathbf{1 1 . 0 2}$ & $\mathbf{2 8 . 9 0 \%}$ \\
\hline CHWST LT 46F (All Data) & $\mathbf{3 8 . 1 3}$ & $\mathbf{2 7 . 1 1}$ & $\mathbf{1 1 . 0 2}$ & $\mathbf{2 8 . 9 0 \%}$ \\
\hline CC SAT GT 50F and LT 52F & \multicolumn{5}{|c|}{$28.90 \%$} \\
\hline CC SAT GT 52F and LT 56F & 38.13 & 27.11 & 11.02 & \\
\hline & &
\end{tabular}




\section{Performance Assessment}

\subsection{Savings analysis methodology}

Although extensive performance monitoring equipment for both airside and waterside were installed on the AHUs, due to the nature of the HEDS system very few data points are required to determine the performance of the system compared to a typical AHU with reheat or "baseline" condition. This is a result of the fact that the cooling load is an independent, uncontrolled variable in the analysis since the cooling load is determined by the space and ambient conditions. Specifically, the leaving AHU cooling coil temperature is controlled to maintain primarily the space dewpoint and secondarily the space temperature within setpoints. (The control system resets the cooling coil leaving temperature based on the dewpoint temperature in the space. As the space dewpoint temperature rises, the cooling coil leaving temperature setpoint drops to provide increased dehumidification. As the space dewpoint falls, the cooling coil leaving temperature is increased to reduce unnecessary dehumidification.) Therefore, the baseline cooling load can be considered to be the load on the cooling coil in the HEDS unit, and the savings due to the cooling recovery coil are determined by the cooling coil load minus the net delivered AHU cooling load to the chiller plant

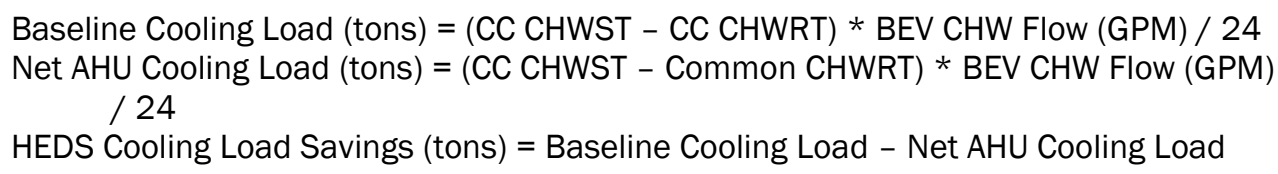

Given the design of the HEDS unit, all of the cooling energy recovered in the cooling recovery coil (by warming the airstream coming off the cooling coil) results in a direct decrease in energy required for reheat associated with dehumidification. Therefore, the cooling load savings in BTUs is exactly equal to the reheat energy savings, as the reheat requirement is displaced by the cooling recovery coil. For both project sites, additional reheat energy for RH control from other sources such as natural gas hot water systems or electric strip heating was completely eliminated, resulting in a $100 \%$ reduction in reheat energy. 
Note that for the purposes of this demonstration, fan energy savings associated the HEDS low pressure drop coils have not been considered. To determine net electricity savings from the cooling load savings, the efficiency of the central plant must be considered

HEDS Electricity Savings $(\mathrm{kW})=$ HEDS Cooling Load Savings (tons) * Chiller Plant $\mathrm{kW} / \mathrm{ton}$

Chiller plant efficiencies, considering all parasitic components, can typically range from $0.5-2.5 \mathrm{~kW} / \mathrm{ton}$, depending on the equipment, configuration, controls, and geographic location. Reheat energy savings calculations depend on the reheat energy source. For electric reheat, the cooling load savings can be converted directly to electricity with no losses

HEDS Electric Reheat Savings $(\mathrm{kW})=$ HEDS Cooling Load Savings (tons) * 3.517 $\mathrm{kW} / \mathrm{ton}$

For boiler systems, the delivered efficiency of the hot water or steam must be considered

HEDS Boiler Reheat Savings (therms) $=$ HEDS Cooling Load Savings (tons) $* 0.12$ therms/ton / Boiler System Efficiency

Considering the boiler efficiency, cycling losses, and distribution losses, typical delivered boiler system efficiencies can range from 30 to $85 \%$ depending on the system design, controls, delivery medium (steam, high temp hot water, hot water), and load factors.

\subsection{Cooling load savings vs. cooling energy savings}

One important distinction to make is that the percent of cooling load savings is a much smaller figure than the actual cooling energy percent savings that will show up at the utility meter.

For 24/7 loads, most chiller plants are equipped with VFDs on pumps and cooling towers, and many chiller plants that are 15 years old (or newer) also have one or more VFD high efficiency chillers. Due to Affinity Laws, equipment that is controlled by a VFD saves energy in a non-linear fashion, meaning a small speed reduction due to a load reduction equates to a much higher energy percent reduction. For example, chilled water pumps with VFDs operate with an Affinity Law power relationship of approximately 2.5 , so if the cooling load goes down by $20 \%$, the pump energy requirement equals $(1-0.2)^{\wedge} 2.5=57 \%$, a savings of $43 \%$. Condenser water pumps and cooling tower fan motors typically unload to the power of 2 , while a VFD chiller may unload to the power of 1.5 , so it can be seen that 
cooling energy savings can be significantly greater than cooling load percent savings.

Additionally, for administrative use facilities that are supposed to have 5 day per week, 12-hour per day HVAC occupancy schedules, but that may be running 24/7 due to inadequate and undersized HVAC AHUs, the switch to a HEDS-based system can reduce AHU and chiller plant runtime by $90+$ hours per week, in addition to the cooling load reduction. This equates to an approximate $50 \%$ run time reduction, which provides not only substantial energy savings, but significant maintenance savings as well.

\subsection{Data collection methodology and quality analysis}

Extensive monitoring equipment has been installed on the HEDS units at both sites to facilitate detailed performance analyses. The following sections give an overview of the sensing equipment and data collection procedures. Appendices D and E include more detailed information and cut sheets.

\subsubsection{Data description}

The data spans from April 1 through November 9, 2016 for the analysis included in this report. During this range, trend data points at Fort Bragg were collected for $98.8 \%$ of the available time period, as some data gaps exist due to equipment outages and upgrades. During this range, trend data points at Tinker AFB were collected for $86.6 \%$ of the available time period, as some data gaps exist due to trend collection issues, equipment outages and upgrades.

Note that Tinker AFB has a Reheat Coil (RHC), and Fort Bragg does not have a RHC, so there are slight differences between the two sites. Appendix $\mathrm{C}$ includes a full list of monitoring points for each site. Key monitoring points used for the calculations are:

- Trend Points Used for Energy Savings Calculations:

- CC Chilled Water Flow from the Belimo Energy Valve (GPM)

- DDC CC Chilled Water Supply Temperature $\left({ }^{\circ} \mathrm{F}\right)$

- DDC CC Chilled Water Return Temperature $\left({ }^{\circ} \mathrm{F}\right)$

- DDC Common Chilled Water Return Temperature $\left({ }^{\circ} \mathrm{F}\right)$.

- Trend Points Used for Data Filtering, Data Quality Analyses, and Reporting:

- CC Chilled Water Flow from the Belimo Energy Valve (GPM) 
- DDC CC Chilled Water Supply Temperature $\left({ }^{\circ} \mathrm{F}\right)$

- $\quad$ DDC CC Chilled Water Return Temperature $\left({ }^{\circ} \mathrm{F}\right)$

- DDC Common Chilled Water Return Temperature $\left({ }^{\circ} \mathrm{F}\right)$

- DDC Cooling Recovery Coil Chilled Water Return Temperature $\left({ }^{\circ} \mathrm{F}\right)$

- Supply Air Flow (CFM) (Fort Bragg only)

- Return Air Flow (CFM) (Tinker AFB only)

- Supply Fan Power (kW)

- CC CHW Valve Position (\%)

- CRC CHW Valve Position (\%)

- Mixed Air Dewpoint Temperature $\left({ }^{\circ} \mathrm{F}\right)$

- Mixed Air Drybulb Temperature $\left({ }^{\circ} \mathrm{F}\right)$

- CC Supply Air Dewpoint Temperature $\left({ }^{\circ} \mathrm{F}\right)$

- CC Supply Air Drybulb Temperature $\left({ }^{\circ} \mathrm{F}\right)$

- Space Dewpoint Temperature $\left({ }^{\circ} \mathrm{F}\right)$

- Return Air Dewpoint Temperature $\left({ }^{\circ} \mathrm{F}\right)$

- Outside Air Dewpoint Temperature $\left({ }^{\circ} \mathrm{F}\right)$

- Cooling Recovery Coil Supply Air Dewpoint Temperature $\left({ }^{\circ} \mathrm{F}\right)$

- Cooling Recovery Coil Supply Air Drybulb Temperature $\left({ }^{\circ} \mathrm{F}\right)$

- Belimo Energy Valve CC CHW Delta T $\left({ }^{\circ} \mathrm{F}\right)$.

\subsubsection{Data quality}

Given the savings validation approach for HEDS that focuses on cooling coil load and net AHU cooling load, that considers the effect of the cooling recovery coil, five sensors are required to accomplish the performance validation and data quality analysis. The sensors included in the performance analysis, along with a description and accuracy ratings are:

CC CHW Entering Temperature (DDC). Minco 4-wire Platinum Resistance Temperature (PRT) sensors with the highest rated accuracy from Minco, at $0.1 \%$. Including the wiring and transducers, the matched system accuracy is $0.75 \%$.

CC CHW Leaving Temperature (DDC). Minco 4-wire Platinum Resistance Temperature (PRT) sensors with the highest rated accuracy from Minco, at $0.1 \%$. Including the wiring and transducers, the matched system accuracy is $0.75 \%$.

Cooling Recovery Coil CHW Leaving Temperature (DDC). Minco 4wire Platinum Resistance Temperature (PRT) sensors with the highest rated accuracy from Minco, at $0.1 \%$. Including the wiring and transducers, the matched system accuracy is $0.75 \%$. 
Common CHW Leaving Temperature (DDC). Minco 4-wire Platinum Resistance Temperature (PRT) sensors with the highest rated accuracy from Minco, at $0.1 \%$. Including the wiring and transducers, the matched system accuracy is $0.75 \%$.

Belimo Energy Valve (BEV) CHW Flow Rate. Belimo Energy Valve internal flowmeter, with a rated accuracy of $\pm 2 \%$ of flow rate, but more importantly, it is rated at $0.50 \%$ for repeatability.

To ensure the quality of the waterside temperature data, sensor validations were performed upon initial installation in the field by Trane personnel. Additionally, in the fall, a sensor calibration procedure was implemented in the controls sequence of each AHU to enable ongoing validation. This was accomplished by turning the AHUs off while opening the cooling coil and cooling recovery coil valves while leaving the chilled water pumps still running, which allows real time comparison of the temperature sensors described above between themselves. Under steady state conditions, each of the sensors in series will see the same chilled water flow, with no air flow so the waterside temperature readings should be nearly identical. To eliminate periods of cooling coil loss even with the fan off, the calibration data were filtered to include only data where the mixed air dewpoint temperature before the cool coil and leaving dewpoint temperature after the cooling coil are within $3{ }^{\circ} \mathrm{F}$, and where chilled water temperature dynamics were low (less than $0.6^{\circ} \mathrm{F}$ change in CHWS temperature in 5 minutes).

For the calibration analysis, the data from the four temperature sensors in series were averaged, then the deviation from the average as calculated for each individual sensor. This deviation was then averaged for the calibration period to determine an adjustment factor to calibrate the sensors against. This will eliminate any persistent bias in the data that may alter the Delta $\mathrm{T}$ results for the cooling coil and AHU net of the cooling recovery coil.

\subsubsection{Fort Bragg data calibration analysis}

Figure 31 shows the data that inform a calibration analysis for the Fort Bragg DDC chilled water sensors that shows that there was less than a $1 \%$ error between the sensors throughout the calibration period when considering the maximum observed range (from highest to lowest sensor) at each data point. On average, the sensors were within $0.2 \%$ of each other during the calibration period. 
Figure 31. Calibration period results highlighting the low error between sensors for Fort Bragg.

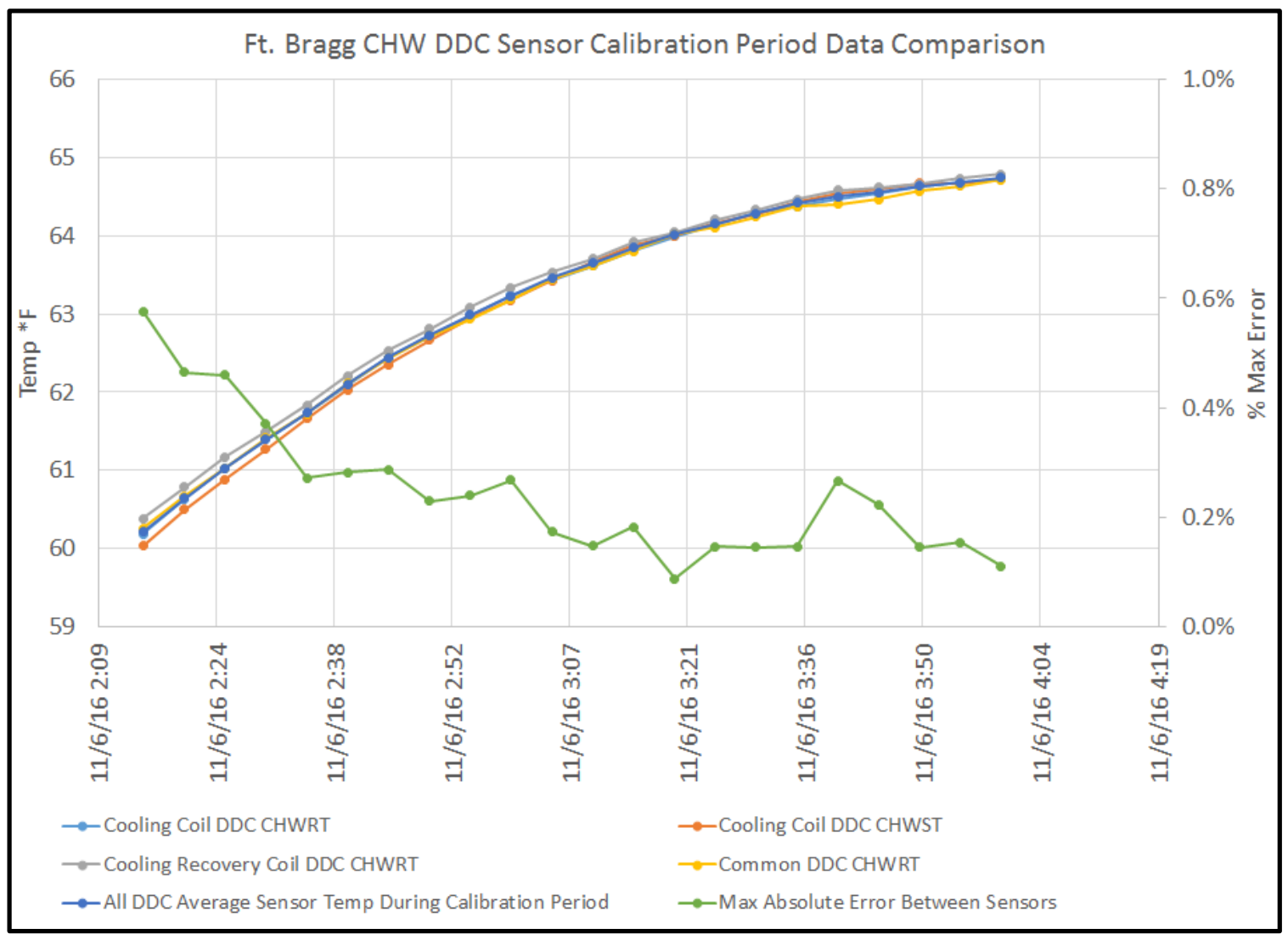

Using these data, calibration offsets were derived for each sensor by comparing the deviation from the average sensor temperature at each point, then averaging this deviation within each sensor. Table 13 lists the resulting offsets, which, although almost insignificant, have been included in the performance analysis, back cast for all data points in the analysis period.

Table 13. Calibration period results highlighting the low error between sensors for Fort Bragg.

\begin{tabular}{|l|l|l|l|}
\hline HEDS, AHU_FTBragg, CC- & HEDS, AHU_FTBragg, CC- & HEDS, AHU_FTBragg, & HEDS, AHU_FTBragg, \\
CHWS Temperature & CHWR Temperature & CRC-CHWR Temperature & Common-CHWR \\
(Units: ${ }^{\circ}$ F) & (Units: ${ }^{\circ}$ F) & (Units: ${ }^{\circ}$ F) & Temperature (Units: ${ }^{\circ}$ F) \\
DEVIATION FROM ALL & DEVIATION FROM ALL & DEVIATION FROM ALL & DEVIATION FROM ALL \\
SENSOR CAL AVG & SENSOR CAL AVG & SENSOR CAL AVG & SENSOR CAL AVG \\
\hline 0.039 & -0.015 & 0.080 & -0.026 \\
\hline
\end{tabular}

\subsubsection{Tinker AFB calibration analysis}

By focusing in on a period where the chilled water supply temperature from the plant was stable, the calibration analysis for the Tinker AFB DDC chilled water sensors showed that there was less than $1.5 \%$ error between 
the sensors throughout the calibration period when considering the maximum observed range (from highest to lowest sensor) at each data point (Figure 32). On average, the sensors were within $0.6 \%$ of each other.

Figure 32. Calibration period results highlighting the low error between sensors for Tinker AFB.

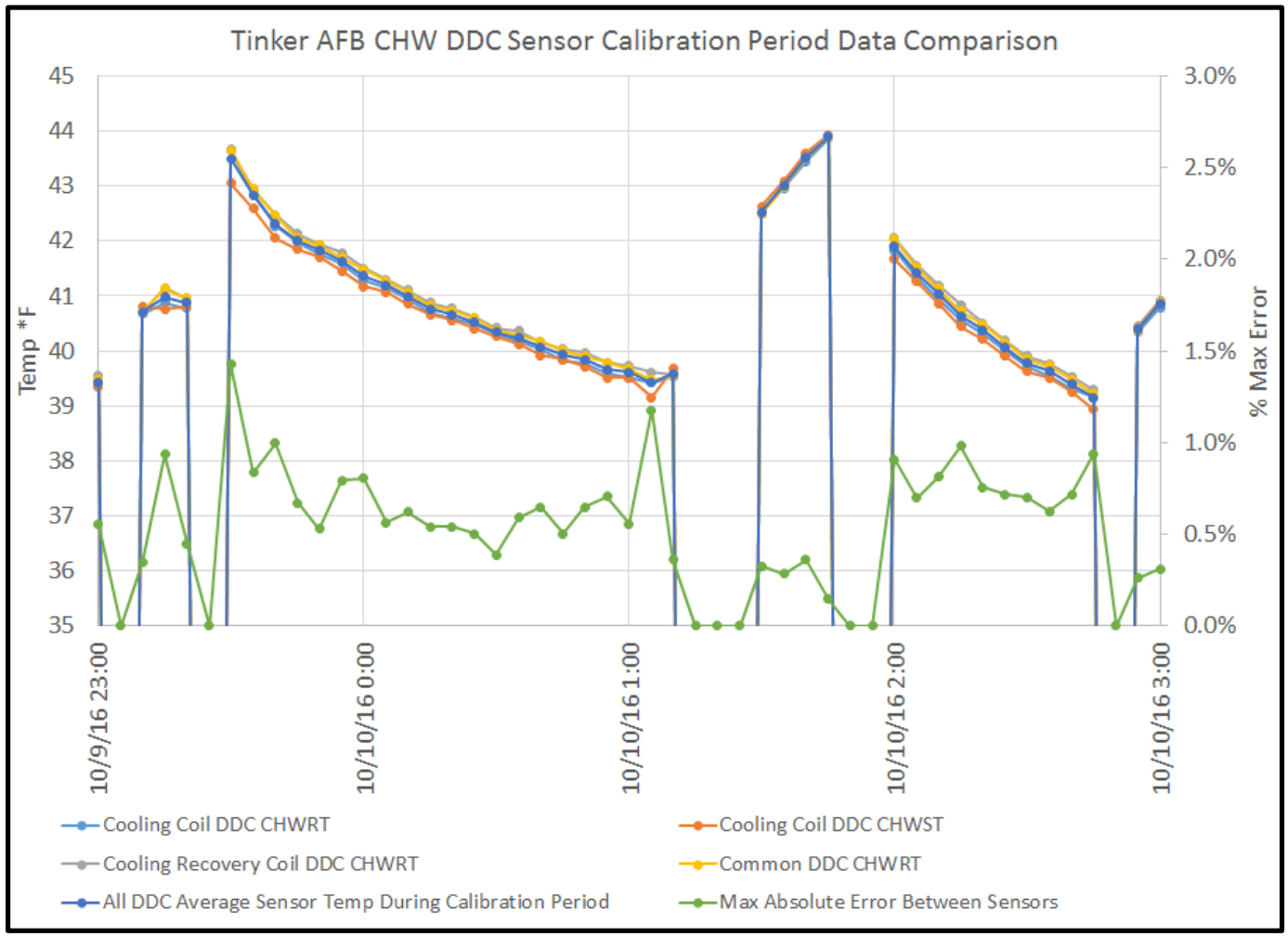

Using these data, calibration offsets were derived for each sensor by comparing the deviation from the average sensor temperature at each point, then averaging this deviation within each sensor. Table 14 lists the resulting offsets, which, although almost insignificant, have been included in the performance analysis, back cast for all data points in the analysis period.

Table 14. Calibration period results highlighting the low error between sensors for Tinker AFB.

\begin{tabular}{|c|c|c|c|}
\hline $\begin{array}{l}\text { HEDS Tinker, VAV_Tinker, } \\
\text { CC-CHWS Temperature } \\
\text { (Units: }{ }^{\circ} \mathrm{F} \text { ) } \\
\text { DEVIATION FROM ALL } \\
\text { SENSOR CAL AVG }\end{array}$ & $\begin{array}{l}\text { HEDS Tinker, VAV_Tinker, } \\
\text { CC-CHWR Temperature } \\
\text { (Units: }{ }^{\circ} \mathrm{F} \text { ) } \\
\text { DEVIATION FROM ALL } \\
\text { SENSOR CAL AVG }\end{array}$ & $\begin{array}{l}\text { HEDS Tinker, VAV_Tinker, } \\
\text { CRC-CHWR Temperature, } \\
\left.\text { (Units: }{ }^{\circ} \mathrm{F}\right) \\
\text { DEVIATION FROM ALL } \\
\text { SENSOR CAL AVG }\end{array}$ & $\begin{array}{l}\text { HEDS Tinker, VAV_Tinker, } \\
\text { Common-CHWR Temperature } \\
\text { (Units: }{ }^{\circ} \mathrm{F} \text { ) } \\
\text { DEVIATION FROM ALL } \\
\text { SENSOR CAL AVG }\end{array}$ \\
\hline-0.160 & -0.096 & -0.021 & -0.058 \\
\hline
\end{tabular}




\subsubsection{Data filtering}

To ensure proper evaluation of HEDS performance before calculating the new cooling load savings and reductions from baseline, data quality filters where applied to remove out of range data and anomalous/ transient conditions that may skew the results. The following conditions were enforced for data to be included in the analysis

Supply Fan On

Fort Bragg: measured supply airflow $>100 \mathrm{CFM}$ and fan power $>0.5 \mathrm{~kW}$ (Typical supply air flow while the unit is running is a constant $8000 \mathrm{CFM}$ and typical fan power is $4 \mathrm{~kW}$ )

Typical return airflow while the unit is running is greater than 180oCFM even during low load conditions)

Cooling being provided (BEV chilled water flow $>3$ GPM and calculated tons cooling $>2$ tons)

Fort Bragg: typical chilled water flow is between 5 and 70 GPM with CC CHW valve open

Tinker AFB: typical chilled water flow is between 5 and 80 GPM with CC CHW valve open

Chilled water supply temperature from the chiller plant between 30 and $70^{\circ} \mathrm{F}$

Fort Bragg: design chilled water supply temperature is $45^{\circ} \mathrm{F}$; typical chilled water supply temperature from the plant is between 42 and $65{ }^{\circ} \mathrm{F}$

Tinker AFB: design chilled water supply temperature is $45^{\circ} \mathrm{F}$; typical chilled water supply temperature from the plant is between 40 and $70^{\circ} \mathrm{F}$

All DDC chilled water temperatures between 30 and $100{ }^{\circ} \mathrm{F}$

Typical temperatures at both locations range between 40 and $80^{\circ} \mathrm{F}$

When applied, these data quality filters resulted in the removal of approximately 820 hours of data from the Fort Bragg dataset, or roughly $15 \%$ of the collected dataset. For Tinker, due to the much lower runtimes from the AHU shutting down at night and the poor plant chilled water supply temperature control with multiple chiller failures that allowed supply temperatures to get as high as $80+{ }^{\circ} \mathrm{F}$, the filtering resulted in the removal of $79 \%$ of the data, leaving $21 \%$ of the data points collected for performance analysis. While this is a significant reduction in the available data points, nearly 
1000 hours (over 40 days) of filtered performance data remain, ensuring significance of the performance results.

\subsubsection{Performance objectives results summary}

Tables 15 and 16 summarize the results of each objective for the test sites. All success criteria were met, and were often substantially exceeded, across all objectives at both test sites.

Table 15. Quantitative performance objective results summary for the Fort Bragg Test Site.

\begin{tabular}{|c|c|c|}
\hline Performance Objective & Success Criterion & $\begin{array}{l}\text { Results } \\
\left.\text { (CHWST<46 }{ }^{\circ} \mathrm{F}\right)\end{array}$ \\
\hline $\begin{array}{l}\text { 1. Peak Cooling Load } \\
\text { Reduction \% }\end{array}$ & $\begin{array}{l}\text { Reduce } 15 \text {-minute cooling load by } 15 \% \text { on a peak } \\
\text { cooling load day during the demonstration period }\end{array}$ & $18.3 \%$ \\
\hline $\begin{array}{l}\text { 2. Greatest Cooling Load } \\
\text { Reduction } \%\end{array}$ & $\begin{array}{l}\text { Highest average cooling load \% reduction exceeds 20\% } \\
\text { during the demonstration period }\end{array}$ & $37.4 \%$ \\
\hline $\begin{array}{l}\text { 3. Dehumidification /Reheat } \\
\text { Coil Energy Reduction }\end{array}$ & $\begin{array}{l}\text { CRC coil eliminates the need for at least } 90 \% \text { of the } \\
\text { RH-control-related reheat energy required from the } \\
\text { reheat coil during the time the system is in } \\
\text { dehumidification-reheat mode during the } \\
\text { demonstration period }\end{array}$ & $100.0 \%$ \\
\hline $\begin{array}{l}\text { 4. Enhance Space Comfort } \\
\text { Conditions }\end{array}$ & $\begin{array}{l}\text { Space conditions fall within UFC comfort guidelines } \\
\text { more than } 90 \% \text { of the time during operating hours }\end{array}$ & $96.0 \%$ \\
\hline $\begin{array}{l}\text { 5. Reduce Cooling Ton-Hours } \\
\text { Consumption }\end{array}$ & $\begin{array}{l}\text { Cooling ton-hours associated with the HEDS unit are } \\
\text { reduced by the CRC by } 7.5 \% \text { compared to the ton-hours } \\
\text { consumed by the cooling coil during the time that the } \\
\text { HEDS is in dehumidification-reheat modes during the } \\
\text { demonstration period }\end{array}$ & $24.7 \%$ \\
\hline $\begin{array}{l}\text { 6. Improve "Low Delta T" } \\
\text { Syndrome }\end{array}$ & $\begin{array}{l}\text { HEDS average cooling coil CHW system TD exceeds } \\
14{ }^{\circ} \mathrm{F} \text { during the time that the HEDS is in } \\
\text { dehumidification-reheat modes during the } \\
\text { demonstration period }\end{array}$ & $17.1 \%$ \\
\hline $\begin{array}{l}\text { 7. Reduce Greenhouse Gas } \\
\text { (GHG) Emissions }\end{array}$ & $\begin{array}{l}\text { GHG emission reductions associated with the } \\
\text { dehumidification/reheat process exceed 3\% (annual } \\
\text { comparison) }\end{array}$ & $45-79 \%$ \\
\hline $\begin{array}{l}\text { 8. Reduce Energy cost of } \\
\text { Dehumidification/ Reheat } \\
\text { process }\end{array}$ & $\begin{array}{l}\text { Cost of dehumidification and reheat with HEDS vs. CV } \\
\text { subcool/terminal reheat is reduced by } 10 \% \text { during } \\
\text { dehumidification -reheat modes of operation }\end{array}$ & $41-51 \%+$ \\
\hline $\begin{array}{l}\text { 9. System Economics Reduce } \\
\text { Lifecycle cost of } \\
\text { Dehumidification/ Reheat } \\
\text { process }\end{array}$ & $5 \%$ reduction in lifecycle costs & $\begin{array}{l}\text { Retrofit: } 26-29 \%+ \\
\text { New construction/ } \\
\text { EUL: } 38-44 \%+\end{array}$ \\
\hline
\end{tabular}


Table 16. Performance objective summary for the Tinker AFB Test Site.

\begin{tabular}{|c|c|c|}
\hline Performance Objective & Success Criterion & $\begin{array}{l}\text { Results } \\
\left(\mathrm{CHWST}<46^{\circ} \mathrm{F}\right)\end{array}$ \\
\hline $\begin{array}{l}\text { 1. Peak Cooling Load } \\
\text { Reduction \% }\end{array}$ & $\begin{array}{l}\text { Reduce } 15-\text { minute cooling load by } 15 \% \text { on a peak } \\
\text { cooling load day during the demonstration period }\end{array}$ & $28.9 \%$ \\
\hline $\begin{array}{l}\text { 2.Greatest Cooling Load } \\
\quad \text { Reduction \% }\end{array}$ & $\begin{array}{l}\text { Highest average cooling load \% reduction exceeds 20\% } \\
\text { during the demonstration period }\end{array}$ & $28.7 \%$ \\
\hline $\begin{array}{l}\text { 3. Dehumidification /Reheat } \\
\text { Coil Energy Reduction }\end{array}$ & $\begin{array}{l}\text { CRC coil eliminates the need for at least } 90 \% \text { of the } \\
\text { RH-control-related reheat energy required from the } \\
\text { reheat coil during the time the system is in } \\
\text { dehumidification-reheat mode during the } \\
\text { demonstration period }\end{array}$ & $100.0 \%$ \\
\hline $\begin{array}{l}\text { 4. Enhance Space Comfort } \\
\text { Conditions }\end{array}$ & $\begin{array}{l}\text { Space conditions fall within UFC comfort guidelines } \\
\text { more than } 90 \% \text { of the time during operating hours }\end{array}$ & $98.0 \%$ \\
\hline $\begin{array}{l}\text { 5. Reduce Cooling Ton-Hours } \\
\text { Consumption }\end{array}$ & $\begin{array}{l}\text { Cooling ton-hours associated with the HEDS unit are } \\
\text { reduced by the CRC by } 7.5 \% \text { compared to the ton-hours } \\
\text { consumed by the cooling coil during the time that the } \\
\text { HEDS is in dehumidification-reheat modes during the } \\
\text { demonstration period }\end{array}$ & $27.6 \%$ \\
\hline $\begin{array}{l}\text { 6. Improve "Low Delta T" } \\
\text { Syndrome }\end{array}$ & $\begin{array}{l}\text { HEDS average cooling coil CHW system TD exceeds } \\
14^{\circ} \mathrm{F} \text { during the time that the HEDS is in } \\
\text { dehumidification-reheat modes during the } \\
\text { demonstration period }\end{array}$ & $24.0 \%$ \\
\hline $\begin{array}{l}\text { 7. Reduce Greenhouse Gas } \\
\text { (GHG) Emissions }\end{array}$ & $\begin{array}{l}\text { GHG emission reductions associated with the } \\
\text { dehumidification/reheat process exceed 3\% (annual } \\
\text { comparison) }\end{array}$ & $70-86 \%$ \\
\hline $\begin{array}{l}\text { 8. Reduce Energy cost of } \\
\text { Dehumidification/ Reheat } \\
\text { process }\end{array}$ & $\begin{array}{l}\text { Cost of dehumidification and reheat with HEDS vs. CV } \\
\text { subcool/terminal reheat is reduced by } 10 \% \text { during } \\
\text { dehumidification - reheat modes of operation }\end{array}$ & $68-75 \%+$ \\
\hline $\begin{array}{l}\text { 9. System Economics Reduce } \\
\text { Lifecycle cost of } \\
\text { Dehumidification/ Reheat } \\
\text { process }\end{array}$ & $5 \%$ reduction in lifecycle costs & $\begin{array}{l}\text { Retrofit: } 13-41 \%+ \\
\text { New construction/ } \\
\text { EUL: } 43-61 \%+\end{array}$ \\
\hline \multicolumn{3}{|c|}{$\begin{array}{l}\text { 10. Savings vary based on central plant chiller and heating system efficiencies; uses eGrid national average } \\
\text { electricity emissions factors. } \\
\text { 11. Savings vary based on central plant chiller and heating system efficiencies, as well as electricity and gas } \\
\text { commodity rates. Average potential savings over a range of potential cost, efficiency, and reheat source } \\
\text { scenarios is shown. }\end{array}$} \\
\hline
\end{tabular}




\section{Cost Assessment}

This chapter describes the cost components of the HEDS system, along with cost-benefit assessments and lifecycle cost analysis.

\subsection{Cost model}

HEDS components are very similar to components in a typical AHU designed for dehumidification duty. As such, cost estimating for the HEDS system is very similar to cost estimating for typical dehumidification-duty AHU deployments in either new construction or retrofit scenarios. One key difference is that the HEDS unit will typically cost 2 to 3 times that of a typical AHU, given the large coil sections, low face velocities, and enhanced controls.

Table 17 lists the elements of a simple cost model for cost estimating support for HEDS projects. Note that the actual equipment and installation costs will vary significantly due to a number of factors, including:

- Requirements for marine environments and coil coatings

- Requirements for special duty such as low dewpoint applications, redundancy, etc.

- Location of the unit (roof, mechanical room, etc.) and whether the unit will be installed as separate components or broken up to fit the unit into an existing space

- Existing available of chilled water distribution.

Table 17. Cost elements of HEDS.

\begin{tabular}{|l|l|l|}
\hline Cost Element & Data Tracked During the Demonstration & Estimated Costs \\
\hline $\begin{array}{l}\text { Equipment capital } \\
\text { costs }\end{array}$ & $\begin{array}{l}\text { Estimates made based on component } \\
\text { costs for demonstration, includes all } \\
\text { HEDS AHU components and controls }\end{array}$ & \$10/CFM \\
\hline Installation costs & $\begin{array}{l}\text { Labor and material required to install, } \\
\text { including curbs/ pads, electrical } \\
\text { connections, etc. }\end{array}$ & \$6/CFM \\
\hline Consumables & $\begin{array}{l}\text { Air Filters are the only consumables, } \\
\text { typical of a normal AHU; data not tracked }\end{array}$ & $\begin{array}{l}\text { Same as typical AHU, no } \\
\text { addional cost }\end{array}$ \\
\hline $\begin{array}{l}\text { Facility operational } \\
\text { costs }\end{array}$ & $\begin{array}{l}\text { Reduction in energy required vs. baseline } \\
\text { data }\end{array}$ & See Performance Results \\
\hline
\end{tabular}




\begin{tabular}{|l|l|l|}
\hline Cost Element & Data Tracked During the Demonstration & Estimated Costs \\
\hline Maintenance & $\begin{array}{l}\text { Frequency of required maintenance } \\
\text { Labor and material per maintenance } \\
\text { action } \\
\text { Data not tracked }\end{array}$ & $\begin{array}{l}\text { Same as typical AHU, no } \\
\text { additional cost }\end{array}$ \\
\hline Hardware lifetime & $\begin{array}{l}\text { Estimate based on components } \\
\text { degradation during demonstration }\end{array}$ & $\begin{array}{l}25 \text { years, based on typical } \\
\text { AHU lifetimes }\end{array}$ \\
\hline Operator training & Estimate of training costs & $\begin{array}{l}\text { Included in equipment } \\
\text { costs, no additional cost }\end{array}$ \\
\hline
\end{tabular}

The following sections describe each cost element.

\subsubsection{Equipment capital costs}

The capital cost for the HEDS AHU is typically the largest cost element of a HEDS project. This cost includes all of the elements typical of a dehumidification-duty AHU, including supply fan(s), return or exhaust fan(s) (if required) preheat coil (if required), cooling coil, cooling recovery coil, control valves, reheat coil or strip heating (if required), instrumentation, controls, filter and access sections, and dampers. The cost data presented are based on multiple cost estimates from Trane for units of similar size to those deployed at the test sites. The test site unit costs could not be used directly due to the enhanced instrumentation, which significantly increase first costs. Future equipment costs can be explored with approved HEDS AHU providers on a case-by-case basis as is typical of the AHU industry.

\subsubsection{Installation costs}

Installation costs are the other key cost element of a HEDS installation. These costs typically include all elements of the physical installation including demolition of existing units (as needed), new pads or curbs to accept the new HEDS unit, electrical and controls connections, ductwork connections, start-up, balancing, and commissioning. Cost estimates were developed based on typical AHU installations on-grade. Note that many factors will influence installation costs in the field, and can be estimated based on typical AHU estimating techniques (assuming a HEDS AHU is roughly twice the size of a standard AHU with 500-ft-per-minute face velocity).

\subsubsection{Consumables}

The only consumables for the HEDS units are air filters, as is typical of any AHU. Typically, air filters in HEDS units will last longer than those in traditional AHUs due to lower face velocities, which reduce the total pressure 
drops experienced by the filters for a given loading. However, there may be more filters in a HEDS unit so it is expected that the net costs of filters will be neutral. At the time of the report, the filters had not yet been changed, but it is expected that the filter cost may be neutral, or slightly less expensive overall than a normal AHU.

\subsubsection{Facility operational costs}

As discussed throughout this report, energy costs will be significantly reduced for HEDS units compared to almost any other dehumidification technology. Energy cost savings will vary based on a number of factors, including utility rates, chilled water plant efficiencies, and reheat plant type and efficiency. The total energy savings will also depend on the baseline system with which HEDS is being compared. This work compared HEDS against a typical dehumidification reheat AHU with a cooling coil and reheat coil provided by hot water or electric strip heat.

\subsubsection{Maintenance}

HEDS AHUs have components typical of any chilled water AHU (as described above). Therefore, maintenance requirements are similar to those of any other AHU. At the time of this writing, the HEDS AHU has required no maintenance. The HEDS AHUs use direct drive, rather than belt drive, fans and motors so the annual maintenance costs should be slightly lower than a normal AHU.

\subsubsection{Hardware lifetime}

Again, since HEDS is so similar to a typical AHU, lifetimes are expected to be similar to any other chilled water AHU. The BOMA Preventative Maintenance Guidebook (Schoen 2010) uses the following average equipment lifetimes for AHU equipment, which will be similar for HEDS units based on application

- Severe Duty or 100\% Outdoor Air Units: 20 years

- Packaged Medium Duty: 25 years

- Built-up Heavy Duty: 30 years. 


\subsubsection{Operator training}

Operator training is an important component of any robust operating and maintenance program. Although HEDS units are very similar to traditional chilled water AHUs in components and layout, specialized control functions require training to support ongoing performance. This training is included with the purchase of the HEDS units based on existing manufacturer licensing agreements, so currently has no upfront cost.

\subsection{Cost drivers}

Many of the key cost drivers for HEDS deployment were discussed in the Sections 7.1.1 to 7.1.7. There are infinite combinations of requirements for any AHU selection that will affect total system cost. Two key elements are crucial to how the net cost of a HEDS project should be considered:

1. First, it is critical to consider what the baseline equipment selection is or would have been, and consider the incremental cost (or savings) associated with the HEDS unit deployment. For example, for a building project with a simple chilled water reheat AHU as the baseline, the cost of the baseline system may be $\$ 3 / \mathrm{CFM}$ compared with a HEDS unit at $\$ 10 / C F M$. Installation costs between the two units are likely similar, when the larger footprint and weight of the HEDS installation compared with this baseline is offset by the smaller pipe diameters and pump flow rates required to serve the HEDS unit. Assuming a \$1/CFM higher installation cost, the net cost of the HEDS installation would be $\$ 8 / \mathrm{CFM}$, typically resulting in a very fast payback when the energy savings are considered compared with a traditional reheat AHU baseline.

Now consider the case where new sources of reheat are not allowable by code (such as governed by ASHRAE 90.1). In this case, the baseline system may be a direct expansion (DX) unit with hot gas reheat, which eliminates the need for new reheat sources. The first cost for this DX unit may be $\$$ 9/CFM, compared with a HEDS unit at $\$ 10 / C F M$. Installation costs may be slightly higher for the HEDS unit for chilled water piping, but this may be offset by the increased electrical distribution costs and higher weight of the DX unit. Even assuming the HEDS unit installation has a net cost \$2/CFM higher, the net cost of the HEDS unit is only $\$ 3 / \mathrm{CFM}$. In this case, HEDS does not provide reheat energy savings compared with the baseline, but does provide significant cooling energy savings given the higher efficiency of a chilled water 
plant compared to air-cooled DX equipment and the reduced load of the HEDS unit from the cooling recovery process for the reheat.

2. Another key element to consider in HEDS installations is that of the space constraints for the unit. In certain applications, particularly retrofit scenarios, there simply may not be adequate space for a HEDS unit to fit properly, given its size compared to tradition dehumidification-reheat solutions. However, in situations where a reheat AHU is not allowed (as discussed above, for example where ASHRAE 90.1 energy code is in effect), a like-for-like retrofit would not be possible anyway, in that such a retrofit would require additional engineering to develop solutions to enable other technologies like HEDS to be deployed to eliminate the use of new energy for reheat. These scenarios can greatly increase the overall installation cost, but this cost would be seen in both the baseline and HEDS scenarios.

\subsection{Cost analysis and comparison}

The following sections give an overview of the cost comparisons and lifecycle analyses for both test sites.

\subsubsection{Fort Bragg}

Translating the cooling and dehumidification-related reheat load savings to energy savings requires an analysis of the central plant operations serving the HEDS units. Given that load reductions have nonlinear impacts on energy use for most chilled water systems, a spreadsheet model was developed to explore potential HEDS energy, GHG, and lifecycle cost savings across a range of chilled water and heating plant efficiencies and types.

To accomplish this, a model of the baseline load and AHU net load with HEDS was developed as a function of average daily outdoor air dewpoint temperatures. Figure 33 shows the resulting modeled performance for each cooling coil supply air temperature bin. 
Figure 33. Characteristic load curves for the baseline and net HEDS cooling loads as a function of average daily outdoor air temperature for Fort Bragg.

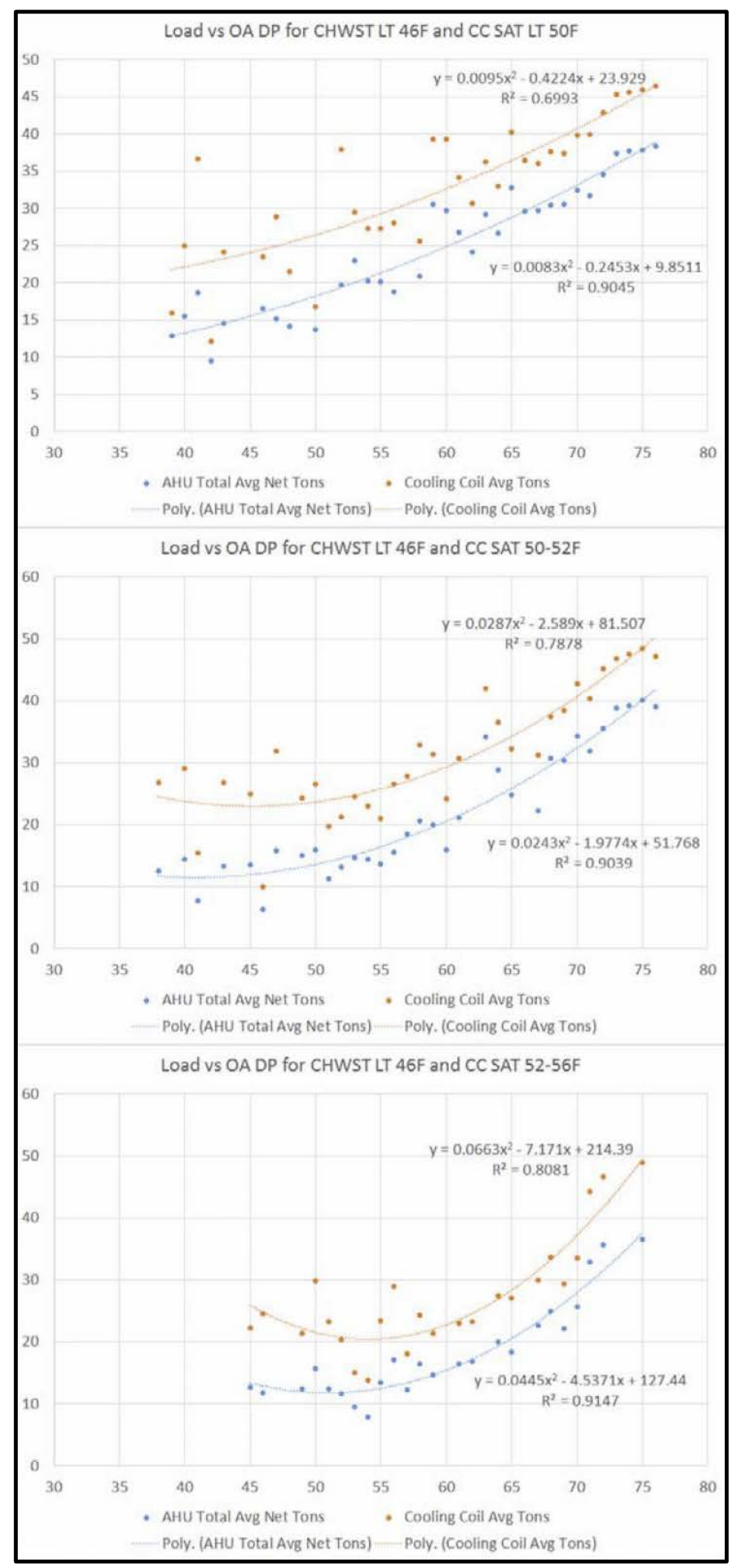


The modeled curves were then applied to typical meteorological year (TMY3) dewpoint data to develop annualized savings estimates for each cooling coil temperature range. An annual schedule was applied to chiller plant operations such that the savings analysis only occurs during the dehumidification season from May through October, reflecting the annual wintertime shutdown from approximately November through April. Also, to appropriately determine total plant energy impacts, it was assumed that HEDS units would be used on the entire load for each chiller plant (i.e., all AHUs would be replaced with HEDS units). This simplifies the analysis of total energy impacts compared with partial HEDS implementations.

As discussed, energy, GHG, and lifecycle cost impacts were calculated across a range of chiller and boiler plant efficiency scenarios

\section{Chilled Water Plant Scenarios:}

- High Efficiency Water Cooled Chillers:

- Moderate Efficiency Water Cooled Chillers:

- Poor Efficiency Water Cooled / High Efficiency Air-Cooled Chillers:

- Moderate Efficiency Air-Cooled Chillers:

- Poor Efficiency Air-Cooled Chillers:
IPLV 0.45

IPLV 0.56

IPLV 0.79

IPLV 1.01

IPLV 1.35.

Heating Plant Scenarios (net efficiencies include boiler, cycling, and distribution losses):

- Electric Resistance:

$100 \%$ net delivery efficiency

- High Efficiency Condensing Boilers: $80 \%$ net delivery efficiency

- High Efficiency Non-Condensing Boilers: $70 \%$ net delivery efficiency

- Moderate Efficiency Non-Condensing Boilers: 60\% net delivery efficiency

- Poor Efficiency Non-Condensing Boilers: 50\% net delivery efficiency.

Tables 18 to 20 list the resulting energy savings, both in total energy and savings percent, for each cooling coil supply air temperature bin. Note that total energy savings associated with cooling and dehumidification-related reheat are greater than $50 \%$ in all cases, and reach as high as $87 \%$ with the combination of a high efficiency chilled water plant and very low efficiency boiler system. Absolute savings are highest at the lower cooling coil supply air temperatures indicative of higher dehumidification loads, given the higher total system load for that condition. 
Table 18. Energy savings results for $\mathrm{CC}$ supply air temperatures below $50^{\circ} \mathrm{F}$ (very high dehumidification loads).

\begin{tabular}{|c|c|c|c|c|c|c|c|}
\hline & \multirow[b]{2}{*}{ Savings } & \multirow[b]{2}{*}{$\begin{array}{c}\text { Plant Electricity Only } \\
\text { Savings (kWh) }\end{array}$} & \multicolumn{5}{|c|}{ Total Energy Savings by Reheat System Type and Efficiency (MMBTU) } \\
\hline & & & Electric & $\begin{array}{l}\text { High Efficiency } \\
\text { Condensing Boilers }\end{array}$ & $\begin{array}{l}\text { High Efficiency Non- } \\
\text { Condensing Boilers }\end{array}$ & $\begin{array}{c}\text { Moderate Efficiency } \\
\text { Non-Condensing } \\
\text { Boilers }\end{array}$ & $\begin{array}{l}\text { Poor Efficiency Non- } \\
\text { Condensing Boilers }\end{array}$ \\
\hline \multirow{7}{*}{ 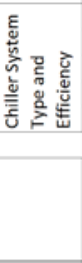 } & High Efficiency Water Cooled & 108,674 & 1,777 & 2,185 & 2,436 & 2,771 & 3,240 \\
\hline & Moderate Efficiency Water Cooled & 131,083 & 1,854 & 2,262 & 2,513 & 2,848 & 3,317 \\
\hline & Poor Efficiency Water Cooled / High Eff Air Cooled & 175,915 & 2,007 & 2,415 & 2,666 & 3,001 & 3,470 \\
\hline & Moderate Efficiency Air Cooled & 220,734 & 2,160 & 2,568 & 2,819 & 3,154 & 3,623 \\
\hline & Poor Efficiency Air Cooled & 287,975 & 2,389 & 2,797 & 3,048 & 3,383 & 3,852 \\
\hline & & & \multicolumn{5}{|c|}{ Total Energy Savings by Reheat System Type and Efficiency } \\
\hline & Savings \% & $\begin{array}{c}\text { Plant Electricity Only } \\
\text { Savings }\end{array}$ & Electric & $\begin{array}{l}\text { High Efficiency } \\
\text { Condensing Boilers }\end{array}$ & $\begin{array}{l}\text { High Efficiency Non- } \\
\text { Condensing Boilers }\end{array}$ & $\begin{array}{l}\text { Moderate Efficiency } \\
\text { Non-Condensing } \\
\text { Boilers }\end{array}$ & $\begin{array}{l}\text { Poor Efficiency Non- } \\
\text { Condensing Boilers }\end{array}$ \\
\hline \multirow{5}{*}{ 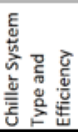 } & High Efficiency Water Cooled & $32.7 \%$ & $70.0 \%$ & $74.1 \%$ & $76.1 \%$ & $78.4 \%$ & $80.9 \%$ \\
\hline & Moderate Efficiency Water Cooled & $32.4 \%$ & $66.5 \%$ & $70.8 \%$ & $72.9 \%$ & $75.3 \%$ & $78.0 \%$ \\
\hline & Poor Efficiency Water Cooled / High Eff Air Cooled & $32.1 \%$ & $61.2 \%$ & $65.5 \%$ & $67.7 \%$ & $70.2 \%$ & $73.2 \%$ \\
\hline & Moderate Efficiency Air Cooled & $31.8 \%$ & $57.3 \%$ & $61.4 \%$ & $63.6 \%$ & $66.2 \%$ & $69.2 \%$ \\
\hline & Poor Efficiency Air Cooled & $31.7 \%$ & $53.0 \%$ & $56.9 \%$ & $59.0 \%$ & $61.5 \%$ & $64.5 \%$ \\
\hline
\end{tabular}

Table 19. Energy savings results for $\mathrm{CC}$ supply air temperatures between 50 and $52^{\circ} \mathrm{F}$ (moderate dehumidification loads).

\begin{tabular}{|c|c|c|c|c|c|c|c|}
\hline & \multirow[b]{2}{*}{ Savings } & \multirow[b]{2}{*}{$\begin{array}{c}\text { Plant Electricity Only } \\
\text { Savings (kWh) }\end{array}$} & \multicolumn{5}{|c|}{ Total Energy Savings by Reheat System Type and Efficiency (MMBTU) } \\
\hline & & & Electric & $\begin{array}{l}\text { High Efficiency } \\
\text { Condensing Boilers }\end{array}$ & $\begin{array}{l}\text { High Efficiency Non- } \\
\text { Condensing Boilers }\end{array}$ & $\begin{array}{c}\text { Moderate Efficiency } \\
\text { Non-Condensing } \\
\text { Boilers }\end{array}$ & $\begin{array}{l}\text { Poor Efficiency Non- } \\
\text { Condensing Boilers }\end{array}$ \\
\hline \multirow{7}{*}{ 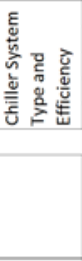 } & High Efficiency Water Cooled & 99,982 & 1,854 & 2,288 & 2,558 & 2,919 & 3,423 \\
\hline & Moderate Efficiency Water Cooled & 120,824 & 1,925 & 2,359 & 2,630 & 2,990 & 3,494 \\
\hline & Poor Efficiency Water Cooled / High Eff Air Cooled & 162,521 & 2,067 & 2,502 & 2,772 & 3,132 & 3,636 \\
\hline & Moderate Efficiency Air Cooled & 204,205 & 2,210 & 2,644 & 2,914 & 3,274 & 3,778 \\
\hline & Poor Efficiency Air Cooled & 266,744 & 2,423 & 2,857 & 3,127 & 3,488 & 3,992 \\
\hline & & & \multicolumn{5}{|c|}{ Total Energy Savings by Reheat System Type and Efficiency } \\
\hline & Savings \% & $\begin{array}{c}\text { Plant Electricity Only } \\
\text { Savings }\end{array}$ & Electric & $\begin{array}{l}\text { High Efficiency } \\
\text { Condensing Boilers }\end{array}$ & $\begin{array}{l}\text { High Efficiency Non- } \\
\text { Condensing Boilers }\end{array}$ & $\begin{array}{c}\text { Moderate Efficiency } \\
\text { Non-Condensing } \\
\text { Boilers }\end{array}$ & $\begin{array}{l}\text { Poor Efficiency Non- } \\
\text { Condensing Boilers }\end{array}$ \\
\hline \multirow{5}{*}{ 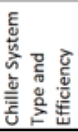 } & High Efficiency Water Cooled & $35.8 \%$ & $75.2 \%$ & $78.9 \%$ & $80.7 \%$ & $82.6 \%$ & $84.8 \%$ \\
\hline & Moderate Efficiency Water Cooled & $35.5 \%$ & $71.9 \%$ & $75.9 \%$ & $77.8 \%$ & $79.9 \%$ & $82.3 \%$ \\
\hline & Poor Efficiency Water Cooled / High Eff Air Cooled & $35.1 \%$ & $66.8 \%$ & $70.9 \%$ & $73.0 \%$ & $75.3 \%$ & $78.0 \%$ \\
\hline & Moderate Efficiency Air Cooled & $34.9 \%$ & $62.9 \%$ & $67.0 \%$ & $69.1 \%$ & $71.5 \%$ & $74.4 \%$ \\
\hline & Poor Efficiency Air Cooled & $34.7 \%$ & $58.5 \%$ & $62.5 \%$ & $64.6 \%$ & $67.0 \%$ & $69.9 \%$ \\
\hline
\end{tabular}

Table 20. Energy savings results for $\mathrm{CC}$ supply air temperatures between 52 and $56^{\circ} \mathrm{F}$ (low dehumidification loads).

\begin{tabular}{|c|c|c|c|c|c|c|c|}
\hline & \multirow[b]{2}{*}{ Savings } & \multirow[b]{2}{*}{$\begin{array}{c}\text { Plant Electricity Only } \\
\text { Savings (kWh) }\end{array}$} & \multicolumn{5}{|c|}{ Total Energy Savings by Reheat System Type and Efficiency (MMBTU) } \\
\hline & & & Electric & $\begin{array}{l}\text { High Efficiency } \\
\text { Condensing Boilers }\end{array}$ & $\begin{array}{l}\text { High Efficiency Non- } \\
\text { Condensing Boilers }\end{array}$ & $\begin{array}{c}\text { Moderate Efficiency } \\
\text { Non-Condensing } \\
\text { Boilers }\end{array}$ & $\begin{array}{l}\text { Poor Efficiency Non- } \\
\text { Condensing Boilers }\end{array}$ \\
\hline \multirow{7}{*}{ 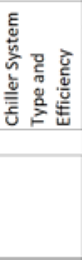 } & High Efficiency Water Cooled & 84,383 & 1,712 & 2,125 & 2,379 & 2,718 & 3,193 \\
\hline & Moderate Efficiency Water Cooled & 102,164 & 1,773 & 2,185 & 2,440 & 2,779 & 3,254 \\
\hline & Poor Efficiency Water Cooled / High Eff Air Cooled & 137,737 & 1,894 & 2,307 & 2,561 & 2,900 & 3,375 \\
\hline & Moderate Efficiency Air Cooled & 173,298 & 2,016 & 2,428 & 2,682 & 3,022 & 3,496 \\
\hline & Poor Efficiency Air Cooled & 226,652 & 2,198 & 2,610 & 2,864 & 3,204 & 3,678 \\
\hline & & & \multicolumn{5}{|c|}{ Total Energy Savings by Reheat System Type and Efficiency } \\
\hline & Savings \% & $\begin{array}{l}\text { Plant Electricity Only } \\
\text { Savings }\end{array}$ & Electric & $\begin{array}{l}\text { High Efficiency } \\
\text { Condensing Boilers }\end{array}$ & $\begin{array}{l}\text { High Efficiency Non- } \\
\text { Condensing Boilers }\end{array}$ & $\begin{array}{l}\text { Moderate Efficiency } \\
\text { Non-Condensing } \\
\text { Boilers }\end{array}$ & $\begin{array}{l}\text { Poor Efficiency Non- } \\
\text { Condensing Boilers }\end{array}$ \\
\hline \multirow{5}{*}{ 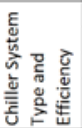 } & High Efficiency Water Cooled & $38.3 \%$ & $78.7 \%$ & $82.1 \%$ & $83.7 \%$ & $85.4 \%$ & $87.3 \%$ \\
\hline & Moderate Efficiency Water Cooled & $37.9 \%$ & $75.6 \%$ & $79.3 \%$ & $81.0 \%$ & $83.0 \%$ & $85.1 \%$ \\
\hline & Poor Efficiency Water Cooled / High Eff Air Cooled & $37.5 \%$ & $70.7 \%$ & $74.6 \%$ & $76.6 \%$ & $78.7 \%$ & $81.2 \%$ \\
\hline & Moderate Efficiency Air Cooled & $37.2 \%$ & $66.9 \%$ & $70.9 \%$ & $72.9 \%$ & $75.2 \%$ & $77.8 \%$ \\
\hline & Poor Efficiency Air Cooled & $37.0 \%$ & $62.5 \%$ & $66.5 \%$ & $68.5 \%$ & $70.9 \%$ & $73.6 \%$ \\
\hline
\end{tabular}

GHG emissions impacts were calculated using the results of the energy savings analysis (Tables 21 to 23). The electric grid GHG emissions rate was applied from the U.S. Environmental Protection Agency (USEPA) eGrid for the 2014 national average (1150.322 lb. CO2e/MWh). The natural gas GHG emissions rate is fixed at $53.2 \mathrm{~kg} \mathrm{CO} 2 \mathrm{e} / \mathrm{MMBtu}$. 
The data show total GHG emissions savings ranging from 290 to 330 tons per year, a reduction of approximately 50 to $80 \%$ from the baseline emissions.

Table 21. GHG emissions savings results for $\mathrm{CC}$ supply air temperatures below $50^{\circ} \mathrm{F}$ (very high dehumidification loads).

\begin{tabular}{|c|c|c|c|c|c|c|c|}
\hline & \multirow[b]{2}{*}{ Savings } & \multirow[b]{2}{*}{$\begin{array}{c}\text { Plant Electricity Only } \\
\text { Savings }\end{array}$} & \multicolumn{5}{|c|}{ Total GHG Savings by Reheat System Type and Efficiency (tons) } \\
\hline & & & Electric & $\begin{array}{l}\text { High Efficiency } \\
\text { Condensing Boilers }\end{array}$ & $\begin{array}{l}\text { High Efficiency Non- } \\
\text { Condensing Boilers }\end{array}$ & $\begin{array}{c}\text { Moderate Efficiency } \\
\text { Non-Condensing } \\
\text { Boilers }\end{array}$ & $\begin{array}{l}\text { Poor Efficiency Non- } \\
\text { Condensing Boilers }\end{array}$ \\
\hline \multirow{7}{*}{ 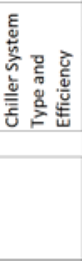 } & High Efficiency Water Cooled & 63 & 300 & 169 & 183 & 203 & 230 \\
\hline & Moderate Efficiency Water Cooled & 75 & 313 & 182 & 196 & 216 & 243 \\
\hline & Poor Efficiency Water Cooled / High Eff Air Cooled & 101 & 338 & 207 & 222 & 242 & 269 \\
\hline & Moderate Efficiency Air Cooled & 127 & 364 & 233 & 248 & 267 & 295 \\
\hline & Poor Efficiency Air Cooled & 166 & 403 & 272 & 287 & 306 & 334 \\
\hline & & & \multicolumn{5}{|c|}{ Total GHG Savings by Reheat System Type and Efficiency } \\
\hline & Savings \% & \begin{tabular}{|c|} 
Plant Electricity Only \\
Savings
\end{tabular} & Electric & $\begin{array}{l}\text { High Efficiency } \\
\text { Condensing Boilers }\end{array}$ & $\begin{array}{l}\text { High Efficiency Non- } \\
\text { Condensing Boilers }\end{array}$ & $\begin{array}{c}\text { Moderate Efficiency } \\
\text { Non-Condensing } \\
\text { Boilers }\end{array}$ & $\begin{array}{l}\text { Poor Efficiency Non- } \\
\text { Condensing Boilers }\end{array}$ \\
\hline \multirow{5}{*}{ 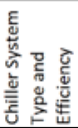 } & High Efficiency Water Cooled & $32.7 \%$ & $70.0 \%$ & $56.7 \%$ & $58.8 \%$ & $61.2 \%$ & $64.2 \%$ \\
\hline & Moderate Efficiency Water Cooled & $32.4 \%$ & $66.5 \%$ & $53.6 \%$ & $55.5 \%$ & $57.8 \%$ & $60.7 \%$ \\
\hline & Poor Efficiency Water Cooled / High Eff Air Cooled & $32.1 \%$ & $61.2 \%$ & $49.2 \%$ & $50.9 \%$ & $53.0 \%$ & $55.6 \%$ \\
\hline & Moderate Efficiency Air Cooled & $31.8 \%$ & $57.3 \%$ & $46.2 \%$ & $47.7 \%$ & $49.6 \%$ & $52.0 \%$ \\
\hline & Poor Efficiency Air Cooled & $31.7 \%$ & $53.0 \%$ & $43.2 \%$ & $44.5 \%$ & $46.1 \%$ & $48.3 \%$ \\
\hline
\end{tabular}

Table 22. GHG emissions savings results for CC supply air temperatures between 50 and $52{ }^{\circ} \mathrm{f}$ (moderate dehumidification loads).

\begin{tabular}{|c|c|c|c|c|c|c|c|}
\hline & \multirow[b]{2}{*}{ Savings } & \multirow[b]{2}{*}{$\begin{array}{c}\text { Plant Electricity Only } \\
\text { Savings }\end{array}$} & \multicolumn{5}{|c|}{ Total GHG Savings by Reheat System Type and Efficiency (tons) } \\
\hline & & & Electric & $\begin{array}{l}\text { High Efficiency } \\
\text { Condensing Boilers }\end{array}$ & $\begin{array}{l}\text { High Efficiency Non- } \\
\text { Condensing Boilers }\end{array}$ & $\begin{array}{c}\text { Moderate Efficiency } \\
\text { Non-Condensing } \\
\text { Boilers }\end{array}$ & $\begin{array}{l}\text { Poor Efficiency Non- } \\
\text { Condensing Boilers }\end{array}$ \\
\hline \multirow{7}{*}{ 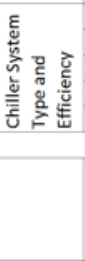 } & High Efficiency Water Cooled & 58 & 313 & 171 & 187 & 208 & 238 \\
\hline & Moderate Efficiency Water Cooled & 69 & 324 & 183 & 199 & 220 & 250 \\
\hline & Poor Efficiency Water Cooled / High Eff Air Cooled & 93 & 348 & 207 & 223 & 244 & 274 \\
\hline & Moderate Efficiency Air Cooled & 117 & 372 & 231 & 247 & 268 & 298 \\
\hline & Poor Efficiency Air Cooled & 153 & 408 & 267 & 283 & 304 & 334 \\
\hline & & & \multicolumn{5}{|c|}{ Total GHG Savings by Reheat System Type and Efficiency } \\
\hline & Savings \% & $\begin{array}{c}\text { Plant Electricity Only } \\
\text { Savings }\end{array}$ & Electric & $\begin{array}{l}\text { High Efficiency } \\
\text { Condensing Boilers }\end{array}$ & $\begin{array}{l}\text { High Efficiency Non- } \\
\text { Condensing Boilers }\end{array}$ & $\begin{array}{l}\text { Moderate Efficiency } \\
\text { Non-Condensing } \\
\text { Boilers }\end{array}$ & $\begin{array}{l}\text { Poor Efficiency Non- } \\
\text { Condensing Boilers }\end{array}$ \\
\hline \multirow{5}{*}{ 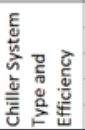 } & High Efficiency Water Cooled & $35.8 \%$ & $75.2 \%$ & $62.4 \%$ & $64.5 \%$ & $66.9 \%$ & $69.7 \%$ \\
\hline & Moderate Efficiency Water Cooled & $35.5 \%$ & $71.9 \%$ & $59.2 \%$ & $61.2 \%$ & $63.5 \%$ & $66.4 \%$ \\
\hline & Poor Efficiency Water Cooled / High Eff Air Cooled & $35.1 \%$ & $66.8 \%$ & $54.5 \%$ & $56.3 \%$ & $58.5 \%$ & $61.3 \%$ \\
\hline & Moderate Efficiency Air Cooled & $34.9 \%$ & $62.9 \%$ & $51.3 \%$ & $53.0 \%$ & $55.0 \%$ & $57.6 \%$ \\
\hline & Poor Efficiency Air Cooled & $34.7 \%$ & $58.5 \%$ & $48.0 \%$ & $49.5 \%$ & $51.3 \%$ & $53.6 \%$ \\
\hline
\end{tabular}

Table 23. GHG emissions savings results for CC supply air temperatures between 52 and $56^{\circ} \mathrm{f}$ (low dehumidification loads).

\begin{tabular}{|c|c|c|c|c|c|c|c|}
\hline & \multirow[b]{2}{*}{ Savings } & \multirow[b]{2}{*}{$\begin{array}{c}\text { Plant Electricity Only } \\
\text { Savings }\end{array}$} & \multicolumn{5}{|c|}{ Total GHG Savings by Reheat System Type and Efficiency (tons) } \\
\hline & & & Electric & $\begin{array}{l}\text { High Efficiency } \\
\text { Condensing Boilers }\end{array}$ & $\begin{array}{l}\text { High Efficiency Non- } \\
\text { Condensing Boilers }\end{array}$ & $\begin{array}{c}\text { Moderate Efficiency } \\
\text { Non-Condensing } \\
\text { Boilers }\end{array}$ & $\begin{array}{l}\text { Poor Efficiency Non- } \\
\text { Condensing Boilers }\end{array}$ \\
\hline \multirow{7}{*}{ 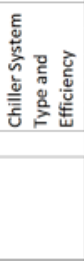 } & High Efficiency Water Cooled & 49 & 289 & 156 & 171 & 191 & 219 \\
\hline & Moderate Efficiency Water Cooled & 59 & 299 & 166 & 181 & 201 & 229 \\
\hline & Poor Efficiency Water Cooled / High Eff Air Cooled & 79 & 319 & 187 & 202 & 221 & 249 \\
\hline & Moderate Efficiency Air Cooled & 100 & 340 & 207 & 222 & 242 & 270 \\
\hline & Poor Efficiency Air Cooled & 130 & 370 & 238 & 253 & 273 & 300 \\
\hline & & & \multicolumn{5}{|c|}{ Total GHG Savings by Reheat System Type and Efficiency } \\
\hline & Savings \% & $\begin{array}{c}\text { Plant Electricity Only } \\
\text { Savings }\end{array}$ & Electric & $\begin{array}{l}\text { High Efficiency } \\
\text { Condensing Boilers }\end{array}$ & $\begin{array}{l}\text { High Efficiency Non- } \\
\text { Condensing Boilers }\end{array}$ & $\begin{array}{l}\text { Moderate Efficiency } \\
\text { Non-Condensing } \\
\text { Boilers }\end{array}$ & $\begin{array}{l}\text { Poor Efficiency Non- } \\
\text { Condensing Boilers }\end{array}$ \\
\hline \multirow{5}{*}{ 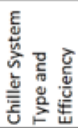 } & High Efficiency Water Cooled & $38.3 \%$ & $78.7 \%$ & $66.6 \%$ & $68.6 \%$ & $70.9 \%$ & $73.6 \%$ \\
\hline & Moderate Efficiency Water Cooled & $37.9 \%$ & $75.6 \%$ & $63.3 \%$ & $65.3 \%$ & $67.6 \%$ & $70.4 \%$ \\
\hline & Poor Efficiency Water Cooled / High Eff Air Cooled & $37.5 \%$ & $70.7 \%$ & $58.6 \%$ & $60.4 \%$ & $62.6 \%$ & $65.4 \%$ \\
\hline & Moderate Efficiency Air Cooled & $37.2 \%$ & $66.9 \%$ & $55.2 \%$ & $56.9 \%$ & $59.0 \%$ & $61.6 \%$ \\
\hline & Poor Efficiency Air Cooled & $37.0 \%$ & $62.5 \%$ & $51.7 \%$ & $53.3 \%$ & $55.1 \%$ & $57.5 \%$ \\
\hline
\end{tabular}


Finally, a lifecycle cost analysis was performed across a selected combination of scenarios representing the most common field conditions and electricity rates for DoD sites. Table 24 lists the low, mid, and high scenarios analyzed for electricity and natural gas rates.

Table 24. Low, mid, and high scenarios.

\begin{tabular}{|l|c|c|}
\hline Scenario & Electricity Rate \$/kWh & Natural Gas Rate \$/therm \\
\hline Low & 0.08 & 0.5 \\
\hline Mid & 0.14 & 0.8 \\
\hline High & 0.20 & 1.1 \\
\hline
\end{tabular}

Additionally, two capital cost values were used in the analysis. A retrofit cost value of $\$ 16 / \mathrm{CFM}$ was used; a retrofit scenario assumes the project bears the entire cost of the HEDS unit and installation, such as equipment replacement before end of useful life (EUL). An incremental cost value of $\$ 8 / \mathrm{CFM}$ was also used. Incremental cost values would apply in new construction, major renovation, and equipment EUL situations; incremental cost values also represent retrofit cases where the AHU can be rebuilt in place without entire unit replacement. Note that in new construction applications, HEDS can significantly reduce other infrastructure costs due to chiller and piping downsizing, cooling tower downsizing, etc. due to the cooling load reductions; these cost savings were not included in the lifecycle cost analysis presented here, but should be considered where possible.

Note that, where energy codes require that simultaneous heating and cooling cannot be used for RH control (such as ASHRAE 90.1), the incremental cost of HEDS would approach \$O/CFM, and could even have significant cost savings, depending on the comparative technology used as baseline.

The charts shown in Figure 34 highlight the lifecycle performance across a range of scenarios. For the purposes of this work, savings for the temperature bin for high dehumidification loads (cooling coil supply air temperature less than $50^{\circ} \mathrm{F}$ ), and savings for mid-level electricity and natural gas are presented. Other temperatures bins have very similar results. Results are shown as a 20-year savings to investment ratio (SIR), where the total savings over 20 years are divided by the project costs.

The results show SIRs above 1 across all scenarios, reaching over 4 for the retrofit applications and over 9 for new construction, EUL, and major renovation applications. Even at the low-level electricity and natural gas rates, SIRs are above 1 in almost all scenarios and reach as high as 2.7. 
Figure 34. Lifecycle performance across a range of scenarios.

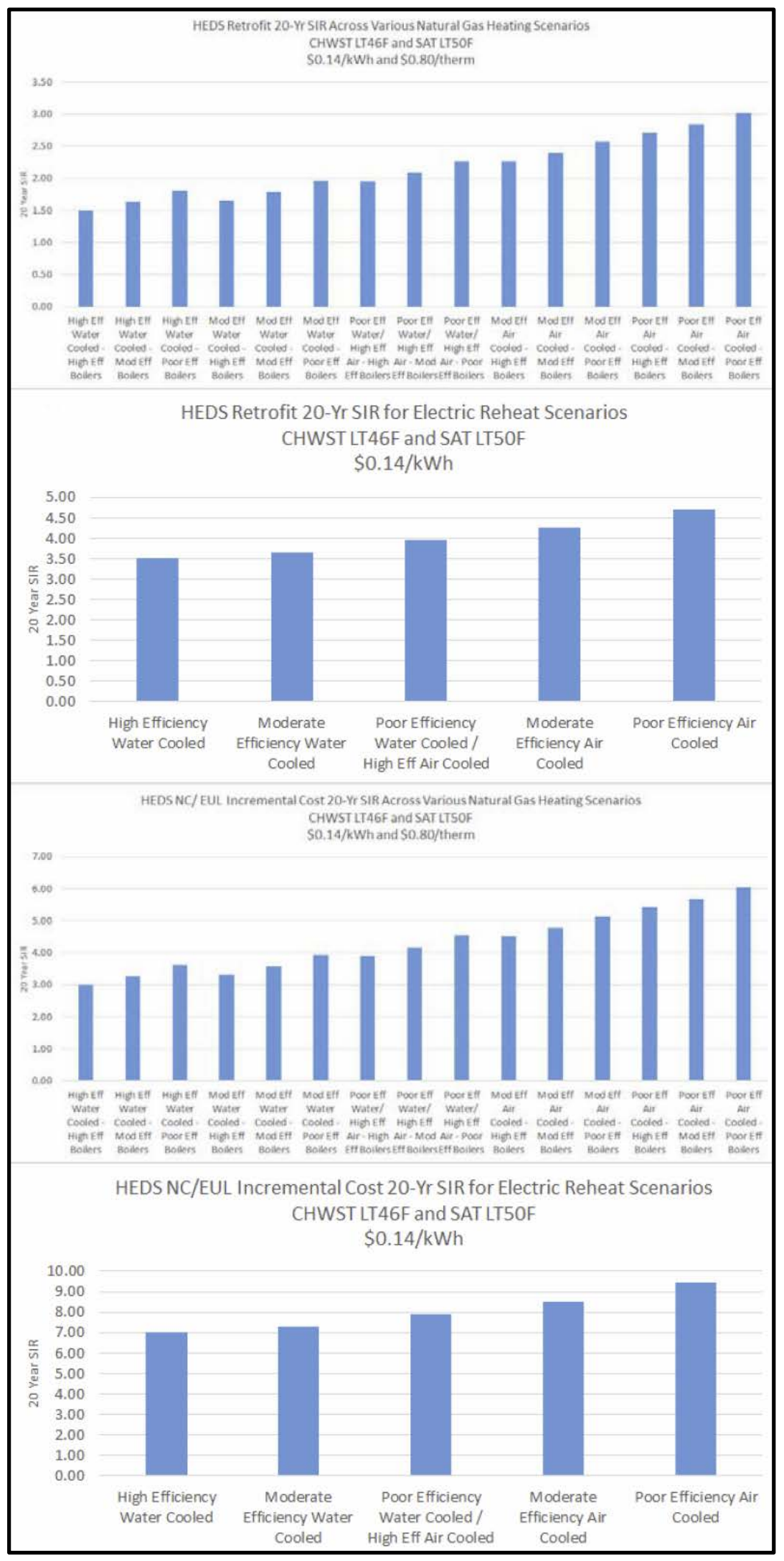




\subsubsection{Tinker AFB}

Translating the cooling and dehumidification-related reheat load savings to energy savings requires analysis of the central plant operations serving the HEDS units. Given that load reductions have nonlinear impacts on energy use for most chilled water systems, a spreadsheet model was developed to explore potential HEDS energy, GHG, and lifecycle cost savings across a range of chilled water and heating plant efficiencies and types.

First, a model of the baseline load and AHU net load with HEDS was developed as a function of average daily outdoor air dewpoint temperatures. Figure 35 shows the resulting modeled performance for the 52 to $56^{\circ} \mathrm{F}$ cooling coil supply air temperature bin. Note that this bin was used for the energy, GHG and lifecycle savings analysis due to limited data sets in other temperature ranges (due to chiller system issues as noted earlier in the report).

Figure 35. Characteristic load curves for the baseline and net HEDS cooling loads as a function of average daily outdoor air temperature for Tinker AFB.

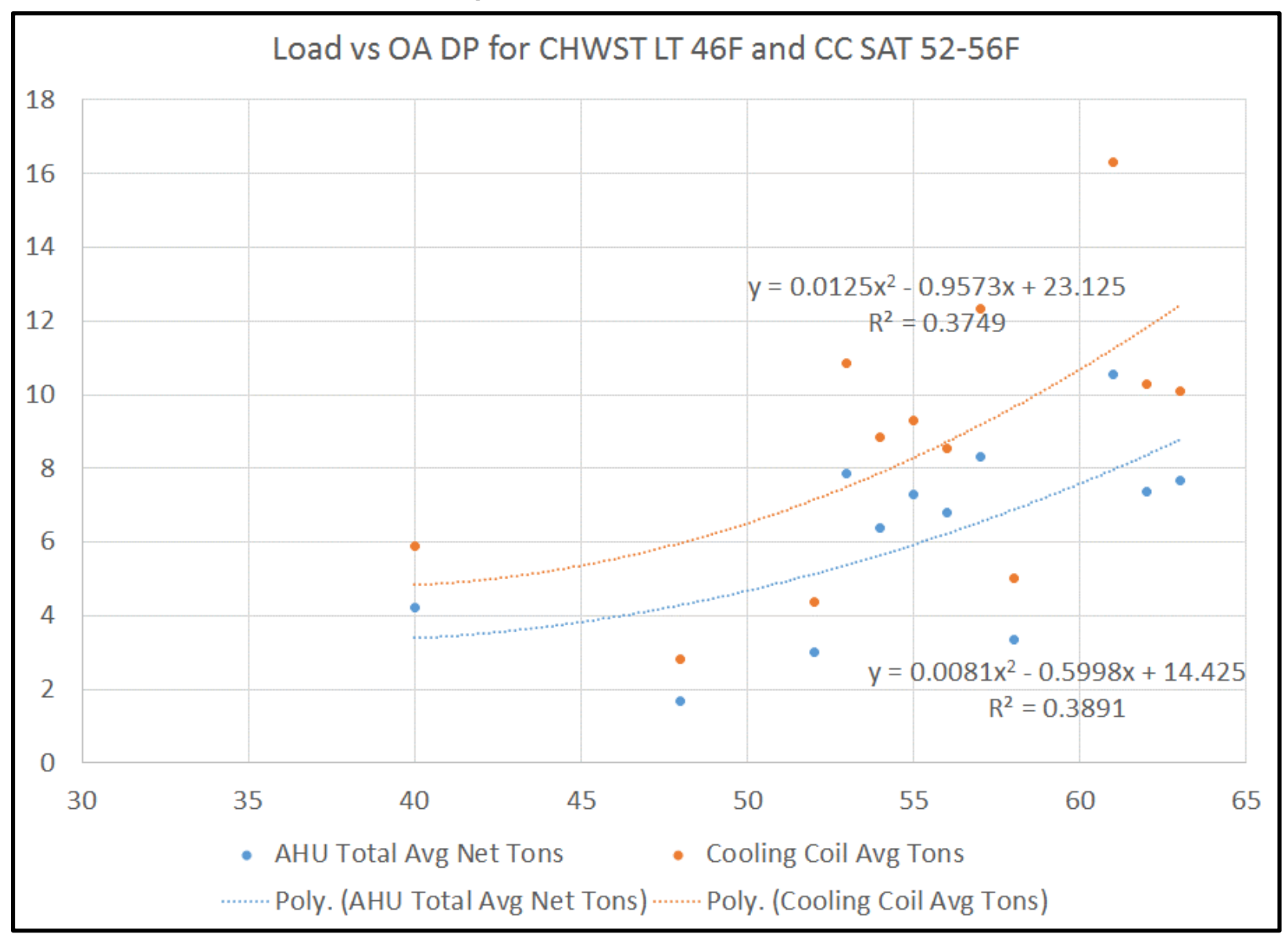


Note that the load model correlations are much weaker for the Tinker AFB data sets. This is due to the lower amount of data available, and to the more dynamic nature of the VAV system, which acts to decouple the observed loads from the outside air dewpoint temperature.

The modeled curves were then applied to typical meteorological year (TMY3) dewpoint data to develop annualized savings estimates for each cooling coil temperature range. An annual schedule was applied to chiller plant operations such that the savings analysis only occurs from May through October, reflecting the annual wintertime shutdown from approximately November through April. Also, to appropriately determine total plant energy impacts, it was assumed that HEDS units would be used on the entire load for each chiller plant (i.e., all AHUs would be replaced with HEDS units). This simplifies the analysis of total energy impacts compared with partial HEDS implementations.

Note that runtime schedule savings are a significant component of the Tinker deployment for HEDS. Due to limitations in dehumidification capacity associated with the existing unit that was replaced, the baseline system operated 24x7 throughout the dehumidification season. Because of the increased cooling and dehumidification capacity associated with the HEDS unit, the schedule was able to be reduced by approximately 10 hours per day during the week and by over 40 hours on the weekend, resulting in an average weekly runtime reduction of nearly 90 hours.

As discussed, energy, GHG, and lifecycle cost impacts were calculated across a range of chiller and boiler plant efficiency scenarios:

\section{Chilled Water Plant Scenarios:}

- High Efficiency Water Cooled Chillers:

IPLV 0.45

- Moderate Efficiency Water Cooled Chillers:

IPLV 0.56

- Poor Efficiency Water Cooled / High Efficiency Air-Cooled Chillers:

IPLV 0.79

- Moderate Efficiency Air-Cooled Chillers:

IPLV 1.01

- Poor Efficiency Air-Cooled Chillers:

IPLV 1.35.

Heating Plant Scenarios (net efficiencies include boiler, cycling, and distribution losses):

- Electric Resistance:

$100 \%$ net delivery efficiency

- High Efficiency Condensing Boilers: 
- High Efficiency Non-Condensing Boilers: 70\% net delivery efficiency

- Moderate Efficiency Non-Condensing Boilers: 60\% net delivery efficiency

- Poor Efficiency Non-Condensing Boilers: 50\% net delivery efficiency.

Table 25 lists the resulting energy savings, both in total energy and savings percent, for each cooling coil supply air temperature bin. Note that total energy savings associated with cooling and dehumidification-related reheat are greater than $70 \%$ in all cases, and reach as high as $91 \%$ with the combination of a high efficiency chilled water plant and very low efficiency boiler system.

Table 25. Energy savings results for CC supply air temperatures between 52 to $56^{\circ} \mathrm{f}$ (office dehumidification loads).

\begin{tabular}{|c|c|c|c|c|c|c|c|}
\hline & \multirow[b]{2}{*}{ Savings } & \multirow[b]{2}{*}{$\begin{array}{c}\text { Plant Electricity Only } \\
\text { Savings (kWh) }\end{array}$} & \multicolumn{5}{|c|}{ Total Energy Savings by Reheat System Type and Efficiency (MMBTU) } \\
\hline & & & Electric & $\begin{array}{c}\text { High Efficiency } \\
\text { Condensing Boilers }\end{array}$ & $\begin{array}{l}\text { High Efficiency Non- } \\
\text { Condensing Boilers }\end{array}$ & $\begin{array}{l}\text { Moderate Efficiency } \\
\text { Non-Condensing } \\
\text { Boilers }\end{array}$ & $\begin{array}{l}\text { Poor Efficiency Non- } \\
\text { Condensing Boilers }\end{array}$ \\
\hline \multirow{7}{*}{ 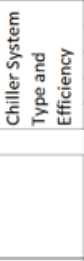 } & High Efficiency Water Cooled & 98,101 & 1,087 & 1,331 & 1,465 & 1,644 & 1,895 \\
\hline & Moderate Efficiency Water Cooled & 116,475 & 1,149 & 1,393 & 1,528 & 1,707 & 1,957 \\
\hline & Poor Efficiency Water Cooled / High Eff Air Cooled & 153,237 & 1,275 & 1,519 & 1,653 & 1,832 & 2,083 \\
\hline & Moderate Efficiency Air Cooled & 189,986 & 1,400 & 1,644 & 1,778 & 1,957 & 2,208 \\
\hline & Poor Efficiency Air Cooled & 245,122 & 1,588 & 1,832 & 1,967 & 2,146 & 2,396 \\
\hline & & & \multicolumn{5}{|c|}{ Total Energy Savings by Reheat System Type and Efficiency } \\
\hline & Savings \% & $\begin{array}{c}\text { Plant Electricity Only } \\
\text { Savings }\end{array}$ & Electric & $\begin{array}{l}\text { High Efficiency } \\
\text { Condensing Boilers }\end{array}$ & $\begin{array}{l}\text { High Efficiency Non- } \\
\text { Condensing Boilers }\end{array}$ & $\begin{array}{c}\text { Moderate Efficiency } \\
\text { Non-Condensing } \\
\text { Boilers }\end{array}$ & $\begin{array}{l}\text { Poor Efficiency Non- } \\
\text { Condensing Boilers }\end{array}$ \\
\hline \multirow{5}{*}{ 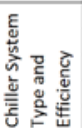 } & High Efficiency Water Cooled & $64.9 \%$ & $85.7 \%$ & $88.0 \%$ & $89.0 \%$ & $90.1 \%$ & $91.3 \%$ \\
\hline & Moderate Efficiency Water Cooled & $64.4 \%$ & $84.0 \%$ & $86.4 \%$ & $87.4 \%$ & $88.6 \%$ & $89.9 \%$ \\
\hline & Poor Efficiency Water Cooled / High Eff Air Cooled & $63.9 \%$ & $81.2 \%$ & $83.7 \%$ & $84.8 \%$ & $86.1 \%$ & $87.6 \%$ \\
\hline & Moderate Efficiency Air Cooled & $63.6 \%$ & $79.0 \%$ & $81.6 \%$ & $82.7 \%$ & $84.1 \%$ & $85.6 \%$ \\
\hline & Poor Efficiency Air Cooled & $63.3 \%$ & $76.6 \%$ & $79.1 \%$ & $80.2 \%$ & $81.6 \%$ & $83.2 \%$ \\
\hline
\end{tabular}

Using the results of the energy savings analysis, GHG emissions impacts were calculated (Table 26). The electric grid GHG emissions rate was applied from the USEPA eGrid for the 2014 national average (1150.322 lb. $\mathrm{CO} 2 \mathrm{e} / \mathrm{MWh}$ ). The natural gas GHG emissions rate is fixed at $53.2 \mathrm{~kg}$ CO2e/MMBtu.

Table 26. GHG emissions savings results for CC supply air temperatures between 52 to $56^{\circ} \mathrm{f}$ (low dehumidification loads).

\begin{tabular}{|c|c|c|c|c|c|c|c|}
\hline & \multirow[b]{2}{*}{ Savings } & \multirow[b]{2}{*}{$\begin{array}{c}\text { Plant Electricity Only } \\
\text { Savings }\end{array}$} & \multicolumn{5}{|c|}{ Total GHG Savings by Reheat System Type and Efficiency (tons) } \\
\hline & & & Electric & $\begin{array}{l}\text { High Efficiency } \\
\text { Condensing Boilers }\end{array}$ & $\begin{array}{l}\text { High Efficiency Non- } \\
\text { Condensing Boilers }\end{array}$ & $\begin{array}{c}\text { Moderate Efficiency } \\
\text { Non-Condensing } \\
\text { Boilers }\end{array}$ & $\begin{array}{l}\text { Poor Efficiency Non- } \\
\text { Condensing Boilers }\end{array}$ \\
\hline \multirow{7}{*}{ 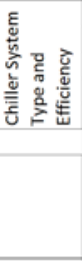 } & High Efficiency Water Cooled & 56 & 183 & 115 & 123 & 133 & 148 \\
\hline & Moderate Efficiency Water Cooled & 67 & 194 & 125 & 133 & 144 & 158 \\
\hline & Poor Efficiency Water Cooled / High Eff Air Cooled & 88 & 215 & 146 & 154 & 165 & 179 \\
\hline & Moderate Efficiency Air Cooled & 109 & 236 & 168 & 175 & 186 & 201 \\
\hline & Poor Efficiency Air Cooled & 141 & 268 & 199 & 207 & 218 & 232 \\
\hline & & & \multicolumn{5}{|c|}{ Total GHG Savings by Reheat System Type and Efficiency } \\
\hline & Savings \% & $\begin{array}{c}\text { Plant Electricity Only } \\
\text { Savings }\end{array}$ & Electric & $\begin{array}{l}\text { High Efficiency } \\
\text { Condensing Boilers }\end{array}$ & $\begin{array}{l}\text { High Efficiency Non- } \\
\text { Condensing Boilers }\end{array}$ & $\begin{array}{c}\text { Moderate Efficiency } \\
\text { Non-Condensing } \\
\text { Boilers }\end{array}$ & $\begin{array}{l}\text { Poor Efficiency Non- } \\
\text { Condensing Boilers }\end{array}$ \\
\hline \multirow{5}{*}{ 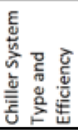 } & High Efficiency Water Cooled & $64.9 \%$ & $85.7 \%$ & $79.0 \%$ & $80.0 \%$ & $81.3 \%$ & $82.9 \%$ \\
\hline & Moderate Efficiency Water Cooled & $64.4 \%$ & $84.0 \%$ & $77.2 \%$ & $78.3 \%$ & $79.5 \%$ & $81.1 \%$ \\
\hline & Poor Efficiency Water Cooled / High Eff Air Cooled & $63.9 \%$ & $81.2 \%$ & $74.6 \%$ & $75.6 \%$ & $76.8 \%$ & $78.3 \%$ \\
\hline & Moderate Efficiency Air Cooled & $63.6 \%$ & $79.0 \%$ & $72.8 \%$ & $73.7 \%$ & $74.8 \%$ & $76.2 \%$ \\
\hline & Poor Efficiency Air Cooled & $63.3 \%$ & $76.6 \%$ & $70.9 \%$ & $71.7 \%$ & $72.7 \%$ & $74.0 \%$ \\
\hline
\end{tabular}


The data show total GHG emissions savings ranging from 115 to 270 tons per year, a reduction of approximately 70 to $85 \%$ from the baseline emissions.

Finally, lifecycle cost analysis was performed across a selected combination of scenarios representing the most common field conditions for DoD sites. Low, mid, and high scenarios for electricity and natural gas rates were analyzed (Table 27).

Table 27. Lifecycle cost analysis

\begin{tabular}{|l|c|c|}
\hline Scenario & Electricity Rate \$/kWh & Natural Gas Rate \$/therm \\
\hline Low & 0.08 & 0.5 \\
\hline Mid & 0.14 & 0.8 \\
\hline High & 0.20 & 1.1 \\
\hline
\end{tabular}

Additionally, two capital cost values were used in the analysis. A retrofit cost value of $\$ 16 / \mathrm{CFM}$ was used; a retrofit scenario assumes the project bears the entire cost of the HEDS unit and installation, such as equipment replacement before EUL. An incremental cost value of $\$ 8 / \mathrm{CFM}$ was also used. Incremental cost values would apply in new construction, major renovation, and equipment EUL situations; incremental cost values also represent retrofit cases where the AHU can be rebuilt in place without entire unit replacement. Note that in new construction applications, HEDS can significantly reduce other infrastructure costs due to chiller and piping downsizing, cooling tower downsizing, etc. due to the cooling load reductions; these cost savings were not included in the lifecycle cost analysis presented here, but should be considered where possible.

Note that, since energy codes require that simultaneous heating and cooling cannot be used for RH control (such as ASHRAE 90.1), the incremental cost of HEDS would approach \$O/CFM, and could even have significant cost savings, depending on the technology used as baseline.

The charts shown in Figure 36 highlight the lifecycle performance across a range of scenarios. Results are shown as a 20-year savings to investment ratio (SIR), where the total savings over 20 years are divided by the project costs. The results show that SIRs are above 1 across all scenarios, nearly 3 for the retrofit applications, and nearly 6 for new construction, EUL, and major renovation applications. Generally, lifecycle cost performance is lower for the Tinker installation due to lower overall cooling loads associated with the VAV system in an administrative building versus the constant volume system in a kitchen at Fort Bragg. 
Figure 36. Lifecycle performance across a range of scenarios.

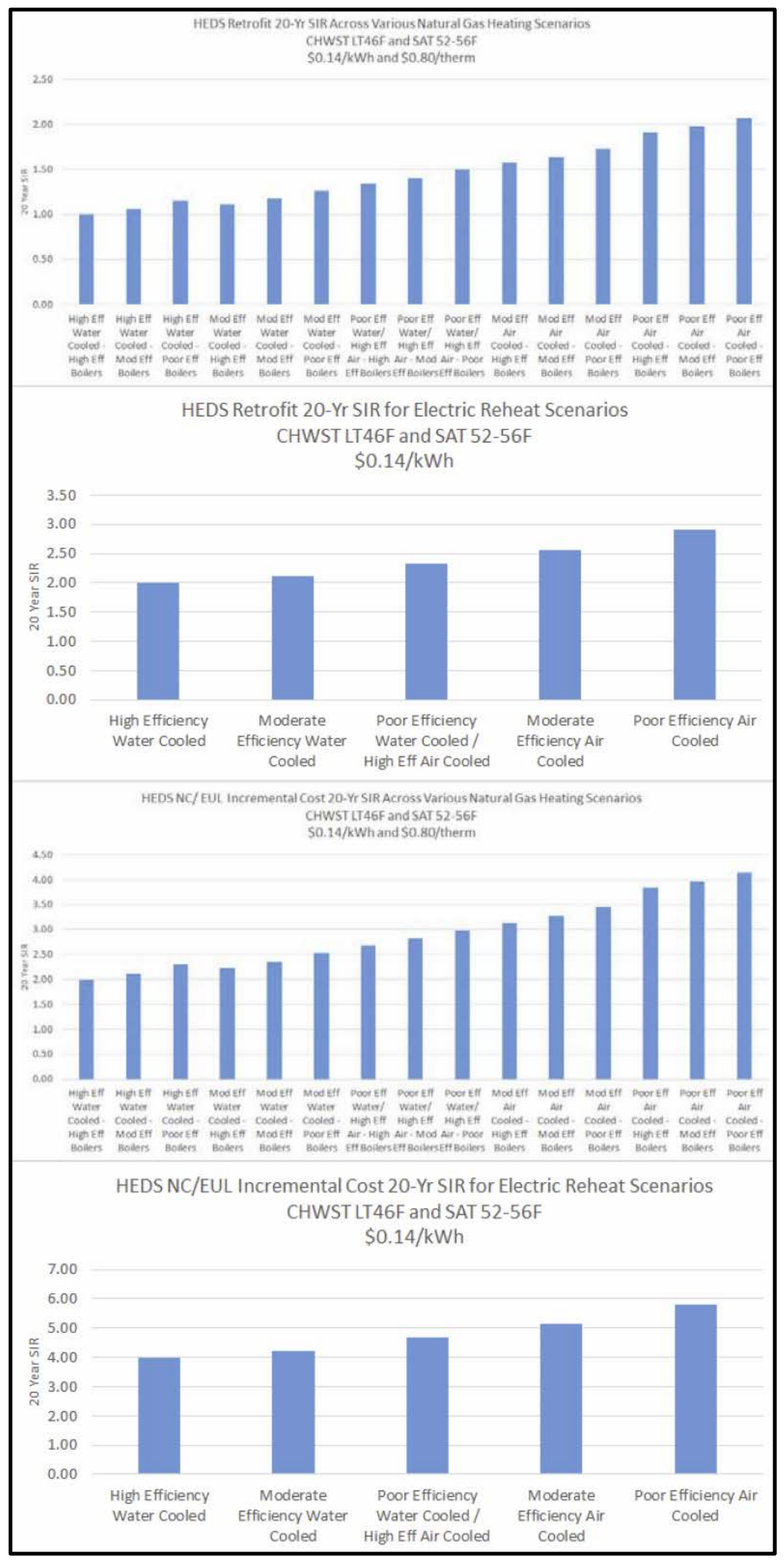




\section{Implementation Issues}

\subsection{Procurement issues}

Currently, HEDS units are only available under license with one manufacturer, which can limit procurement options. The current plan is to evaluate several different manufacturers to determine their ability to meet the expected quality and support levels, and to license the technology to at least two more manufacturers. Given that few AHUs are commercial off-theshelf items (they are mostly built to order), HEDS units will need to use the same market channels of mechanical product vendors, installers, and AHU manufacturers to achieve market scale. This will require deep engineering support from the vendor networks, which requires training, education, and experience with HEDS systems.

\subsection{Potential barriers to acceptance}

One major barrier to acceptance is market skepticism with new technologies that claim such high savings levels. It is common to encounter situations where there is a great potential project, or projects, but the engineer is able to stop the projects by asking "where have you done HEDS in a facility similar to mine, in a climate similar to mine?” More technology demonstration projects in different applications and third party validation are needed to substantiate the savings claims. Additionally, there is often significant pushback within the industry that requires demonstrated performance in similar applications, which slows the adoption of HEDS and any new and potentially market-disruptive technologies.

Insufficient resources to properly operate and maintain HVAC systems on DoD installations is an ongoing concern for public works staff. With limited funding and/or understaffed personnel available to accommodate their existing building stock and associated equipment, installation directorates of public works are often reluctant, unwilling, or unable to work with new technologies that they are unfamiliar with.

The simplicity of the HEDS design and operating strategy should help to overcome public works staff reluctance to embrace a new technology. Documenting and publicizing the implementation of the HEDS ESTCP project at the two demonstration sites should help to encourage further adoption of the technology. Users of the new technology must be confident that it will 
consistently and reliably save energy, reduce biological growth, reduce lifecycle costs, and improve the comfort of the buildings' occupants over the long term, without increasing their manpower and funding requirements.

\subsection{ASHRAE 90.1 Prescriptive energy code requirements}

The latest version of ASHRAE 90.1 prescriptive energy codes explicitly disallows any form of simultaneous cooling and heating or reheating of air for RH control, if the heat or reheat is not from a reclaimed or solar-thermal source. HEDS is one of the few HVAC system designs that is compliant with ASHRAE 90.1 prescriptive energy code regarding RH control, as it uses reclaimed energy for the reheat energy source.

The vast majority of HVAC systems in Federal facilities do not comply with the latest versions of ASHRAE 90.1 (90.1-2007, -2010, -2013 and -2016) with respect to RH Control. HEDS may be the most cost effective solution for DoD and also for the tens of thousands of Federal office buildings, embassies and consulates in humid climates to reduce energy and water waste; improve comfort, health and wellness; and to comply with ASHRAE.

When HVAC systems must be replaced, repaired or upgraded, HEDS may be the only cost effective solution to provide ASHRAE 90.1 compliance across a broad range of HVAC system sizes and types, given some of the following attributes

- HEDS can be a cost effective ASHRAE 90.1 RH control solution that can be applied for systems ranging from $100 \mathrm{CFM}$ (i.e., barracks), to 1,000,000 + CFM (i.e., aircraft paint hangars, known as corrosion control facilities) and all sizes in between.

- HEDS is the only ASHRAE 90.1 compliant solution that will physically fit in many of the existing AHU, DOAS, RTU, Packaged Terminal Air Conditioner (PTAC) and FCU locations.

- HEDS maintenance requirements are lower than any other RH control option. 


\subsection{Lessons learned}

In addition to validating the key performance objectives, several key lessons were gleaned from the demonstration project, as described below.

- Chilled water plant performance can significantly impact HEDS performance. Both test sites experienced chiller plant failures and capacity limitations that resulted in very high and unstable chilled water temperature control. Since dehumidification is limited by the chilled water temperature entering the AHU, this impacts any AHU's ability to provide dehumidification. However, even under these conditions HEDS was able to provide more dehumidification and reduce total cooling loads compared with a traditional dehumidification-reheat AHU.

- Accessibility of operating staff and maintenance data on DoD sites can be challenging. Given the significant turnover and lack of documentation of maintenance practices, quantifying non-energy impacts of systems demonstrations can be difficult on military bases.

- Other system operating constraints may limit overall HEDS impact. At Fort Bragg, the three other AHUs serving the DFAC had capacity limitations and operating issues that limited the ability to realize additional savings from reducing the runtimes of the building. If all units had been replaced with HEDS units, it is expected that the operating times of the equipment could be better aligned with the actual occupied hours of the facility, instead of running 24x7 as is currently required. For the Tinker AFB demonstration site, the runtimes were able to be reduced for the HEDS unit compared to the previous unit operation.

\subsection{Future potential HEDS applications for DoD}

The overall objective is to position the HEDS technology for immediate and widespread commercialization and adoption in DoD facilities and floating assets. Target facilities would have some combination of the following conditions

- Facilities that are mandated to reduce energy and water use

- Facilities that must reduce thermal and or electrical loads and costs

- Facilities that must comply with ASHRAE 90.1 prescriptive energy codes that do not allow simultaneous heating and cooling for RH control

- Facilities that use chilled water from a chiller plant as their source of cooling 
- Facilities that have large Direct Expansion (DX) RTUs can be candidates if they are converted to chilled water coil systems

- Facilities where the climate is humid at least 4 months per year, or facilities in many milder climates that need 48 to $50^{\circ} \mathrm{F}$ dewpoint supply air conditions, (e.g., hospitals and semiconductor fabrication facilities in Southern California)

- Facilities that must comply with the UFC indoor dewpoint temperature requirement of no greater than $55^{\circ} \mathrm{F}$ dewpoint

- Facilities that do not have a cost effective source of reheat thermal energy for use in the cooling-dehumidification-reheat process

- Facilities that are currently experiencing, or have previously experienced unwanted biological growth

- Facilities where cooling loads may have met or exceeded the available chiller plant cooling capacity

- Facilities where chilled water distribution system may be at, or above, its capacity limit for current or planned loads

- Facilities where heating hot water distribution system may be at its capacity limit for current or planned loads

- Facilities that operate outside of UFC comfort guidelines on a regular basis

- Facilities with water-cooled chiller plants that must reduce cooling tower water use

- Facilities with two-pipe switchover water distribution systems - chilled water in the pipes in the summer, hot water in the pipes in the winter

- Healthcare facilities that are mandated to reduce energy and water use

- Healthcare facilities that have high rates of Hospital Acquired Infections (HAIs)

- Healthcare facilities that struggle to maintain proper temperature and RH setpoints in occupied areas

- Military Sealift Command (MSC) ships of all sorts that operate in hot/humid climates (ship-based applications, which are currently being investigated under award No0167-17-BAA-01 with NSWC Carderock Division)

- Combat vessels that must not have thermal stress on Sailors during engagements. 


\section{References}

Arundel, Anthony V., Elia M. Sterling, Judith H. Biggin, and Theodor D. Sterling. 1986.

"Indoor Health Effects of Relative Humidity in Indoor Environments."

Environmental Health Perspectives. 65:351-361, https://www.ncbi.nlm.nih.gov/pmc/articles/PMC1474709/

Mumma, Stanley A. 2006. "Decoupling the Building Latent and Sensible Loads Using 100\% Outside Air Systems." PowerPoint presentation. ASHRAE Chicago Seminar 39, January 24, 2006, https://www.powershow.com/view/3c6212MjA1M/Decoupling_the_Building_Latent_and_Sensible_Loads_Using_100_Outside_Air_Syste ms_powerpoint_ppt_presentation

Schoen, L. J. 2010. Preventive Maintenance Guidebook: Best Practices to Maintain Efficient and Sustainable Buildings. Washington, DC: Building Owners and Managers Association (BOMA) International, p 76.

Vavrin, John. 2006. Ventilation and Humidity Control in Army Barracks Using DOAS for Better Indoor Air Quality and Energy Conservation. PowerPoint Presentation (Presenter: Dale L. Herron). Champaign, IL: Engineer Research and Development Center, Construction Engineering Research Laboratory (ERDCCERL), https://www.aiha.org/aihce06/handouts/d1herron.pdf 


\section{Appendix A: Points of Contact}

\begin{tabular}{|c|c|c|c|}
\hline $\begin{array}{l}\text { POINT OF } \\
\text { CONTACT } \\
\text { Name }\end{array}$ & $\begin{array}{l}\text { ORGANIZATION } \\
\text { Name } \\
\text { Address }\end{array}$ & $\begin{array}{l}\text { Phone } \\
\text { Fax } \\
\text { E-mail }\end{array}$ & Role in Project \\
\hline Dahtzen Chu & $\begin{array}{l}\text { U.S. Army Engineer } \\
\text { Research and } \\
\text { Development Center, } \\
\text { Construction } \\
\text { Engineering Research } \\
\text { Laboratory } \\
\text { 2902 Newmark Dr. } \\
\text { Champaign, IL 61822 }\end{array}$ & $\mid \begin{array}{l}(217) 373-6784 \\
(217) 373-6740 \text { (fax) } \\
\text { dahtzen.chu@usace.army.mil }\end{array}$ & $\begin{array}{l}\text { Government Partner, } \\
\text { Lead Project } \\
\text { Manager }\end{array}$ \\
\hline Scot M. Duncan & \begin{tabular}{|l|} 
Retrofit Originality Inc. \\
26441 Houston Trail \\
Laguna Hills CA, 92653
\end{tabular} & $\begin{array}{l}\text { (949) 370-8582 } \\
\text { sduncan@roi-engineering.com }\end{array}$ & $\begin{array}{l}\text { Industry Partner, } \\
\text { Lead Project } \\
\text { Manager }\end{array}$ \\
\hline Ron Miller & $\begin{array}{l}\text { Trane Commercial } \\
\text { Systems, } \\
\text { An Ingersoll Rand } \\
\text { Company } \\
3253 \text { E. Imperial Hwy } \\
\text { Brea, CA 92821 }\end{array}$ & $\begin{array}{l}\text { (714) 983-0405 } \\
\text { Rmiller4@trane.com }\end{array}$ & Project Manager \\
\hline Omar Chamma & $\begin{array}{l}\text { Trane Commercial } \\
\text { Systems, } \\
\text { An Ingersoll Rand } \\
\text { Company } \\
3253 \text { E. Imperial Hwy } \\
\text { Brea, CA } 92821\end{array}$ & \begin{tabular}{|l} 
(626) 255-3170 \\
ochamma@trane.com
\end{tabular} & Sales Engineer \\
\hline $\begin{array}{l}\text { W. Curtis Phillips, } \\
\text { CEM, CMVP }\end{array}$ & Fort Bragg, NC & $\begin{array}{l}(\text { ofc) (910) 396-4824 } \\
\text { (cell) (919) 896-3889 } \\
\text { william.c.phillips174.ctr@mail. } \\
\underline{\text { mil }}\end{array}$ & Site REM \\
\hline Joey Hunter & \begin{tabular}{|l|} 
Tinker AFB, OK \\
7535 5th St., Bldg. 400 \\
Tinker AFB, OK 73145- \\
9010
\end{tabular} & 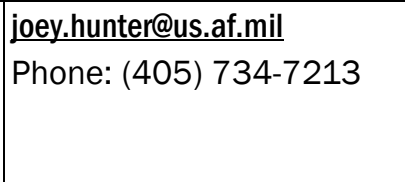 & $\begin{array}{l}\text { Site Mechanical } \\
\text { Engineer }\end{array}$ \\
\hline
\end{tabular}




\section{Appendix B: HEDS Frequently Asked Questions (FAQs)}

\section{B.1 Index to Questions:}

Q1: Why is HEDS so much more effective than a "normal" heat recovery system?

Q2: The energy savings percentages look extremely high, in fact, they are nearly unbelievable, how is this possible?

Q3: Are there other ways that HEDS helps to save energy?

Q4: Since the coils are so big, does the chilled water pump energy increase?

Q5: Is the cooling tower fan energy or air-cooled condenser fan energy affected by HEDS?

Q6: Is the condenser water pump energy affected by HEDS?

Q7: Besides boiler energy savings are there any other hot water system savings?

Q8: How does HEDS work with my Waterside "Free Cooling" Heat Exchanger System?

Q9: How can HEDS provide a Return On Investment (ROI) of greater than $100 \%$ ?

Q10: Is HEDS acceptable to be used in a retrofit, or only new installations?

Q11: Will HEDS allow chiller plant downsizing?

Q12: The cooling coils in HEDS units are much larger than in "normal" AHUs. How does the fan energy get reduced instead of increased?

Q13: How can HEDS reduce HVAC system run time in non-24/7 load facilities?

Q14: For non-24/7 load types, what is the potential energy savings associated with a HEDS project?

Q15: For 24/7 load types, what is the potential energy savings associated with a HEDS project?

Q16: In the answer above, you note that the cooling load savings may be 30 to $40 \%$, but the total energy savings may fall into the 45 to $65 \%$ range. How can the overall energy savings be greater than the cooling loads percent reduction? 
Q17: How much energy can be saved in Hospital/OSHPD operating room facilities?

Q18: Can HEDS reduce Infrastructure Costs?

Q19: Can HEDS improve efficiencies of added facilities?

Q20: Can HEDS help to solve the "Low Delta T Syndrome"?

Q21: Can HEDS handle added loads without additional equipment and reduce expensive upgrades?

Q22: Does HEDS require a two-pipe system, or will it also work with a four-pipe system?

Q23: How will the HEDS design work with an existing boiler during the heating season?

Q24: Does HEDS need a pre-heat coil for my application?

Q25: Desiccant wheels and rotary HX wheels require that the exhaust streams be filtered to reduce clogging of the wheels. Does HEDS have this requirement?

Q26: Many desiccant wheels need a 200 to $300^{\circ} \mathrm{F}$ heat source to regenerate the wheel. Does HEDS have any need like this?

Q27: How does the air pressure drop through a desiccant-based system compare to a HEDS system?

Q28: How does the air pressure drop through a run-around coil-based system compare to a HEDS system?

Q29: How does the accuracy of the supply air temperature control compare between the various options?

Q30: Is a separate heating coil also needed downstream of this arrangement?

Q31: Since the return temperature for the chilled water is increasing above a standard $10-^{\circ} \mathrm{F}$ Delta $\mathrm{T}$, does this mean that the chiller also needs to be evaluated to see if it can handle this large spread of water temperatures without causing issues?

Q32: In many cases, condensed water is carried off the cooling coils into the downstream ductwork and re-evaporated into the airstream. The water can saturate the insulation systems and become mold infested. Can HEDS stop this from happening?

Q33: It seems like the CHW temperature differential of most dehumidification systems is very low. That precludes the use of piping the chillers to operate in series. Can HEDS use series chiller operation to increase the capacity and efficiency of the upstream chiller by 20 to $25 \%$ ? 
Q34: What size ranges can HEDS provide that other dehumidification technologies are not cost effective at?

Q35: Many desiccant-based systems have supply air temperatures in excess of 90 to $100^{\circ} \mathrm{F}+$ and need post-unit cooling coils and chiller capacity. Does HEDS have this trait?

Q36: Some desiccant-based systems need mixed air preheat coils to lower the $\mathrm{RH}$ of the air entering the wheel, does HEDS have this trait?

Q37: A typical subcool/reheat AHU design running a 100-ton load at the cooling coil, delivering a $54^{\circ} \mathrm{F}$ dewpoint at an $8{ }^{\circ} \mathrm{F} \mathrm{CHW}$ temperature differential requires $300 \mathrm{GPM}$. How much flow is required from a HEDS unit with the same 100-ton load?

Q38: Can HEDS produce water?

Q39: The standard method of performing dehumidification/reheat for $\mathrm{RH}$ control (Sub-cooling the air, then adding new heat for reheat energy), is essentially banned for the prescriptive method of complying with ASHRAE 90.1-2013 and -2016. Does HEDS comply with that energy code?

Q40: What is the lowest dewpoint temperature that HEDS can achieve? 


\section{B.2 FAQs}

\section{Q1: Why is HEDS so much more effective than a "normal" heat recovery system?}

A: In a normal heat recovery system, like a cogeneration plant, you are recovering heat that would otherwise be wasted, and using it for another purpose. Using the otherwise wasted heat does not reduce the load on the generator, or increase the capacity of the generator, or reduce the energy consumption of the generator. A $1,000 \mathrm{~kW}$ generator can still only provide an effective $1,000 \mathrm{~kW}$ of electrical output at the same energy input.

In the case of HEDS, the energy being recovered is actually cooling load that the chiller would have to serve if HEDS were not present, so the cooling load on the chiller plant is decreased by the exact same amount of BTUs as the energy that is being recovered is saving on the heating system. Contrary to a "Normal" heat recovery system, the equivalent HEDS system can reduce the load on the chiller, reduce the energy consumption of the chiller plant by over $30 \%$, and allow the system to provide an effective, usable 20 to $40 \%$ greater cooling capacity from the chiller, so the 1,000 -ton chiller can look like a 1,200- to 1,400-ton chiller. As a side benefit, the amount of heat load BTUH reduced is exactly equal to the amount of cooling load BTUH reduced.

\section{Q2: The energy savings percentages look extremely high, in fact, they are nearly unbelievable, how is this possible?}

A: The energy savings percentages look extremely high primarily due to the elimination of new reheat energy being needed for RH control. For many system types, the reheat energy dominates the amount of energy used by the cooling system for the dehumidification/reheat process, so that by saving $100 \%$ of this reheat energy source that dominates, the overall percent savings will naturally be very high. Another way to think about it is that the energy is actually "saved twice." It is saved once by using the cooling-sourced heat to eliminate the need for new reheat energy, and it is saved again by reducing the cooling load on the chiller plant by the exact same number of BTUs that were saved by the reheat system.

Note that in most applications the savings percent are not reflective of the entire year HVAC energy savings; the energy savings shown are for the cooling plant and boiler plant dehumidification/reheat process only. For most facilities, the annual HVAC savings percent will be lower. For hot and humid climates such as Hawaii, Guam and the South Pacific, where dehumidification loads dominate the total load profile, the annual savings will approach the ranges presented in this report. 


\section{Q3: Are there other ways that HEDS helps to save energy?}

A: Yes, in addition to the chiller and boiler energy savings, HEDS can help save energy in several different ways:

- Chilled water pump energy savings

- Cooling Tower Fan energy savings

- Condenser water pump energy savings

- Eliminating or reducing the "Low Delta T Syndrome"

- Potential for series chiller operation

- Reduced equipment run time

- Hot water pump energy savings

- Enhances Waterside "Free Cooling” Heat Exchanger System Savings.

Each of these items are addressed in greater detail in the following Question and Answer (Q\&A) section.

\section{Q4: Since the coils are so big, does the chilled water pump energy increase?}

A: In the case of HEDS, the $2.5 \mathrm{X}$ to $3.5 \mathrm{X}$ larger cooling coil heat transfer surface area results in a much higher cooling coil chilled water temperature differential, and a higher $\mathrm{CHW}$ temperature differential results in a much lower CHW flow rate.

The cooling coil chilled water temperature differential (TD) for the Tinker AFB test site ranged from a $14^{\circ} \mathrm{F} \mathrm{CHW} \mathrm{TD} \mathrm{at} 25 \%$ load, up to a peak of around $24{ }^{\circ} \mathrm{F}$. The cooling coil chilled water TD for Fort Bragg ranged from a low of about $12^{\circ} \mathrm{F}$ to a high of $22^{\circ} \mathrm{F}$. The base case systems chilled water temperature differential (TD) at those sites ranged from 3 to $10^{\circ} \mathrm{F}$.

The chilled water pump energy savings will typically be on the order of 50 to $70 \%+$, depending on the base case system that is installed. Chilled water pump energy is an approximate ${ }^{\wedge} 2.5$ power relationship to flow and an approximate ${ }^{\wedge} 1.5+$ power relationship to pressure drop. 
The chilled water flow rate will be cut by between 30 to over $50 \%$ compared to typically installed systems, so the chilled water pump energy savings related to flow reductions will be between $(1-0.3)^{\wedge} 2.5 * \mathrm{HP}=0.41 *$ $\mathrm{HP}(59 \%$ savings $)$ to $(1-0.5)^{\wedge} 2.5 * \mathrm{HP}=0.18 * \mathrm{HP}(82 \%$ savings $)$. A savings range of 50 to $70 \%$ is shown to be conservative.

Regarding coil water pressure drop energy savings or penalty, the combined HEDS coils are designed to have the same approximate water pressure drop as a normal cooling coil water pressure drop, and with HEDS, a lower water pressure drop control valve system was designed. The lower overall water pressure drop would result in a slight energy savings with the HEDS design, but those savings are neglected in this discussion.

\section{Q5: Is the cooling tower fan energy or air-cooled condenser fan energy af- fected by HEDS?}

A: To maintain exactly the same condenser water temperatures with a 20 to $37 \%$ chiller load reduction that is available from a HEDS installation, the speed of the Cooling Tower Fan (CTF) motors can be reduced by approximately 20 to $37 \%$. Assuming a direct squared function with speed for CTF motors, the CTF energy consumption would see between $(1-0.2)^{\wedge} 2.0 * \mathrm{HP}$ $=0.64 * \mathrm{HP}(36 \%$ savings $)$ to $(1-0.37)^{\wedge} 2.0 * \mathrm{HP}=0.40 * \mathrm{HP}(60 \% \mathrm{sav}-$ ings).

\section{Q6: Is the condenser water pump energy affected by HEDS?}

A: Condenser water pump (CDWP) energy. If the CDWPs are constant speed, there would be no energy savings and no energy penalty if the same number of pumps are run with the normal and HEDS designs. This will typically not be the case.

If the system being evaluated is like most chiller plants, it suffers from the Low Delta T Syndrome, so there will be savings as described in the "Low Delta T Syndrome" section of this Q\&A.

If the CDWP system is variable flow, the CDWP energy savings percent would be similar to the CTF motor energy savings, on the order of 30 to $50 \%$, depending on the vertical hydraulic height of the CT system and the minimum chiller and cooling tower flow rates.

\section{Q7: Besides boiler energy savings are there any other hot water system sav- ings?}

A: By not having to run the boilers for reheat energy during the dehumidification season, the hot water pumps do not have to be run to serve those loads. Hot water pumps are relatively small for individual buildings, but even shutting a 5 HP pump off for the summer can save $12,000 \mathrm{kWh}$ per year. If 
the boiler has to be run for domestic water systems, local alternates to centralized boilers should be looked at to serve these typically small loads.

\section{Q8: How does HEDS work with my Waterside "Free Cooling" Heat Ex- changer System?}

A: Many facilities are equipped with "Waterside Economizers" or a "Free Cooling Heat Exchanger (FCHX)" System. A "Free Cooling" system shuts the chillers off when the weather is cool/cold and uses the cooling towers and condenser water pumps to create cold water, which is then sent through a heat exchanger out to the cooling loads. Because the HEDS coils are so much larger than the normal design coils, the free cooling HX system can run for many more hours per year while still meeting comfort conditions.

A FCHX system can run at $0.05 \mathrm{kWh}$ per ton hour to $0.15 \mathrm{kWh}$ per ton hour, where a typical chiller plant may be operating at 0.80 to $3.0 \mathrm{kWh}$ per ton hour under similar light load conditions. During these weather conditions, there may not be any reheat required for RH control, so in this case, it is the sheer size of the coils that is creating the added savings.

\section{Q9: How can HEDS provide a Return On Investment (ROI) of greater than $100 \%$ ?}

A: Although it seems strange to have an ROI greater than $100 \%$, this may result from several different pathways.

- Code Compliance Retrofit. If a system is in need of replacement and it must be code compliant, and code says "no simultaneous heating and cooling," then HEDS will most likely be the least cost option. Since the HEDS option is less expensive than the alternative, even if there were no savings, the relative ROI would be over $100 \%$, since you are saving money, rather than spending additional money and getting a return on that added investment.

- Code Compliance New Construction. Similar to the above, if a new system must be code compliant, and code says "no simultaneous heating and cooling," then HEDS will most likely be the least cost option. The same logic applies here.

- Adding New Buildings or Loads. If the project consists of adding new buildings or cooling/dehumidification loads, HEDS might be less expensive than the alternatives being considered, if any ex- 
pansions to the chiller plant, or piping loop is needed. For example if you have a 1,000-ton plant, and to install a new facility or to integrate a new load into the plant there is a need to add chiller and cooling tower capacity, it may be more cost effective to do a widespread HEDS retrofit to free up an added $20 \%$ or more capacity from the same installed chiller and piping system. This would be especially true if there is a need to expand the chiller plant building or cooling tower yard and enclosure to fit the added equipment. If there is adequate chiller capacity, but a need to increase the CHW distribution piping to meet the new loads, HEDS may also be more cost effective, since it is possible to push 40 to $100 \%$ more BTUs through the same pipes, due to the higher CHW system temperature differential afforded by HEDS.

- Infrastructure Capacities Being Exceeded Due to Low Delta T Problems. If a facility suffers from the Low Delta T Syndrome, and many/ most of them do, it is possible to have not only significant energy waste, but significant stranded chiller and piping capacity that cannot be accessed due to the Low TD problem. For example, if a chiller plant is designed with a $16^{\circ} \mathrm{F}$ CHW TD, and it only receives an $8^{\circ} \mathrm{F}$ TD back from the system, that means that $50 \%$ of the chiller capacity cannot be used $(8 / 16=50 \%)$. Under these, fairly typical design and TD conditions, a 1,00o-ton chiller "looks" like a 500-ton chiller. It cannot load up past the $8^{\circ} \mathrm{F}$ TD, so it can only deliver $50 \%$ capacity, or 500 tons. To serve a $550-$ ton load, you must run two (2) 1,ooo-ton chillers, each at about $28 \%$ load. This is a very poor efficiency point for most chillers, especially in the summer, when cooling tower temperatures tend to be pretty high and chilled water supply temperatures must be pretty low in many locations. If you do not fix the cooling coils, you will need to add CHW pipe capacity, and modify the chillers to run with an $8^{\circ} \mathrm{F}$ TD. If it is a Pri/Sec plant, you will need to double the primary loop flow, which means a complete re-pipe of the plant to single pass machines from two pass, and installing primary $\mathrm{CHW}$ pumps that are $6 \mathrm{X}$ to $8 \mathrm{X}$ more $\mathrm{HP}$ to move double the CHW flow through them. The CHW distribution piping will also need to be replaced with pipe capable of $2 \mathrm{X}$ the $\mathrm{CHW}$ flow rate. HEDS will be less expensive in this case, so the ROI would, once again, be greater than $100 \%$. 


\section{Q10: Is HEDS acceptable to be used in a retrofit, or only new installations?}

A: The biggest target market is the retrofit market, where the most problems exist and the most obvious benefits are to be had. Based on these findings at the two DoD test sites, in a retrofit application, it appears that HEDS will solve the high $\mathrm{RH} / \mathrm{mold} /$ mildew problems that exist, substantially cut energy and water waste, solve the Low Delta $\mathrm{T}$ problem, and help to solve cooling capacity problems. By evaluating the results that were obtained from these tests, it can be inferred that HEDS will help to solve undersized infrastructure problems, reduce manpower and maintenance costs, and lower the overall lifecycle costs associated with the cooling/dehumidification/reheat process.

If HEDS is designed into new construction or facility expansion projects, there is the potential for lower overall installation costs and lower overall lifecycle costs, such that the Return On Investment (ROI) can actually exceed 100\%.

If HEDS is designed into retrofit projects that must upgrade their systems to be ASHRAE 90.1 Energy Code compliant, there is the potential HEDS will have the least first cost impact. The relative Return On Investment (ROI) can exceed $100 \%$ in these cases.

\section{Q11: Will HEDS allow chiller plant downsizing?}

A: Yes, based on the evaluations completed so far. The peak day cooling load reduction is approximately $20 \%$ for both of the two DoD test sites. When weather conditions are less severe and very low dewpoint air $\left(<50^{\circ} \mathrm{F}\right)$ is no longer required, the cooling load reductions vary between approximately 25 and $40 \%$. Constant air volume systems show the largest percent savings, in the 30 to $40 \%$ cooling load savings region, as expected, and the VAV system, with its lower volume of air needing reheat, shows a lower, but still significant 25 to $30 \%$ cooling load reduction. In all circumstances, the amount of reheat energy was reduced to zero for the RH control process, so the reheat energy savings are $100 \%$.

\section{Q12: The cooling coils in HEDS units are much larger than in "normal" AHUs. How does the fan energy get reduced instead of increased?}

A: HEDS coils have typically $300 \%+$ greater heat transfer surface area than base case dehumidification AHUs. This added surface area is a combination of more rows, which add pressure drop; a higher fins per inch count, which also adds air pressure drop; and a greater width or height, which reduces air velocity and reduces air pressure drop. The reduced air velocity part of the design more than makes up for the deeper coils with higher fins per inch density. Normal AHUs can have combined coil pressure drops of 0.80 to 1.0 in. WC, run-around coil AHUs can have combined coil pressure drops of 0.90 to $1.1 \mathrm{in}$. WC. Desiccant-based systems can have added pressure drops of 2.0-in. for the inlet air, and an added 2-in. WC pressure drop for the exhaust side. 
The combined coil air pressure drop of HEDS is about 40 to $50 \%$ less than a "normal" dehumidification AHU. This is because the air velocity through the coils is substantially lower for HEDS, and air pressure drop is an approximate ${ }^{\wedge} 1.7$ function with HP, so for the coil air pressure drop part of the fan $\mathrm{HP}$, it would be $(1-0.4)^{\wedge} 1.7 * \mathrm{HP}=0.42 * \mathrm{HP}$, so almost $60 \%$ savings for the coil air pressure drop portion of the fan energy. You can see the data in the Draft DoD ESTCP report showing that worst case, maximum total combined air pressure drop across the cooling coil and the cooling recovery coil is 0.40 -in., whereas typical high face velocity coils would have air pressure drops of 0.80 to 1.00 in. under similar dehumidification conditions.

There are actually slight fan energy savings associated with HEDS, rather than a fan energy penalty, due to the lower air pressure drop across the coil systems. Fan energy savings are not included in these savings analysis, although it really should be included.

\section{Q13: How can HEDS reduce HVAC system run time in non-24/7 load facilities?}

A: Many, if not most, office type facilities in humid climates that are supposed to run on a 5/12 schedule actually run their HVAC systems 24/7 during the heat of the summer in an attempt to maintain comfort and RH conditions within the buildings. That means that they are simultaneously cooling then reheating the air for nearly 3,600 hours per year. If the facility is in a tropical location, similar systems must simultaneously cool then reheat the air for 8,760 hours per year. This is because the cooling coils or chillers (or both) have inadequate capacity to provide "cool-down" functions. When the buildings are unoccupied at night and on weekends, if the HVAC systems are shut down, the buildings can become moisture and heat saturated, and it becomes difficult, if not impossible for the installed equipment to bring the buildings under control in a reasonable amount of time, so the entire HVAC system is run continuously to try to meet desired indoor $\mathrm{RH}$ and temperature conditions.

Contrary to typical designs, HEDS has huge cooling coil heat transfer surface areas that can be used to rapidly pull the heat and moisture from a facility, and the HEDS functionality can provide a near $40 \%$ boost in the cooling capacity that is available to provide cooling to the facility. This is the equivalent of adding a 400-ton chiller to a 1,000-ton chiller plant. The large coils and the HEDS design and control strategies allow the loads to be brought under control far more rapidly than any of the typically designed options. It is typical to see facilities that have been retrofit with high capacity cooling coils be able to significantly reduce their run times. In the case of humid to tropical locations, it is felt that run time will be able to be reduced by $90+$ hours per week.

For Hawaii, the South Pacific, and much of the Southeast United States, the hot/muggy weather happens 52 weeks per year, so the entire HVAC system, including the fan systems, run time can be reduced by over $50 \%$ on an 
annual basis when a HEDS implementation occurs. Cutting HVAC system run time by over $50 \%$ not only provides significant energy savings, but also a dramatic improvement of equipment lifecycles. Running excessive amounts of equipment is an incredible waste of energy, and for locations where fuel must be shipped in, there is added energy waste from the tankers for the fuel shipping process.

\section{Q14: For non-24/7 load types, what is the potential energy savings associated with a HEDS project?}

A: This is very site specific, but if the base case facility runs their HVAC system $24 / 7$ and the occupancy only requires $5 / 12$ operation, the savings can easily be in the $60 \%$ to more than $70 \%$ range. This is a blended combination of 40 to $50 \%$ runtime reduction and 20 to $40 \%$ cooling load reduction savings, and with HEDS, the RH-control related reheat energy gets cut by $100 \%$. Many facilities use electric reheat, so this can be a significant cost savings.

Q15: For 24/7 load types, what is the potential energy savings associated with a HEDS project?

A: This depends to a great extent on the dewpoint temperature that is required and the supply air temperature that is required. For MAUs, (Make up Air Units), PTOAs (Pre-Treat Outside Air units), and DOASs that must deliver low RH tempered air to the spaces or the downstream HVAC system, the cooling load savings can be in excess of $20 \%$. If the required dewpoint temperature is in the mid-50s and the required supply air temperature is in the mid-60s, HEDS can deliver between 30 and $40 \%$ cooling load reductions. The associated overall energy savings can be in the 45 to $65 \%$ range, or higher.

Q16: In the answer above, you note that the cooling load savings may be 30 to $40 \%$, but the total energy savings may fall into the 45 to $65 \%$ range. How can the overall energy savings be greater than the cooling loads percent reduction?

A: Most modern chiller plants have already been retrofit with VFDs on their pumping and cooling tower systems. VFD equipped fans and pumps respond to reduced speeds at a near cubic relationship. A HEDS related 25\% cooling load reduction with a corresponding CHW system TD increase of $40 \%+$ can result in a 50\%+ savings for the pumps and CTF motors. If the facility is equipped with a properly selected VFD chiller, the savings can be even greater. Additionally, the reheat energy can be a significant figure, and that has been reduced by $100 \%$.

\section{Q17: How much energy can be saved in Hospital/OSHPD operating room fa- cilities?}

A: In many OSHPD spaces, there is the ability for a HEDS project to cut the circulated air volumes down by $75 \%$ when the spaces are not occupied. 
During these non-occupied hours, HEDS controls are set up to deliver low dewpoint air at very low RH conditions to prevent the spaces from becoming subcooled, which has the tendency to create areas of condensation.

A recent evaluation for just this facility configuration is showing a greater than $80 \%$ cooling, dehumidification, and reheat energy savings for the dehumidification/reheat process in Southern California. This is not typical, as the base case at that facility is very energy intensive, so the savings $\%$ can look fantastic, even in a dry environment. A more typical result may be in the 50 to $70 \%$ chiller plant and boiler plant heating and cooling energy savings for the cooling/dehumidification/reheat process.

\section{Q18: Can HEDS reduce Infrastructure Costs?}

A: Yes, based on the evaluations completed so far. A benefit of HEDS is that the chilled water flow rate required to meet peak day cooling/dehumidification needs will be reduced by approximately $50 \%$ by a combination of reduced cooling plant loads and increased chilled water system temperature differentials provided by the very large cooling coils.

On sites that may be stretching the limits of their piping infrastructure, the ability to meet the same cooling loads with a $50 \%$ reduction in the flow rate can mean that the avoided costs from not having to replace the piping infrastructure can cover the most or all of the costs of HEDS retrofit projects. While not a HEDS project, one of the team members has been working with the USC since 1992, and has helped raise their CHW system temperature differential from 8 to $9^{\circ} \mathrm{F}$ during peak summer months in 1992, up to 25 to $27^{\circ} \mathrm{F}$ today. This has allowed USC to avoid replacing their underground piping, as the installed piping can now move $300 \%$ more BTUs per gallon due to the $3 \mathrm{X}$ higher chilled water temperature differential. This is a savings of over $\$ 10,000,000$ for the campus.

\section{Q19: Can HEDS improve efficiencies of added facilities?}

A: Yes. When new facilities are being added, or facilities are being rehabilitated or expanded, the HEDS design can be incorporated to reduce lifecycle costs. If a chiller plant has reached the maximum capacity that it can deliver, the piping infrastructure may also be maxed out as described above. The piping system may actually be maxed out before the plant being maxed out. If the plant and piping system capacity is maxed out, there are two remedies: (1) add more chiller, cooling tower, pumping and piping capacity, and potentially an addition to the chiller plant building to house the new equipment, which can all add up to tens of millions of dollars just to add one more building, or (2) install HEDS projects to make better use of the installed equipment and piping by decreasing the cooling loads on the plant and increasing the chilled water system temperature differential and $\mathrm{CHW}$ piping infrastructure capacity. 


\section{Q20: Can HEDS help to solve the "Low Delta T Syndrome"?}

A: Yes. One of the key drivers for the Low Delta T Syndrome is undersized cooling coils and the need to serve dehumidification loads. By nature of the HEDS design, the heat transfer surface area of the cooling coils is more than $300 \%$ greater than a typical six-row, 10 fins per inch coil at the normal $550 \mathrm{ft}$-per-minute face velocity. HEDS will typically be delivering $1.5 \mathrm{X}$ to $2 \mathrm{X}$ the actual operating chilled water system temperature differential.

Many, if not most, facilities with more than one chiller suffer from the "Low Delta T Syndrome." The Low Delta T Syndrome is a condition where the chilled water system temperature differential can be significantly lower than the system is designed to operate properly at, so significant amounts of energy are wasted each year. Two of the main reasons for this problem are undersized cooling coils and lack of control for the maximum cooling coil chilled water flow rates. The Low Delta T Syndrome can more than double the energy use of chiller plants. In essence, a chiller can only provide capacity in proportion to its actual chilled water (CHW) temperature differential (TD) divided by its design CHW TD. So a chiller that was designed for a $16^{\circ} \mathrm{F}$ TD that is only operating with an $8{ }^{\circ} \mathrm{F}$ TD can only provide $(8 / 16=$ $50 \%$ ) of its design capacity, assuming constant chilled water flow through the evaporator. What that means is that small cooling coil/low CHW TD systems may have to run twice as much chiller plant equipment, at very poor efficiencies, in comparison to a HEDS system that operates with a significantly higher CHW TD.

A HEDS designed coil system that has $2.5 \mathrm{X}$ to $3.5 \mathrm{X}$ greater heat transfer surface area, and a built in maximum flow limiting device, will always provide a significantly higher CHW system TD in comparison to the typically installed smaller coil with no flow limiting device. HEDS can be a cure for the Low Delta T Syndrome, vs. normally sized coils and design strategies, which contribute to the chiller plant energy waste problem. HEDS reduction of, or complete elimination of the Low Delta T Syndrome during the dehumidification season can contribute to significant additional energy savings, not even associated with the HEDS process.

The ESTCP test sites are showing $14{ }^{\circ} \mathrm{F}$ CHW system TDs at $25 \%$ load and $15^{\circ} \mathrm{F}$ CHW TDs at 50\% loads for the CAV system at Fort Bragg, with peak load TDs varying between 13.5 and $22^{\circ} \mathrm{F}$, depending on the dewpoint setpoint. The Tinker AFB VAV site is showing over $24^{\circ} \mathrm{F}$ CHW TDs at peak load and better than $17^{\circ} \mathrm{F} \mathrm{CHW} \mathrm{TDs} \mathrm{for} \mathrm{minimal} \mathrm{loads.} \mathrm{Comparative} \mathrm{base-}$ lines at the sites were 3 to $5^{\circ} \mathrm{F}$ CHW TDs at part load conditions and $10^{\circ} \mathrm{F}$ TDs at peak loads. 


\section{Q21: Can HEDS handle added loads without additional equipment and re- duce expensive upgrades?}

A: Yes. As described above, if HEDS is incorporated, it will free up additional capacity in the cooling plants and the chilled water distribution piping systems. If all loads are converted to HEDS, the chiller plant should be able serve a minimum $20 \%$ increase in loads, and the piping infrastructure should be able to serve at least $50 \%$ more capacity.

\section{Q22: Does HEDS require a two-pipe system, or will it also work with a four- pipe system?}

A: HEDS works with both system types. One of the beauties of the HEDS design is that it can provide cooled and dehumidified air with a two-pipe system, without requiring electric reheat or complex and hard to maintain desiccant wheel-based equipment. With a two-pipe system in the winter, the hot water return (HWR) temperature approaches the coil entering air temperature, since there is so much heat transfer surface area available and the air is moving at such a low velocity through the coils. This means that with a $180^{\circ} \mathrm{F}$ hot water supply (HWS) temperature, you will end up with a 100 to $120^{\circ} \mathrm{F}$ temperature differential, delivering substantial efficiency gains to the hot water (HW) system. With a four-pipe system, the CRC can either be piped to operate as a heating coil in the winter (via a Belimo six-way valve or the equivalent), or a heating coil can be used in the unit. If the CRC is used as a heating coil, the chemical treatment systems for the HW and CHW should be checked for compatibility

\section{Q23: How will the HEDS design work with an existing boiler during the heating season?}

A: If the HEDS system is used in a two-pipe system, the hot water system temperature differential will be larger than with a typical coil selection, allowing a few different things to occur - substantial pump energy savings due to the larger HW system temperature differential that occurs due to the much larger coils, potential infrastructure savings when facilities are added - the existing piping infrastructure can carry at least $25 \%$ more BTUs per gallon of water delivered. With a 4 pipe system, either a typical heating coil can be installed, or, if the hot water and chilled water systems have compatible chemical treatment systems, the CRC or cooling coils can be used as heating coils with a switchover valve system, similar to the Belimo six-way valves. When it is time for boiler upgrade or augmentation, condensing type boilers that can deliver efficiencies in the high $90 \%$ range can be used, since it would be possible to serve the heating loads with 100 to $120^{\circ} \mathrm{F}$ hot water supply temperatures vs. needing 180 to $200^{\circ} \mathrm{F}$ required by typical designs. 


\section{Q24: Does HEDS need a pre-heat coil for my application?}

A: In many cold weather environments, preheat coils are used to help keep the cooling coils from freezing. If your application would typically have a preheat coil, it will still need a preheat coil with HEDS.

Q25: Desiccant wheels and rotary $H X$ wheels require that the exhaust streams be filtered to reduce clogging of the wheels. Does HEDS have this requirement?

A: HEDS does not require any use of the exhaust air streams, so there is no worry about cross-contamination of the exhaust and supply airstreams.

Q26: Many desiccant wheels need a 200 to $300{ }^{\circ} \mathrm{F}$ heat source to regenerate the wheel. Does HEDS have any need like this?

A: HEDS does not have any form of a rotating wheel, and there are no desiccant components in the system at all, there is no need for a high temperature regeneration source, as no regeneration is required.

Q27: How does the air pressure drop through a desiccant-based system compare to a HEDS system?

A: Many desiccant-based systems have a 3 to 4-in. pressure drop when the exhaust and supply airstreams are included. Typical HEDS coil air pressure drops are less than 0.5-in. WC.

Q28: How does the air pressure drop through a run-around coil-based system compare to a HEDS system?

A: Total run-around coil AHU pressure drop will typically be in the 1.0 to $1.2-$ in. range. Typical HEDS coil air pressure drops are less than 0.5-in. WC.

Q29: How does the accuracy of the supply air temperature control compare between the various options?

A: The only option that does not offer fairly precise supply air temperature control are the run-around coil options. The chilled water-based run-around coil system and the single stage refrigerant-based run-around coil systems basically deliver whatever you get, there is no control. The refrigerantbased run-around coil system equipped with added rows of coils and multistage controls is better, but still not precise.

Q30: Is a separate heating coil also needed downstream of this arrangement?

A: In a two-pipe system, the cooling coil or CRC can be used as the heating coil, so a downstream heating coil is not required for heating. The Tinker 
HEDS unit is using the existing reheat coil as needed, and the Fort Bragg HEDS unit does not have a reheat coil (it mimics the installed unit).

In a four-pipe system, if the CRC or cooling coils are not used in a switchover design to act as heating coils in the winter, there will be the need for either an upstream or downstream heating coil to provide heat to the facility. The data will be evaluated to determine if a downstream heating coil is needed when it is cool and muggy outside and the internal cooling loads are low, but still exist.

Q31: Since the return temperature for the chilled water is increasing above a standard $10-^{\circ} \mathrm{F}$ Delta $\mathrm{T}$, does this mean that the chiller also needs to be evaluated to see if it can handle this large spread of water temperatures without causing issues?

A: Typically, not. Chiller plants work much better with a high CHW system TD than they work with a low CHW system TD, which is why there is a "Low Delta T Syndrome" and not a "High Delta T Syndrome." If you get into the details of the factory acceptable CHW flow rate range, you will find that most chillers are able to work with a much wider flow rate (and thus temperature differential) range than most people think.

Many chillers are designed with an evaporator tube velocity of 5 to 6 feet per second (FPS). Most chiller manufacturers have an allowable evaporator tube water velocity range of between 3 to 12 FPS. If a chiller was designed for a $15^{\circ} \mathrm{F}$ temperature differential at full load at 5 FPS water velocity in the evaporator tubes, it can usually handle a 3 FPS velocity at full load as well. This 3 FPS water velocity would yield an allowable $25^{\circ} \mathrm{F}$ TD at full load, without even using any bypass flow from the CHWS side to the CHWR side. Field testing and factory performance runs have shown that it is possible to operate a $15^{\circ} \mathrm{F}$ TD two pass chiller at 24 to $29^{\circ} \mathrm{F}$ TD, without using any bypass water at all. Many chillers designed for a 10 to $11^{\circ} \mathrm{F}$ CHW TD can operate within factory-acceptable flow rate ranges that provide CHW TDs of 20 to $25^{\circ} \mathrm{F}$, again, without using any bypass water at all. If you allow the bypass system to do its job, the chillers can handle almost any CHW system TD that is possible to achieve.

Thirty to $36^{\circ} \mathrm{F} \mathrm{CHW} \mathrm{system} \mathrm{TDs} \mathrm{have} \mathrm{been} \mathrm{used} \mathrm{since} \mathrm{the} \mathrm{mid-1980s} \mathrm{in}$ new and retrofit projects using chillers designed for 10 to $15^{\circ} \mathrm{F}$ TDs with the two basic mechanical designs out there - primary/secondary, (Pri/Sec) and primary-only variable flow (POVF), sometimes called "Variable Primary Flow" (VPF). Both designs automatically accommodate higher than "normal" chilled water distribution system temperature splits by recirculating some of the cold supply water back into the chiller return line when site TDs greatly exceed chiller design TD. This lowers the effective TD that the chillers see. With a Pri/Sec system, as the secondary CHW loop flow drops off due to the higher system TD, the primary loop flow remains the same, 
which recirculates more chilled water from the supply into the return line, creating the desired TD through the chiller. As an example, if there was a 500 -ton load that was operating at a $20^{\circ} \mathrm{F} \mathrm{TD}$, (use $45^{\circ} \mathrm{F} / 65^{\circ} \mathrm{F}$ as example) and the chiller was originally designed for a $10^{\circ} \mathrm{F} \mathrm{TD}$, the secondary CHW flow would be 600 GPM. The design primary $\mathrm{CHW}$ flow would be 1,200 GPM - consisting of $600 \mathrm{GPM}$ of recirculated $45^{\circ} \mathrm{F}$ supply water, and $600 \mathrm{GPM}$ of $65^{\circ} \mathrm{F}$ return water for a blended temperature of $55^{\circ} \mathrm{F}$ at 1200 GPM into the chiller.

Similarly, a POVF/VPF system will reduce flow through the chiller as the site TD increases and the site flow is reduced. At some point in time, the minimum CHW flow limit through the chiller evaporator is reached, and the minimum CHW evaporator flow bypass valve will start to open, sending some of the cold supply water back to blend with the CHWR and the return water temperature entering the chiller will be reduced.

To dramatically improve chiller plant efficiency, chiller plants with high potential TDs can be slightly modified to allow a "series or parallel" piping arrangement with the addition of a few valves and some control logic. These valves allow the chillers to run in parallel when the TDs are normal, and in series when the TDs get to about 15 to $18^{\circ} \mathrm{F}$. This allows the upstream chiller to operate at an increased efficiency of at least $20 \%$ due to lower lift required on the upstream chiller. An example of these design strategies is a low temperature CHW TES-based system designed for a Pacific Gas and Electric facility, the SRVCC. The peak day CHW loop TD ever recorded was $45^{\circ} \mathrm{F}$, consisting of $32^{\circ} \mathrm{F}$ CHWS temperature and $77^{\circ} \mathrm{F}$ CHWR temperature. The chillers were designed for a $15^{\circ} \mathrm{F}$ split each; using POVF and the series-parallel design, chilled water was created at $32^{\circ} \mathrm{F}$ at less than $0.60 \mathrm{~kW} /$ ton for the entire chiller plant electrical consumption, including chillers, CHW pumps, Condenser Water (CDW) pumps TES pumps and CT fans.

Typical, existing, old chillers can usually operate with CHW flow rates of less than $50 \%$ of design flow if the flows are varied at less than $10 \%$ every couple of-minutes. Cutting the flow in half results in a TD of double the design TD.

\section{Q32: In many cases, condensed water is carried off the cooling coils into the downstream ductwork and re-evaporated into the airstream. The wa- ter can saturate the insulation systems and become mold infested. Can HEDS stop this from happening?}

A: Yes. The HEDS design typically uses cooling coil airstream face velocities that are 50\% lower than typical cooling coil face velocities. HEDS also uses cooling coil heights that can be 50\% shorter than typical designs, to prevent the buildup of condensed water in the cooling coil finned surface. These two attributes make it nearly impossible to carry water off the HEDS cooling coil. If there were ever a situation that water was carried off the cooling 
coil, it would hit the cooling recovery coil, and either be drained from the unit or re-evaporated into the airstream.

Q33: It seems like the CHW temperature differential of most dehumidification systems is very low. That precludes the use of piping the chillers to operate in series. Can HEDS use series chiller operation to increase the capacity and efficiency of the upstream chiller by 20 to $25 \%$ ?

A: The larger CHW system TD provided by a HEDS design can allow a piping strategy known as "Series/ Parallel" piping to be implemented. With this simple piping/controls strategy, when more than one chiller is operational and CHW system TDs are above a certain threshold, perhaps $18^{\circ} \mathrm{F}$, the chillers will switch to series piping. When the CHW system TD drops to perhaps $14^{\circ} \mathrm{F}$, they would revert back to parallel operation.

When chillers are operated in series, the upstream chiller has to do less work, due to the need for that chiller to provide chilled water at a warmer temperature than the downstream chiller, so the refrigerant lift is reduced for that chiller. In many cases the efficiency and capacity of the upstream chiller are both improved by $20 \%$ or more. The higher CHW system TD provided by HEDS can provide the conditions required for the series chiller configuration, and the associated energy savings and capacity enhancement.

Q34: What size ranges can HEDS provide that other dehumidification technologies are not cost effective at?

A: None of the other "efficient" options are able to be cost effectively scaled down to FCU sizes. This precludes their use in a multiplicity of facility types. Desiccant Systems are expensive, and they have an upper limit that is significantly smaller than the upper limit of a HEDS design.

Q35: Many desiccant-based systems have supply air temperatures in excess of 90 to $100{ }^{\circ} \mathrm{F}+$ and need post-unit cooling coils and chiller capacity. Does HEDS have this trait?

A: HEDS does not need added cooling coils after the CRC.

Q36: Some desiccant-based systems need mixed air preheat coils to lower the RH of the air entering the wheel, does HEDS have this trait?

A: One thing that could not be tested adequately was the ability to provide dehumidified and reheated air under cool, 100\% RH outside air conditions, i.e., $56^{\circ} \mathrm{F}$ and foggy or raining. It is believed that this design adequately addresses this situation although it has not been field tested. 
Q37: A typical subcool/reheat AHU design running a 100-ton load at the cooling coil, delivering a $54^{\circ} \mathrm{F}$ dewpoint at an $8^{\circ} \mathrm{F}$ CHW temperature differential requires 300 GPM. How much flow is required from a HEDS unit with the same 100-ton load?

A: The HEDS unit will require approximately 150 GPM (or less) vs 300 GPM, and the load delivered to the chiller plant will typically be between 60 and 80 tons, depending on the supply air temperature that is needed to serve the end use loads.

\section{Q38: Can HEDS produce water?}

A: Yes, especially at deep dehumidification conditions. There can be significant amounts of condensate leaving the HEDS unit, depending on ambient conditions and the desired supply air temperature dewpoint temperature.

Q39: The standard method of performing dehumidification/reheat for RH control (Sub-cooling the air, then adding new heat for reheat energy), is essentially banned for the prescriptive method of complying with ASHRAE 90.1-2013 and -2016. Does HEDS comply with that energy code?

A: Based on current knowledge of the code requirements, it is believed to be compliant with ASHRAE 90.1.

Q40: What is the lowest dewpoint temperature that HEDS can achieve?

A: A low dewpoint version of the HEDS system can provide $35^{\circ} \mathrm{F}$ supply air dewpoint temperatures. Dewpoint temperatures lower than this will require a glycol system and potentially defrost cycles if the entering cooling fluid is less than $32^{\circ} \mathrm{F}$.

Custom HEDS units can deliver dew point temperatures as low as $24^{\circ} \mathrm{F}$. Defrost cycles will be required for these applications. If those conditions are desired, the desiccant wheel system would probably be a better option, assuming that there are maintenance staff and maintenance budget for that system type.

End of FAQs 


\section{Appendix C: HEDS Data Points List}

\section{C.1 Fort Bragg Point List}

HEDS, AHU_FTBragg, 100\% Ventilation, 100\% Ventilation

HEDS, AHU_FTBragg, 100\% Ventilation Time (Minutes), 100\% Ventilation Time (Minutes) HEDS, AHU_FTBragg, ABS Command AHU Start/Stop, ABS Command AHU Start/Stop HEDS, AHU_FTBragg, ABS Command AHU Start/Stop ( Ft Bragg), ABS Command AHU Start/Stop ( Ft Bragg) HEDS, AHU_FTBragg, Calibrate Supply Fan Airflow Offset, Calibrate Supply Fan Airflow Offset (Units: CFM) HEDS, AHU_FTBragg, CC BTU/Hr by GPM, CC BTU/Hr by GPM (Units: Btu/hr) HEDS, AHU_FTBragg, CC BTU/Hr by GPM from BEV, CC BTU/Hr by GPM from BEV (Units: Btu/hr) HEDS, AHU_FTBragg, CC BTUH BEV Temp/Flow vs Enthalpy_CFM, CC BTUH BEV Temp/Flow vs Enthalpy_CFM (Units: Btu/hr) HEDS, AHU_FTBragg, CC BTUH Temp/Flow vs BEV Temp/Flow, CC BTUH Temp/Flow vs BEV Temp/Flow (Units: Btu/hr) HEDS, AHU_FTBragg, CC BTUH Temp/Flow vs Enthalpy_CFM, CC BTUH Temp/Flow vs Enthalpy_CFM (Units: Btu/hr) HEDS, AHU_FTBragg, CC CHW Differential Pressure, CC CHW Differential Pressure (Units: Pounds per Square Inch [PSI]) HEDS, AHU_FTBragg, CC CHW Valve Control, CC CHW Valve Control (Units: \%) HEDS, AHU_FTBragg, CC CHWR Temp from BEV, CC CHWR Temp from BEV (Units: ${ }^{\circ} \mathrm{F}$ ) HEDS, AHU_FTBragg, CC CHWS Temp from BEV, CC CHWS Temp from BEV (Units: ${ }^{\circ} \mathrm{F}$ ) HEDS, AHU_FTBragg, CC Delta Temp vs CC Delta Temp from BEV, CC Delta Temp vs CC Delta Temp from BEV (Units: $\left.{ }^{\circ} \mathrm{F}\right)$ HEDS, AHU_FTBragg, CC Delta Water Temp from BEV, CC Delta Water Temp from BEV (Units: $\left.{ }^{\circ} \mathrm{F}\right)$ HEDS, AHU_FTBragg, CC Dewpoint Temperature (AV), CC Dewpoint Temperature (AV) (Units: ${ }^{\circ} \mathrm{F}$ ) HEDS, AHU_FTBragg, CC Differential DryBulb Temp across Coil, CC Differential DryBulb Temp across Coil (Units: ${ }^{\circ} \mathrm{F}$ ) HEDS, AHU_FTBragg, CC Differential Water Temp across Coil, CC Differential Water Temp across Coil (Units: ${ }^{\circ} \mathrm{F}$ ) HEDS, AHU_FTBragg, CC Differential Water Temp across Coil from BEV, CC Differential Water Temp across Coil from BEV (Units: $\left.{ }^{\circ} \mathrm{F}\right)$ HEDS, AHU_FTBragg, CC Drybulb Temp Setpoint, CC Drybulb Temp Setpoint (Units: ${ }^{\circ} \mathrm{F}$ ) HEDS, AHU_FTBragg, CC Drybulb Temperature, CC Drybulb Temperature (Units: ${ }^{\circ} \mathrm{F}$ ) HEDS, AHU_FTBragg, CC Enthalpy, CC Enthalpy (Units: BTU/lb.) HEDS, AHU_FTBragg, CC GPM, CC GPM (Units: GPM) HEDS, AHU_FTBragg, CC Grains/lb., CC Grains/lb. HEDS, AHU_FTBragg, CC Humidity, CC Humidity (Units: \%) HEDS, AHU_FTBragg, CC Latent BTU/Hr, CC Latent BTU/Hr (Units: Btu) HEDS, AHU_FTBragg, CC Sensible \& Latent BTU/Hr, CC Sensible \& Latent BTU/Hr (Units: Btu) HEDS, AHU_FTBragg, CC Sensible \& Latent Tonnage, CC Sensible \& Latent Tonnage (Units: Tons Refrigeration) HEDS, AHU_FTBragg, CC Sensible BTU/Hr, CC Sensible BTU/Hr (Units: Btu) HEDS, AHU_FTragg, CC Tonnage by GPM, CC Tonnage by GPM (Units: Tons Refrigeration) HEDS, AHU_FTBragg, CC Tonnage by GPM from BEV, CC Tonnage by GPM from BEV (Units: Tons Refrigeration) HEDS, AHU_FTBragg, CC Water Flow from BEV, CC Water Flow from BEV (Units: GPM) HEDS, AHU_FTBragg, CC WPD, CC WPD (Units: in W.C.) HEDS, AHU_FTBragg, CC-CHWR Temperature, CC-CHWR Temperature (Units: ${ }^{\circ} \mathrm{F}$ ) HEDS, AHU_FTBragg, CC-CHWS Temperature, CC-CHWS Temperature (Units: ${ }^{\circ} \mathrm{F}$ ) HEDS, AHU_FTBragg, Chiller Plant Enable/Disable Status, Chiller Plant Enable/Disable Status HEDS, AHU_FTBragg, CHWS - Common CHWR Differential Water Temp, CHWS - Common CHWR Differential Water Temp (Units: $\left.{ }^{\circ} \mathrm{F}\right)$ HEDS, AHU_FTBragg, CHWS Greater Than 48 degrees for 15 Min Alarm, CHWS Greater Than 48 degrees for 15 Min Alarm HEDS, AHU_FTBragg, CHWS Greater Than 50 degrees for 30 Min Alarm, CHWS Greater Than 50 degrees for 30 Min Alarm HEDS, AHU_FTBragg, Common-CHWRTemperature, Common-CHWRTemperature (Units: ${ }^{\circ} \mathrm{F}$ ) HEDS, AHU_FTBragg, CRC BTU/Hr by GPM, CRC BTU/Hr by GPM (Units: Btu/hr) HEDS, AHU_FTBragg, CRC CHW Differential Pressure, CRC CHW Differential Pressure (Units: PSI) HEDS, AHU_FTBragg, CRC CHW Valve Control, CRC CHW Valve Control (Units: \%) HEDS, AHU_FTBragg, CRC Dewpoint Temperature (AV), CRC Dewpoint Temperature (AV) (Units: $\left.{ }^{\circ} \mathrm{F}\right)$ HEDS, AHU_FTBragg, CRC Differential DryBulb Temp across Coil, CRC Differential DryBulb Temp across Coil (Units: $\left.{ }^{\circ} \mathrm{F}\right)$ HEDS, AHU_FTBragg, CRC Differential Water Temp across Coil, CRC Differential Water Temp across Coil (Units: ${ }^{\circ} \mathrm{F}$ ) HEDS, AHU_FTBragg, CRC Drybulb Temperature, CRC Drybulb Temperature (Units: ${ }^{\circ} \mathrm{F}$ ) HEDS, AHU_FTBragg, CRC Duct Static Pressure, CRC Duct Static Pressure (Units: in W.C.) HEDS, AHU_FTBragg, CRC Enthalpy, CRC Enthalpy (Units: BTU/lb.) HEDS, AHU_FTBragg, CRC GPM, CRC GPM (Units: GPM) HEDS, AHU_FTragg, CRC Grains/lb. of dry air, CRC Grains/lb. of dry air HEDS, AHU_FTBragg, CRC Humidity, CRC Humidity (Units: \%) HEDS, AHU_FTBragg, CRC Sensible BTU/Hr, CRC Sensible BTU/Hr (Units: Btu) HEDS, AHU_FTBragg, CRC Tonnage by Enthalpy, CRC Tonnage by Enthalpy (Units: Tons Refrigeration) HEDS, AHU_FTBragg, CRC Tonnage by GPM, CRC Tonnage by GPM (Units: Tons Refrigeration) HEDS, AHU_FTBragg, CRC WPD, CRC WPD (Units: in W.C.) HEDS, AHU_FTBragg, CRC-CHWR Temperature, CRC-CHWR Temperature (Units: ${ }^{\circ} \mathrm{F}$ ) HEDS, AHU_FTBragg, Dehumidify Batch Command, Dehumidify Batch Command HEDS, AHU_FTBragg, Dehumidify Continuous Command, Dehumidify Continuous Command HEDS, AHU_FTBragg, Dehumidify Occupied Command, Dehumidify Occupied Command HEDS, AHU_FTBragg, Differential BTU - CC to CRC, Differential BTU - CC to CRC (Units: Btu) HEDS, AHU_FTBragg, Differential BTU - MA to CC, Differential BTU - MA to CC (Units: Btu) HEDS, AHU_FTBragg, Differential BTU - MA to CRC, Differential BTU - MA to CRC (Units: Btu) HEDS, AHU_FTBragg, Differential BTU - MA to SF, Differential BTU - MA to SF (Units: Btu) 
HEDS, AHU_FTBragg, Differential BTU - OSA to MA, Differential BTU - OSA to MA (Units: Btu) HEDS, AHU_FTBragg, Differential Enthalpy OSA to MA, Differential Enthalpy OSA to MA (Units: BTU/lb.) HEDS, AHU_FTBragg, Differential Enthalpy OSA to Return Air (RA), Differential Enthalpy OSA to RA (Units: BTU/lb.) HEDS, AHU_FTBragg, Differential Enthalpy OSA to SF, Differential Enthalpy OSA to SF (Units: BTU/Ib.) HEDS, AHU_FTBragg, Differential Enthalpy OSA to Space, Differential Enthalpy OSA to Space (Units: BTU/lb.) HEDS, AHU_FTBragg, Differential Enthalpy PHC to CC, Differential Enthalpy PHC to CC (Units: BTU/lb.) HEDS, AHU_FTBragg, Differential Enthalpy PHC to MA, Differential Enthalpy PHC to MA (Units: BTU/lb.) HEDS, AHU_FTBragg, Differential Enthalpy PHC to SF, Differential Enthalpy PHC to SF (Units: BTU/Ib.) HEDS, AHU_FTBragg, Differential Enthalpy RA to MA, Differential Enthalpy RA to MA (Units: BTU/lb.) HEDS, AHU_FTBragg, Differential Enthalpy RA to SF, Differential Enthalpy RA to SF (Units: BTU/lb.) HEDS, AHU_FTBragg, Differential Enthalpy RA to Space, Differential Enthalpy RA to Space (Units: BTU/lb.) HEDS, AHU_FTBragg, Differential Enthalpy SF to CC, Differential Enthalpy SF to CC (Units: BTU/lb.) HEDS, AHU_FTBragg, Differential Enthalpy SF to CRC, Differential Enthalpy SF to CRC (Units: BTU/lb.) HEDS, AHU_FTBragg, Discharge Air Temperature Setpoint Active, Discharge Air Temperature Setpoint Active (Units: $\left.{ }^{\circ} \mathrm{F}\right)$ HEDS, AHU_FTBragg, DOAS Command, DOAS Command HEDS, AHU_FTBragg, DOAS Mode, DOAS Mode HEDS, AHU_FTBragg, DOAS Overnight Command, DOAS Overnight Command HEDS, AHU_FTBragg, DOAS Overnight MinOffTimer, DOAS Overnight MinOffTimer HEDS, AHU_FTBragg, DOAS Overnight Mode, DOAS Overnight Mode HEDS, AHU_FTBragg, EA Damper Control, EA Damper Control HEDS, AHU_FTBragg, Filter-DPT Filter Status, Filter-DPT Filter Status (Units: in W.C.) HEDS, AHU FTBragg, Heat Cool Mode, Heat Cool Mode HEDS, AHU_FTBragg, Heat Cool Mode Request, Heat Cool Mode Request HEDS, AHU_FTBragg, Heat Cool Mode Status, Heat Cool Mode Status HEDS, AHU_FTBragg, Kitchen Exhaust Fan Status, Kitchen Exhaust Fan Status HEDS, AHU_FTBragg, Kitchen Exhaust Outside Airflow Setpoint, Kitchen Exhaust Outside Airflow Setpoint (Units: CFM) HEDS, AHU_FTBragg, Lon occup_t, Lon occup_t HEDS, AHU_FTBragg, MA Dewpoint Temperature (AV), MA Dewpoint Temperature (AV) (Units: $\left.{ }^{\circ} \mathrm{F}\right)$ HEDS, AHU_FTBragg, MA Drybulb Temperature, MA Drybulb Temperature (Units: $\left.{ }^{\circ} \mathrm{F}\right)$ HEDS, AHU_FTBragg, MA Enthalpy, MA Enthalpy (Units: BTU/lb.) HEDS, AHU_FTBragg, MA Grains/lb., MA Grains/lb. HEDS, AHU_FTBragg, MA Humidity, MA Humidity (Units: \%) HEDS, AHU_FTBragg, MA Low Limit Temp Cutout Status, MA Low Limit Temp Cutout Status HEDS, AHU_FTBragg, Maximum Discharge Air Temperature, Maximum Discharge Air Temperature (Units: ${ }^{\circ} \mathrm{F}$ ) HEDS, AHU_FTBragg, Maximum Supply Fan CFM Setpoint, Maximum Supply Fan CFM Setpoint (Units: CFM) HEDS, AHU_FTBragg, Minimum Discharge Air Temperature, Minimum Discharge Air Temperature (Units: $\left.{ }^{\circ} \mathrm{F}\right)$ HEDS, AHU_FTBragg, Minimum Outside Air Flow Setpoint, Minimum Outside Air Flow Setpoint (Units: CFM) HEDS, AHU_FTBragg, Minimum Supply Fan CFM Setpoint, Minimum Supply Fan CFM Setpoint (Units: CFM) HEDS, AHU_FTBragg, MinOffTimer, MinOffTimer HEDS, AHU_FTBragg, Morning Warmup or Pre-Cool, Morning Warmup or Pre-Coo HEDS, AHU_FTBragg, Night Heat Cool, Night Heat Cool HEDS, AHU_FTBragg, Night Purge, Night Purge HEDS, AHU_FTBragg, Not Unoccupied, Not Unoccupied HEDS, AHU_FTBragg, Occupancy Request, Occupancy Request HEDS, AHU_FTBragg, Occupancy Status, Occupancy Status HEDS, AHU_FTBragg, Occupied Bypass Time, Occupied Bypass Time HEDS, AHU_FTBragg, Occupied Offset, Occupied Offset (Units: ${ }^{\circ} \mathrm{F}$ ) HEDS, AHU_FTBragg, Occupied Standby Offset, Occupied Standby Offset (Units: ${ }^{\circ} \mathrm{F}$ ) HEDS, AHU_FTBragg, Ok to Economize, Ok to Economize HEDS, AHU_FTBragg, OSA by Position/CFM, OSA by Position/CFM HEDS, AHU_FTBragg, OSA Damper 2 Control, OSA Damper 2 Control (Units: \%) HEDS, AHU_FTBragg, OSA Dewpoint Temperature (AV), OSA Dewpoint Temperature (AV) (Units: ${ }^{\circ} \mathrm{F}$ ) HEDS, AHU_FTBragg, OSA Drybulb Temperature, OSA Drybulb Temperature (Units: ${ }^{\circ} \mathrm{F}$ ) HEDS, AHU_FTBragg, OSA Enthalpy, OSA Enthalpy (Units: BTU/lb.) HEDS, AHU_FTBragg, OSA Grains/lb., OSA Grains/lb. HEDS, AHU_FTBragg, OSA Humidity, OSA Humidity (Units: \%) HEDS, AHU_FTBragg, OSA Latent BTU/Hr, OSA Latent BTU/Hr (Units: Btu) HEDS, AHU_FTBragg, OSA Min Damper 1 Control, OSA Min Damper 1 Control (Units: \%) HEDS, AHU_FTBragg, OSA Sensible \& Latent BTU/Hr, OSA Sensible \& Latent BTU/Hr (Units: Btu) HEDS, AHU_FTBragg, OSA Sensible \& Latent Tonnage, OSA Sensible \& Latent Tonnage (Units: Tons Refrigeration) HEDS, AHU_FTBragg, OSA Sensible BTU/Hr, OSA Sensible BTU/Hr (Units: Btu) HEDS, AHU_FTBragg, OSA Total Flow, OSA Total Flow (Units: CFM) HEDS, AHU_FTBragg, OSA-1 Min Flow Local, OSA-1 Min Flow Local (Units: CFM) HEDS, AHU_FTBragg, OSA-2 Flow Local, OSA-2 Flow Local (Units: CFM) HEDS, AHU_FTBragg, OverNight Dehumidification Mode, OverNight Dehumidification Mode HEDS, AHU_FTBragg, Overnight Ventilate CFM Setpoint, Overnight Ventilate CFM Setpoint (Units: CFM) HEDS, AHU_FTBragg, Overnight Ventilation Mode, Overnight Ventilation Mode HEDS, AHU_FTBragg, PHC BTU/Hr by GPM, PHC BTU/Hr by GPM (Units: Btu/hr) HEDS, AHU_FTBragg, PHC BTU/Hr by GPM from BEV, PHC BTU/Hr by GPM from BEV (Units: Btu/hr) HEDS, AHU_FTBragg, PHC BTUH BEV Temp/Flow vs Enthalpy_CFM, PHC BTUH BEV Temp/Flow vs Enthalpy_CFM (Units: Btu/hr) HEDS, AHU_FTBragg, PHC BTUH Temp/Flow vs BEV Temp/Flow, PHC BTUH Temp/Flow vs BEV Temp/Flow (Units: Btu/hr) HEDS, AHU_FTBragg, PHC BTUH Temp/Flow vs Enthalpy_CFM, PHC BTUH Temp/Flow vs Enthalpy_CFM (Units: Btu/hr) 
HEDS, AHU_FTBragg, PHC Delta Temp vs PHC Delta Temp from BEV, PHC Delta Temp vs PHC Delta Temp from BEV (Units: $\left.{ }^{\circ} \mathrm{F}\right)$ HEDS, AHU_FTBragg, PHC Delta Water Temp from BEV, PHC Delta Water Temp from BEV (Units: $\left.{ }^{\circ} \mathrm{F}\right)$ HEDS, AHU_FTBragg, PHC Dewpoint Temperature (AV), PHC Dewpoint Temperature (AV) (Units: $\left.{ }^{\circ} \mathrm{F}\right)$ HEDS, AHU_FTBragg, PHC Differential DryBulb Temp across Coil, PHC Differential DryBulb Temp across Coil (Units: ${ }^{\circ} \mathrm{F}$ ) HEDS, AHU_FTBragg, PHC Differential Water Temp across Coil, PHC Differential Water Temp across Coil (Units: ${ }^{\circ} \mathrm{F}$ ) HEDS, AHU_FTBragg, PHC Differential Water Temp across Coil from BEV, PHC Differential Water Temp across Coil from BEV (Units: $\left.{ }^{\circ} \mathrm{F}\right)$ HEDS, AHU_FTBragg, PHC Drybulb Temperature, PHC Drybulb Temperature (Units: ${ }^{\circ} \mathrm{F}$ ) HEDS, AHU_FTBragg, PHC Enthalpy, PHC Enthalpy (Units: BTU/lb.) HEDS, AHU_FTBragg, PHC GPM, PHC GPM (Units: GPM) HEDS, AHU_FTBragg, PHC Grains/lb., PHC Grains/lb. HEDS, AHU_FTBragg, PHC Humidity, PHC Humidity (Units: \%) HEDS, AHU_FTBragg, PHC HW Differential Pressure, PHC HW Differential Pressure (Units: PSI) HEDS, AHU_FTBragg, PHC HW Valve Control, PHC HW Valve Control (Units: \%) HEDS, AHU_FTBragg, PHC HWR Temp from BEV, PHC HWR Temp from BEV (Units: ${ }^{\circ} \mathrm{F}$ ) HEDS, AHU_FTBragg, PHC HWS Temp from BEV, PHC HWS Temp from BEV (Units: ${ }^{\circ} \mathrm{F}$ ) HEDS, AHU_FTBragg, PHC Sensible BTU/Hr, PHC Sensible BTU/Hr (Units: Btu) HEDS, AHU_FTBragg, PHC Tonnage by Enthalpy, PHC Tonnage by Enthalpy (Units: Tons Refrigeration) HEDS, AHU_FTBragg, PHC Tonnage by GPM, PHC Tonnage by GPM (Units: Tons Refrigeration) HEDS, AHU_FTBragg, PHC Tonnage by GPM from BEV, PHC Tonnage by GPM from BEV (Units: Tons Refrigeration) HEDS, AHU_FTBragg, PHC Water Flow from BEV, PHC Water Flow from BEV (Units: GPM) HEDS, AHU_FTBragg, PHC WPD, PHC WPD (Units: in W.C.) HEDS, AHU_FTBragg, PHC-HWR Temperature, PHC-HWR Temperature (Units: ${ }^{\circ} \mathrm{F}$ ) HEDS, AHU_FTBragg, PHC-HWS Temperature, PHC-HWS Temperature (Units: ${ }^{\circ} \mathrm{F}$ ) HEDS, AHU_FTBragg, RA Damper Control, RA Damper Control (Units: \%) HEDS, AHU_FTBragg, RA Dewpoint Temperature (AV), RA Dewpoint Temperature (AV) (Units: $\left.{ }^{\circ} \mathrm{F}\right)$ HEDS, AHU_FTBragg, RA Drybulb Temperature, RA Drybulb Temperature (Units: ${ }^{\circ} \mathrm{F}$ ) HEDS, AHU_FTBragg, RA Enthalpy, RA Enthalpy (Units: BTU/lb.) HEDS, AHU_FTBragg, RA Flow, RA Flow (Units: CFM) HEDS, AHU_FTBragg, RA Grains/lb., RA Grains/lb. HEDS, AHU_FTBragg, RA Humidity, RA Humidity (Units: \%) HEDS, AHU_FTBragg, RA Lo Press Cutout SW Status, RA Lo Press Cutout SW Status HEDS, AHU_FTBragg, Supply Air (SA) Enthalpy, SA Enthalpy (Units: BTU/lb.) HEDS, AHU_FTBragg, SA Grains/lb., SA Grains/lb. HEDS, AHU_FTBragg, SF Airflow, SF Airflow (Units: CFM) HEDS, AHU_FTBragg, SF Dewpoint Temperature (AV), SF Dewpoint Temperature (AV) (Units: ${ }^{\circ} \mathrm{F}$ ) HEDS, AHU_FTBragg, SF Differential DryBulb Temp across Fans, SF Differential DryBulb Temp across Fans (Units: ${ }^{\circ} \mathrm{F}$ ) HEDS, AHU_FTBragg, SF Disch Drybulb Temperature, SF Disch Drybulb Temperature (Units: ${ }^{\circ} \mathrm{F}$ ) HEDS, AHU_FTBragg, SF Disch Humidity, SF Disch Humidity (Units: \%) HEDS, AHU_FTBragg, SF Enthalpy, SF Enthalpy (Units: BTU/lb.) HEDS, AHU_FTBragg, SF Grains/lb., SF Grains/lb. HEDS, AHU_FTBragg, SF Heat Gain BTUH Rise Calculated, SF Heat Gain BTUH Rise Calculated (Units: ${ }^{\circ} \mathrm{F}$ ) HEDS, AHU_FTBragg, SF Heat Gain Temp Rise Calculated, SF Heat Gain Temp Rise Calculated (Units: ${ }^{\circ} \mathrm{F}$ ) HEDS, AHU_FTBragg, SF Inlet Velocity feet/minute (FPM), SF Inlet Velocity FPM HEDS, AHU_FTBragg, SF Sensible BTU/Hr, SF Sensible BTU/Hr (Units: Btu) HEDS, AHU_FTBragg, SF-KW from VFD, SF-KW from VFD (Units: kW) HEDS, AHU_FTBragg, Space Dewpoint Setpoint Active, Space Dewpoint Setpoint Active (Units: ${ }^{\circ} \mathrm{F}$ ) HEDS, AHU_FTBragg, Space Dewpoint Setpoint Occupied, Space Dewpoint Setpoint Occupied (Units: $\left.{ }^{\circ} \mathrm{F}\right)$ HEDS, AHU_FTBragg, Space Dewpoint Setpoint Unoccupied, Space Dewpoint Setpoint Unoccupied (Units: ${ }^{\circ} \mathrm{F}$ ) HEDS, AHU_FTBragg, Space Dewpoint Temperature (AV), Space Dewpoint Temperature (AV) (Units: ${ }^{\circ} \mathrm{F}$ ) HEDS, AHU_FTBragg, Space Drybulb Temperature, Space Drybulb Temperature (Units: ${ }^{\circ} \mathrm{F}$ ) HEDS, AHU_FTBragg, Space Enthalpy, Space Enthalpy (Units: BTU/lb.) HEDS, AHU_FTBragg, Space Grains/lb. of dry air, Space Grains/lb. of dry air HEDS, AHU_FTBragg, Space Humidity, Space Humidity (Units: \%) HEDS, AHU_FTBragg, Space Temperature Active, Space Temperature Active (Units: ${ }^{\circ} \mathrm{F}$ ) HEDS, AHU_FTBragg, Space Temperature Setpoint Active, Space Temperature Setpoint Active (Units: $\left.{ }^{\circ} \mathrm{F}\right)$ HEDS, AHU_FTBragg, Space Temperature Setpoint BAS, Space Temperature Setpoint BAS (Units: ${ }^{\circ} \mathrm{F}$ ) HEDS, AHU_FBragg, Space Temperature Setpoint Local, Space Temperature Setpoint Local (Units: ${ }^{\circ} \mathrm{F}$ ) HEDS, AHU_FTBragg, Supply Fan Control Start Stop, Supply Fan Control Start Stop HEDS, AHU_FTBragg, Supply Fan Failure, Supply Fan Failure HEDS, AHU_FTBragg, Supply Fan Speed Control, Supply Fan Speed Control (Units: \%) HEDS, AHU_FTBragg, Supply Fan Status, Supply Fan Status HEDS, AHU_FTBragg, Supply Fan Status to ABS, Supply Fan Status to ABS HEDS, AHU_FBragg, Timed Override Status, Timed Override Status HEDS, AHU_FTBragg, Unoccupied Cooling Setpoint, Unoccupied Cooling Setpoint (Units: ${ }^{\circ} \mathrm{F}$ ) HEDS, AHU_FTBragg, Unoccupied Heating Setpoint, Unoccupied Heating Setpoint (Units: ${ }^{\circ} \mathrm{F}$ ) HEDS, CC Energy Valve, ControlMode, ControlMode HEDS, CC Energy Valve, DeltaT_US, DeltaT_US (Units: $\left.{ }^{\circ} \mathrm{F}\right)$ HEDS, CC Energy Valve, E_Cooling_US1, E_Cooling_US1 HEDS, CC Energy Valve, E_Cooling_US2, E_Cooling_US2 (Units: ton hr) HEDS, CC Energy Valve, RelFlow, RelFlow (Units: \%) HEDS, CC Energy Valve, RelPos, RelPos (Units: \%) HEDS, CC Energy Valve, RelPower, ReIPower (Units: \%) 
HEDS, CC Energy Valve, SpPosReached, SpPosReached HEDS, CC Energy Valve, T1_US, T1_US (Units: ${ }^{\circ} \mathrm{F}$ ) HEDS, CC Energy Valve, T2_US, T2_US (Units: ${ }^{\circ} \mathrm{F}$ ) HEDS, CC Energy Valve, Vmax_US, Vmax_US (Units: GPM) HEDS, CC Energy Valve, Vnom_US, Vnom_US (Units: GPM) HEDS, Data_FTBragg, Differential Dewpoint CC to CRC, Differential Dewpoint CC to CRC (Units: ${ }^{\circ} \mathrm{F}$ ) HEDS, Data_FTBragg, Differential Dewpoint MA to CC, Differential Dewpoint MA to CC (Units: ${ }^{\circ} \mathrm{F}$ ) HEDS, Data_FTBragg, Differential Dewpoint MA to SF, Differential Dewpoint MA to SF (Units: ${ }^{\circ} \mathrm{F}$ ) HEDS, Data_FTBragg, Differential Dewpoint OSA to MA, Differential Dewpoint OSA to MA (Units: ${ }^{\circ} \mathrm{F}$ ) HEDS, Data_FTBragg, Differential Dewpoint OSA to RA, Differential Dewpoint OSA to RA (Units: ${ }^{\circ} \mathrm{F}$ ) HEDS, Data_FTBragg, Differential Dewpoint OSA to SF, Differential Dewpoint OSA to SF (Units: ${ }^{\circ} \mathrm{F}$ ) HEDS, Data_FTBragg, Differential Dewpoint OSA to Space, Differential Dewpoint OSA to Space (Units: ${ }^{\circ} \mathrm{F}$ ) HEDS, Data_FTBragg, Differential Dewpoint PHC to CC, Differential Dewpoint PHC to CC (Units: ${ }^{\circ} \mathrm{F}$ ) HEDS, Data_FTBragg, Differential Dewpoint PHC to MA, Differential Dewpoint PHC to MA (Units: ${ }^{\circ} \mathrm{F}$ ) HEDS, Data_FTBragg, Differential Dewpoint PHC to SF, Differential Dewpoint PHC to SF (Units: ${ }^{\circ} \mathrm{F}$ ) HEDS, Data_FTBragg, Differential Dewpoint RA to MA, Differential Dewpoint RA to MA (Units: ${ }^{\circ} \mathrm{F}$ ) HEDS, Data_FTBragg, Differential Dewpoint RA to SF, Differential Dewpoint RA to SF (Units: ${ }^{\circ} \mathrm{F}$ ) HEDS, Data_FTBragg, Differential Dewpoint RA to Space, Differential Dewpoint RA to Space (Units: ${ }^{\circ} \mathrm{F}$ ) HEDS, Data_FTBragg, Differential Dewpoint SF to CC, Differential Dewpoint SF to CC (Units: ${ }^{\circ} \mathrm{F}$ ) HEDS, Data_FTBragg, Differential Drybulb CC to CRC, Differential Drybulb CC to CRC (Units: ${ }^{\circ} \mathrm{F}$ ) HEDS, Data_FTBragg, Differential Drybulb MA to CC, Differential Drybulb MA to CC (Units: ${ }^{\circ} \mathrm{F}$ ) HEDS, Data_FTBragg, Differential Drybulb MA to SF, Differential Drybulb MA to SF (Units: ${ }^{\circ} \mathrm{F}$ ) HEDS, Data_FTBragg, Differential Drybulb OSA to MA, Differential Drybulb OSA to MA (Units: ${ }^{\circ} \mathrm{F}$ ) HEDS, Data_FTBragg, Differential Drybulb OSA to RA, Differential Drybulb OSA to RA (Units: ${ }^{\circ} \mathrm{F}$ ) HEDS, Data_FTBragg, Differential Drybulb OSA to SF, Differential Drybulb OSA to SF (Units: ${ }^{\circ} \mathrm{F}$ ) HEDS, Data_FTBragg, Differential Drybulb OSA to Space, Differential Drybulb OSA to Space (Units: ${ }^{\circ} \mathrm{F}$ ) HEDS, Data_FTBragg, Differential Drybulb PHC to CC, Differential Drybulb PHC to CC (Units: ${ }^{\circ} \mathrm{F}$ ) HEDS, Data_FTBragg, Differential Drybulb PHC to MA, Differential Drybulb PHC to MA (Units: ${ }^{\circ} \mathrm{F}$ ) HEDS, Data_FTBragg, Differential Drybulb PHC to SF, Differential Drybulb PHC to SF (Units: ${ }^{\circ} \mathrm{F}$ ) HEDS, Data_FTBragg, Differential Drybulb RA to MA, Differential Drybulb RA to MA (Units: ${ }^{\circ} \mathrm{F}$ ) HEDS, Data_FTBragg, Differential Drybulb RA to SF, Differential Drybulb RA to SF (Units: ${ }^{\circ} \mathrm{F}$ ) HEDS, Data_FTBragg, Differential Drybulb RA to Space, Differential Drybulb RA to Space (Units: ${ }^{\circ} \mathrm{F}$ ) HEDS, Data_FTBragg, Differential Drybulb SF to CC, Differential Drybulb SF to CC (Units: ${ }^{\circ} \mathrm{F}$ ) HEDS, Data_FTBragg, Differential Humidity CC to CRC, Differential Humidity CC to CRC (Units: \%) HEDS, Data_FTBragg, Differential Humidity MA to CC, Differential Humidity MA to CC (Units: \%) HEDS, Data_FTBragg, Differential Humidity MA to SF, Differential Humidity MA to SF (Units: \%) HEDS, Data_FTBragg, Differential Humidity OSA to MA, Differential Humidity OSA to MA (Units: \%) HEDS, Data_FTBragg, Differential Humidity OSA to RA, Differential Humidity OSA to RA (Units: \%) HEDS, Data_FTBragg, Differential Humidity OSA to SF, Differential Humidity OSA to SF (Units: \%) HEDS, Data_FTBragg, Differential Humidity OSA to Space, Differential Humidity OSA to Space (Units: \%) HEDS, Data_FTBragg, Differential Humidity PHC to CC, Differential Humidity PHC to CC (Units: \%) HEDS, Data_FTBragg, Differential Humidity PHC to MA, Differential Humidity PHC to MA (Units: \%) HEDS, Data_FTBragg, Differential Humidity PHC to SF, Differential Humidity PHC to SF (Units: \%) HEDS, Data_FTBragg, Differential Humidity RA to MA, Differential Humidity RA to MA (Units: \%) HEDS, Data_FTBragg, Differential Humidity RA to SF, Differential Humidity RA to SF (Units: \%) HEDS, Data_FTBragg, Differential Humidity RA to Space, Differential Humidity RA to Space (Units: \%) HEDS, Data_FTBragg, Differential Humidity SF to CC, Differential Humidity SF to CC (Units: \%) HEDS, Data_FTBragg, Mister Dewpoint Setpoint, Mister Dewpoint Setpoint (Units: ${ }^{\circ} \mathrm{F}$ ) HEDS, Data_FTBragg, Mister Stage 1, Mister Stage 1 HEDS, Data_FTBragg, Mister Stage 2, Mister Stage 2 HEDS, Data_FTBragg, Mister Stage 3, Mister Stage 3 HEDS, Data_FTBragg, Mister Stage 4, Mister Stage 4 HEDS, Data_FTBragg, ReturnDP LT 56 and Occ, ReturnDP LT 56 and Occ HEDS, Data_FTBragg, ReturnDP LT 57 and Occ, ReturnDP LT 57 and Occ HEDS, Data_FTBragg, ReturnDP LT 58 and Occ, ReturnDP LT 58 and Occ HEDS, Data_FTBragg, ReturnDP LT 59 and Occ, ReturnDP LT 59 and Occ HEDS, Data_FTBragg, ReturnDP LT 60 and Occ, ReturnDP LT 60 and Occ HEDS, Data_FTBragg, ReturnT GT 68 and Occ and Heat, ReturnT GT 68 and Occ and Heat HEDS, Data_FTBragg, ReturnT GT 68 and SpaceDP LT 55 and Occ and Cool, ReturnT GT 68 and SpaceDP LT 55 and Occ and Cool HEDS, Data_FTBragg, ReturnT GT 68 and SpaceT LT 78, ReturnT GT 68 and SpaceT LT 78 HEDS, Data_FTBragg, ReturnT GT 69 and Occ and Heat, ReturnT GT 69 and Occ and Heat HEDS, Data_FTBragg, ReturnT GT 70 and Occ and Heat, ReturnT GT 70 and Occ and Heat HEDS, Data_FTBragg, ReturnT GT 71 and Occ and Heat, ReturnT GT 71 and Occ and Heat HEDS, Data_FTBragg, ReturnT GT 72 and Occ and Heat, ReturnT GT 72 and Occ and Heat HEDS, Data_FTBragg, ReturnT GT 73 and Occ and Heat, ReturnT GT 73 and Occ and Heat HEDS, Data_FTBragg, ReturnT GT 74 and Occ and Heat, ReturnT GT 74 and Occ and Heat HEDS, Data_FTBragg, ReturnT LT 72 and SpaceDP LT 55 and Occ and Cool, ReturnT LT 72 and SpaceDP LT 55 and Occ and Cool HEDS, Data_FTBragg, ReturnT LT 73 and SpaceDP LT 55 and Occ and Cool, ReturnT LT 73 and SpaceDP LT 55 and Occ and Cool HEDS, Data_FTBragg, ReturnT LT 74 and SpaceDP LT 55 and Occ and Cool, ReturnT LT 74 and SpaceDP LT 55 and Occ and Cool HEDS, Data_FTBragg, ReturnT LT 75 and SpaceDP LT 55 and Occ and Cool, ReturnT LT 75 and SpaceDP LT 55 and Occ and Cool HEDS, Data_FTBragg, ReturnT LT 76 and SpaceDP LT 55 and Occ and Cool, ReturnT LT 76 and SpaceDP LT 55 and Occ and Cool HEDS, Data_FTBragg, ReturnT LT 77 and SpaceDP LT 55 and Occ and Cool, ReturnT LT 77 and SpaceDP LT 55 and Occ and Cool 
HEDS, Data_FTBragg, ReturnT LT 78 and Occ and Cool, ReturnT LT 78 and Occ and Cool HEDS, Data_FTBragg, ReturnT LT 78 and SpaceDP LT 55 and Occ and Cool, ReturnT LT 78 and SpaceDP LT 55 and Occ and Cool HEDS, Data_FTBragg, SpaceDP LT 55 and Occ, SpaceDP LT 55 and Occ HEDS, Data_FTBragg, SpaceDP LT 56 and Occ, SpaceDP LT 56 and Occ HEDS, Data_FTBragg, SpaceDP LT 57 and Occ, SpaceDP LT 57 and Occ HEDS, Data_FTBragg, SpaceDP LT 58 and Occ, SpaceDP LT 58 and Occ HEDS, Data_FTBragg, SpaceDP LT 59 and Occ, SpaceDP LT 59 and Occ HEDS, Data_FTBragg, SpaceDP LT 60 and Occ, SpaceDP LT 60 and Occ HEDS, Data_FTBragg, SpaceT GT 68 and Occ and Heat, SpaceT GT 68 and Occ and Heat HEDS, Data_FTBragg, SpaceT GT 68 and SpaceDP LT 55 and Occ and Cool, SpaceT GT 68 and SpaceDP LT 55 and Occ and Cool HEDS, Data_FTBragg, SpaceT GT 68 and SpaceT LT 78, SpaceT GT 68 and SpaceT LT 78

HEDS, Data_FTBragg, SpaceT LT 72 and SpaceDP LT 55 and Occ and Cool, SpaceT LT 72 and SpaceDP LT 55 and Occ and Cool HEDS, Data_FTBragg, SpaceT LT 73 and SpaceDP LT 55 and Occ and Cool, SpaceT LT 73 and SpaceDP LT 55 and Occ and Cool HEDS, Data_FTBragg, SpaceT LT 74 and SpaceDP LT 55 and Occ and Cool, SpaceT LT 74 and SpaceDP LT 55 and Occ and Cool HEDS, Data_FTBragg, SpaceT LT 75 and SpaceDP LT 55 and Occ and Cool, SpaceT LT 75 and SpaceDP LT 55 and Occ and Cool HEDS, Data_FTBragg, SpaceT LT 76 and SpaceDP LT 55 and Occ and Cool, SpaceT LT 76 and SpaceDP LT 55 and Occ and Cool HEDS, Data_FTBragg, SpaceT LT 77 and SpaceDP LT 55 and Occ and Cool, SpaceT LT 77 and SpaceDP LT 55 and Occ and Cool HEDS, Data_FTBragg, SpaceT LT 78 and SpaceDP LT 55 and Occ and Cool, SpaceT LT 78 and SpaceDP LT 55 and Occ and Cool HEDS, Data_FTBragg, VDF Fault, VDF Fault

HEDS, Data_FTBragg, VDF Hand/Auto Reference, VDF Hand/Auto Reference HEDS, Data_FTBragg, VDF Run/Stop Monitor, VDF Run/Stop Monitor HEDS, Data_FTBragg, VFD Current, VFD Current HEDS, Data_FTBragg, VFD Frequency, VFD Frequency HEDS, Data_FTBragg, VFD Output Speed, VFD Output Speed (Units: \%) HEDS, Data_FTBragg, VFD Output Voltage, VFD Output Voltage HEDS, Data_FTBragg, VFD Power in Watts, VFD Power in Watts HEDS, Data_FTBragg, VFD Running Hours, VFD Running Hours HEDS, Data_FTBragg, VFD Speed Reference, VFD Speed Reference (Units: \%) HEDS, Data_FTBragg, Water Mister Control, Water Mister Control HEDS, Data_FTBragg, Water Mister Status, Water Mister Status HEDS, PHC Energy Valve, AbsFlow_US, AbsFlow_US (Units: GPM) HEDS, PHC Energy Valve, AbsPos, AbsPos HEDS, PHC Energy Valve, AbsPower_US1, AbsPower_US1 HEDS, PHC Energy Valve, AbsPower_US2, AbsPower_US2 HEDS, PHC Energy Valve, ControlMode, ControlMode HEDS, PHC Energy Valve, DeltaT_US, DeltaT_US (Units: ${ }^{\circ} \mathrm{F}$ ) HEDS, PHC Energy Valve, E_Cooling_US1, E_Cooling_US1 HEDS, PHC Energy Valve, E_Cooling_US2, E_Cooling_US2 (Units: ton hr) HEDS, PHC Energy Valve, E_Heating_US1, E_Heating_US1 HEDS, PHC Energy Valve, E_Heating_US2, E_Heating_US2 (Units: ton hr) HEDS, PHC Energy Valve, Override, Override HEDS, PHC Energy Valve, Pmax, Pmax (Units: \%) HEDS, PHC Energy Valve, Pmax_US, Pmax_US HEDS, PHC Energy Valve, Pnom_US, Pnom_US HEDS, PHC Energy Valve, RelFlow, RelFlow (Units: \%) HEDS, PHC Energy Valve, RelPos, RelPos (Units: \%) HEDS, PHC Energy Valve, RelPower, RelPower (Units: \%) HEDS, PHC Energy Valve, SpDeltaT_US, SpDeltaT_US (Units: ${ }^{\circ} \mathrm{F}$ ) HEDS, PHC Energy Valve, SpFlow_DeltaT_US, SpFlow_DeltaT_US (Units: GPM) HEDS, PHC Energy Valve, SpPosReached, SpPosReached HEDS, PHC Energy Valve, SpRel, SpRel (Units: \%) HEDS, PHC Energy Valve, T1_US, T1_US (Units: ${ }^{\circ} \mathrm{F}$ ) HEDS, PHC Energy Valve, T2_US, T2_US (Units: ${ }^{\circ} \mathrm{F}$ ) HEDS, PHC Energy Valve, Vmax, Vmax (Units: \%) HEDS, PHC Energy Valve, Vmax_US, Vmax_US (Units: GPM) HEDS, PHC Energy Valve, Vnom_US, Vnom_US (Units: GPM)

\section{C.2 Tinker AFB Point List}

HEDS Tinker, CC Energy Valve, AbsFlow_US, AbsFlow_US (Units: GPM) HEDS Tinker, CC Energy Valve, AbsPower_US2, AbsPower_US2 HEDS Tinker, CC Energy Valve, DeltaT_US, DeltaT_US (Units: ${ }^{\circ} \mathrm{F}$ ) HEDS Tinker, CC Energy Valve, E_Cooling_US1, E_Cooling_US1 HEDS Tinker, CC Energy Valve, E_Cooling_US2, E_Cooling_US2 (Units: ton hr) HEDS Tinker, CC Energy Valve, RelFlow, RelFlow (Units: \%) HEDS Tinker, CC Energy Valve, RelPos, RelPos (Units: \%) HEDS Tinker, CC Energy Valve, T1_US, T1_US (Units: ${ }^{\circ} \mathrm{F}$ ) HEDS Tinker, CC Energy Valve, T2_US, T2_US (Units: ${ }^{\circ} \mathrm{F}$ ) HEDS Tinker, CC Energy Valve, Vnom_US, Vnom_US (Units: GPM) HEDS Tinker, Data_Tinker, Differential Dewpoint CC to CRC, Differential Dewpoint CC to CRC (Units: ${ }^{\circ} \mathrm{F}$ ) HEDS Tinker, Data_Tinker, Differential Dewpoint CRC to RHC, Differential Dewpoint CRC to RHC (Units: $\left.{ }^{\circ} \mathrm{F}\right)$ 
HEDS Tinker, Data_Tinker, Differential Dewpoint MA to CC, Differential Dewpoint MA to CC (Units: $\left.{ }^{\circ} \mathrm{F}\right)$ HEDS Tinker, Data_Tinker, Differential Dewpoint MA to RHC, Differential Dewpoint MA to RHC (Units: ${ }^{\circ} \mathrm{F}$ ) HEDS Tinker, Data_Tinker, Differential Dewpoint MA to SF, Differential Dewpoint MA to SF (Units: $\left.{ }^{\circ} \mathrm{F}\right)$ HEDS Tinker, Data_Tinker, Differential Dewpoint OSA to MA, Differential Dewpoint OSA to MA (Units: ${ }^{\circ} \mathrm{F}$ ) HEDS Tinker, Data_Tinker, Differential Dewpoint OSA to RA, Differential Dewpoint OSA to RA (Units: ${ }^{\circ} \mathrm{F}$ ) HEDS Tinker, Data_Tinker, Differential Dewpoint OSA to SF, Differential Dewpoint OSA to SF (Units: ${ }^{\circ} \mathrm{F}$ ) HEDS Tinker, Data_Tinker, Differential Dewpoint OSA to Space, Differential Dewpoint OSA to Space (Units: ${ }^{\circ} \mathrm{F}$ ) HEDS Tinker, Data_Tinker, Differential Dewpoint PHC to CC, Differential Dewpoint PHC to CC (Units: ${ }^{\circ} \mathrm{F}$ ) HEDS Tinker, Data_Tinker, Differential Dewpoint PHC to MA, Differential Dewpoint PHC to MA (Units: $\left.{ }^{\circ} \mathrm{F}\right)$ HEDS Tinker, Data_Tinker, Differential Dewpoint PHC to SF, Differential Dewpoint PHC to SF (Units: ${ }^{\circ} \mathrm{F}$ ) HEDS Tinker, Data_Tinker, Differential Dewpoint RA to MA, Differential Dewpoint RA to MA (Units: $\left.{ }^{\circ} \mathrm{F}\right)$ HEDS Tinker, Data_Tinker, Differential Dewpoint RA to SF, Differential Dewpoint RA to SF (Units: ${ }^{\circ} \mathrm{F}$ ) HEDS Tinker, Data_Tinker, Differential Dewpoint RA to Space, Differential Dewpoint RA to Space (Units: ${ }^{\circ} \mathrm{F}$ ) HEDS Tinker, Data_Tinker, Differential Dewpoint SF to CC, Differential Dewpoint SF to CC (Units: $\left.{ }^{\circ} \mathrm{F}\right)$ HEDS Tinker, Data_Tinker, Differential Dewpoint SF to RHC, Differential Dewpoint SF to RHC (Units: $\left.{ }^{\circ} \mathrm{F}\right)$ HEDS Tinker, Data_Tinker, Differential Drybulb CC to CRC, Differential Drybulb CC to CRC (Units: ${ }^{\circ} \mathrm{F}$ ) HEDS Tinker, Data_Tinker, Differential Drybulb MA to CC, Differential Drybulb MA to CC (Units: ${ }^{\circ} \mathrm{F}$ ) HEDS Tinker, Data_Tinker, Differential Drybulb MA to RHC, Differential Drybulb MA to RHC (Units: ${ }^{\circ} \mathrm{F}$ ) HEDS Tinker, Data_Tinker, Differential Drybulb MA to SF, Differential Drybulb MA to SF (Units: ${ }^{\circ} \mathrm{F}$ ) HEDS Tinker, Data_Tinker, Differential Drybulb OSA to MA, Differential Drybulb OSA to MA (Units: $\left.{ }^{\circ} \mathrm{F}\right)$ HEDS Tinker, Data_Tinker, Differential Drybulb OSA to RA, Differential Drybulb OSA to RA (Units: ${ }^{\circ} \mathrm{F}$ ) HEDS Tinker, Data_Tinker, Differential Drybulb OSA to SF, Differential Drybulb OSA to SF (Units: ${ }^{\circ} \mathrm{F}$ ) HEDS Tinker, Data_Tinker, Differential Drybulb OSA to Space, Differential Drybulb OSA to Space (Units: $\left.{ }^{\circ} \mathrm{F}\right)$ HEDS Tinker, Data_Tinker, Differential Drybulb PHC to CC, Differential Drybulb PHC to CC (Units: ${ }^{\circ} \mathrm{F}$ ) HEDS Tinker, Data_Tinker, Differential Drybulb PHC to MA, Differential Drybulb PHC to MA (Units: ${ }^{\circ} \mathrm{F}$ ) HEDS Tinker, Data_Tinker, Differential Drybulb PHC to SF, Differential Drybulb PHC to SF (Units: ${ }^{\circ} \mathrm{F}$ ) HEDS Tinker, Data_Tinker, Differential Drybulb RA to MA, Differential Drybulb RA to MA (Units: ${ }^{\circ} \mathrm{F}$ ) HEDS Tinker, Data_Tinker, Differential Drybulb RA to SF, Differential Drybulb RA to SF (Units: ${ }^{\circ} \mathrm{F}$ ) HEDS Tinker, Data_Tinker, Differential Humidity RA to Space, Differential Humidity RA to Space (Units: \%) HEDS Tinker, Data_Tinker, Differential Humidity SF to CC, Differential Humidity SF to CC (Units: \%) HEDS Tinker, Data_Tinker, Differential Humidity SF to RHC, Differential Humidity SF to RHC (Units: \%) HEDS Tinker, Data_Tinker, ReturnDP LT 55 and Occ, ReturnDP LT 55 and Occ HEDS Tinker, Data_Tinker, ReturnDP LT 56 and Occ, ReturnDP LT 56 and Occ HEDS Tinker, Data_Tinker, ReturnDP LT 57 and Occ, ReturnDP LT 57 and Occ HEDS Tinker, Data_Tinker, ReturnDP LT 58 and Occ, ReturnDP LT 58 and Occ HEDS Tinker, Data_Tinker, ReturnDP LT 59 and Occ, ReturnDP LT 59 and Occ HEDS Tinker, Data_Tinker, ReturnDP LT 60 and Occ, ReturnDP LT 60 and Occ HEDS Tinker, Data_Tinker, ReturnT GT 68 and Occ and Heat, ReturnT GT 68 and Occ and Heat HEDS Tinker, Data_Tinker, ReturnT GT 68 and SpaceDP LT 55 and Occ and Cool, ReturnT GT 68 and SpaceDP LT 55 and Occ and Cool HEDS Tinker, Data_Tinker, ReturnT GT 68 and SpaceT LT 78, ReturnT GT 68 and SpaceT LT 78 HEDS Tinker, Data_Tinker, ReturnT GT 69 and Occ and Heat, ReturnT GT 69 and Occ and Heat HEDS Tinker, Data_Tinker, ReturnT GT 70 and Occ and Heat, ReturnT GT 70 and Occ and Heat HEDS Tinker, Data_Tinker, ReturnT GT 71 and Occ and Heat, ReturnT GT 71 and Occ and Heat HEDS Tinker, Data_Tinker, ReturnT GT 72 and Occ and Heat, ReturnT GT 72 and Occ and Heat HEDS Tinker, Data_Tinker, ReturnT GT 73 and Occ and Heat, ReturnT GT 73 and Occ and Heat HEDS Tinker, Data_Tinker, ReturnT GT 74 and Occ and Heat, ReturnT GT 74 and Occ and Heat HEDS Tinker, Data_Tinker, ReturnT LT 72 and SpaceDP LT 55 and Occ and Cool, ReturnT LT 72 and SpaceDP LT 55 and Occ and Cool HEDS Tinker, Data_Tinker, ReturnT LT 73 and SpaceDP LT 55 and Occ and Cool, ReturnT LT 73 and SpaceDP LT 55 and Occ and Cool HEDS Tinker, Data_Tinker, ReturnT LT 74 and SpaceDP LT 55 and Occ and Cool, ReturnT LT 74 and SpaceDP LT 55 and Occ and Cool HEDS Tinker, Data_Tinker, ReturnT LT 75 and SpaceDP LT 55 and Occ and Cool, ReturnT LT 75 and SpaceDP LT 55 and Occ and Cool HEDS Tinker, Data_Tinker, ReturnT LT 76 and SpaceDP LT 55 and Occ and Cool, ReturnT LT 76 and SpaceDP LT 55 and Occ and Cool HEDS Tinker, Data_Tinker, ReturnT LT 77 and SpaceDP LT 55 and Occ and Cool, ReturnT LT 77 and SpaceDP LT 55 and Occ and Cool HEDS Tinker, Data_Tinker, ReturnT LT 78 and Occ and Cool, ReturnT LT 78 and Occ and Cool HEDS Tinker, Data_Tinker, ReturnT LT 78 and SpaceDP LT 55 and Occ and Cool, ReturnT LT 78 and SpaceDP LT 55 and Occ and Cool HEDS Tinker, Data_Tinker, SpaceDP LT 55 and Occ, SpaceDP LT 55 and Occ HEDS Tinker, Data_Tinker, SpaceDP LT 56 and Occ, SpaceDP LT 56 and Occ HEDS Tinker, Data_Tinker, SpaceDP LT 57 and Occ, SpaceDP LT 57 and Occ HEDS Tinker, Data_Tinker, SpaceDP LT 58 and Occ, SpaceDP LT 58 and Occ HEDS Tinker, Data_Tinker, SpaceDP LT 59 and Occ, SpaceDP LT 59 and Occ HEDS Tinker, Data_Tinker, SpaceDP LT 60 and Occ, SpaceDP LT 60 and Occ HEDS Tinker, Data_Tinker, SpaceT GT 68 and Occ and Heat, SpaceT GT 68 and Occ and Heat HEDS Tinker, Data_Tinker, SpaceT GT 68 and SpaceDP LT 55 and Occ and Cool, SpaceT GT 68 and SpaceDP LT 55 and Occ and Cool HEDS Tinker, Data_Tinker, SpaceT GT 68 and SpaceT LT 78, SpaceT GT 68 and SpaceT LT 78 HEDS Tinker, Data_Tinker, SpaceT LT 72 and SpaceDP LT 55 and Occ and Cool, SpaceT LT 72 and SpaceDP LT 55 and Occ and Cool HEDS Tinker, Data_Tinker, SpaceT LT 73 and SpaceDP LT 55 and Occ and Cool, SpaceT LT 73 and SpaceDP LT 55 and Occ and Cool HEDS Tinker, Data_Tinker, SpaceT LT 74 and SpaceDP LT 55 and Occ and Cool, SpaceT LT 74 and SpaceDP LT 55 and Occ and Cool HEDS Tinker, Data_Tinker, SpaceT LT 75 and SpaceDP LT 55 and Occ and Cool, SpaceT LT 75 and SpaceDP LT 55 and Occ and Cool HEDS Tinker, Data_Tinker, SpaceT LT 76 and SpaceDP LT 55 and Occ and Cool, SpaceT LT 76 and SpaceDP LT 55 and Occ and Cool HEDS Tinker, Data_Tinker, SpaceT LT 77 and SpaceDP LT 55 and Occ and Cool, SpaceT LT 77 and SpaceDP LT 55 and Occ and Cool HEDS Tinker, Data_Tinker, SpaceT LT 78 and SpaceDP LT 55 and Occ and Cool, SpaceT LT 78 and SpaceDP LT 55 and Occ and Cool HEDS Tinker, Data_Tinker, VFD Current, VFD Current

HEDS Tinker, Data_Tinker, VFD Fault, VFD Fault 
HEDS Tinker, Data_Tinker, VFD Frequency, VFD Frequency HEDS Tinker, Data_Tinker, VFD Hand/Auto Reference, VFD Hand/Auto Reference HEDS Tinker, Data_Tinker, VFD Output Speed, VFD Output Speed (Units: \%) HEDS Tinker, Data_Tinker, VFD Output Voltage, VFD Output Voltage HEDS Tinker, Data_Tinker, VFD Power KW, VFD Power KW (Units: kW) HEDS Tinker, Data_Tinker, VFD Run/Stop, VFD Run/Stop HEDS Tinker, Data_Tinker, VFD Running Hours, VFD Running Hours HEDS Tinker, Data_Tinker, VFD Speed Reference, VFD Speed Reference (Units: \%) HEDS Tinker, PHC Energy Valve, AbsFlow_US, AbsFlow_US (Units: GPM) HEDS Tinker, PHC Energy Valve, AbsPos, AbsPos HEDS Tinker, PHC Energy Valve, AbsPower_US1, AbsPower_US1 HEDS Tinker, PHC Energy Valve, AbsPower_US2, AbsPower_US2 HEDS Tinker, PHC Energy Valve, DeltaT_US, DeltaT_US (Units: ${ }^{\circ} \mathrm{F}$ ) HEDS Tinker, PHC Energy Valve, E_Cooling_US1, E_Cooling_US1 HEDS Tinker, PHC Energy Valve, E_Cooling_US2, E_Cooling_US2 (Units: ton hr) HEDS Tinker, PHC Energy Valve, E_Heating_US1, E_Heating_US1 HEDS Tinker, PHC Energy Valve, E_Heating_US2, E_Heating_US2 (Units: ton hr) HEDS Tinker, PHC Energy Valve, RelFlow, RelFlow (Units: \%) HEDS Tinker, PHC Energy Valve, RelPos, RelPos (Units: \%) HEDS Tinker, PHC Energy Valve, RelPower, RelPower (Units: \%) HEDS Tinker, PHC Energy Valve, T1_US, T1_US (Units: ${ }^{\circ} \mathrm{F}$ ) HEDS Tinker, PHC Energy Valve, T2_US, T2_US (Units: ${ }^{\circ} \mathrm{F}$ ) HEDS Tinker, PHC Energy Valve, Vnom_US, Vnom_US (Units: GPM) HEDS Tinker, RHC Energy Valve, AbsFlow_US, AbsFlow_US (Units: GPM) HEDS Tinker, RHC Energy Valve, AbsPower_US1, AbsPower_US1 HEDS Tinker, RHC Energy Valve, AbsPower_US2, AbsPower_US2 HEDS Tinker, RHC Energy Valve, DeltaT_US, DeltaT_US (Units: ${ }^{\circ} \mathrm{F}$ ) HEDS Tinker, RHC Energy Valve, E_Cooling_US1, E_Cooling_US1 HEDS Tinker, RHC Energy Valve, E_Cooling_US2, E_Cooling_US2 (Units: ton hr) HEDS Tinker, RHC Energy Valve, E_Heating_US1, E_Heating_US1 HEDS Tinker, RHC Energy Valve, E_Heating_US2, E_Heating_US2 (Units: ton hr) HEDS Tinker, RHC Energy Valve, RelFlow, RelFlow (Units: \%) HEDS Tinker, RHC Energy Valve, RelPos, RelPos (Units: \%) HEDS Tinker, RHC Energy Valve, RelPower, RelPower (Units: \%) HEDS Tinker, RHC Energy Valve, T1_US, T1_US (Units: ${ }^{\circ} \mathrm{F}$ ) HEDS Tinker, RHC Energy Valve, T2_US, T2_US (Units: ${ }^{\circ} \mathrm{F}$ ) HEDS Tinker, RHC Energy Valve, Vnom_US, Vnom_US (Units: GPM) HEDS Tinker, VAV_Tinker, 100\% Ventilation, 100\% Ventilation HEDS Tinker, VAV_Tinker, 100\% Ventilation Time (Minutes), 100\% Ventilation Time (Minutes) HEDS Tinker, VAV_Tinker, ABS Command AHU Start/Stop, ABS Command AHU Start/Stop HEDS Tinker, VAV_Tinker, Average Mixed Air Temp, Average Mixed Air Temp (Units: ${ }^{\circ} \mathrm{F}$ ) HEDS Tinker, VAV_Tinker, CC BTU/Hr by GPM, CC BTU/Hr by GPM (Units: Btu) HEDS Tinker, VAV_Tinker, CC BTU/Hr by GPM from BEV, CC BTU/Hr by GPM from BEV (Units: Btu/hr) HEDS Tinker, VAV_Tinker, CC BTUH BEV Temp/Flow vs Enthalpy_CFM, CC BTUH BEV Temp/Flow vs Enthalpy_CFM (Units: Btu/hr) HEDS Tinker, VAV_Tinker, CC BTUH Temp/Flow vs BEV Temp/Flow, CC BTUH Temp/Flow vs BEV Temp/Flow (Units: Btu/hr) HEDS Tinker, VAV_Tinker, CC BTUH Temp/Flow vs Enthalpy_CFM, CC BTUH Temp/Flow vs Enthalpy_CFM (Units: Btu/hr) HEDS Tinker, VAV_Tinker, CC CHW Differential Pressure, $\mathrm{CC}$ CHW Differential Pressure (Units: $\left.{ }^{\circ} \mathrm{F}\right)$ HEDS Tinker, VAV_Tinker, CC CHW Valve Control, CC CHW Valve Control (Units: \%) HEDS Tinker, VAV_Tinker, CC Delta Temp vs CC Delta Temp from BEV, CC Delta Temp vs CC Delta Temp from BEV (Units: $\left.{ }^{\circ} \mathrm{F}\right)$ HEDS Tinker, VAV_Tinker, CC Dewpoint Temperature (AV), CC Dewpoint Temperature (AV) (Units: $\left.{ }^{\circ} \mathrm{F}\right)$ HEDS Tinker, VAV_Tinker, CC Differential Water Temp across Coil, CC Differential Water Temp across Coil (Units: ${ }^{\circ} \mathrm{F}$ ) HEDS Tinker, VAV_Tinker, CC Differential Water Temp across Coil from BEV, CC Differential Water Temp across Coil from BEV (Units: $\left.{ }^{\circ} \mathrm{F}\right)$ HEDS Tinker, VAV_Tinker, CC Drybulb Temp Setpoint, CC Drybulb Temp Setpoint (Units: ${ }^{\circ} \mathrm{F}$ ) HEDS Tinker, VAV_Tinker, CC Drybulb Temperature, CC Drybulb Temperature (Units: ${ }^{\circ} \mathrm{F}$ ) HEDS Tinker, VAV_Tinker, CC Enthalpy, CC Enthalpy (Units: BTU/Ib.) HEDS Tinker, VAV_Tinker, CC GPM, CC GPM (Units: GPM) HEDS Tinker, VAV_Tinker, CC Grains/lb., CC Grains/lb. HEDS Tinker, VAV_Tinker, CC Humidity, CC Humidity (Units: \%) HEDS Tinker, VAV_Tinker, CC Latent BTU/Hr, CC Latent BTU/Hr (Units: Btu) HEDS Tinker, VAV_Tinker, CC Leaving Air Enthalpy, CC Leaving Air Enthalpy (Units: BTU/lb.) HEDS Tinker, VAV_Tinker, CC Leaving Air Grains/lb., CC Leaving Air Grains/lb. HEDS Tinker, VAV_Tinker, CC Sensible \& Latent BTU/Hr, CC Sensible \& Latent BTU/Hr (Units: Btu) HEDS Tinker, VAV_Tinker, CC Sensible \& Latent Tonnage, CC Sensible \& Latent Tonnage (Units: Tons Refrigeration) HEDS Tinker, VAV_Tinker, CC Sensible BTU/Hr, CC Sensible BTU/Hr (Units: Btu) HEDS Tinker, VAV_Tinker, CC Tonnage by Enthalpy, CC Tonnage by Enthalpy (Units: Tons Refrigeration) HEDS Tinker, VAV_Tinker, CC Tonnage by GPM, CC Tonnage by GPM (Units: Btu/hr) HEDS Tinker, VAV_Tinker, CC Tonnage by GPM from BEV, CC Tonnage by GPM from BEV (Units: Tons Refrigeration) HEDS Tinker, VAV_Tinker, CC WPD, CC WPD (Units: in W.C.) HEDS Tinker, VAV_Tinker, CC-CHWR Temperature, CC-CHWR Temperature (Units: ${ }^{\circ} \mathrm{F}$ ) HEDS Tinker, VAV_Tinker, CC-CHWS Temperature, CC-CHWS Temperature (Units: ${ }^{\circ} \mathrm{F}$ ) HEDS Tinker, VAV_Tinker, CHWS - Common CHWR Differential Water Temp, CHWS - Common CHWR Differential Water Temp (Units: $\left.{ }^{\circ} \mathrm{F}\right)$ HEDS Tinker, VAV_Tinker, CHWS Greater Than 48 Degrees for 15 Minutes, CHWS Greater Than 48 Degrees for 15 Minutes 
HEDS Tinker, VAV_Tinker, CHWS Greater Than 50 Degrees for 30 Minutes, CHWS Greater Than 50 Degrees for 30 Minutes HEDS Tinker, VAV_Tinker, Common-CHWRTemperature, Common-CHWRTemperature (Units: ${ }^{\circ} \mathrm{F}$ ) HEDS Tinker, VAV_Tinker, CRC BTU/Hr by GPM, CRC BTU/Hr by GPM (Units: Btu) HEDS Tinker, VAV_Tinker, CRC CHW Differential Pressure, CRC CHW Differential Pressure (Units: PSI) HEDS Tinker, VAV_Tinker, CRC CHW Valve Control, CRC CHW Valve Control (Units: \%) HEDS Tinker, VAV_Tinker, CRC Dewpoint Temperature (AV), CRC Dewpoint Temperature (AV) (Units: $\left.{ }^{\circ} \mathrm{F}\right)$ HEDS Tinker, VAV_Tinker, CRC Differential Water Temp across Coil, CRC Differential Water Temp across Coil (Units: ${ }^{\circ} \mathrm{F}$ ) HEDS Tinker, VAV_Tinker, CRC Drybulb Temperature, CRC Drybulb Temperature (Units: ${ }^{\circ} \mathrm{F}$ ) HEDS Tinker, VAV_Tinker, CRC Enthalpy, CRC Enthalpy (Units: BTU/lb.) HEDS Tinker, VAV_Tinker, CRC GPM, CRC GPM (Units: GPM) HEDS Tinker, VAV_Tinker, CRC Grains/lb., CRC Grains/lb. HEDS Tinker, VAV_Tinker, CRC Humidity, CRC Humidity (Units: \%) HEDS Tinker, VAV_Tinker, CRC Sensible BTU/Hr, CRC Sensible BTU/Hr (Units: Btu) HEDS Tinker, VAV_Tinker, CRC System Tonnage by GPM, CRC System Tonnage by GPM (Units: Tons Refrigeration) HEDS Tinker, VAV_Tinker, CRC Tonnage by Enthalpy, CRC Tonnage by Enthalpy (Units: Tons Refrigeration) HEDS Tinker, VAV_Tinker, CRC Tonnage by GPM, CRC Tonnage by GPM (Units: Btu/hr) HEDS Tinker, VAV_Tinker, CRC WPD, CRC WPD (Units: in W.C.) HEDS Tinker, VAV_Tinker, CRC-CHWR Temperature, CRC-CHWR Temperature (Units: ${ }^{\circ} \mathrm{F}$ ) HEDS Tinker, VAV_Tinker, Dedicated Outdoor Air Unit, Dedicated Outdoor Air Unit HEDS Tinker, VAV_Tinker, Dehumidify Batch Command, Dehumidify Batch Command HEDS Tinker, VAV_Tinker, Dehumidify Continuous Command, Dehumidify Continuous Command HEDS Tinker, VAV_Tinker, Dehumidify Occupied Command, Dehumidify Occupied Command HEDS Tinker, VAV_Tinker, Dehumidify Unoccupied Command, Dehumidify Unoccupied Command HEDS Tinker, VAV_Tinker, Differential BTU - CC to CRC, Differential BTU - CC to CRC (Units: BTU/Ib.) HEDS Tinker, VAV_Tinker, Differential BTU - CRC to RHC, Differential BTU - CRC to RHC (Units: BTU/Ib.) HEDS Tinker, VAV_Tinker, Differential BTU - MA to CC, Differential BTU - MA to CC (Units: BTU/Ib.) HEDS Tinker, VAV_Tinker, Differential BTU - MA to CRC, Differential BTU - MA to CRC (Units: BTU/Ib.) HEDS Tinker, VAV_Tinker, Differential BTU - MA to RHC, Differential BTU - MA to RHC (Units: BTU/lb.) HEDS Tinker, VAV_Tinker, Differential BTU - MA to SF, Differential BTU - MA to SF (Units: BTU/lb.) HEDS Tinker, VAV_Tinker, Differential BTU - OSA to MA, Differential BTU - OSA to MA (Units: BTU/lb.) HEDS Tinker, VAV_Tinker, Differential BTU - OSA to RA, Differential BTU - OSA to RA (Units: BTU/Ib.) HEDS Tinker, VAV_Tinker, Differential BTU - OSA to SF, Differential BTU - OSA to SF (Units: BTU/Ib.) HEDS Tinker, VAV_Tinker, Differential BTU - OSA to Space, Differential BTU - OSA to Space (Units: BTU/Ib.) HEDS Tinker, VAV_Tinker, Differential BTU - PHC to CC, Differential BTU - PHC to CC (Units: BTU/lb.) HEDS Tinker, VAV_Tinker, Differential BTU - PHC to MA, Differential BTU - PHC to MA (Units: BTU/Ib.) HEDS Tinker, VAV_Tinker, Differential BTU - PHC to SF, Differential BTU - PHC to SF (Units: BTU/Ib.) HEDS Tinker, VAV_Tinker, Differential BTU - RA to MA, Differential BTU - RA to MA (Units: BTU/Ib.) HEDS Tinker, VAV_Tinker, Differential BTU - RA to SF, Differential BTU - RA to SF (Units: BTU/lb.) HEDS Tinker, VAV_Tinker, Differential BTU - RA to Space, Differential BTU - RA to Space (Units: BTU/lb.) HEDS Tinker, VAV_Tinker, Differential BTU - SF to CC, Differential BTU - SF to CC (Units: BTU/Ib.) HEDS Tinker, VAV_Tinker, Differential BTU - SF to CRC, Differential BTU - SF to CRC (Units: BTU/lb.) HEDS Tinker, VAV_Tinker, Differential BTU - SF to RHC, Differential BTU - SF to RHC (Units: BTU/lb.) HEDS Tinker, VAV_Tinker, Differential Enthalpy CC to CRC, Differential Enthalpy CC to CRC (Units: BTU/Ib.) HEDS Tinker, VAV_Tinker, Differential Enthalpy CRC to RHC, Differential Enthalpy CRC to RHC (Units: BTU/Ib.) HEDS Tinker, VAV_Tinker, Differential Enthalpy MA to CC, Differential Enthalpy MA to CC (Units: BTU/Ib.) HEDS Tinker, VAV_Tinker, Differential Enthalpy MA to CRC, Differential Enthalpy MA to CRC (Units: BTU/Ib.) HEDS Tinker, VAV_Tinker, Differential Enthalpy MA to RHC, Differential Enthalpy MA to RHC (Units: BTU/lb.) HEDS Tinker, VAV_Tinker, Differential Enthalpy MA to SF, Differential Enthalpy MA to SF (Units: BTU/lb.) HEDS Tinker, VAV_Tinker, Differential Enthalpy OSA to MA, Differential Enthalpy OSA to MA (Units: BTU/Ib.) HEDS Tinker, VAV_Tinker, Differential Enthalpy OSA to RA, Differential Enthalpy OSA to RA (Units: BTU/lb.) HEDS Tinker, VAV_Tinker, Differential Enthalpy OSA to SF, Differential Enthalpy OSA to SF (Units: BTU/Ib.) HEDS Tinker, VAV_Tinker, Differential Enthalpy OSA to Space, Differential Enthalpy OSA to Space (Units: BTU/lb.) HEDS Tinker, VAV_Tinker, Differential Enthalpy PHC to CC, Differential Enthalpy PHC to CC (Units: BTU/Ib.) HEDS Tinker, VAV_Tinker, Differential Enthalpy PHC to MA, Differential Enthalpy PHC to MA (Units: BTU/Ib.) HEDS Tinker, VAV_Tinker, Differential Enthalpy PHC to SF, Differential Enthalpy PHC to SF (Units: BTU/Ib.) HEDS Tinker, VAV_Tinker, Differential Enthalpy RA to MA, Differential Enthalpy RA to MA (Units: BTU/Ib.) HEDS Tinker, VAV_Tinker, Differential Enthalpy RA to SF, Differential Enthalpy RA to SF (Units: BTU/Ib.) HEDS Tinker, VAV_Tinker, Differential Enthalpy RA to Space, Differential Enthalpy RA to Space (Units: BTU/lb.) HEDS Tinker, VAV_Tinker, Differential Enthalpy SF to CC, Differential Enthalpy SF to CC (Units: BTU/Ib.) HEDS Tinker, VAV_Tinker, Differential Enthalpy SF to CRC, Differential Enthalpy SF to CRC (Units: BTU/Ib.) HEDS Tinker, VAV_Tinker, Differential Enthalpy SF to RHC, Differential Enthalpy SF to RHC (Units: BTU/Ib.) HEDS Tinker, VAV_Tinker, Discharge Air Enthalpy, Discharge Air Enthalpy (Units: BTU/lb.) HEDS Tinker, VAV_Tinker, Discharge Air Grains/lb. of dry air, Discharge Air Grains/lb. of dry air HEDS Tinker, VAV_Tinker, Discharge Air Heating Setpoint BAS, Discharge Air Heating Setpoint BAS (Units: ${ }^{\circ} \mathrm{F}$ ) HEDS Tinker, VAV_Tinker, Discharge Air Temperature Setpoint Active, Discharge Air Temperature Setpoint Active (Units: $\left.{ }^{\circ} \mathrm{F}\right)$ HEDS Tinker, VAV_Tinker, DOAS Command, DOAS Command HEDS Tinker, VAV_Tinker, DOAS Mode, DOAS Mode HEDS Tinker, VAV_Tinker, DOAS Overnight Command, DOAS Overnight Command HEDS Tinker, VAV_Tinker, DOAS Overnight MinOffTimer, DOAS Overnight MinOffTimer HEDS Tinker, VAV_Tinker, DOAS Overnight Mode, DOAS Overnight Mode HEDS Tinker, VAV_Tinker, Duct Static Pressure Setpoint BAS, Duct Static Pressure Setpoint BAS (Units: in W.C.) HEDS Tinker, VAV_Tinker, EA Damper Control, EA Damper Control (Units: \%) 
HEDS Tinker, VAV_Tinker, Filter-DPT Filter Status, Filter-DPT Filter Status (Units: in W.C.) HEDS Tinker, VAV_Tinker, Fire Life Safety, Fire Life Safety HEDS Tinker, VAV_Tinker, Heat Cool Mode, Heat Cool Mode HEDS Tinker, VAV_Tinker, Heat Cool Mode Request, Heat Cool Mode Request HEDS Tinker, VAV_Tinker, Heat Cool Mode Status, Heat Cool Mode Status HEDS Tinker, VAV_Tinker, MA Dewpoint Temperature (AV), MA Dewpoint Temperature (AV) (Units: $\left.{ }^{\circ} \mathrm{F}\right)$ HEDS Tinker, VAV_Tinker, MA Drybulb Temperature, MA Drybulb Temperature (Units: ${ }^{\circ} \mathrm{F}$ ) HEDS Tinker, VAV_Tinker, MA Enthalpy, MA Enthalpy (Units: BTU/lb.) HEDS Tinker, VAV_Tinker, MA Grains/lb., MA Grains/lb. HEDS Tinker, VAV_Tinker, MA Humidity, MA Humidity (Units: \%) HEDS Tinker, VAV_Tinker, MA Low Limit Temp Cutout Status, MA Low Limit Temp Cutout Status HEDS Tinker, VAV_Tinker, Maximum Discharge Air Temperature, Maximum Discharge Air Temperature (Units: ${ }^{\circ} \mathrm{F}$ ) HEDS Tinker, VAV_Tinker, Minimum Discharge Air Temperature, Minimum Discharge Air Temperature (Units: ${ }^{\circ} \mathrm{F}$ ) HEDS Tinker, VAV_Tinker, Minimum Outside Air Flow Setpoint, Minimum Outside Air Flow Setpoint (Units: CFM) HEDS Tinker, VAV_Tinker, Morning Warmup, Morning Warmup HEDS Tinker, VAV_Tinker, Night Heat Cool, Night Heat Cool HEDS Tinker, VAV_Tinker, Night Purge, Night Purge HEDS Tinker, VAV_Tinker, Not Unoccupied, Not Unoccupied HEDS Tinker, VAV_Tinker, Occupancy Status, Occupancy Status HEDS Tinker, VAV_Tinker, Occupied Offset, Occupied Offset (Units: ${ }^{\circ} \mathrm{F}$ ) HEDS Tinker, VAV_Tinker, Ok to Economize, Ok to Economize HEDS Tinker, VAV_Tinker, OSA by Position/CFM, OSA by Position/CFM HEDS Tinker, VAV_Tinker, OSA Damper 2 Control, OSA Damper 2 Control (Units: \%) HEDS Tinker, VAV_Tinker, OSA Dewpoint Temperature (AV), OSA Dewpoint Temperature (AV) (Units: ${ }^{\circ} \mathrm{F}$ ) HEDS Tinker, VAV_Tinker, OSA Drybulb Temperature, OSA Drybulb Temperature (Units: ${ }^{\circ} \mathrm{F}$ ) HEDS Tinker, VAV_Tinker, OSA Enthalpy, OSA Enthalpy (Units: BTU/Ib.) HEDS Tinker, VAV_Tinker, OSA Enthalpy Active, OSA Enthalpy Active (Units: BTU/Ib.) HEDS Tinker, VAV_Tinker, OSA Enthalpy BTU/Hr, OSA Enthalpy BTU/Hr (Units: Btu) HEDS Tinker, VAV_Tinker, OSA Enthalpy Tonnage, OSA Enthalpy Tonnage (Units: Tons Refrigeration) HEDS Tinker, VAV_Tinker, OSA Flow-2 Local, OSA Flow-2 Local (Units: CFM) HEDS Tinker, VAV_Tinker, OSA Grains/lb., OSA Grains/lb. HEDS Tinker, VAV_Tinker, OSA Humidity, OSA Humidity (Units: \%) HEDS Tinker, VAV_Tinker, OSA Latent BTU/Hr, OSA Latent BTU/Hr (Units: Btu) HEDS Tinker, VAV_Tinker, OSA Min Damper 1 Control, OSA Min Damper 1 Control (Units: \%) HEDS Tinker, VAV_Tinker, OSA Min Flow-1 Local, OSA Min Flow-1 Local (Units: CFM) HEDS Tinker, VAV_Tinker, OSA Sensible \& Latent BTU/Hr, OSA Sensible \& Latent BTU/Hr (Units: Btu) HEDS Tinker, VAV_Tinker, OSA Sensible \& Latent Tonnage, OSA Sensible \& Latent Tonnage (Units: Tons Refrigeration) HEDS Tinker, VAV_Tinker, OSA Sensible BTU/Hr, OSA Sensible BTU/Hr (Units: Btu) HEDS Tinker, VAV_Tinker, OSA Total Flow, OSA Total Flow (Units: CFM) HEDS Tinker, VAV_Tinker, OverNight Dehumidification Mode, OverNight Dehumidification Mode HEDS Tinker, VAV_Tinker, Overnight Ventilation Mode, Overnight Ventilation Mode HEDS Tinker, VAV_Tinker, Overnight Ventilate CFM Setpoint, Overnight Ventilate CFM Setpoint (Units: CFM) HEDS Tinker, VAV_Tinker, PHC BTU/Hr by GPM, PHC BTU/Hr by GPM (Units: Btu) HEDS Tinker, VAV_Tinker, PHC BTU/Hr by GPM from BEV, PHC BTU/Hr by GPM from BEV (Units: Btu/hr) HEDS Tinker, VAV_Tinker, PHC BTUH BEV Temp/Flow vs Enthalpy_CFM, PHC BTUH BEV Temp/Flow vs Enthalpy_CFM (Units: Btu/hr) HEDS Tinker, VAV_Tinker, PHC BTUH Temp/Flow vs BEV Temp/Flow, PHC BTUH Temp/Flow vs BEV Temp/Flow (Units: Btu/hr) HEDS Tinker, VAV_Tinker, PHC BTUH Temp/Flow vs Enthalpy_CFM, PHC BTUH Temp/Flow vs Enthalpy_CFM (Units: Btu/hr) HEDS Tinker, VAV_Tinker, PHC Delta Temp vs PHC Delta Temp from BEV, PHC Delta Temp vs PHC Delta Temp from BEV (Units: $\left.{ }^{\circ} \mathrm{F}\right)$ HEDS Tinker, VAV_Tinker, PHC Dewpoint Temperature (AV), PHC Dewpoint Temperature (AV) (Units: ${ }^{\circ} \mathrm{F}$ ) HEDS Tinker, VAV_Tinker, PHC Differential Water Temp across Coil, PHC Differential Water Temp across Coil (Units: ${ }^{\circ} \mathrm{F}$ ) HEDS Tinker, VAV_Tinker, PHC Differential Water Temp across Coil, PHC Differential Water Temp across Coil (Units: ${ }^{\circ} \mathrm{F}$ ) HEDS Tinker, VAV_Tinker, PHC Differential Water Temp across Coil from BEV, PHC Differential Water Temp across Coil from BEV (Units: ${ }^{\circ} \mathrm{F}$ ) HEDS Tinker, VAV_Tinker, PHC Drybulb Temperature, PHC Drybulb Temperature (Units: ${ }^{\circ} \mathrm{F}$ ) HEDS Tinker, VAV_Tinker, PHC Enthalpy, PHC Enthalpy (Units: BTU/lb.) HEDS Tinker, VAV_Tinker, PHC GPM, PHC GPM (Units: GPM) HEDS Tinker, VAV_Tinker, PHC Grains/lb., PHC Grains/lb. HEDS Tinker, VAV_Tinker, PHC Humidity, PHC Humidity (Units: \%) HEDS Tinker, VAV_Tinker, PHC HW Differential Pressure, PHC HW Differential Pressure (Units: PSI) HEDS Tinker, VAV_Tinker, PHC HW Valve Control, PHC HW Valve Control (Units: \%) HEDS Tinker, VAV_Tinker, PHC Leaving Air Enthalpy, PHC Leaving Air Enthalpy (Units: BTU/lb.) HEDS Tinker, VAV_Tinker, PHC Leaving Air Grains/lb. of dry air, PHC Leaving Air Grains/lb. of dry air HEDS Tinker, VAV_Tinker, PHC Sensible BTU/Hr, PHC Sensible BTU/Hr (Units: Btu) HEDS Tinker, VAV_Tinker, PHC Tonnage by Enthalpy, PHC Tonnage by Enthalpy (Units: Tons Refrigeration) HEDS Tinker, VAV_Tinker, PHC Tonnage by GPM, PHC Tonnage by GPM (Units: Btu/hr) HEDS Tinker, VAV_Tinker, PHC Tonnage by GPM from BEV, PHC Tonnage by GPM from BEV (Units: Tons Refrigeration) HEDS Tinker, VAV_Tinker, PHC WPD, PHC WPD (Units: in W.C.) HEDS Tinker, VAV_Tinker, PHC-HWR Temperature, PHC-HWR Temperature (Units: ${ }^{\circ} \mathrm{F}$ ) HEDS Tinker, VAV_Tinker, PHC-HWS Temperature, PHC-HWS Temperature (Units: ${ }^{\circ} \mathrm{F}$ ) HEDS Tinker, VAV_Tinker, Preheat Coil Pump Failure, Preheat Coil Pump Failure HEDS Tinker, VAV_Tinker, RA Damper Control, RA Damper Control (Units: \%) HEDS Tinker, VAV_Tinker, RA Dewpoint Temperature (AV), RA Dewpoint Temperature (AV) (Units: $\left.{ }^{\circ} \mathrm{F}\right)$ HEDS Tinker, VAV_Tinker, RA Drybulb Temperature, RA Drybulb Temperature (Units: ${ }^{\circ} \mathrm{F}$ ) 
HEDS Tinker, VAV_Tinker, RA Enthalpy, RA Enthalpy (Units: BTU/lb.)

HEDS Tinker, VAV_Tinker, RA Enthalpy Active, RA Enthalpy Active (Units: BTU/lb.)

HEDS Tinker, VAV_Tinker, RA Flow, RA Flow (Units: CFM)

HEDS Tinker, VAV_Tinker, RA Grains/lb., RA Grains/lb.

HEDS Tinker, VAV_Tinker, RA Humidity, RA Humidity (Units: \%)

HEDS Tinker, VAV_Tinker, RA Lo Press Cutout SW Status, RA Lo Press Cutout SW Status

HEDS Tinker, VAV_Tinker, Reset Discharge Air Cooling Max Setpoint BAS, Reset Discharge Air Cooling Max Setpoint BAS (Units: $\left.{ }^{\circ} \mathrm{F}\right)$

HEDS Tinker, VAV_Tinker, Reset Discharge Air Cooling Min Setpoint BAS, Reset Discharge Air Cooling Min Setpoint BAS (Units: ${ }^{\circ} \mathrm{F}$ ) HEDS Tinker, VAV_Tinker, RHC BTU/Hr by GPM, RHC BTU/Hr by GPM (Units: Btu)

HEDS Tinker, VAV_Tinker, RHC BTU/Hr by GPM from BEV, RHC BTU/Hr by GPM from BEV (Units: Btu/hr)

HEDS Tinker, VAV_Tinker, RHC BTUH BEV Temp/Flow vs Enthalpy_CFM, RHC BTUH BEV Temp/Flow vs Enthalpy_CFM (Units: Btu/hr)

HEDS Tinker, VAV_Tinker, RHC BTUH Temp/Flow vs BEV Temp/Flow, RHC BTUH Temp/Flow vs BEV Temp/Flow (Units: Btu/hr)

HEDS Tinker, VAV_Tinker, RHC BTUH Temp/Flow vs Enthalpy_CFM, RHC BTUH Temp/Flow vs Enthalpy_CFM (Units: Btu/hr)

HEDS Tinker, VAV_Tinker, RHC Delta Temp vs RHC Delta Temp from BEV, RHC Delta Temp vs RHC Delta Temp from BEV (Units: $\left.{ }^{\circ} \mathrm{F}\right)$

HEDS Tinker, VAV_Tinker, RHC Dewpoint Temperature (AV), RHC Dewpoint Temperature (AV) (Units: ${ }^{\circ} \mathrm{F}$ )

HEDS Tinker, VAV_Tinker, RHC Differential Water Temp across Coil, RHC Differential Water Temp across Coil (Units: $\left.{ }^{\circ} \mathrm{F}\right)$

HEDS Tinker, VAV_Tinker, RHC Differential Water Temp across Coil from BEV, RHC Differential Water Temp across Coil from BEV (Units: $\left.{ }^{\circ} \mathrm{F}\right)$ HEDS Tinker, VAV_Tinker, RHC Drybulb Temperature, RHC Drybulb Temperature (Units: ${ }^{\circ} \mathrm{F}$ )

HEDS Tinker, VAV_Tinker, RHC Enthalpy, RHC Enthalpy (Units: BTU/Ib.)

HEDS Tinker, VAV_Tinker, RHC GPM, RHC GPM (Units: GPM)

HEDS Tinker, VAV_Tinker, RHC Grains/lb., RHC Grains/lb.

HEDS Tinker, VAV_Tinker, RHC Humidity, RHC Humidity (Units: \%)

HEDS Tinker, VAV_Tinker, RHC HW Differential Pressure, RHC HW Differential Pressure (Units: PSI)

HEDS Tinker, VAV_Tinker, RHC HW Valve Control, RHC HW Valve Control (Units: \%)

HEDS Tinker, VAV_Tinker, RHC Sensible BTUH, RHC Sensible BTUH (Units: Btu)

HEDS Tinker, VAV_Tinker, Space Enthalpy, Space Enthalpy (Units: BTU/lb.)

HEDS Tinker, VAV_Tinker, Space Grains/llb. of dry air, Space Grains/lb. of dry air

HEDS Tinker, VAV_Tinker, Space Humidity, Space Humidity (Units: \%)

HEDS Tinker, VAV_Tinker, Space Temperature Active, Space Temperature Active (Units: ${ }^{\circ} \mathrm{F}$ )

HEDS Tinker, VAV_Tinker, Space Temperature Setpoint Active, Space Temperature Setpoint Active (Units: ${ }^{\circ} \mathrm{F}$ )

HEDS Tinker, VAV_Tinker, Supply Fan Control Start Stop, Supply Fan Control Start Stop

HEDS Tinker, VAV_Tinker, Supply Fan Failure, Supply Fan Failure

HEDS Tinker, VAV_Tinker, Supply Fan Speed Control, Supply Fan Speed Control (Units: \%)

HEDS Tinker, VAV_Tinker, Supply Fan Status, Supply Fan Status

HEDS Tinker, VAV_Tinker, System Tonnage by GPM, System Tonnage by GPM (Units: Tons Refrigeration)

HEDS Tinker, VAV_Tinker, Unoccupied Cooling Setpoint, Unoccupied Cooling Setpoint (Units: ${ }^{\circ} \mathrm{F}$ )

HEDS Tinker, VAV_Tinker, Unoccupied Heating Setpoint, Unoccupied Heating Setpoint (Units: ${ }^{\circ} \mathrm{F}$ )

HEDS Tinker, VAV_Tinker, RHC Tonnage by Enthalpy, RHC Tonnage by Enthalpy (Units: Tons Refrigeration)

HEDS Tinker, VAV_Tinker, RHC Tonnage by GPM, RHC Tonnage by GPM (Units: Btu/hr)

HEDS Tinker, VAV_Tinker, RHC Tonnage by GPM from BEV, RHC Tonnage by GPM from BEV (Units: Tons Refrigeration)

HEDS Tinker, VAV_Tinker, RHC WPD, RHC WPD (Units: in W.C.)

HEDS Tinker, VAV_Tinker, RHC-HWR Temperature, RHC-HWR Temperature (Units: ${ }^{\circ} \mathrm{F}$ )

HEDS Tinker, VAV_Tinker, RHC-HWS Temperature, RHC-HWS Temperature (Units: ${ }^{\circ} \mathrm{F}$ )

HEDS Tinker, VAV_Tinker, SA Duct Static Pressure, SA Duct Static Pressure (Units: in W.C.)

HEDS Tinker, VAV_Tinker, SF Airflow, SF Airflow (Units: CFM)

HEDS Tinker, VAV_Tinker, SF Dewpoint Temperature (AV), SF Dewpoint Temperature (AV) (Units: $\left.{ }^{\circ} \mathrm{F}\right)$

HEDS Tinker, VAV_Tinker, SF Disch Drybulb Temperature, SF Disch Drybulb Temperature (Units: $\left.{ }^{\circ} \mathrm{F}\right)$

HEDS Tinker, VAV_Tinker, SF Disch Humidity, SF Disch Humidity (Units: \%)

HEDS Tinker, VAV_Tinker, SF Enthalpy, SF Enthalpy (Units: BTU/lb.)

HEDS Tinker, VAV_Tinker, SF Grains/lb., SF Grains/lb.

HEDS Tinker, VAV_Tinker, SF Heat Gain BTUH Rise Calculated, SF Heat Gain BTUH Rise Calculated (Units: $\left.{ }^{\circ} \mathrm{F}\right)$

HEDS Tinker, VAV_Tinker, SF Heat Gain Temp Rise Calculated, SF Heat Gain Temp Rise Calculated (Units: ${ }^{\circ} \mathrm{F}$ )

HEDS Tinker, VAV_Tinker, SF Inlet Velocity (FPM), SF Inlet Velocity (FPM)

HEDS Tinker, VAV_Tinker, SF Sensible BTU/Hr, SF Sensible BTU/Hr (Units: Btu)

HEDS Tinker, VAV_Tinker, SF-KW from VFD, SF-KW from VFD (Units: kW)

HEDS Tinker, VAV_Tinker, SFSF Airflow Setpoint, SFSF Airflow Setpoint (Units: CFM)

HEDS Tinker, VAV_Tinker, Space Dewpoint, Space Dewpoint (Units: ${ }^{\circ} \mathrm{F}$ )

HEDS Tinker, VAV_Tinker, Space Dewpoint Setpoint Active, Space Dewpoint Setpoint Active (Units: $\left.{ }^{\circ} \mathrm{F}\right)$

HEDS Tinker, VAV_Tinker, Space Dewpoint Setpoint Occupied, Space Dewpoint Setpoint Occupied (Units: ${ }^{\circ} \mathrm{F}$ )

HEDS Tinker, VAV_Tinker, Space Dewpoint Setpoint Unoccupied, Space Dewpoint Setpoint Unoccupied (Units: $\left.{ }^{\circ} \mathrm{F}\right)$

HEDS Tinker, VAV_Tinker, Space Dewpoint Temperature (AV), Space Dewpoint Temperature (AV) (Units: $\left.{ }^{\circ} \mathrm{F}\right)$

HEDS Tinker, VAV_Tinker, Space Drybulb Temperature, Space Drybulb Temperature (Units: ${ }^{\circ} \mathrm{F}$ ) 


\section{Appendix D: HEDS Instrumentation Drawings}




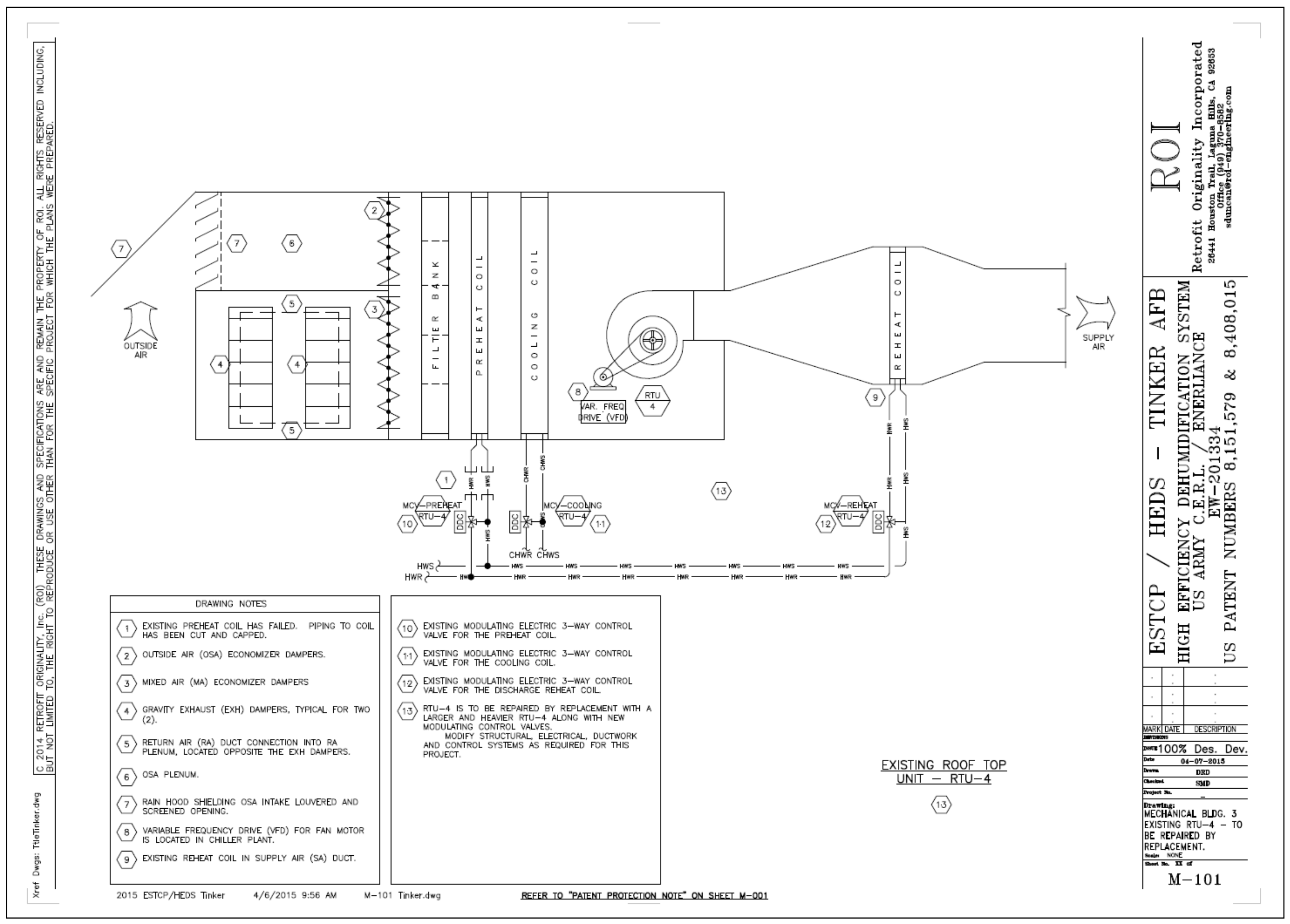


(15) Rervence

$1 \quad \operatorname{loc}_{10}-v$

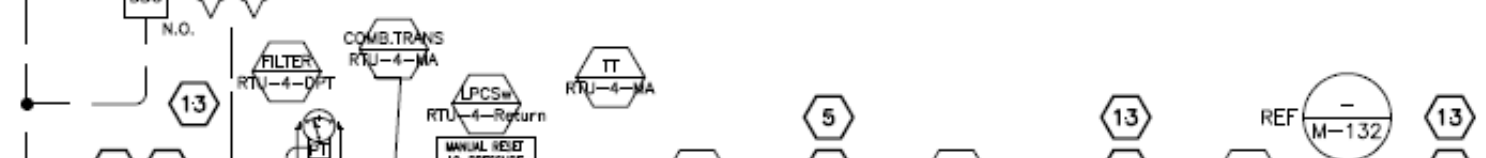

(13)

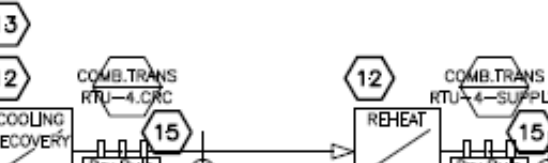

|

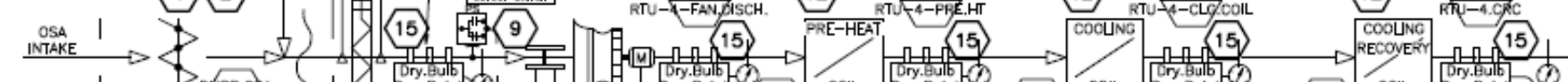

nor

然

।

|

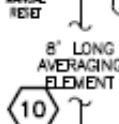
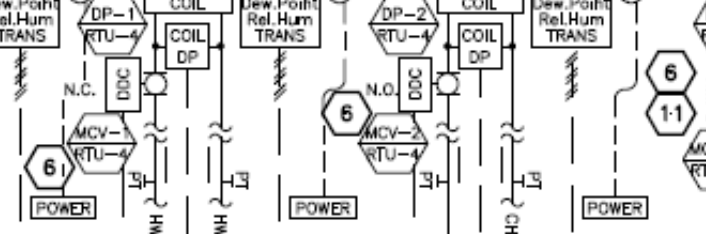

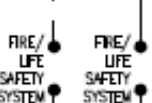

|

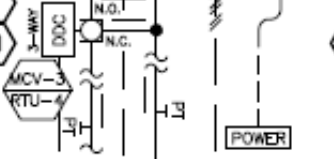

$\rightarrow \infty$ | 1

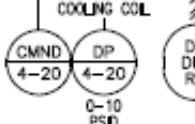
$\frac{1}{\mid-1}$

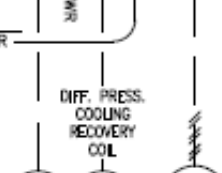

\section{年}

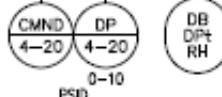

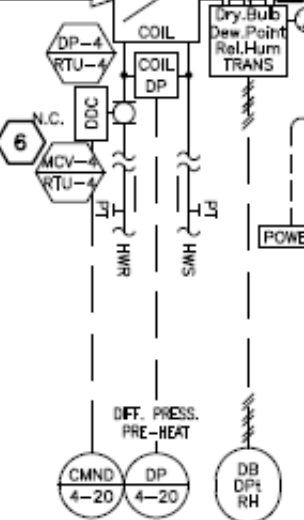

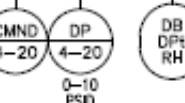

(14)

\begin{tabular}{|c|c|}
\hline & \\
\hline 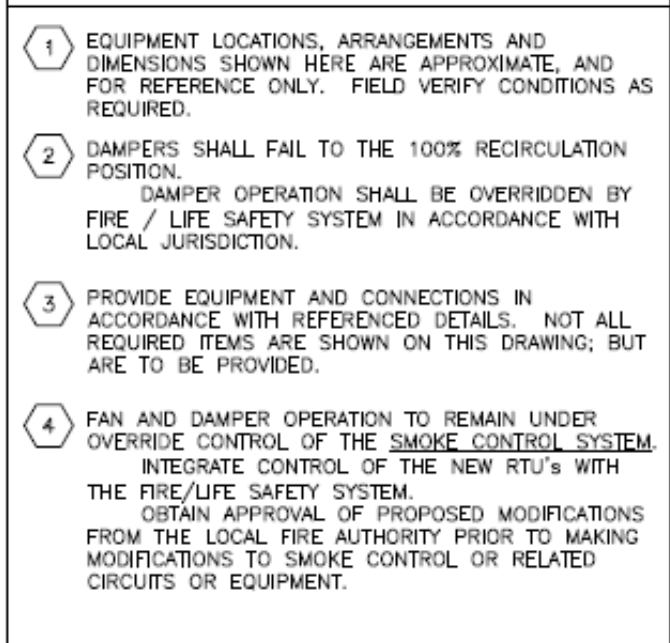 & 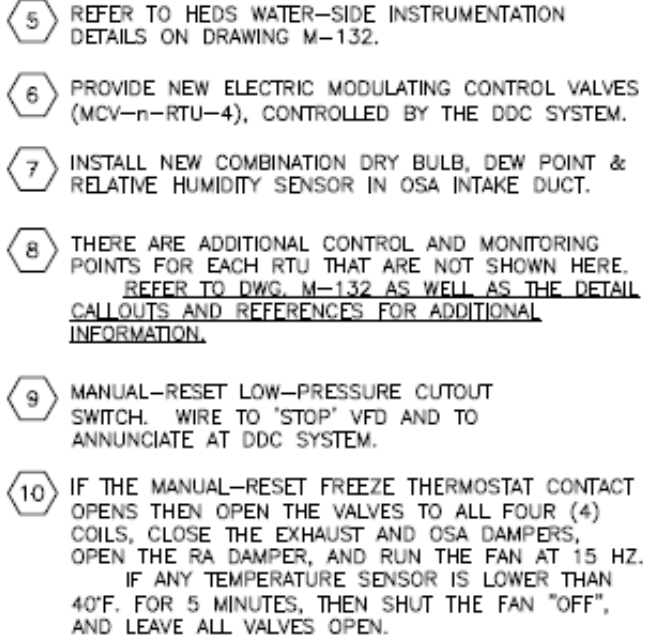 \\
\hline
\end{tabular}

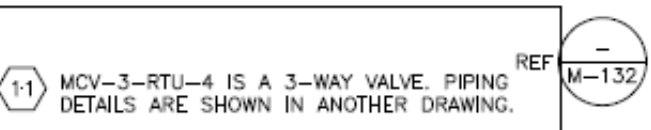

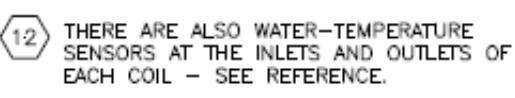

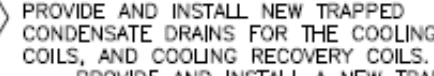

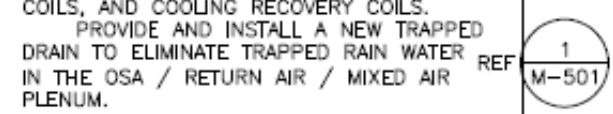

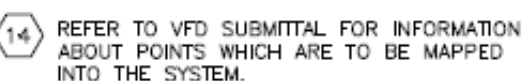

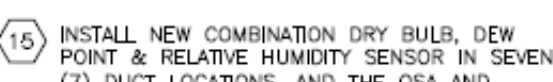

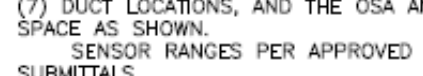

SUBSIESTSLR. RANGES PER APPRQ

N NOTE" ON SHET W-001

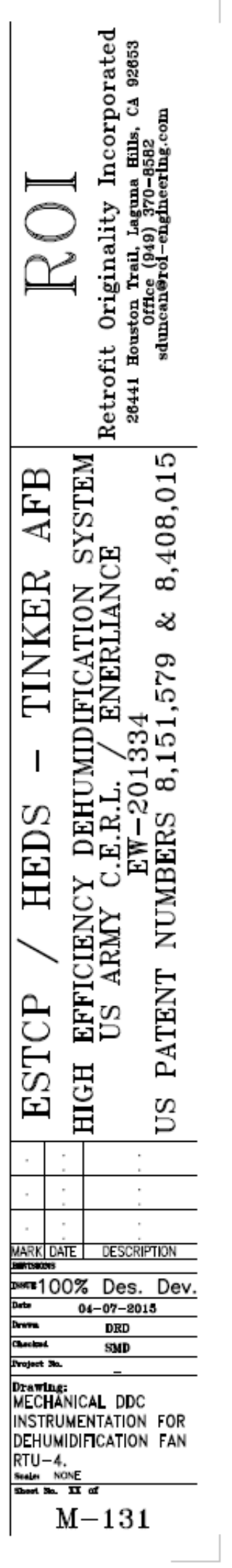




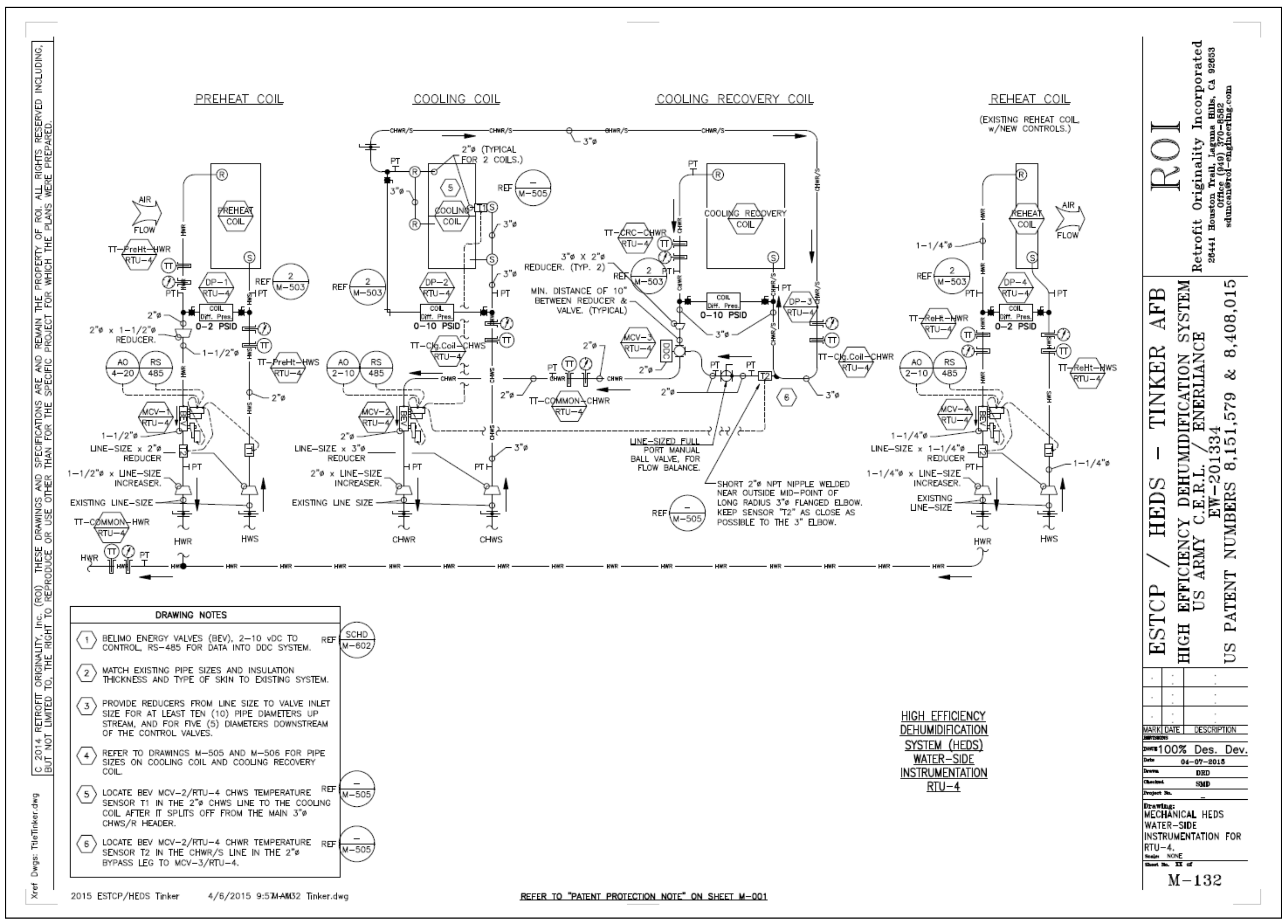




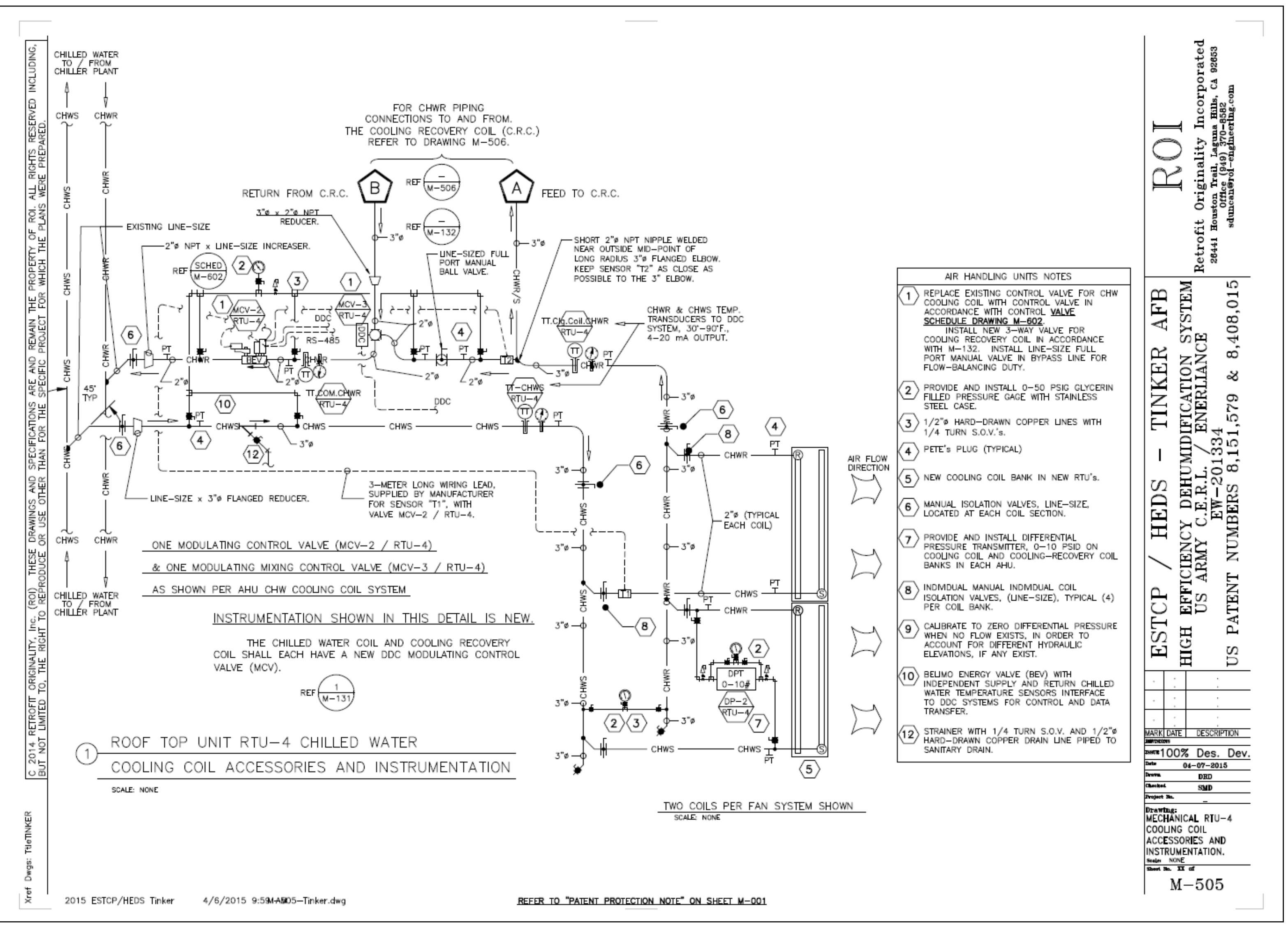




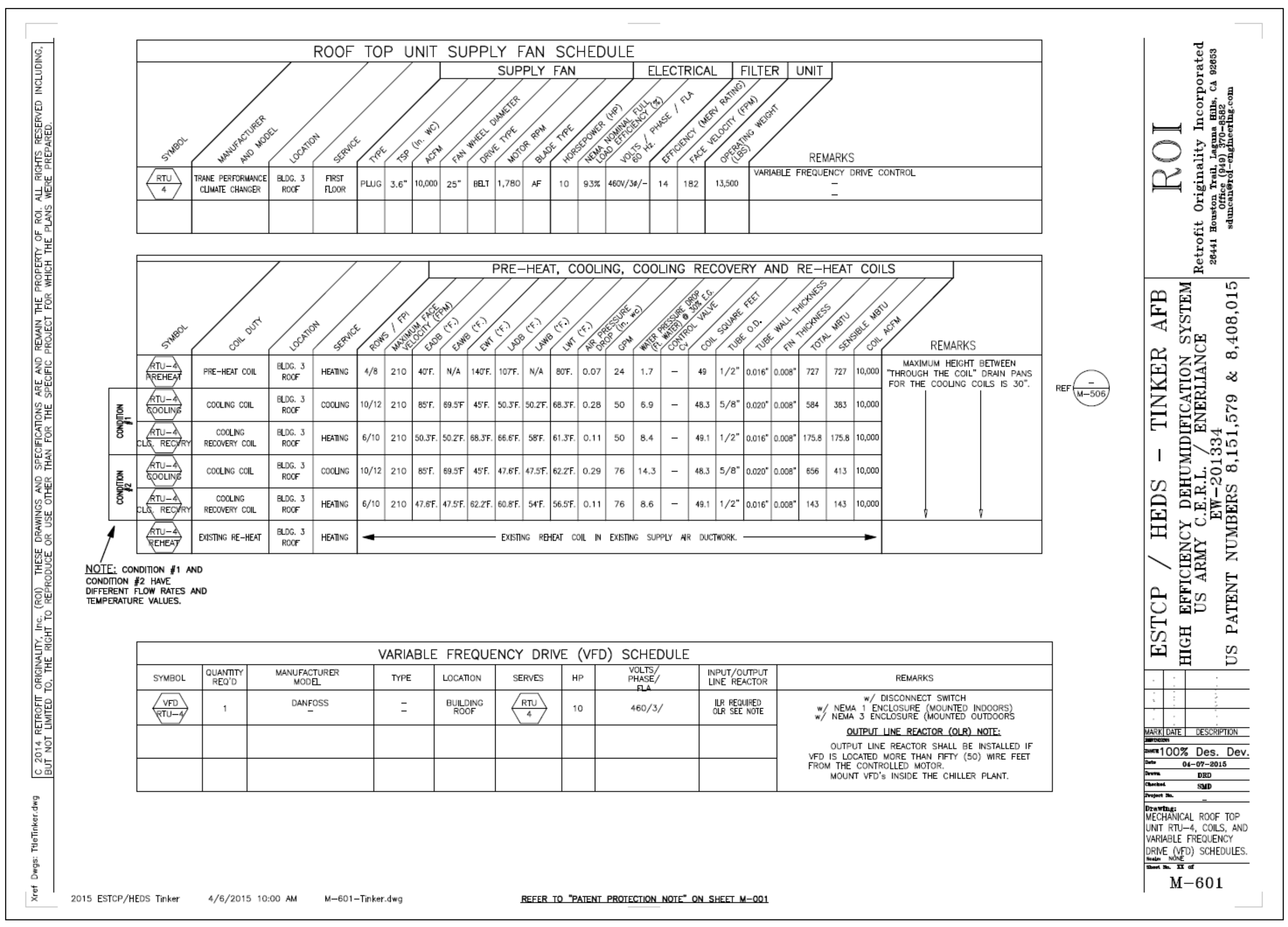




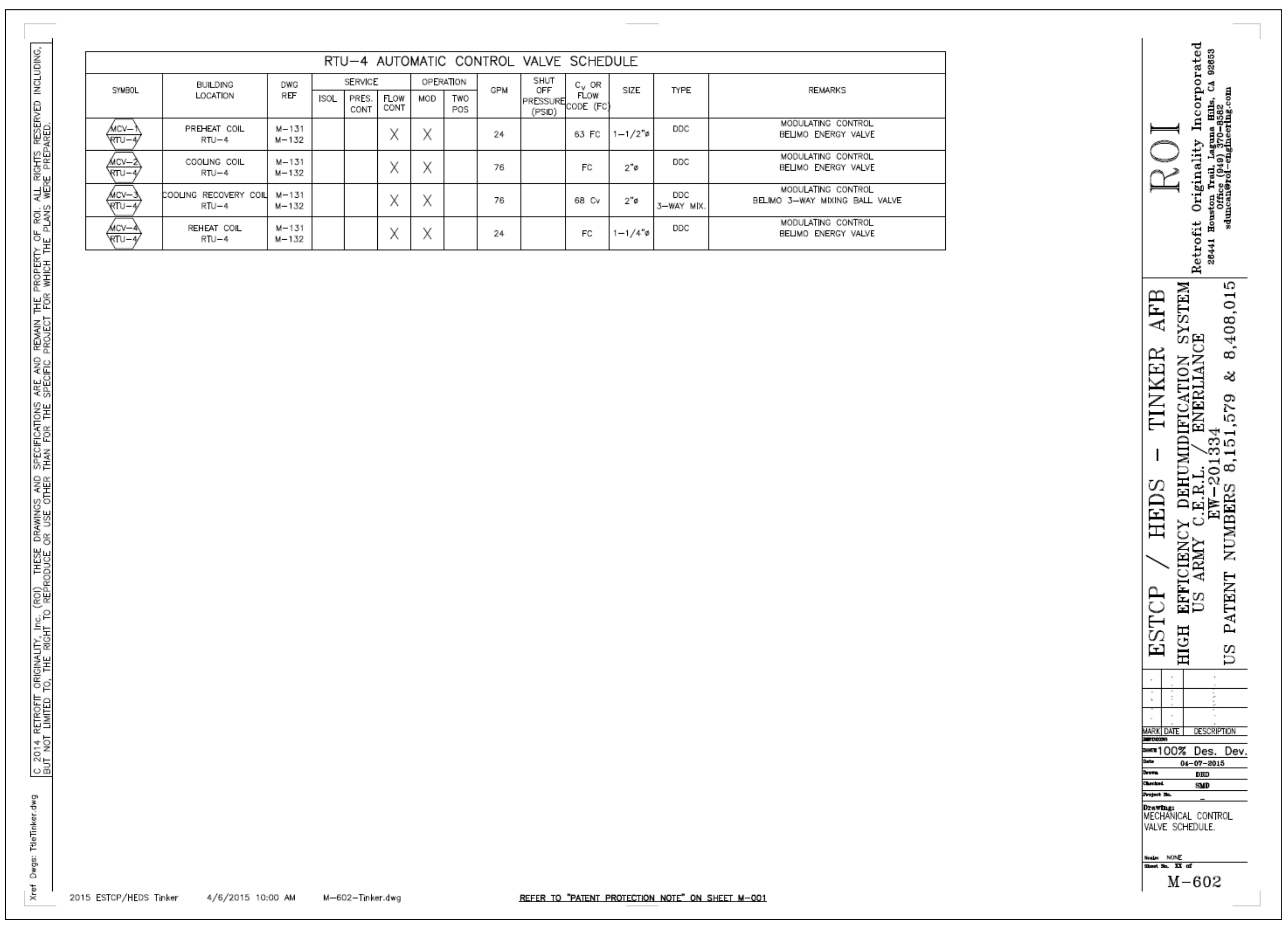




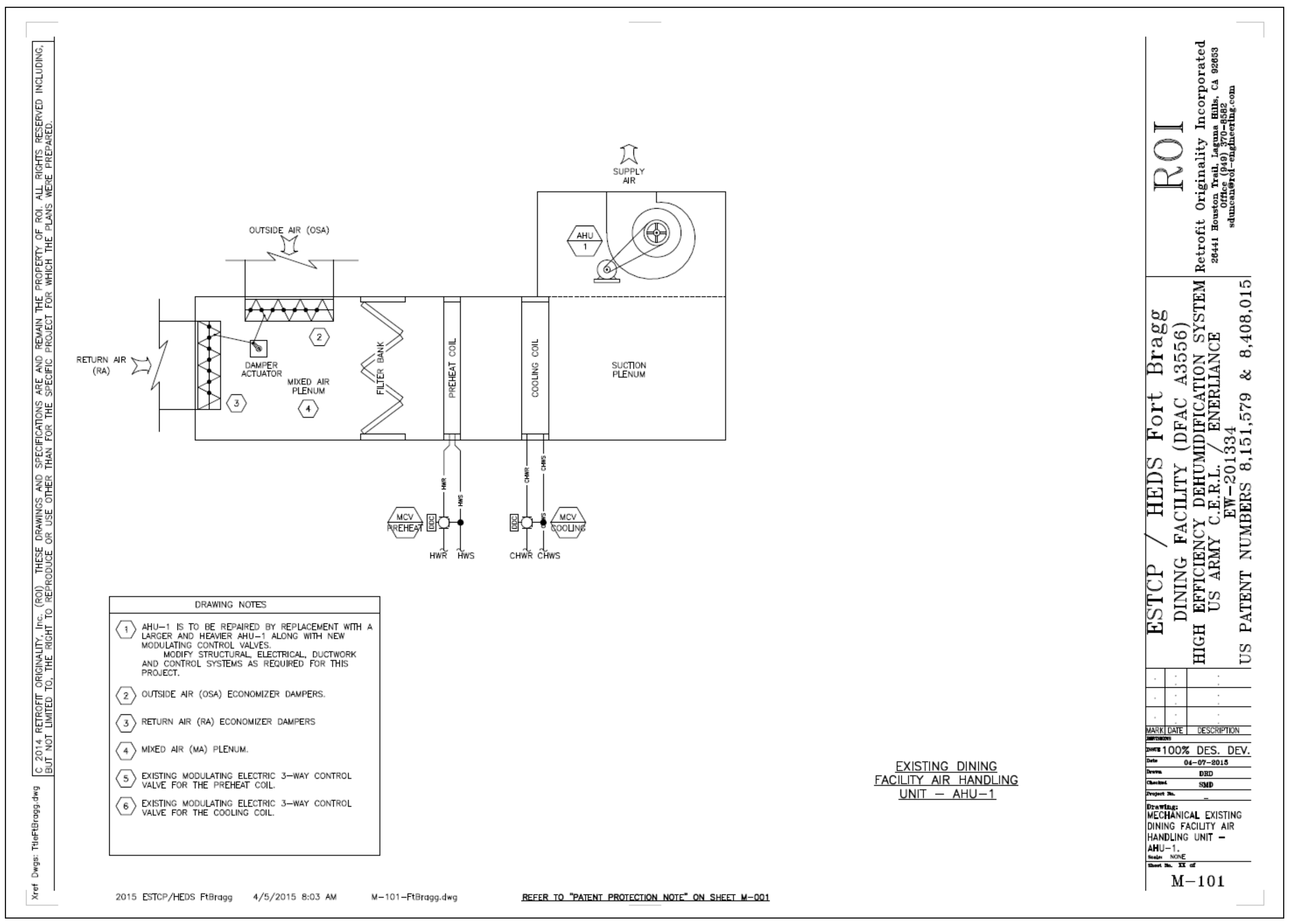




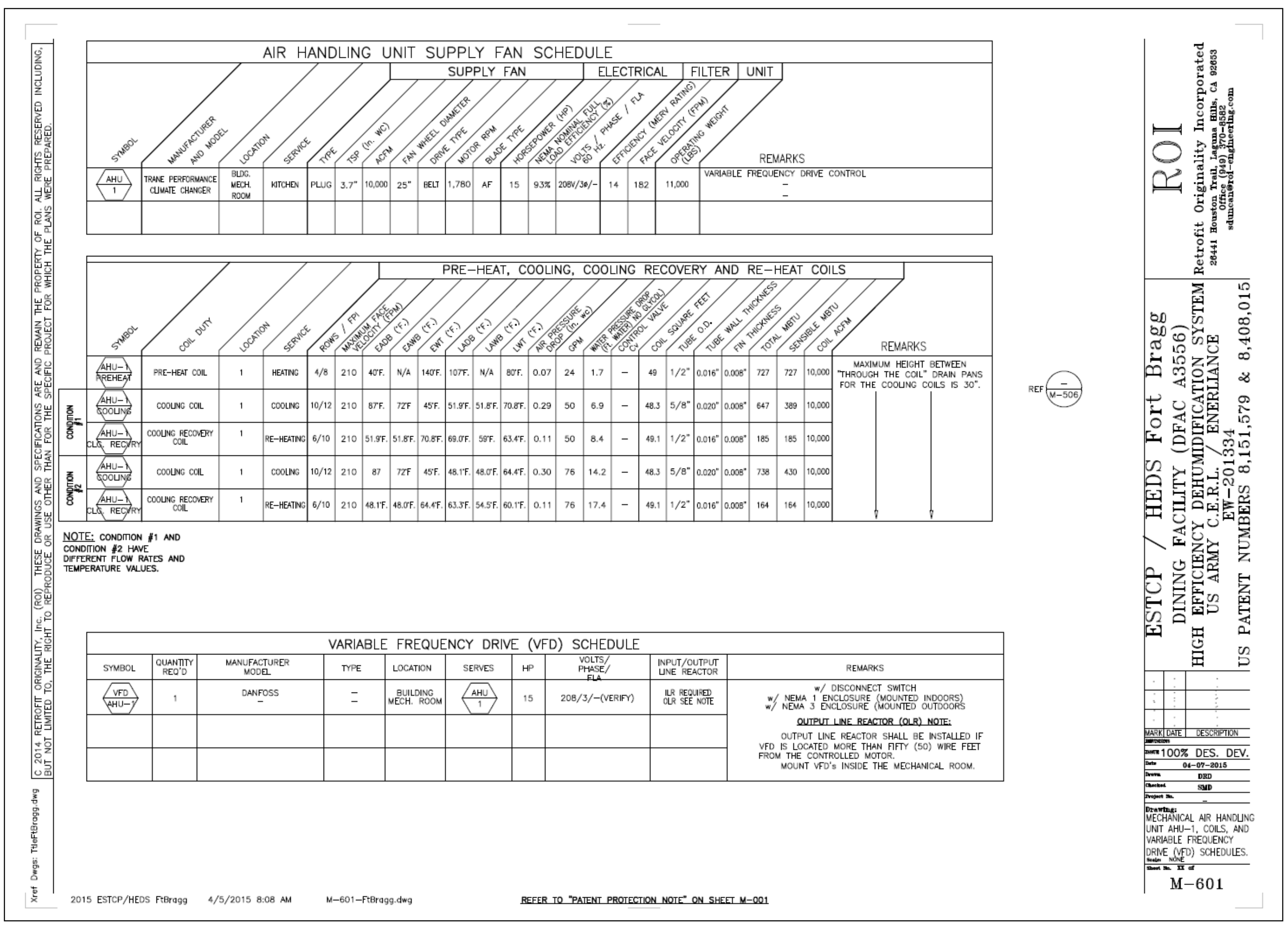




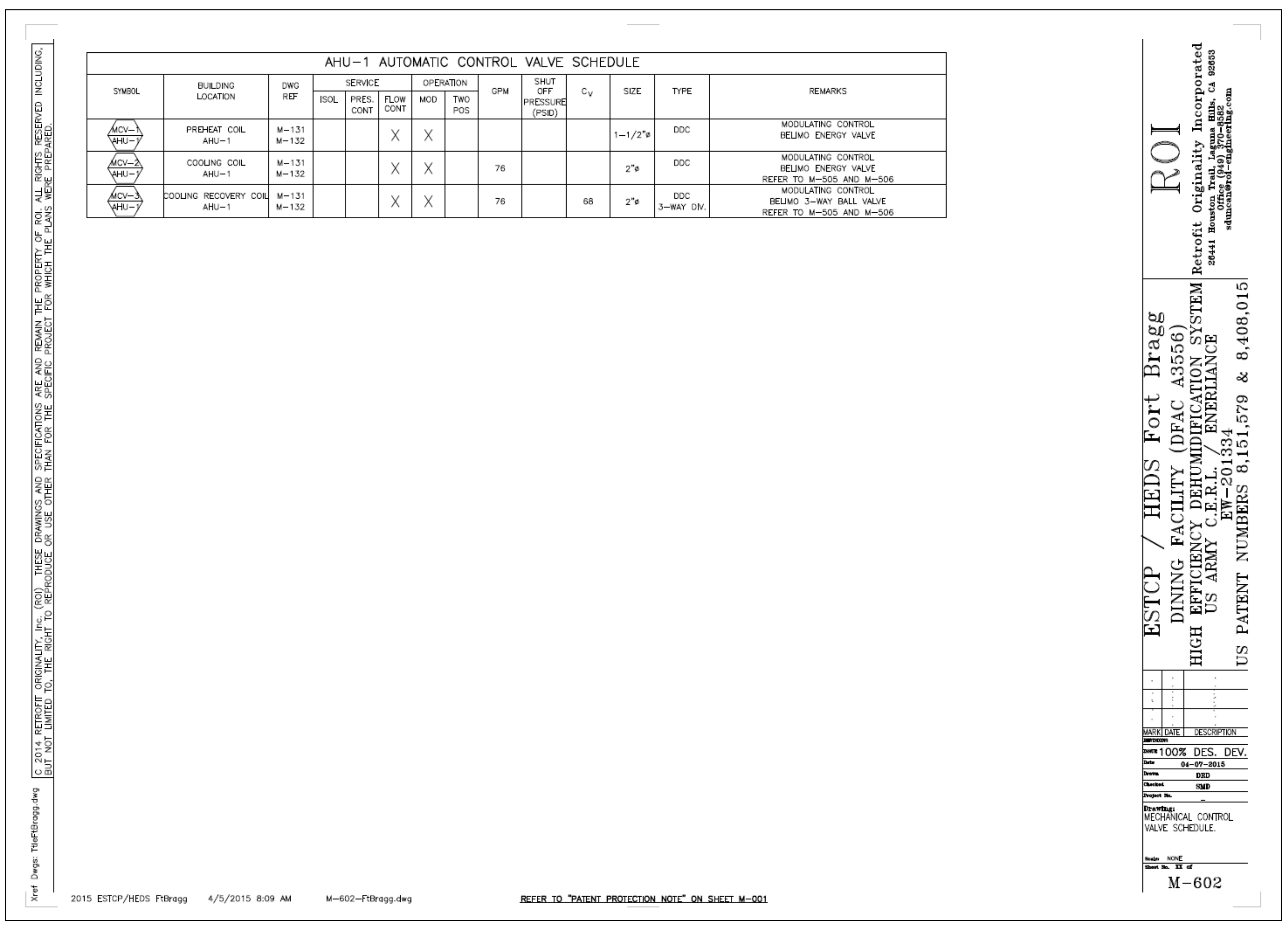




\section{Appendix E: HEDS Instrumentation Cut Sheets}


EV... Series Energy Valve Stainless Steel Ball, NPT Female Ends

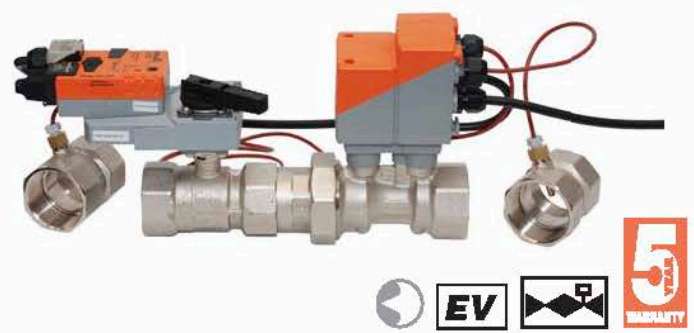

Valve Specifications

\begin{tabular}{|c|c|}
\hline Senvice & $\begin{array}{l}\text { chilled or hot water, } 60 \% \text { glycol max (open } \\
\text { loop/steam not allowed) }\end{array}$ \\
\hline Flow characteristic & equal percentage//inear \\
\hline Controllable flow range & $75^{\circ}$ \\
\hline Size & $1 / 2^{\prime \prime}, 34^{\prime \prime}, 1^{\prime \prime}, 114^{\prime \prime}, 12^{\prime \prime}, 2^{\prime \prime}$ \\
\hline Type of end fitting & NPT female ends \\
\hline \multicolumn{2}{|l|}{ Materials } \\
\hline Body & \\
\hline Value & forged brass, nickel plated \\
\hline Sensor housing & fo rged brass, nickel plated \\
\hline & stainless steal \\
\hline Stem & stainless steel \\
\hline & Teflon ${ }^{\oplus}$ PTFE \\
\hline Characterizing disc & Tetze $^{\circ}$ \\
\hline 0 -ring & EPDM \\
\hline Packing & EPDM \\
\hline Bodyp ressure rating & $250 \mathrm{psi}$ \\
\hline Media temperature range & $14^{\circ} \mathrm{F}$ to $250^{\circ} \mathrm{F}\left[-10^{\circ} \mathrm{C}\right.$ to $\left.+120^{\circ} \mathrm{C}\right]$ \\
\hline Maximum sound level & $\angle 35 \mathrm{~dB}(\mathrm{~A})$ \\
\hline Leakage & $0 \%$ \\
\hline Close-off pressure & $200 \mathrm{psi}$ \\
\hline Differential pressure range $(\Delta P)$ & 1 to $50 \mathrm{psi}^{*}, 5$ to $50 \mathrm{psi}$ \\
\hline $\begin{array}{l}\text { Inlet length required to meet } \\
\text { specified measurement accuracy }\end{array}$ & 5x nominal pipe size (NPS) \\
\hline Humidity & $\angle 95 \%$ RH non-condensing \\
\hline Flow metering technology & $\begin{array}{l}\text { ultrasonic with temperature and glycol } \\
\text { compensation }\end{array}$ \\
\hline Flow control tolerance & $\pm 5 \%$ \\
\hline Flow measurement tolerance & $\pm 2 \%$ \\
\hline Flow measurement repeatability & $\pm 0.5 \%$ \\
\hline Temperature sensors & PTt000 insertion sensors w/NPT pipe body \\
\hline Remote temperature sensor length & $2 \mathrm{ft} .7 .5 \mathrm{in} .[0.8 \mathrm{~m}]$ short, $9.8 \mathrm{ft} .[3 \mathrm{~m}]$ long \\
\hline $\begin{array}{l}\text { Temperature measurement } \\
\text { tolerance }\end{array}$ & According to PTT000 DIN EN6075t Class B. \\
\hline $\begin{array}{l}\text { Resolution of temperature } \\
\text { sensor }\end{array}$ & $0.18^{\circ} \mathrm{F}\left(0.1^{\circ} \mathrm{C}\right)$ \\
\hline Rated impulse voltage & $\begin{array}{l}\text { actuator/sensor: } 0.8 \mathrm{kV} \text { (in accordance with } \\
\text { EN 60730-1) }\end{array}$ \\
\hline Power supply for the flow sensor & actuator is powered by the flow sensor \\
\hline Quality standard & $150900 t$ \\
\hline Agency listings & $\begin{array}{l}\text { UL } 60730-1 / 2-14,2-18, \text { CE according to } \\
\text { 2004/108/EC and 2006/95/EC }\end{array}$ \\
\hline
\end{tabular}

Application

Water-side control of heating and cooling systems for AHUs and water coils. Equal Percentage: heating / cooling applications

\section{Mode of Operation}

The Energy Valve is an energy metering pressure independent control valve that optimizes, documents and proves water coil performance.

\section{Product Features}

The Energy Valve is a two-way pressure independent valve that optimizes, documents, and proves water coil performance. The Energy Valve measure the coil energy using an embedded electronic flow sensor, water supply and return temperature sensors
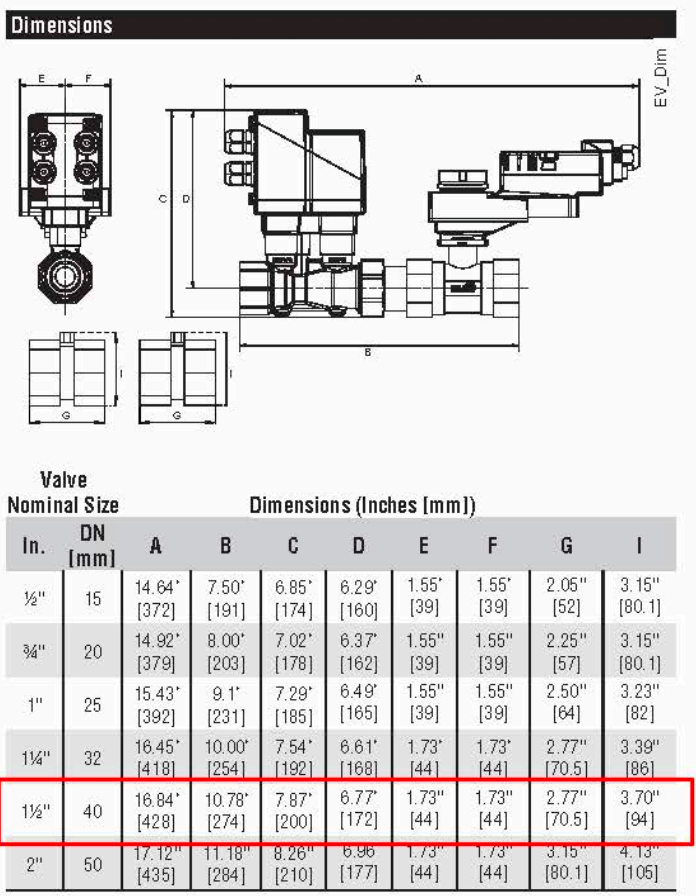

\begin{tabular}{|c|c|c|c|c|c|}
\hline \multirow[b]{2}{*}{$\begin{array}{l}\text { GPM } \\
\text { Range }\end{array}$} & \multicolumn{2}{|c|}{$\begin{array}{l}\text { Valve Nominal } \\
\text { Size }\end{array}$} & \multirow{2}{*}{$\begin{array}{c}\text { Type } \\
\text { 2-way } \\
\text { Female NPT }\end{array}$} & \multirow{2}{*}{$\begin{array}{c}\text { Actuator } \\
\text { Type } \\
\text { Non-Spring } \\
\text { Return }\end{array}$} & \multirow[b]{2}{*}{$\begin{array}{l}\text { Electronic } \\
\text { Fail-Sate }\end{array}$} \\
\hline & Inches & $\begin{array}{c}\text { DN } \\
\text { [mm] }\end{array}$ & & & \\
\hline $1.65-5.5$ & $1 / 2$ & 15 & EV050S-5.5 & LRB, LRX & AKRB, AKRX \\
\hline $5.7-10.3$ & $3 / 4$ & 20 & EV075s-10.3 & LRB, LRX & AKRB, AKRX \\
\hline $10-18.2$ & 1 & 25 & EV100S-18.2 & LRB, LRX & AKRB, AKRX \\
\hline $18.0-28.5$ & $11 / 4$ & 32 & $E V+25 S-28.5$ & NRB, NRX & AKRB, AKRX \\
\hline $24.9-39.6$ & $11 / 2$ & 40 & EV150S-39.6 & NRB, NRX & AKRB, AKRX \\
\hline $34.2-76.1$ & 2 & 50 & EV200S-76.1 & ARB,ARX & AKRB, AKRX \\
\hline
\end{tabular}




\section{EV...Series Energy Valve Non-Spring Return and Electronic Fail-Safe Actuator Series}

\section{Operation}

The actuator is electronically protected against overload.

The actuators use a brushless DC motor, which is controlled by an Application Specific Integrated Circuit (ASIC). The ASIC monitors and controls the actuators rotation and provides a digital rotation sensing (DRS) function to prevent damage to the actuator in a stall condition. Power consumption is reduced in a holding mode.

Add-on auxiliary switches or feedback potentiometers are easily fastened directly onto the actuator body for signaling and switching functions

Non-Spring Return LR, NR, GR, AR and Electronic Fail-Safe Actuators AKR and GKR

\begin{tabular}{|c|c|}
\hline \multicolumn{2}{|l|}{ Actuator Specifications } \\
\hline Power supply & $\begin{array}{l}24 \mathrm{VAC} \pm 20 \% \\
24 \mathrm{VDC} \pm 10 \%\end{array}$ \\
\hline Electric frequency & $50 / 60 \mathrm{~Hz}$ \\
\hline \multicolumn{2}{|l|}{ Power consumption } \\
\hline LR Series & $4.5 \mathrm{~W}$ \\
\hline NR Series & $5.5 \mathrm{~W}$ \\
\hline GR Series & $8 \mathrm{~W}$ \\
\hline AR Series & $7 \mathrm{~W}$ \\
\hline AKR Series & $10.5 \mathrm{~W}$ \\
\hline GKR Series & $14 \mathrm{~W}$ \\
\hline \multicolumn{2}{|l|}{ Transformer sizing } \\
\hline LR Series & 8 VA (class 2 power source) \\
\hline NR Series & 9 VA (class 2 power source) \\
\hline GR Series & 12 VA (class 2 power source) \\
\hline AR Series & 11 VA (class 2 power source) \\
\hline AKR Series & 22 VA (class 2 power source) \\
\hline GKR Series & 24 VA (class 2 power source) \\
\hline Electrical connection & $\begin{array}{l}18 \mathrm{GA} \text {, plenum rated cable } \\
1 / 2 \text { conduit connector } \\
\text { protected NEMA } 2 \text { (IP54) } 3 \mathrm{ft} \text {. }[1 \mathrm{~m}] \text { cable }\end{array}$ \\
\hline Overload protection & electronic throughout $0^{\circ}$ to $90^{\circ}$ rotation \\
\hline Operation range $Y$ & 2 to $10 \mathrm{VDC}$ (default) VDC variable \\
\hline Control & proportional \\
\hline Input impedance & $100 \mathrm{k} \Omega(0.1 \mathrm{~mA}) .500 \Omega$ \\
\hline How Feedback & 0 to 10 VDC (default), VDC variable \\
\hline Communication & BACnet IP. BACnet MS/TP, web interface \\
\hline \multicolumn{2}{|l|}{ Torque } \\
\hline LR Series & 45 in-lbs [5 Nm] \\
\hline NR Series & 90 in-lbs [10 Nm] \\
\hline GR/GK Series & 180 in-lbs [20 Nm] \\
\hline AR/AK Series & 360 in-lbs [40 Nm] \\
\hline Direction of rotation & electronically variable \\
\hline Manual override & extemal push button \\
\hline Running time normal operation & 90 seconds \\
\hline Running time fail-sale & 35 seconds \\
\hline Humidity & 5 to $95 \%$ RH, non-condensing \\
\hline Ambient temperature & $-22^{\circ} \mathrm{F}$ to $122^{\circ} \mathrm{F}\left[-30^{\circ} \mathrm{C}\right.$ to $\left.50^{\circ} \mathrm{C}\right]$ \\
\hline Storage temperature & $-40^{\circ} \mathrm{F}$ to $176^{\circ} \mathrm{F}\left[-40^{\circ} \mathrm{C}\right.$ to $\left.80^{\circ} \mathrm{C}\right]$ \\
\hline Housing & NEMA 2, IP54, UL enclosure type 2 \\
\hline Noise level & $\angle 45 \mathrm{~dB}(\mathrm{~A})$ at 90 seconds \\
\hline Servicing & maintenance free \\
\hline Quality standard & ISO 9001 \\
\hline \multicolumn{2}{|l|}{ Weight } \\
\hline AR Series & $2.65 \mathrm{lbs}[1.2 \mathrm{~kg}]$ \\
\hline GR Series & $4.85 \mathrm{lbs}[2.2 \mathrm{~kg}]$ \\
\hline AK Series & $3.30 \mathrm{lbs}[1.5 \mathrm{~kg}]$ \\
\hline GK Series & $5.51 \mathrm{lbs}[2.5 \mathrm{~kg}]$ \\
\hline LR Series & $1.02 \mathrm{lbs}[462 \mathrm{~g}]$ \\
\hline NR Series & $1.20 \mathrm{lbs}[544 \mathrm{~g}]$ \\
\hline Agency listings & $\begin{array}{l}\text { UL 60730-1/2-14, 2-18, CE according to } \\
\text { 2004/108/EC and 2006/95/EC }\end{array}$ \\
\hline
\end{tabular}

Wiring Diagrams

\section{× installation notes}

(A) Actuators with appliance cables are numbered

2. CAUTION Equipment damage!

Actuators may be connected in parallel.

Power consumption and input impedance must be observed.

3. Actuators may also be powered by $24 \mathrm{VDC}$

Actuators with plenum rated cable do not have numbers on 18 wires; use color codes instead.

\section{$\checkmark$ APPLICATION NOTES}

Meets cULus requirements without the need of an electrical ground connection

1. WARNING Live Electrical Components!

. During installation, testing, servicing and troubleshooting of this product, it may be necessary to work with live electrical components. Have a qualified licensed electrician or other individual who has been properly trained in handling live electrical components perform these tasks. Failure to follow all electrical safety precautions when exposed to live electrical components could result in death or serious injury.

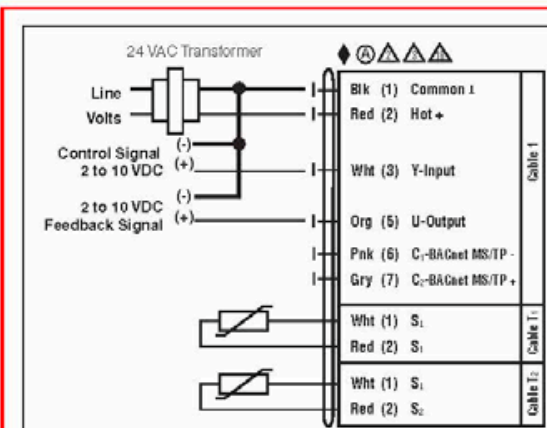

2-10 VDC

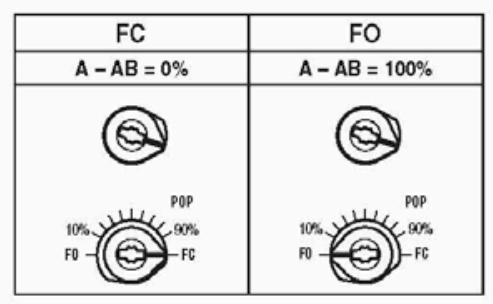

Fail-Safe Power-0ff Position, AKRB, AKRX, GKRB, GKRX

\section{System Ground}

In cases where the valve body is electrically isolated from the water pipe, an earth ground should be installed in order for the sensor to work properly. Earth ground can be connected directly on the sensor body. A connection point is provided on the flange of the sensor body. 


\section{BELIMO}

Energy Valve

Flow Pressure Characteristics

Flow Reduction Chart

\begin{tabular}{|c|c|c|c|c|c|c|}
\hline \multicolumn{2}{|c|}{ Size } & \multirow[b]{2}{*}{$5 \mathrm{Psi}^{*}$} & \multirow[b]{2}{*}{4 Psi } & \multirow[b]{2}{*}{3 Psi } & \multirow[b]{2}{*}{2 Psi } & \multirow[b]{2}{*}{1 Psi } \\
\hline Inches & DN [mm] & & & & & \\
\hline $1 / 2$ & 15 & $5.5 \mathrm{GPM}$ & $5.5 \mathrm{GPM}$ & $5.5 \mathrm{GPM}$ & $4.8 \mathrm{GPM}$ & $3.4 \mathrm{GPM}$ \\
\hline $3 / 4$ & 20 & $10.3 \mathrm{GPM}$ & $10.3 \mathrm{GPM}$ & $9.9 \mathrm{GPM}$ & $8.1 \mathrm{GPM}$ & $5.7 \mathrm{GPM}$ \\
\hline 1 & 25 & $18.2 \mathrm{GPM}$ & $18.2 \mathrm{GPM}$ & $17.2 \mathrm{GPM}$ & $14.1 \mathrm{GPM}$ & $9.9 \mathrm{GPM}$ \\
\hline $11 / 4$ & 32 & $28.5 \mathrm{GPM}$ & $28.5 \mathrm{GPM}$ & $28.5 \mathrm{GPM}$ & $23.3 \mathrm{GPM}$ & $16.5 \mathrm{GPM}$ \\
\hline $11 / 2$ & 40 & $39.6 \mathrm{GPM}$ & 39.6 GPM & $39.6 \mathrm{GPM}$ & 34.9 GPM & $24.7 \mathrm{GPM}$ \\
\hline 2 & 50 & $76.1 \mathrm{GPM}$ & 74 GPM & $64.1 \mathrm{GPM}$ & $52.3 \mathrm{GPM}$ & $37 \mathrm{GPM}$ \\
\hline $21 / 2$ & 65 & 127 GPM & $93 \mathrm{GPM}$ & 81 GPM & $66 \mathrm{GPM}$ & $47 \mathrm{GPM}$ \\
\hline 3 & 80 & $180 \mathrm{GPM}$ & $138 \mathrm{GPM}$ & $120 \mathrm{GPM}$ & $97 \mathrm{GPM}$ & $69 \mathrm{GPM}$ \\
\hline 4 & 100 & $317 \mathrm{GPM}$ & 235 GPM & 203 GPM & $166 \mathrm{GPM}$ & $117 \mathrm{GPM}$ \\
\hline 5 & 125 & $495 \mathrm{GPM}$ & $367 \mathrm{GPM}$ & $318 \mathrm{GPM}$ & $260 \mathrm{GPM}$ & $183 \mathrm{GPM}$ \\
\hline 6 & 150 & 713 GPM & $550 \mathrm{GPM}$ & $476 \mathrm{GPM}$ & 389 GPM & 275 GPM \\
\hline
\end{tabular}

*V'nom = Maximum flow for each valve body size.

Equal Percentage Flow Characteristic Flow Response to Signal Input

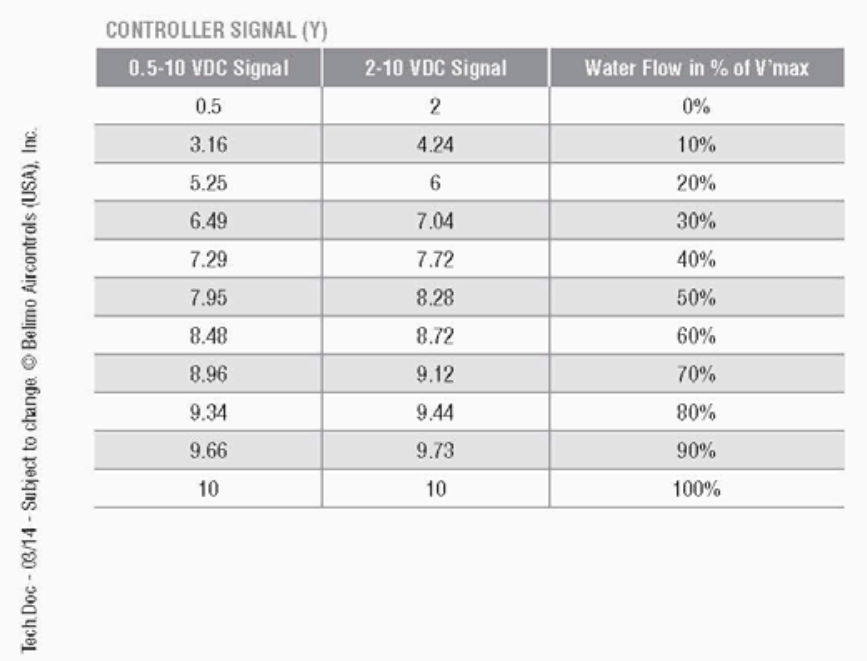




\section{B3 Series, Three Way, Characterized Control Valve}

Stainless Steel Ball and Stem

\section{BELIMO}
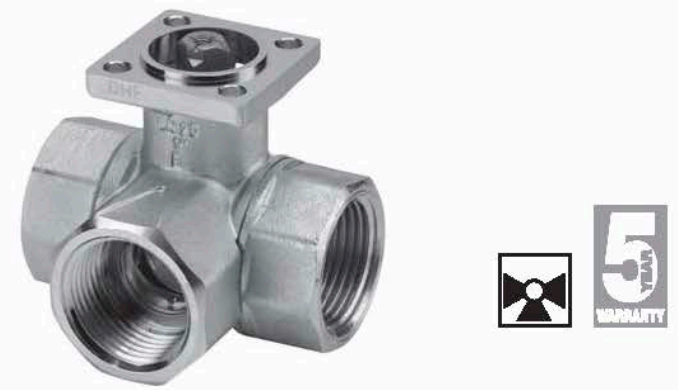

\begin{tabular}{|c|c|}
\hline \multicolumn{2}{|l|}{ Technical Data } \\
\hline Service & chilled or hot water, $60 \%$ glycol \\
\hline Flow characteristic & $\begin{array}{l}\text { A-port equal percentage } \\
\text { B-port modified for constant common por } \\
\text { flow }\end{array}$ \\
\hline Controllable Flow Range & $75^{\circ}$ \\
\hline Sizes & $112^{\prime \prime}, 3 / 4^{\prime \prime}, 1^{\prime \prime}, 11 / 4^{\prime \prime}, 11 / 2^{\prime \prime}, 2^{\prime \prime}$ \\
\hline Type of end fitting & NPT female ends \\
\hline $\begin{array}{l}\text { Materials: } \\
\text { Body } \\
\text { Ball } \\
\text { Stem } \\
\text { Seats } \\
\text { Characterizing disc } \\
\text { Packing } \\
\end{array}$ & $\begin{array}{l}\text { forged brass, nickel plated } \\
\text { stainless steal } \\
\text { stainless steel } \\
\text { PTFE } \\
\text { Tefzel }^{(9} \\
2 \text { EPDM 0-rings, lubricated }\end{array}$ \\
\hline $\begin{array}{l}\text { Body pressure rating } \\
600 \mathrm{psi} \\
400 \mathrm{psi} \\
\end{array}$ & $\begin{array}{l}1 / 2 " 1 " \\
-1 / 4^{\prime \prime}-2^{\prime \prime}\end{array}$ \\
\hline Media temp. range & $0^{\circ} \mathrm{F}$ to $250^{\circ} \mathrm{F}\left[-18^{\circ} \mathrm{C}\right.$ to $\left.120^{\circ} \mathrm{C}\right]$ \\
\hline $\begin{array}{l}\text { Close off pressure } \\
200 \mathrm{psi}\end{array}$ & $1 / 2^{\prime \prime}-2^{\prime \prime}$ \\
\hline $\begin{array}{l}\text { Maximum differential } \\
\text { pressure }(\Delta \mathrm{P})\end{array}$ & 50 psi for typical applications \\
\hline Leakage & $\begin{array}{l}0 \% \text { for } \mathrm{A} \text { to } \mathrm{AB} \\
<2.0 \% \text { for } \mathrm{B} \text { to } \mathrm{AB}\end{array}$ \\
\hline External leakage & according to EN $12266-1: 2003$ \\
\hline $\mathrm{C}_{v}$ rating & $\begin{array}{l}\text { A-port: see p roduct chart for values } \\
\text { B-port: } 70 \% \text { of } A \text { to } A B C_{v}\end{array}$ \\
\hline
\end{tabular}

\section{Dimensions}
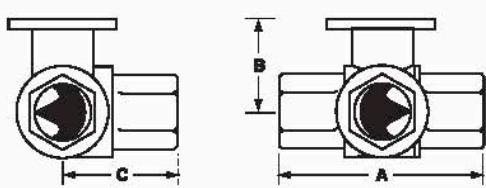

Value Nominal Size

\begin{tabular}{|c|c|c|c|c|c|}
\hline & \multicolumn{3}{|c|}{ S pintines } \\
\hline Valve Body & Inches & DN [mm] & A & B & C \\
\hline B307-B311 & $1 / 2$ & 15 & $2.41 "[61.1]$ & $1.39^{\prime \prime}[35.2]$ & $1.20^{\prime \prime}[30.6]$ \\
\hline$B 312-B 316$ & $1 / 2 "$ & 15 & $2.38^{\prime \prime}[60.4]$ & $1.78^{\prime \prime}[45.2]$ & $1.29^{\prime \prime}[32.8]$ \\
\hline $\mathrm{B} 317-\mathrm{B} 321$ & $3 / 4$ & 20 & $2.73^{\prime \prime}[69.3]$ & $1.87^{\prime \prime}[47.4]$ & $1.47^{\prime \prime}[37.3]$ \\
\hline $\mathrm{B} 322-\mathrm{B} 325$ & $1^{\prime \prime}$ & 25 & $3.09^{\prime \prime}[78.4]$ & $1.87^{\prime \prime}[47.4]$ & $1.59^{\prime \prime}[40.3]$ \\
\hline $82020-204$ & -1141 & 20 & $206 " 1-1006]$ & $227^{\prime \prime}[67.7]$ & $2+14^{\prime \prime}[54.2]$ \\
\hline B338-B341 & $11 / 2 "$ & 40 & $4.39^{\prime \prime}[111.6]$ & 2.51 " [63.7] & $2.40^{\prime \prime}[61.1]$ \\
\hline $0047=$ & & & $4.900^{\prime \prime}+124.5$ & 2.701009 .5 & 2.74 [09.7] \\
\hline
\end{tabular}

\section{Application}

This valye is typically used in air handling units on heating or cooling coils, and fan coil unit heating or cooling coils. Some other common applications include Unit Ventilators, VAV box re-heat coils and bypass loops. This valye is suitable for use in a hyd ronic system with variable or constant flow.

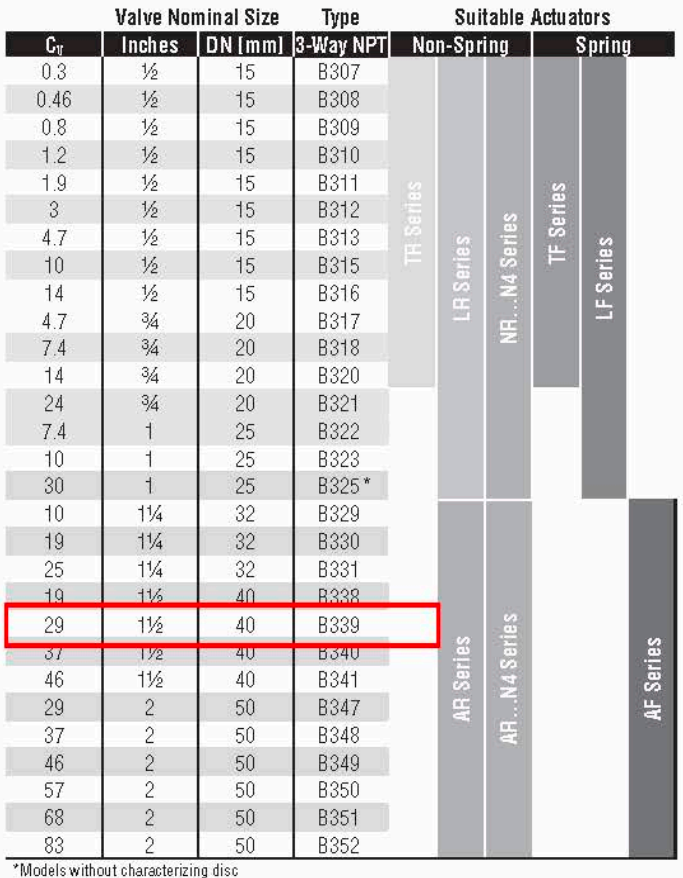

\section{Flow Patterns}

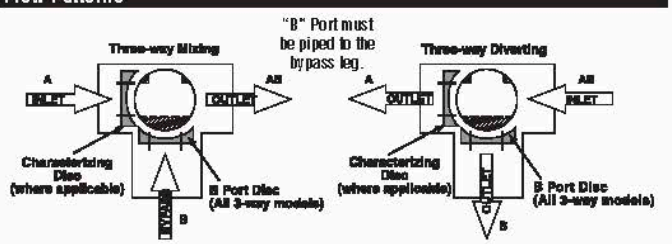


AFRB24-SR, AFRX24-SR

Proportional, Spring Return, $24 \mathrm{~V}$, for 2 to 10 VDC or 4 to $20 \mathrm{~mA}$ Control Signal

BELIMO

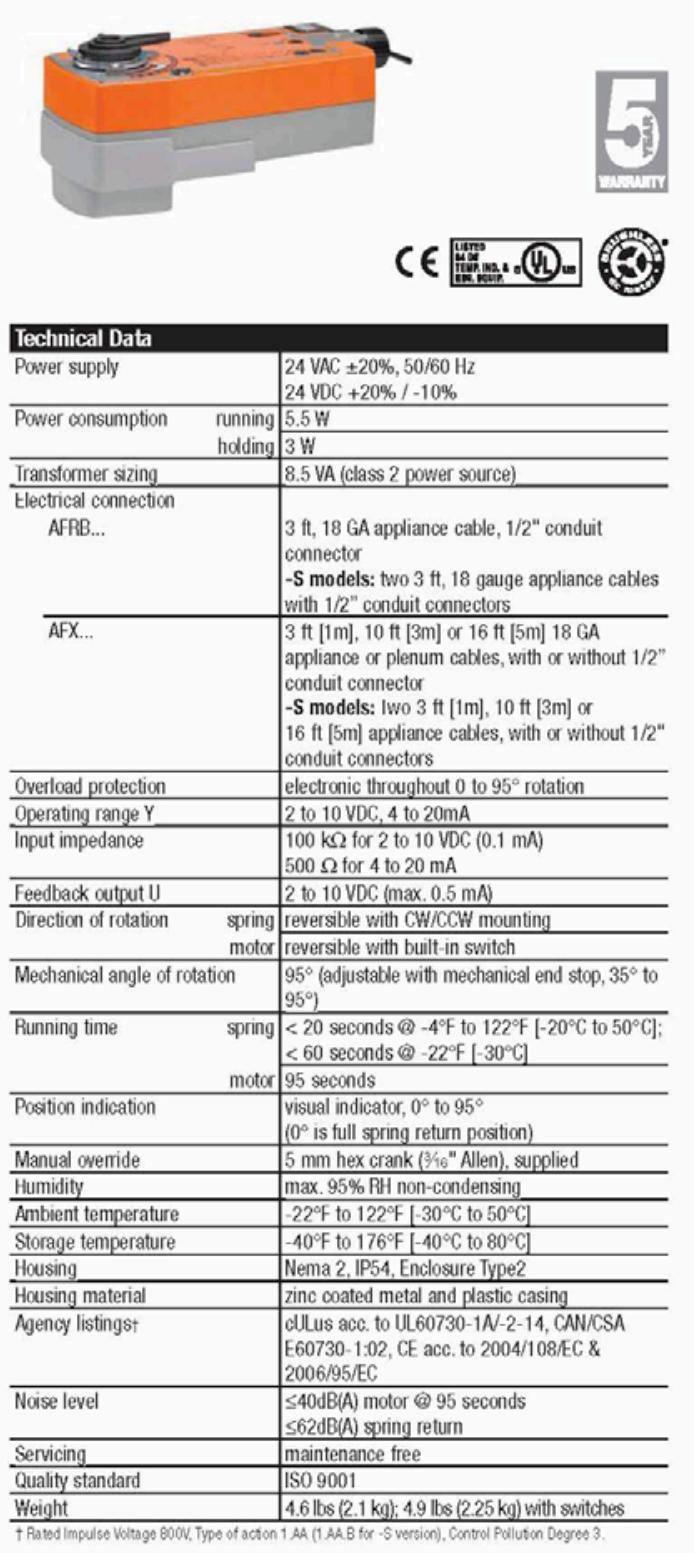

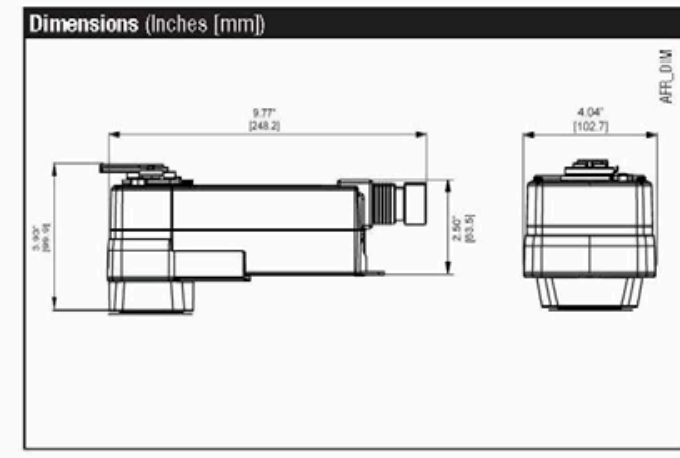




\begin{tabular}{|c|c|}
\hline \multicolumn{2}{|l|}{ Accessories } \\
\hline AV 8-25 & Shaft extension \\
\hline IND-AFB & Damper position indicator \\
\hline KH-AFB & Crank arm \\
\hline K7-2 & Universal damp for up to $1.05^{\prime \prime}$ dia jackshafts \\
\hline IF-CCUS & Conduit fitting \\
\hline Tool-06 & $8 \mathrm{~mm}$ and $10 \mathrm{~mm}$ wrench \\
\hline ZG-100 & Universal mounting bracket \\
\hline$Z \mathrm{G}-101$ & Universal mounting bracket \\
\hline ZG-118 & $\begin{array}{l}\text { Mounting bracket for Barber Colmans MA } 3 . / 4 \text {.., Honeywello } \\
\text { Mod III or IV or Johnsone Series } 100 \text { replacement or new crank } \\
\text { arm type installations }\end{array}$ \\
\hline ZG-AFB & Crank arm adaptor kit \\
\hline ZG-AFB118 & Crank arm adaptor kit \\
\hline ZS-100 & Weather shield (metal) \\
\hline$Z S-150$ & Weather shield (polycarbonate) \\
\hline$Z \mathrm{~S}-260$ & Explosion-proof housing \\
\hline$\underline{Z S-300}$ & NEMA 4X housing \\
\hline 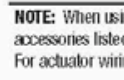 & 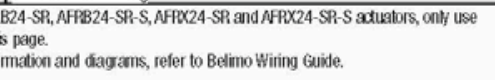 \\
\hline
\end{tabular}

Spring return control damper actuators shall be direct coupled type which require no crank amm and linkage and be capable of direct mounting to a jackshaft up to a $1.05^{\circ}$ crank arm and linkage and be capable of direct mounting to a jackshaft up to a $1.05^{\circ}$
diameter. The actuator must provide proportional damper control in response to a 2 to $10 \mathrm{VDC}$ or, with the addition of a $500 \Omega$ resistor, a 4 to $20 \mathrm{~mA}$ control input from an electronic controller or positioner. The actuators must be designed so that they may be used for either clockwise or counterdockwise fail-sate operation. Actuators shall use a brushless DC motor controlled by a microprocessor and be protected from overload at all angles of rotation. Run time shall be canstant, and independent of torgue. A 2 to 10 VDC feedback signal shall be prowided for position feedback. Actuators shall be clllus Approved and have a 5 year warr anty, and be manufactured under IS0 9001 International Quality Control Standards. Actuators shall be as manufactured by Belimo.

\section{Wiring Diagrams}

\section{× installation notes}

1. Provide overload protection and disconnect as required.

2. CAUTION Equipment Damage!

Actuators may be connected in parallel.

Power consumption and input impedance must be observed.

Up to 4 actuators may be connected in paralle if not mechanically mounted

2 to the same shaft. With 4 actuators wired to one $500 \Omega$ resistor.

Power consumption must be observed.

3. Actuator may also be powered by $24 \mathrm{VDC}$.

For end position indication, interlock control, tan startup, etc.. AFB24-SR-S and AFX24-SR-S incorporates two built in auxiliary switches: 2 XSDT, $3 A$ $(0.5 \mathrm{~A}) @ 250$ VAC, UL Approved, one switch is fixed at $+10^{\circ}$, one is adjust. able $10^{\circ}$ to $90^{\circ}$.

A. Only connect common to neg. $(-)$ leg of control circuits

\section{APPLICATION NOTES}

The ZG-R01 $500 \Omega$ resistor converts the 4 to $20 \mathrm{~mA}$ control signal to 2 to $10 \mathrm{VDC}$

ATTENTION: AFRBZ4-SH(S) and ARRX24-SR(-S) Gannor be tandem mounted on the same damper or valve shaft. Only On/Off and MFT AF models can be used for tandem mount applications.
WARNING Live Electrical Components!

Duing instalation, testing, servicing and troublesh ooting of this product, it may be necessary by work with live electrical components. Have a qualified iserned electrician or other indivitual who has been property trained in handing live electrizad components perform these tasks. Failure to bollow all electrical saltely precaulions when exposed to live electrical compo-

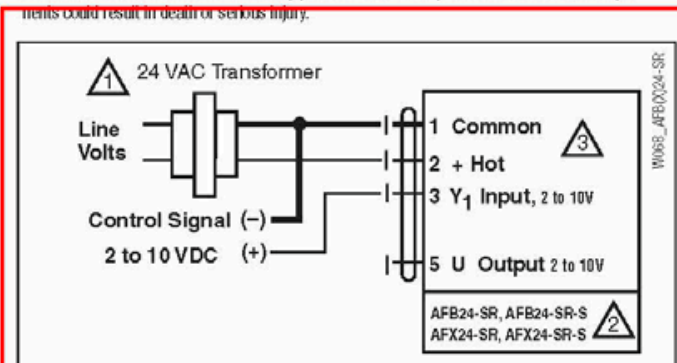

2 to $10 \mathrm{VDC}$ control of AFRB24-SR and AFRX24-SR

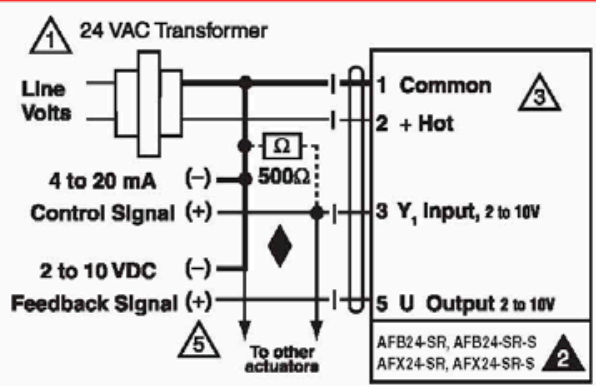

4 to $20 \mathrm{~mA}$ control of AFRB24-SR and AFRX24-SR with

2 to 10 VDC feedback output

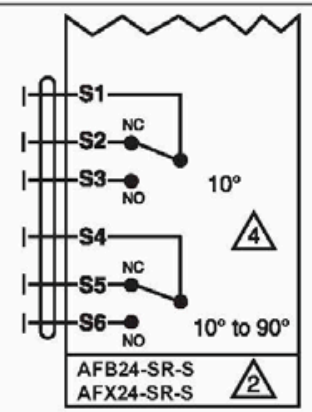

Auxiliary switches for AFRB24-SR-S, AFX24-SR-S 


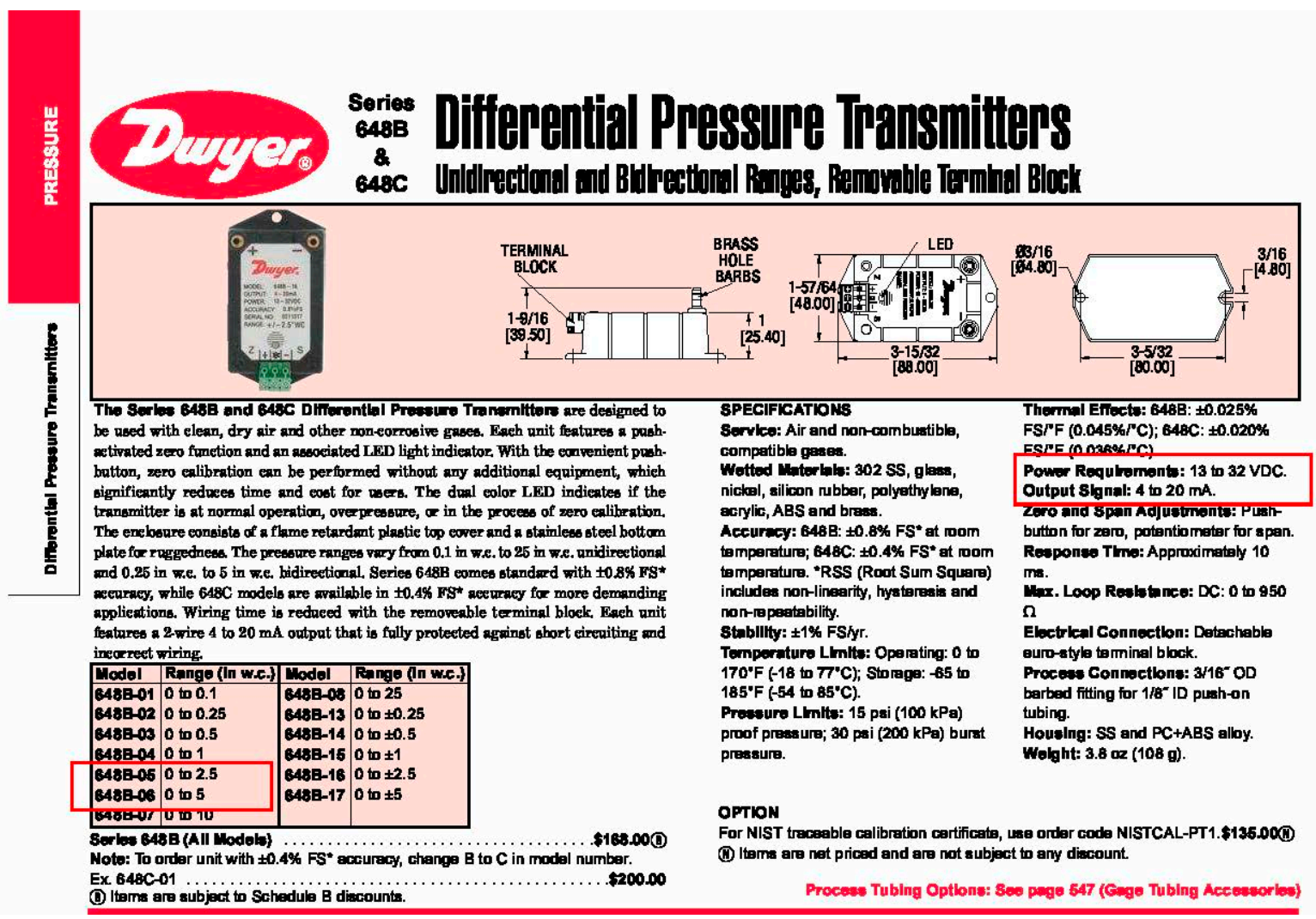


Hybrid Series Thermal Dispersion Airflow/Temperature Measurement Device (ATMD)

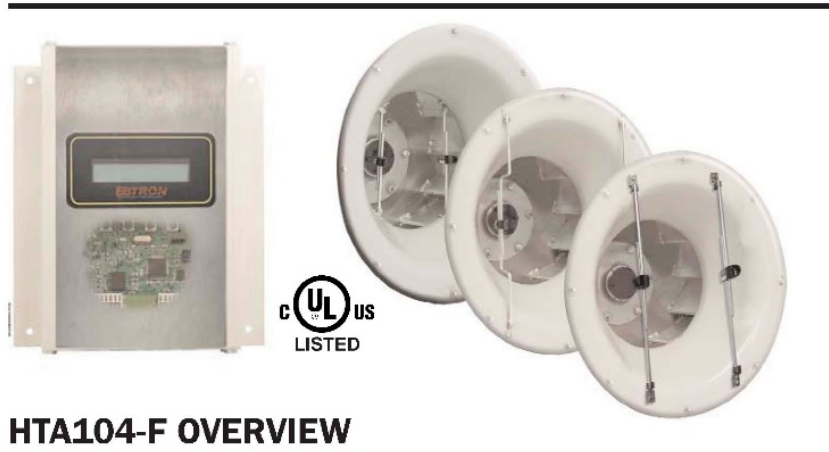

The Hybrid series model HTA104-F advanced thermal dispersion airflow measurement device combines features of EBTRON's top of the line Gold Series and economical Silver Series products with innovative new features designed for throat, face or forward mounting in centrifugal, vane axial and plenum fan inlets. The HTA104 $F$ is ideal for fan tracking applications where duct configurations preclude the use of duct and plenum probes and where repeatability and accuracy is paramount from $0-10,000$ feet per minute. Where field adjustment is required, a built in Field Calibration Wizard allows for simple one or two point field adjustment to factory calibration. The ATMD includes an HTA104 industrial grade integrated transmitter with independent analog airflow/temperature outputs of 0-5VDC/0-10 VDC or 4-20 mA for virtually all modern building automation systems (BAS).

\section{APPLICATIONS}

- Volumetric airflow rate tracking for single and dual-inlet fan applications.

- Building pressurization control.

- Monitoring air changes.

- Temperature and humidity control.

- Programmable local/remote alarm for $\mathrm{Hi} / \mathrm{Lo} /$ Setpoint with hysteresis.

\section{SYSTEM FEATURES}

- EBTRON Advanced Thermal Dispersion (TD) airflow measurement technology ensures accurate, repeatable measurement from zero flow (still air).

- Each sensor is factory calibrated at 16 points to NIST-traceable standards.

- Versatile design permit installation directly in the throat of centrifugal or vane axial fans, or on the face of more sensitive plenum fans.

- Altitude compensation feature for flow correc tion at elevations up to $18,000 \mathrm{ft}(5,486 \mathrm{~m})$

- Highest quality, reliable and stable hermetically sealed "bead-in-glass" thermistors.

- Simple push-button user interface for field configuration and diagnostics.

\section{HTA104-F SPECIFICATIONS}

\section{System}

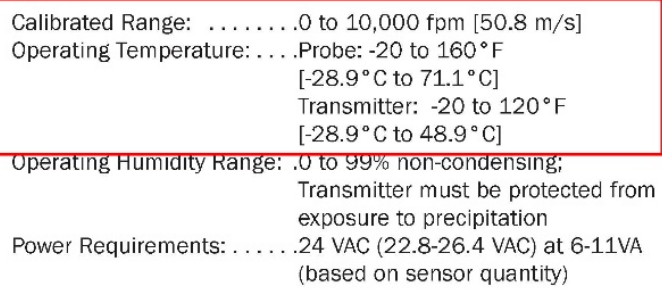

Transmitter and Enclosure

Transmitter Construction: . . Heavy duty with industrial grade IC's and rugged aluminum chassis with sliding cover

Transmitter Dimensions: ...6.475 x $5.750 \times 2.000$ in $(\mathrm{H} \times \mathrm{W} \times \mathrm{D})$ [164.47 x $146.05 \times 50.8 \mathrm{~mm}]$

Transmitter Mounting: . . . . . Four 0.188 in $(4.76 \mathrm{~mm})$ diameter mounting holes at 0.375 in $(9.525$ $\mathrm{mm}$ ) from top/bottom and left/right edges on integral mounting plate

\section{Sensor Probes}

Sensor Construction: . . . . . Two bead-in-glass thermistors in a GFP sensor housing sealed with waterproof marine grade epoxy.
Mounting Brackets: . . . . . . Type 304 stainless steel, zinc-plated adjustable rods

Standard Size Ranges: . . . . From 7 to 77 in (17.78 to 195.58

$\mathrm{cm}$ ) diameter (depending on mount style) for single or dual inlet applications.

Maximum Probes/Sensors: .Single Inlet: 2 probes/ 2 sensors Dual Inlet: 4 probes $/ 2$ sensors

\begin{tabular}{|c|c|}
\hline $\begin{array}{l}\text { Factory Calibrated Sensor } \\
\text { Accuracy: } \ldots \ldots \ldots \ldots \ldots \\
\text { Probe/Transmitter Cable: }\end{array}$ & $\begin{array}{l}\text { Airflow: } \pm 2 \% \text { of reading } \\
\text { Temperature: } \pm 0.15^{\circ} \mathrm{F}\left[ \pm 0.08^{\circ} \mathrm{C}\right] \\
.10 \mathrm{ft} \text {. [3.05 m] plenum rated FEP } \\
\text { cable, positive locking connector } \\
\text { with circular DIN plug (Optional cable } \\
\text { length to } 50 \text { feet }[15.24 \mathrm{~m}] \text { ) }\end{array}$ \\
\hline
\end{tabular}

\section{Output Interface}

\begin{tabular}{|c|}
\hline 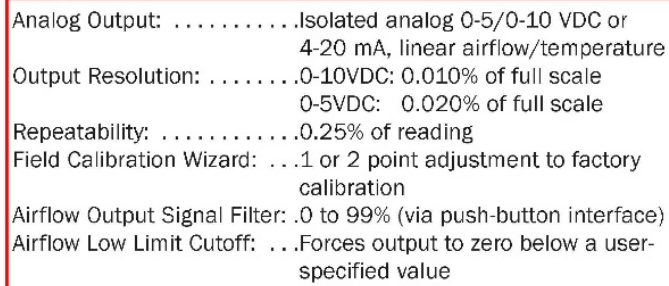 \\
\hline
\end{tabular}

EBTRON, Inc. 1663 Hwy. 701 S., Loris SC 29569 • Toll Free: 800.2EBTRON (232.8766) • Fax: 843.756.1838 - Internet: EBTRON.com 


\section{HYBRID SERIES TECHNOLOGY OVERVIEW}

The HTA104 transmitter can process up to 4 individual sensing nodes for fan inlet applications and requires 24 VAC to provide airflow and temperature measurement outputs. Models are available with outputs for analog (HTA104) and RS-485 (HTN104) BAS networks. The transmitter is independent of the sensor probes thus eliminating field matching. The transmitter includes a 16 character LCD display that indicates airflow, temperature and system status, and is also useful during configuration and diagnostic modes. Field configuration and diagnostics are accomplished through a simple push-button interface on the main circuit board for selection of units of measure, display units, output scaling, digital filtering, diagnostics and instrument status. Individual sensor airflow and temperature measurements can be displayed and are beneficial as an HVAC system diagnostic tool. A Field Calibration Wizard permits one or two point field adjustment of factory calibration, ideal for applica- tions where obstructions in and near the fan inlet bell mouth can result in measurement uncertainty in excess of sensor accuracy. The airflow output signal can be digitally filtered and a process low limit can be set to force the transmitter output to zero when airflow falls below a user defined value; important in applications that can be affected by transient wind gusts at low airflow rates.

EBTRON's HF1 sensor probes are available for single or dual fan inlet designs in six standard sizes spanning inlet diameters from 11 to 64 in $(27.9$ to $162.56 \mathrm{~cm})$. A Throat Mount installation option is available for conventional vane-axial type fans, while Face Mount and Forward Mount installation options permit installation on more sensitive plenum fan applications to minimize both noise and fan performance effects.

FAN INLET PROBE STANDARD SIZE TABLES

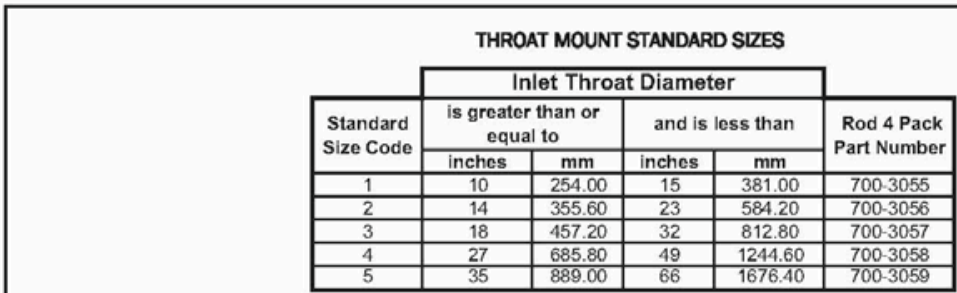

"D"Inlet Throat Diameter is measured across the smaller inside diameter of the fan bell.

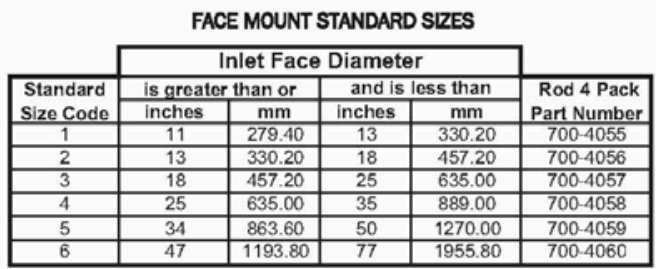

"D"Inlet Face Dlameter is measured across the Elat Face at the Flare Edge at the dlameter where the flare Just begins.

\begin{tabular}{|c|c|c|c|c|c|}
\hline & \multicolumn{4}{|c|}{ FORWARD MOUNT STANDARD SIZES } & \\
\hline & \multicolumn{4}{|c|}{ Inlet Face Diameter } & \\
\hline \multirow{2}{*}{$\begin{array}{l}\text { Standard } \\
\text { Size Code }\end{array}$} & \multicolumn{2}{|c|}{ is greater than or } & \multicolumn{2}{|c|}{ and is less than } & \multirow{2}{*}{$\begin{array}{l}\text { Rod } 4 \text { Pack } \\
\text { Part Number }\end{array}$} \\
\hline & inches & $\mathrm{mm}$ & inches & $\mathrm{mm}$ & \\
\hline 1 & 7 & 177.80 & 13 & 330.20 & $700-5055$ \\
\hline 2 & 10 & 254.00 & 18 & 457.20 & $700-5056$ \\
\hline 3 & 14 & 355.60 & 25 & 635.00 & $700-5057$ \\
\hline$\frac{4}{4}$ & 19 & 482.60 & 35 & 889.00 & $700-5058$ \\
\hline$\frac{1}{5}$ & 27 & 685.80 & 50 & 1270.00 & $700-5059$ \\
\hline$\frac{5}{6}$ & 40 & 1016.00 & 64 & 1625.60 & $700-5060$ \\
\hline
\end{tabular}

"D"Inlet Face Diameter - Measure Across Flat. Face at Flare Edge 


\section{FAN INLET PROBE TYPICAL APPLICATIONS}

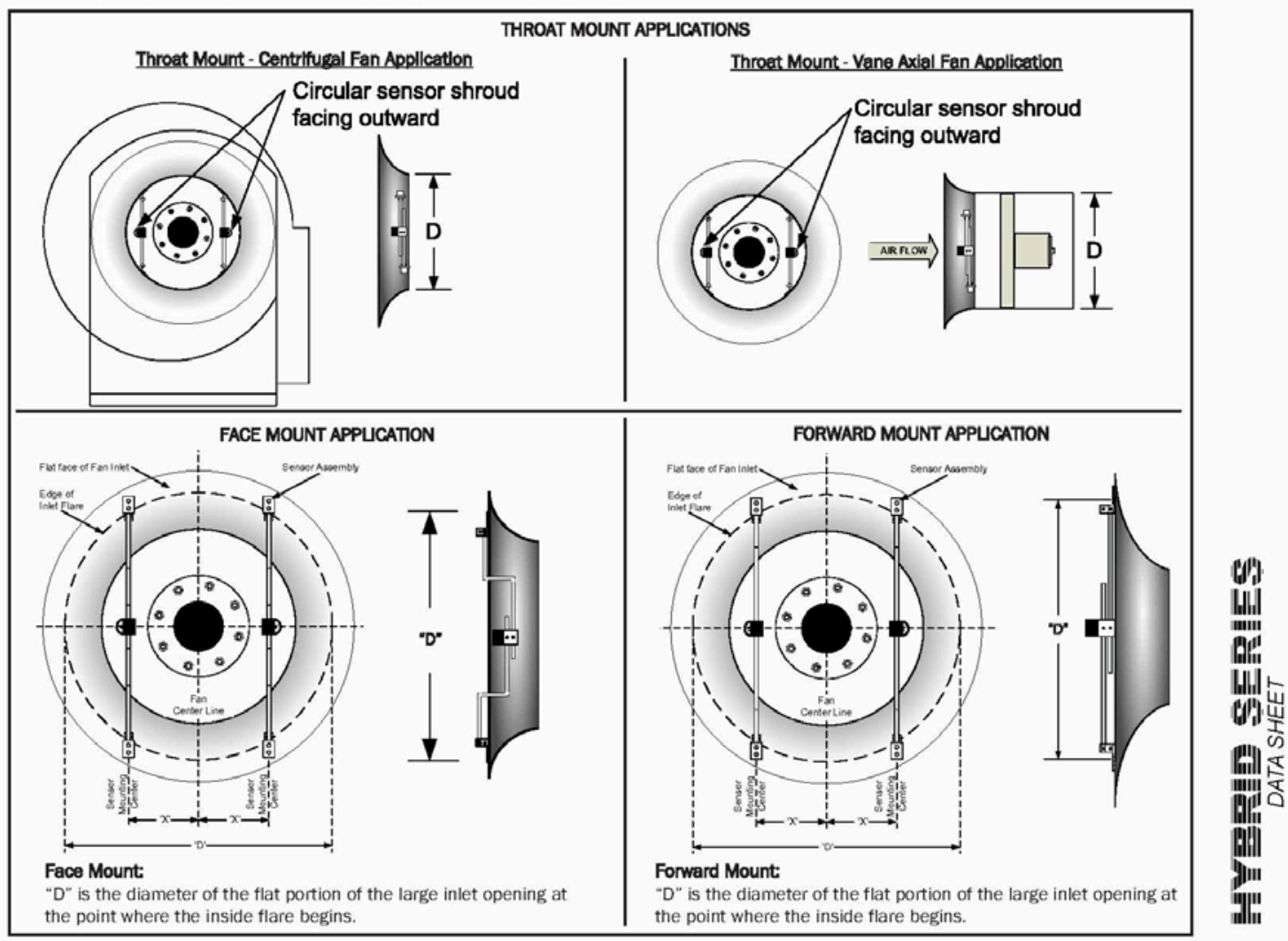

\section{FAN INLET PROBE MOUNTING STYLES AND DETAILS}

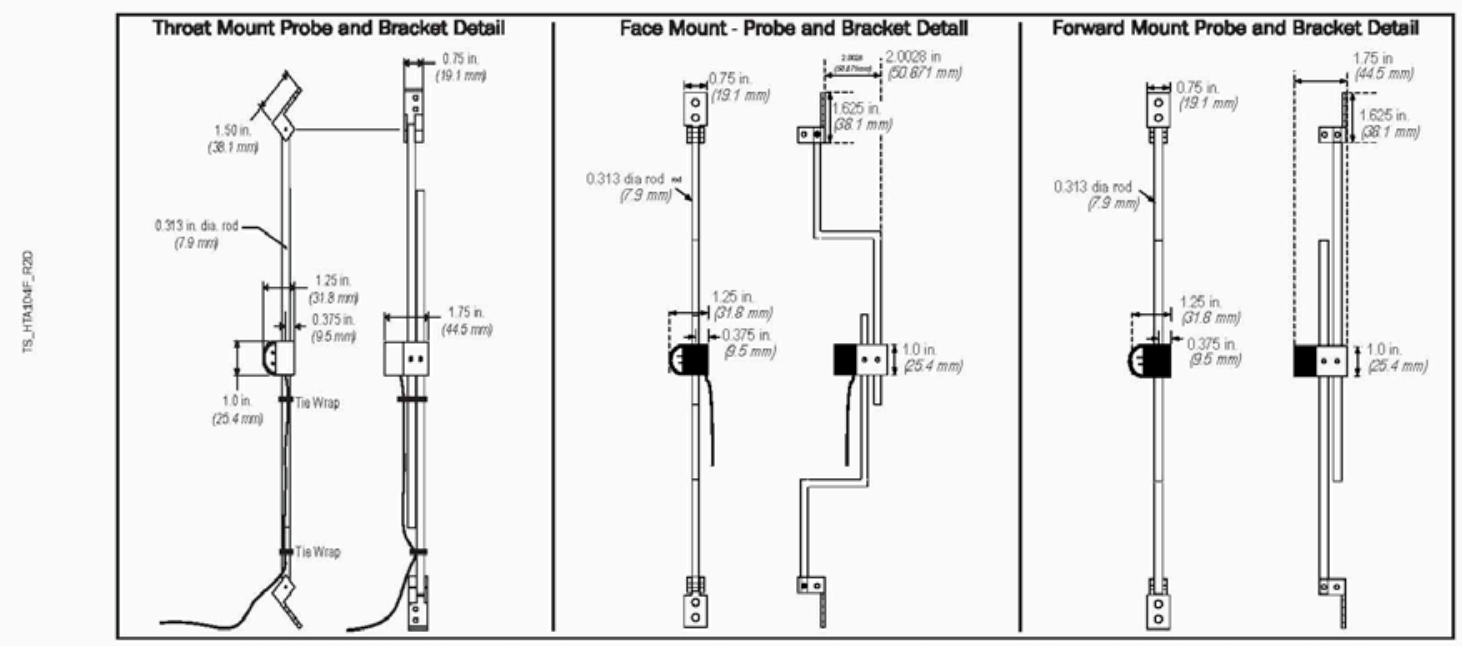

EBTRON, Inc. 1663 Hwy. 701 S., Loris SC 29569 • Toll Free: 800.2EBTRON(232.8766) • Fax: 843.756.1838 • Internet: EBTRON.com 
TYPICAL WIRING DIAGRAM

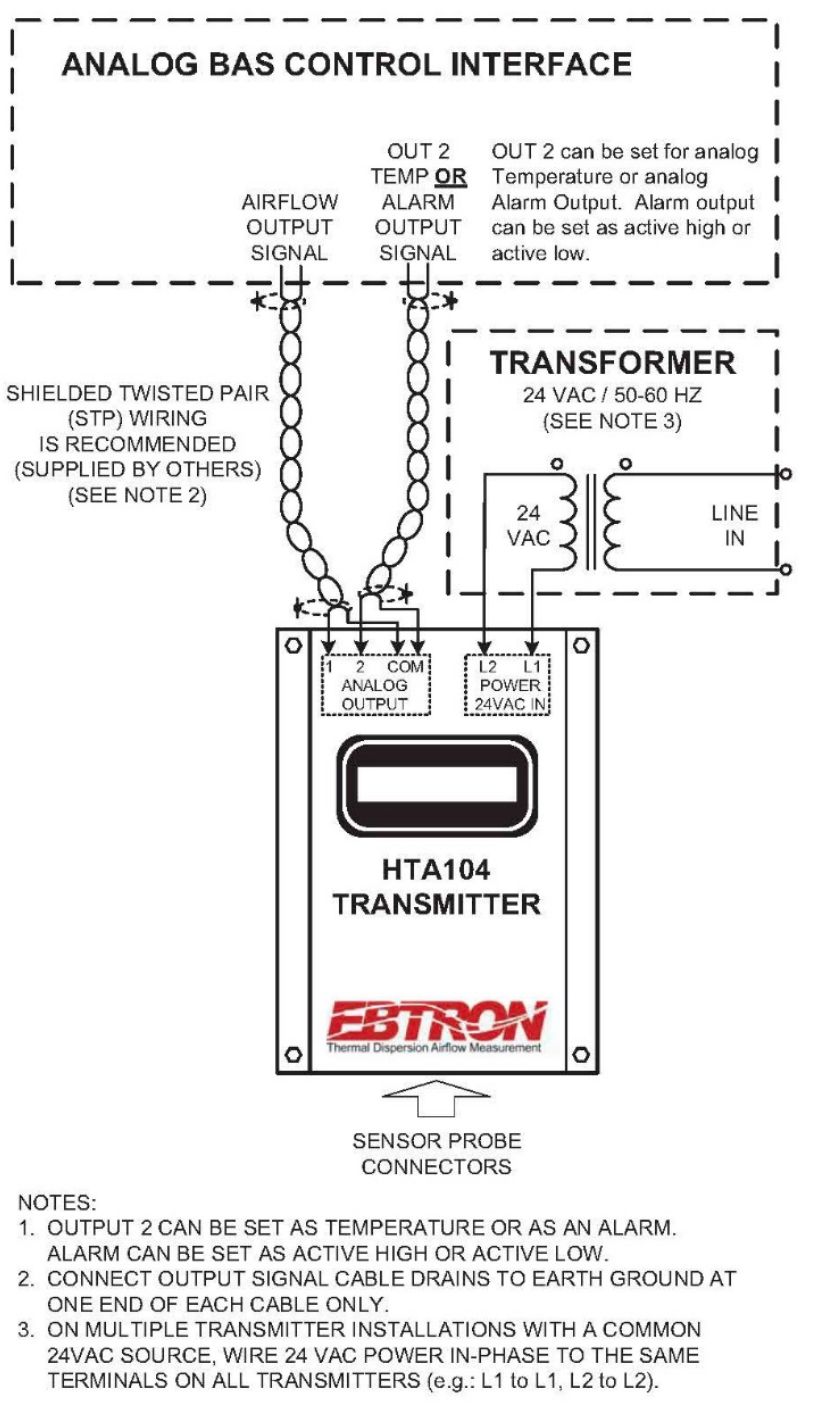




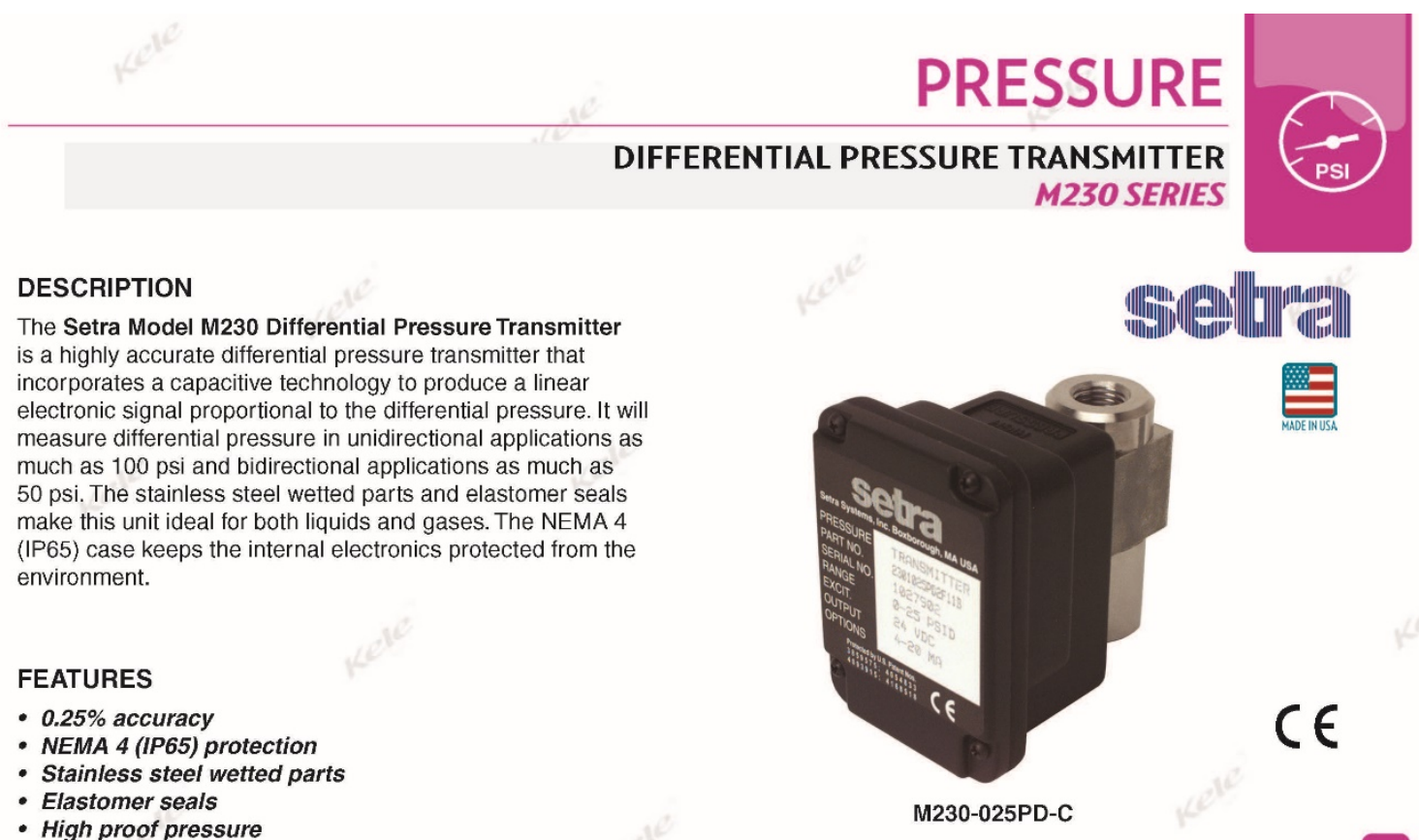

- Current or voltage outputs

- Mounting bracket included

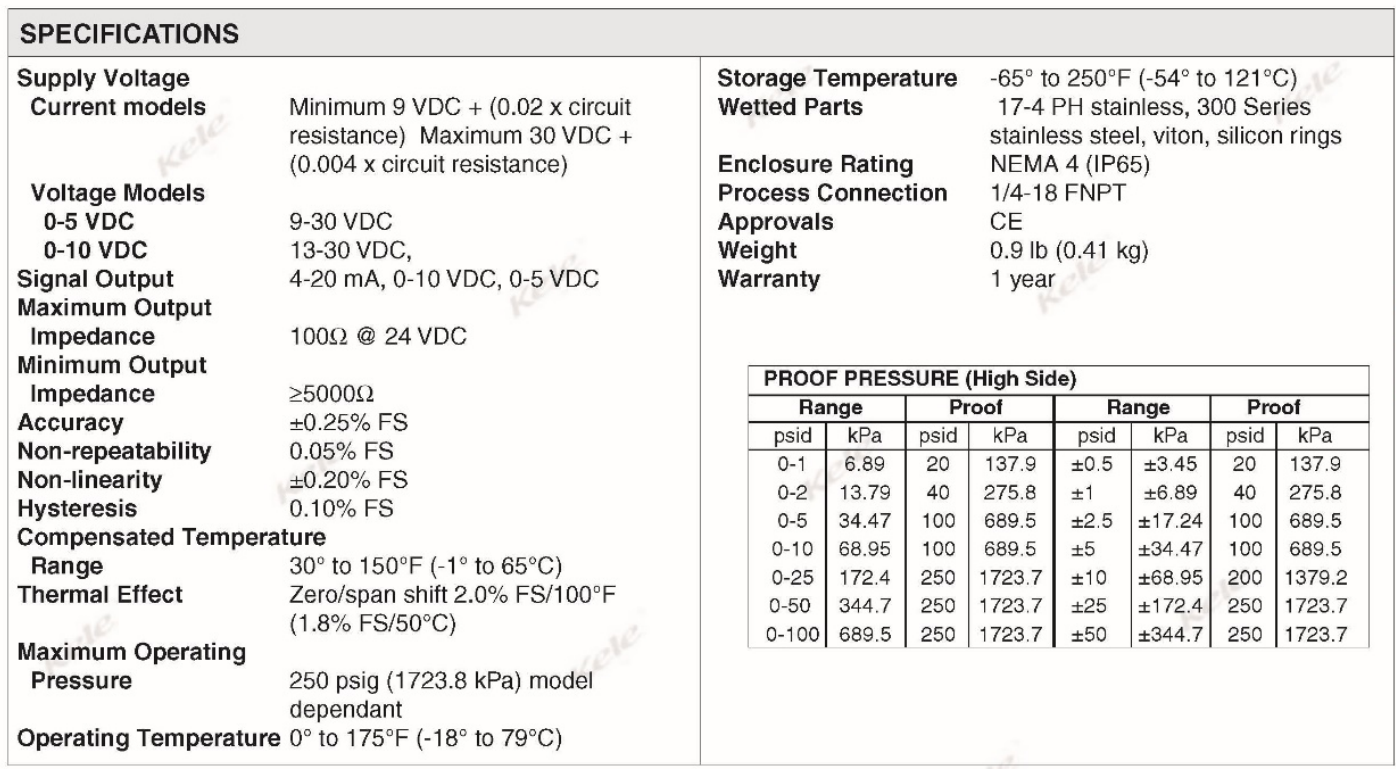



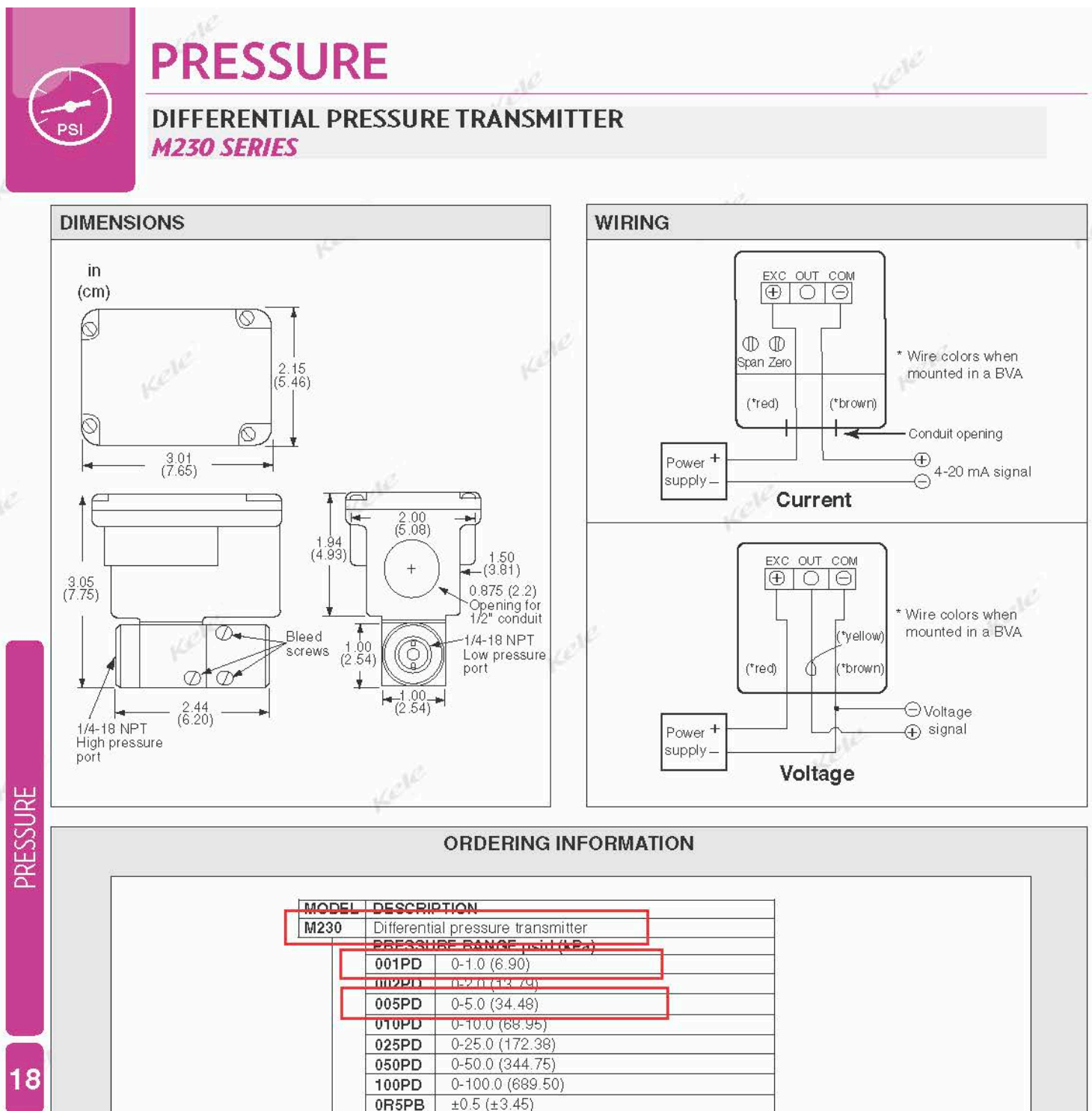

\section{ORDERING INFORMATION}

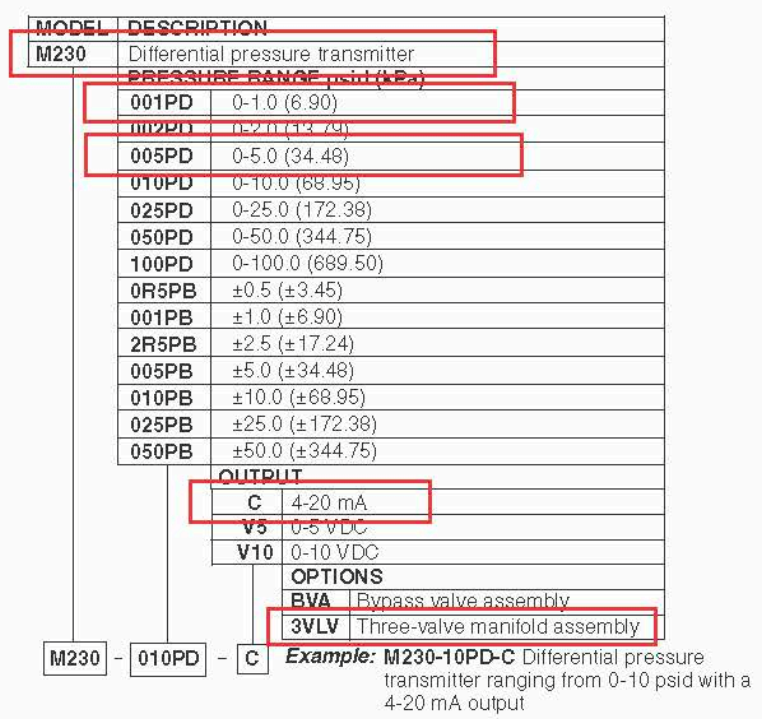

transmitter ranging from $0-10 \mathrm{psid}$ with a 


\section{Tip-sensitive RTDs with Thermowells}

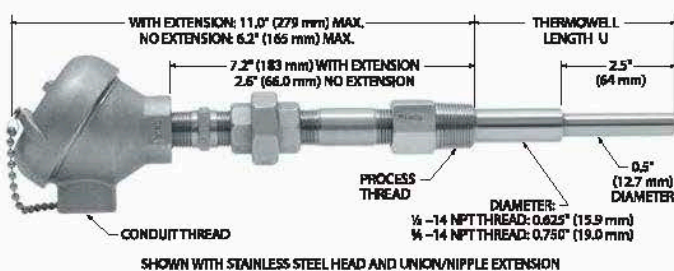

\section{Overview}

Thermowells protect sensors from the effects of fluid flow and pressure. These assemblies are spring-loaded for positive probe contact against the bottom of the thermowell. The probe's copper alloy tip provides superior time response and reduces error from stem conduction.

- 316 stainless steel thermowell

- Tip-sensitive RTD probe for use to $260^{\circ} \mathrm{C}\left(500^{\circ} \mathrm{F}\right)$

- Spring-loaded probe

- Cast Iron, stalnless steel, or aluminum connection head

\section{Specifications}

Temperature range: -50 to $260^{\circ} \mathrm{C}\left(-58\right.$ to $\left.500^{\circ} \mathrm{F}\right)$.

Material:

Probe: Stainless steel with copper alloy tip.

Connectlon head: Cast iron, aluminum, or stainless steel.

Thermowell: 316 stainless steel.

Extension: Stainless steel.

Pressure rating: $7000 \mathrm{psi}$ (483 bar) at $21^{\circ} \mathrm{C}$, reducing to $6300 \mathrm{psi}\left(433\right.$ bar) at $260^{\circ} \mathrm{C}$

Standard U dimensions: $2.5,4.5,6.0,7.5,8.0,10.5,13.5,16.5$, and 22.5:

Insulation resistance: 100 megohms minimum at $100 \mathrm{VDC}$, leads to case.

Connection: Terminal block for wires to AWG 14.

Time constant: 17 seconds typical in moving water.

\section{Sensing elements}

\begin{tabular}{|ll|l|}
\hline Element & Code \\
\hline Platinum (0.00392 TCR) & $100 \Omega \pm 0.5 \%$ at $0^{\circ} \mathrm{C}$ & $\mathrm{PA}$ \\
\hline $\begin{array}{c}\text { Platinum (0.00385 TCR) } \\
\text { (Mieets EN60751, Class B) }\end{array}$ & $100 \Omega \pm 0.1 \%$ at $0^{\circ} \mathrm{C}$ & $\mathrm{PD}$ \\
\hline Platinum (0.00385 TCR) & $100 \Omega \pm 0.5 \%$ at $0^{\circ} \mathrm{C}$ & $\mathrm{PE}$ \\
\hline $\begin{array}{c}\text { Copper (0.00427 TCR) } \\
\text { (dual) }\end{array}$ & $10 \Omega \pm 0.2 \%$ at $25^{\circ} \mathrm{C}$ & $\mathrm{CA}$ \\
\hline Nickel (0.00672 TCR) & $10 \Omega \pm 0.5 \%$ at $25^{\circ} \mathrm{C}$ & $\mathrm{CC}$ \\
\hline
\end{tabular}

\section{Temperature Transmitters}

Minco's Temptran ${ }^{\text {Tw }}$ RTD transmitters provide a 4 to $20 \mathrm{~mA}$ signal or HART" Protocol that can be sent over long distances with a simple 2-wire system. See Section 5 for complete temperature transmitter specifications.

Special high-accuracy calibration: For high system accuracy, specify transmitters with matched calibration. Calibration data traceable to NIST will also be provlded. Get more information on page 5-22.

\begin{tabular}{|c|c|}
\hline AS5140 & $\begin{array}{l}\text { Assembly number } \\
\text { AS5140: Single element RTD } \\
\text { AS5141: Dual element RTD }\end{array}$ \\
\hline CA & Sensing element from table \\
\hline 60 & $\begin{array}{l}\text { Thermowell length U: } \\
\text { Specify in } 0.1^{\prime} \text { increments (Ex: } 60=6.0 \text { inches) }\end{array}$ \\
\hline$z$ & $\begin{array}{l}\text { Leads per sensing element: } \\
Y=2 \text { leads } \\
Z=3 \text { leads (required for } C A \text { and CC elements) } \\
X=4 \text { leads (PD elements only) }\end{array}$ \\
\hline 2 & $\begin{array}{l}\text { Senduit thread: } \\
1=1 / 2-14 \text { NPT } \\
2=3 / 4-14 N P T\end{array}$ \\
\hline c & $\begin{array}{l}\text { Connection head: } \\
\begin{array}{c}\text { C }=\text { Cast iron } \\
\text { A }=\text { Aluminum } \\
5=\text { Stainless steel }\end{array}\end{array}$ \\
\hline 1 & $\begin{array}{l}\text { Thermowsell process thread: } \\
\begin{array}{l}1=1 / 2-14 \text { NPT } \\
2=3 / 4-14 \text { NPT }\end{array}\end{array}$ \\
\hline$u$ & $\begin{array}{l}\text { Extension option: } \\
\mathrm{P}=\text { Cnupling/nipple extension }\end{array}$ \\
\hline & $\begin{array}{l}\mathrm{N}=\text { No extension } \\
\mathrm{U}=\text { Union/Nipple extension }\end{array}$ \\
\hline $\begin{array}{l}\text { To order } \\
\text { To order }\end{array}$ & $\begin{array}{l}\text { sensor assembly, stop here. } \\
\text { with transmitters (single platinum element only) add: }\end{array}$ \\
\hline 520 & 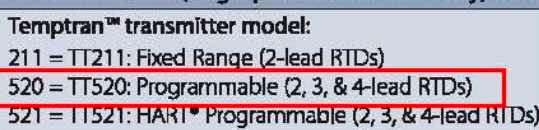 \\
\hline A & $\begin{array}{l}\text { Temperature range codes starting on page } 5-20 \text { or at } \\
\text { www.minca.com }\end{array}$ \\
\hline 1 & $\begin{array}{l}\text { Calibration: } \\
\text { 1- Nominal calibration } \\
2 \text { = Match calibrated, } 0.75 \% \text { total systern accuracy. } \\
\text { For other callibration options, contact Minco }\end{array}$ \\
\hline AS514 & A60Z2C1U520A1 = Sample part number \\
\hline
\end{tabular}




\section{HMT330 Series Humidity and Temperature Transmitters for Demanding Humidity Measurement}

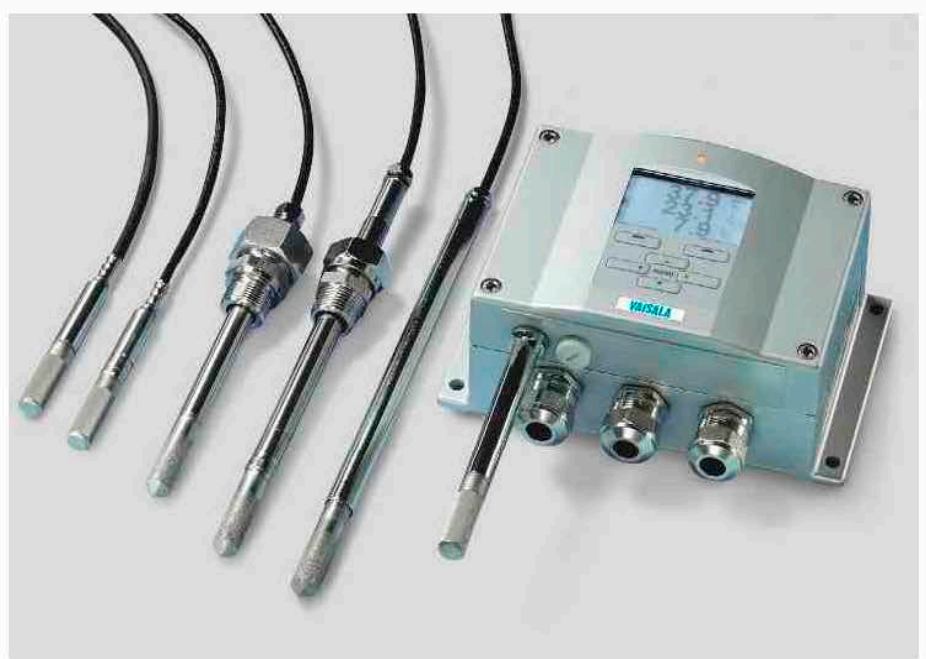

The HMT330 transmitter family offers reliable perfomance for a wide variety of demanding industrial humidity measurements.

The Vaisala HUMICAP ${ }^{\circledR}$ Humidity and Temperature Transmitter Series HMT330 is designed for demanding industrial applications where stable measurements and extensive customization are essential. With multiple options to choose from, the instrument can be tailored to meet the specific needs of each individual application.

Proven Vaisala HUMICAP Performance

The HMT330 series incorporates Vaisala's 40 years of experience in industrial humidity measurement. The updated fourth-generation HUMICAP sensor provides accurate and stable measurement even in environments with high humidity or chemical contaminants.

\section{Chemical Purge Minimizes} Effects of Contaminants

In environments with high concentrations of chemicals and cleaning agents, the chemical purge option helps to maintain measurement accuracy between calibration intervals.

The chemical purge involves heating the sensor to remove harmful chemicals. The function can be initiated manually or programmed to occur at set intervals.

\section{Features/Benefits}

- Six models for demanding industrial applications

- Full O ... $100 \% \mathrm{RH}$ measurement, temperature range up to $+180^{\circ} \mathrm{C}\left(+356^{\circ} \mathrm{F}\right)$ depending on model

- Pressure tolerance up to 100 bar depending on model

- 4th generation Vaisala HUMICAP ${ }^{\infty}$ sensor for superior accuracy and stability

- Graphical display and keypad for convenient operation

- Multilingual user interface

- Excellent performance in harsh conditions; good chemical tolerance

- Corrosion-resistant IP65/IP66 housing

- 6-point NIST traceable calibration (certificate included)

- 10-year warranty when annually calibrated at the Vaisala Service Center

- Analog outputs, RS232/485, WLAN/LAN

- MODBUS protocol support (RTU/TCP)

- Compatible with Vaisala viewLinc software 


\section{Wide Range of Installation Options}

The wide variety of measurement probes, several installation accessories, and universal mains and DC power options make the instruments easy to install in various locations and kinds of environment; walls, poles, pipelines, and ducts, for example. The input/output cable can be fed through the back of the transmitter, which is a useful feature, especially for cleanroom installations.

The HMT330 series includes six models:

- HMT331 for wall-mounted applications

- HMT333 for ducts and tight spaces

- HMT334 for high-pressure and vacuum applications

- HMT335 for high-temperature applications

- HMT337 for high-humidity applications

- HMT338 for pressurized pipelines
Graphical Display of Measurement Data and Trends for Convenient Operation

The HMT330 series features a large numerical and graphical display with a multilingual menu and keypad. It allows users to easily monitor operational data, measurement trends, and access measurement history for the past 12 months. The optional data logger, with real-time clock, makes it possible to generate over four years of measurement history, and zoom in on any desired time or time frame.

The display alarm allows any measured parameter to be tracked, with freely configurable low and high limits.

\section{Versatile Outputs and Data Collection}

The HMT330 can support up to three analog outputs; an isolated galvanic power supply and relay outputs are also available.

For serial interface the USB connection, RS232, and RS485 can be used.

HMT330 is also capable of applying the MODBUS communication protocol and, together with an appropriate connection option, provides either MODBUS RTU (RS485) or MODBUS TCP/IP (Ethernet) communication.

The data logger, with real-time clock and battery backup, guarantees reliable logging of measurement data for over four years. The recorded

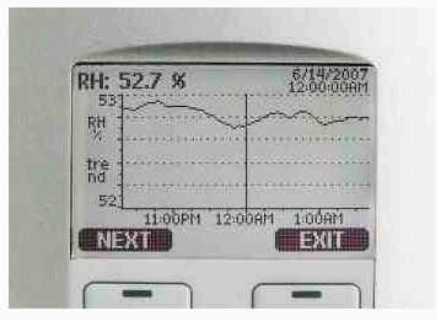

The display shows measurement trends and over four years of real-time measurement history.

data can be viewed on the local display or transferred to a $\mathrm{PC}$ with Microsoft Windows ${ }^{\circledR}$ software. The transmitter can also be connected to a network with an optional (W)LAN interface, which enables a (wireless) Ethernet connection. A USB service cable makes it easy to connect the HMT330 to a PC via the service port.

\section{Flexible Calibration}

The HMT330 instruments are calibrated at six humidity points at the factory and come with a calibration certificate that meets all the relevant traceability and compliance requirements.

A quick, one-point field calibration can be performed with the handheld HM70 meter. A two-point field calibration can be performed, for example, with the HMK15 salt bath calibrator in a controlled environment. The transmitter can also be sent to Vaisala for recalibration, and accredited calibrations are available. 


\section{Technical Data}

\section{Performance}

\section{RELATIVE HUMIDITY}

Measurement range

with Vaisala HUMICAP 180 or $180 R^{*} \quad$ for typical applications with Vaisala HUMICAP® $180 \mathrm{C}$ or $180 \mathrm{RC}^{\star} \quad$ for applications with

with Vaisala HUMICAPФ $180 \mathrm{VC}$

chemical purge/warmed probe catalytic sensor with chemical purge for $\mathrm{H}_{2} \mathrm{O}_{2}$ environments $\pm 1 \% \mathrm{RH}(0 \ldots 90 \%)$

at $+15 \ldots+25^{\circ} \mathrm{C}\left(59 \ldots+77^{\circ} \mathrm{F}\right)$

at $-20 \ldots+40^{\circ} \mathrm{C}\left(4 \ldots+104^{\circ} \mathrm{F}\right)$

at $40 \ldots+180^{\circ} \mathrm{C}\left(40 \ldots+356^{\circ} \mathrm{F}\right)$

Factory calibration uncertainty $\left(+20^{\circ} \mathrm{C}\right)$

$+1.7 \% \mathrm{RH}(90 \ldots 100 \% \mathrm{RH})$

$\pm(1.0+0.008 \times$ reading $) \% \mathrm{RH}$

$\pm(1.5+0.015 \times$ reading $) \% \mathrm{RH}$ $\pm 0.6 \% \mathrm{RH}(0 \ldots .40 \% \mathrm{RH})$ $\pm 1.0 \% \mathrm{RH}(40 \ldots 97 \% \mathrm{RH})$

(Defined as \pm 2 standard deviation limits. Small variations possible; see also calibration certificate.) Response time $(90 \%)$ at $+20^{\circ} \mathrm{C}\left(+68^{\circ} \mathrm{F}\right) \quad 8 \mathrm{~s} / 17 \mathrm{~s}^{* *}$ with grid filter in still air $\quad 20 \mathrm{~s} / 50 \mathrm{~s}^{* *}$ with grid + steel netting filter $40 \mathrm{~s} / 60 \mathrm{~s}^{* *}$ with sintered filter

*HUMICAP $180 \mathrm{R}$ or $180 \mathrm{RC}$ recommended

** with HUMICAP $180 \mathrm{R}$ or $180 \mathrm{RC}$ or $180 \mathrm{VC}$ sensor TEMPERATURE

Accuracy at $+20^{\circ} \mathrm{C}\left(+68^{\circ} \mathrm{F}\right)$

$\pm 0.2^{\circ} \mathrm{C}\left( \pm 0.36^{\circ} \mathrm{F}\right)$

Accuracy over temperature range (measurement range

depends on model)

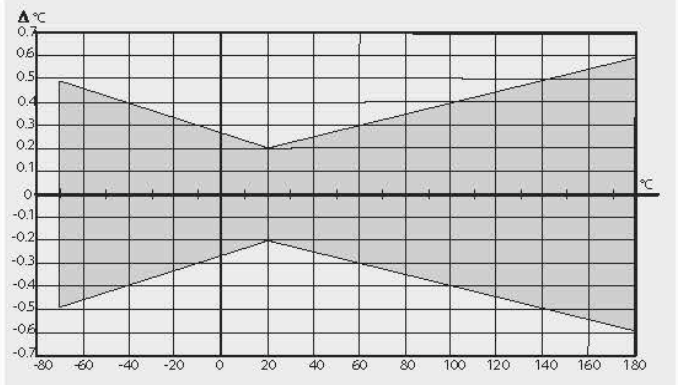

Temperature sensor

Pt100 RTD Class F0.1 IEC 60751

Other available variables (model-dependent)

dew point temperature, mixing ratio, absolute humidity, wet bulb temperature, enthalpy, water vapor pressure

\section{Inputs and Outputs}

Operating voltage $10 \ldots 35 \mathrm{VDC}, 24 \mathrm{VAC} \pm 20 \%$

with optional power supply module $\quad 100 \ldots 240 \mathrm{VAC}, 50 / 60 \mathrm{HZ}$

Power consumption at $+20^{\circ} \mathrm{C}\left(\mathrm{U}_{\text {in }} 24 \mathrm{VDC}\right)$ RS232

$\mathrm{U}_{\text {out }} 2 \times 0 \ldots 1 \mathrm{~V} / 0 \ldots 5 \mathrm{~V} / 0 \ldots 10 \mathrm{~V}$

$\mathrm{I}_{\text {out }} 2 \times 0 \ldots 20 \mathrm{~mA}$

display and backlight

during chemical purge

during probe heating (HMT337)

$\max .25 \mathrm{~mA}$

$\max .25 \mathrm{~mA}$

$\max .60 \mathrm{~mA}$

$+20 \mathrm{~mA}$ $\max .110 \mathrm{~mA}$

$+120 \mathrm{~mA}$

Analog outputs (2 standard, 3rd optional)

current output

voltage output

Accuracy of analog outputs at $+20^{\circ} \mathrm{C}$

$0 \ldots 20 \mathrm{~mA}, 4 \ldots 20 \mathrm{~mA}$

$0 \ldots 1 \mathrm{~V}, 0 \ldots 5 \mathrm{~V}, 0 \ldots 10 \mathrm{~V}$

$\pm 0.05 \%$ full scale

Temperature dependence of the

analog outputs

$\pm 0.005 \% /{ }^{\circ} \mathrm{C}$ full scale

External loads

$\begin{array}{lr}\text { current outputs } & \mathrm{R}_{\mathrm{L}}<500 \mathrm{ohm} \\ 0 \ldots 1 \text { V output } & \mathrm{R}_{\mathrm{L}}>2 \mathrm{kohm} \\ 0 \ldots 5 \mathrm{~V} \text { and } 0 \ldots 10 \text { V outputs } & \mathrm{R}_{\mathrm{L}}>10 \mathrm{kohm} \\ \text { Max. wire size } & 0.5 \mathrm{~mm}^{2} \text { (AWG 20) }\end{array}$

Digital outputs

Protocols

stranded wires recommended

RS232, RS485 (optional)

Service connection

ASCII commands, MODBUS RTU

RS232, USB

Relay outputs (optional)

Ethernet interface (optional)

$0.5 \mathrm{~A}, 250 \mathrm{VAC}$

Supported standards

Connector

IPv4 address assignment

Protocols

WLAN interface (optional)

Supported standards

Antenna connector type

IPv4 address assignment

Protocols

Security

Authentication / Encryption (WLAN)

10BASE-T, 100BASE-TX 8P8C (RJ45)

DHCP (automatic), static Telnet, MODBUS TCP/IP

$802.11 \mathrm{~b}$

RPSMA

DHCP (automatic), static Telnet, MODBUS TCP/IP WEP 64/128, WPA2/802.11i

Open / no encryption

Open / WEP

WPA Pre-shared key / TKIP

WPA Pre-shared key / CCMP (a.k.a. WPA2)

Optional data logger with real-time clock

Logged parameters $\quad \max$. four with trend $/ \mathrm{min} / \max$ values

Logging interval

Max. logging period

Logged points

Battery lifetime

Display

Menu languages
$10 \mathrm{sec}$. (fixed)

4 years, 5 months

13.7 million points per parameter $\min .5$ years

LCD with backlight, graphical trend display

of any parameter English, Chinese, Finnish, French, German, Japanese, Russian, Spanish, Swedish 


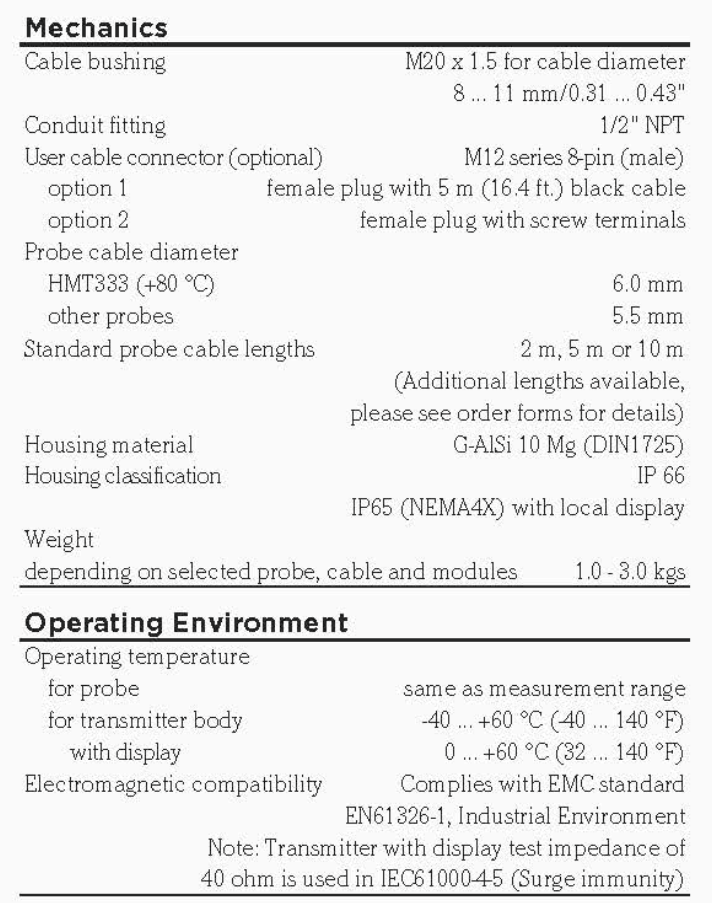

\section{Dimensions}

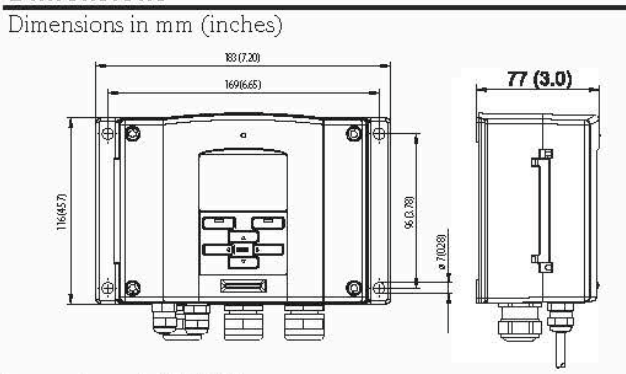

Transmitter with WLAN antenna

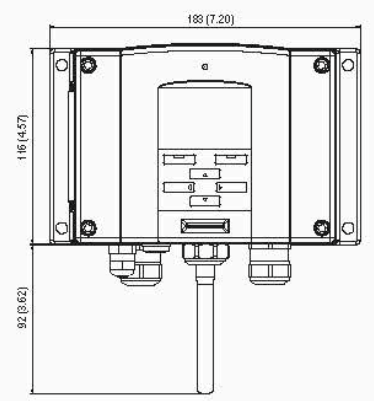

\section{Mounting Options}

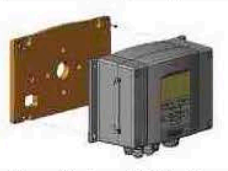

Mounting with Wall Mounting Kit*

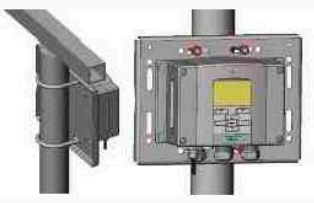

Pole Installation with Installation Kit for Pole or Pipeline

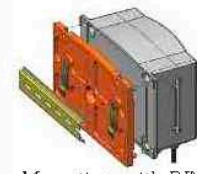

Mounting with DIN Rail Installation Kit

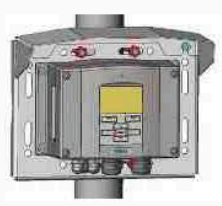

Mounting Rain Shield with Installation Kit

\section{踆 -in} TYPE APPROVED PRODUCT CERTIFICATE NO.:A-13529

${ }^{\star}$ not mandatory for wall installations

Please contact us at

www.vaisala.com/requestinfo

www.vaisala.com

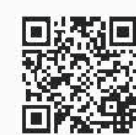

Ref. B210951EN-G OVaisala 2014

This material is subject to copyright protection, with all copyrights retained by Vaisala and its individual partners. All
rights resonved any of Wisala or its individual partners The reproduction tran for distribution or storage of information oontained in this brochure in ary form without the prior written consert of Vaisala is stricthy prohibited. All specificotions - technical included - are subject 


\section{HMT331 Humidity and Temperature Transmitter for Demanding} Wall-Mounted Applications

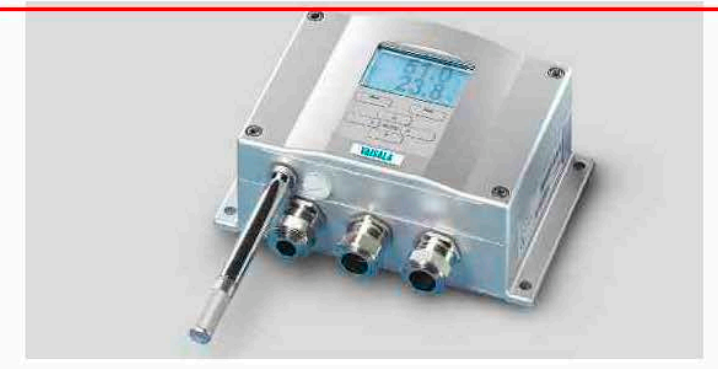

The HMT331 is a state-of the-ant wall-mounted humidity measurement instrument.

The Vaisala HUMICAP ${ }^{\oplus}$ Humidity and Temperature Transmitter HMT331 is a high-quality wall-mounted transmitter for demanding HVAC and condition-monitoring applications.

\author{
Typical Applications \\ - cleanrooms \\ - pharmaceutical \\ processes \\ - swimming halls \\ - museums and archives
}

HMT331 Humidity and Temperature Transmitter with short flexible probe and optional WLAN.

Technical Data

\begin{tabular}{lr}
\hline Temperature measurement range & $-40 \ldots+60^{\circ} \mathrm{C}\left(-40 \ldots+140^{\circ} \mathrm{F}\right)$ \\
\hline Accessories & \\
\hline USB service port cable with PC software & 219916 \\
Connection cable for HM70 & 211339 \\
Wall-mounting plate (plastic) & 214829 \\
Pole installation kit with rain shield & 215109 \\
DIN rail installation set & 215094 \\
PPS plastic grid filter with stainless steel net & DRW010281SP \\
Stainless steel sintered filter & HM47280SP \\
\hline
\end{tabular}

\section{HMT333 Humidity and Temperature Transmitter for Ducts and Tight Spaces}

The vaisala HUMICAPU

Humidity and Temperature Transmitter HMT 333 is a versatile instrument for applications where a small remote probe is needed, for example in demanding HVAC applications. Its small thermal mass enables rapid response to temperature changes.

Flexible Installation To install the probe in ducts, channels, and through walls, an installation kit is available with a stainless steel flange, lead-through piece, and steel support bar. The HMT333 has two probe cable options - a flexible rubber cable that withstands temperatures of up to $+80^{\circ} \mathrm{C}$, and a durable cable that withstands temperatures of up to $+120^{\circ} \mathrm{C}$. Both cable options are available in lengths of 2,5 , and 10 meters. Additionally, flexible rubber cable $\left(+80^{\circ} \mathrm{C}\right)$ is available in 20 -meter lengths.

For outdoor environments, the DTR502B solar radiation shield provides protection for the probe. The shield can be installed on a pole, beam, or flat surface.
The HMT333 transmitter's compact probe is designed for remote applications.
Typical Applications

- cleanrooms

- pharmaceutical processes

- environmental chambers

- processes with moderate temperature and humidity

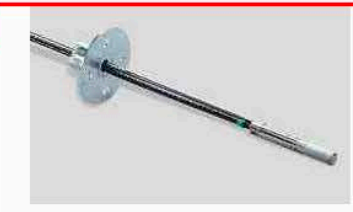

Duct installation kit for HMT333 and HMT337.

\section{Technical Data}

\begin{tabular}{lr}
\hline Temperature measurement range & $-40 \ldots+80^{\circ} \mathrm{C}\left(-40 \ldots+176^{\circ} \mathrm{F}\right)$ or \\
& $40 \ldots+120^{\circ} \mathrm{C}\left(-40 \ldots+248^{\circ} \mathrm{F}\right)$ \\
\hline Accessories & 210697 \\
\hline Duct installation kit & HMP247CC \\
Cable gland with split seal & 219916 \\
USB service port cable with PC software & 211339 \\
Connection cable for HM70 & 214829 \\
Wall-mounting plate (plastic) & 215109 \\
Pole installation kit with rain shield & DTR502B \\
Solar radiation shield & 215094 \\
DIN rail installation set & DRW010281SP \\
PPS plastic grid filter with stainless steel net & DRW010276SP \\
PPS plastic grid filter & HM47280SP \\
Stainless steel sintered filter &
\end{tabular}




\section{HMT334 Humidity and Temperature Transmitter for High Pressure and Vacuum Applications}

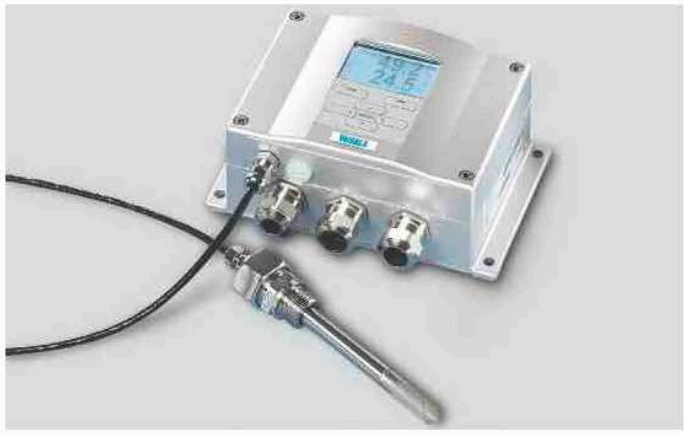

The HMT334 is ideal for pemanent installations in pressurized or vacuum processes.

The Vaisala HUMICAP ${ }^{\oplus}$ Humidity and Temperature Transmitter HMT334 is designed for humidity measurement in pressurized spaces or vacuum chambers. Every probe is tested for gas and vacuum-tight installation.

\section{Typical Applications}

- test chambers

- high-pressure and vacuum processes

\section{Technical Data}

\begin{tabular}{lr}
\hline $\begin{array}{l}\text { Temperature measurement range } \\
\text { Operating pressure }\end{array}$ & $-70 \ldots+180^{\circ} \mathrm{C}\left(-94 \ldots+356^{\circ} \mathrm{F}\right)$ \\
\hline Accessories & $0 \ldots 10 \mathrm{MPa}(0 \ldots 100 \mathrm{bar})$ \\
\hline Fitting body ISO M22 $\times 1.5$ & $17223 \mathrm{SP}$ \\
Fitting body NPT $1 / 2 "$ & $17225 \mathrm{SP}$ \\
USB service port cable with PC software & 219916 \\
Connection cable for HM70 & 211339 \\
Wall-mounting plate (plastic) & 214829 \\
Pole installation kit with rain shield & 215109 \\
DIN rail installation set & 215094 \\
PPS plastic grid filter with stainless steel net & DRW010281SP \\
PPS plastic grid filter & DRW010276SP \\
Stainless steel sintered filter & HM47280SP \\
Stainless steel grid filter & HM47453SP \\
\hline
\end{tabular}

\section{HMT335 Humidity and Temperature Transmitter for High Temperatures}

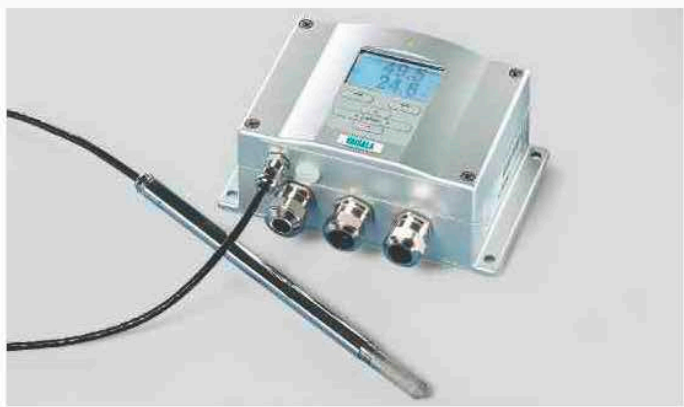

The HMT335 has a robust stainless steel probe, ideal for hot processes with high flow rates.

The Vaisala HUMICAP ${ }^{\circledR}$ Humidity and Temperature Transmitter HMT335 has a long stainless steel probe designed for high temperatures.

Robust Probe Ideal for High Flow Rates With high tolerance for mechanical stress and high flow rates, the HMT335 is ideal for duct measurements. The stainless steel installation flange allows easy adjustment of the probe's installation depth.

\section{Typical Applications \\ - hot drying processes \\ - food processes, e.g baking ovens}

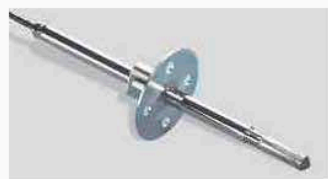

The installation flange allows easy adjustment of the probe installation depth.

\section{Technical Data}

\begin{tabular}{lr}
\hline Temperature measurement range & $-70 \ldots+180^{\circ} \mathrm{C}\left(-94 \ldots+356^{\circ} \mathrm{F}\right)$ \\
\hline Accessories & \\
\hline Mounting flange & 210696 \\
USB service port cable with PC software & 219916 \\
Connection cable for HM70 & 211339 \\
Wall-mounting plate (plastic) & 214829 \\
Pole installation kit with rain shield & 215109 \\
DIN rail installation set & 215094 \\
PPS plastic grid filter with stainless steel net & DRW010281SP \\
PPS plastic grid filter & DRW010276SP \\
Stainless steel sintered filter & HM47280SP \\
Stainless steel grid filter & HM47453SP \\
\hline
\end{tabular}




\section{HMT337 Humidity and Temperature Transmitter for High Humidity Applications}

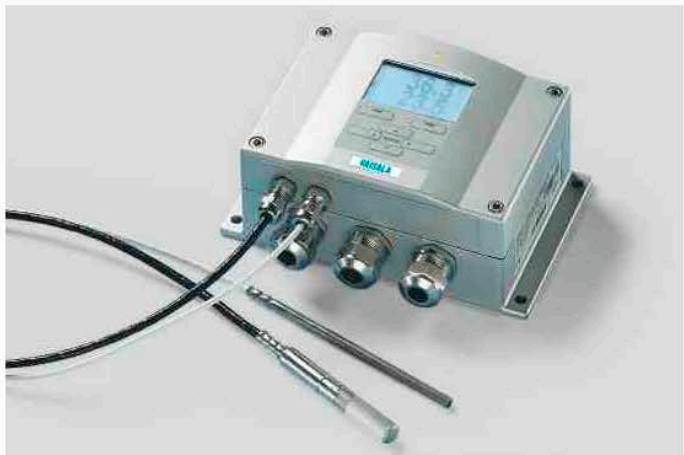

The HMT337 is ideal for the most demanding process and meteorological measurements in high humidity condensing environments.

The Vaisala HUMICAP ${ }^{\oplus}$ Humidity and Temperature Transmitter HMT337 is delivered in one of three configurations:

- Basic, with a non-warmed probe for moderate humidity

- With a warmed probe, for near-condensing conditions and dew point measurement

- With a warmed probe and an additional temperature sensor, for near-condensing conditions and relative humidity measurement

\section{True Humidity Readings in Condensation Conditions}

Vaisala's unique warmed probe provides fast and reliable measurement in environments where humidity is near saturation. The heating prevents condensation from forming on the sensor.

As the probe is heated, the humidity level inside it stays below the ambient level. With accurate temperature measurement, the ambient dew point can be calculated precisely.

If the relative humidity value is needed, an additional temperature sensor is used. The measured ambient temperature provides the compensation for calculating relative humidity and other humidity parameters.

\section{Installation Options}

Tight installation through a process wall can be achieved with Swagelok ${ }^{\oplus}$ fittings. The optional HMT330MIK

Installation Kit is available for outdoor installations; duct installation kits are also available.

\section{Typical Applications}

- professional

meteorology

- intake air monitoring of

engines and gas turbines

timber drying kilns

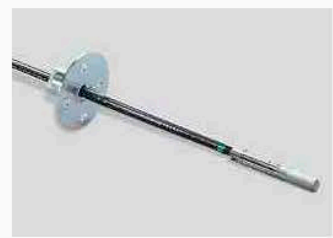

Duct installation kit for HMT333 and HMT337.
Technical Data

\begin{tabular}{lr}
\hline Temperature measurement range & $-70 \ldots+180^{\circ} \mathrm{C}\left(-94 \ldots+356^{\circ} \mathrm{F}\right)$ \\
\hline Accessories* & HMP247CG \\
\hline Cable gland and AGRO & 210697 \\
Duct installation kit (RH probe) & 215003 \\
Duct installation kit (T probe) & \\
Swagelok fittings (NPT and ISO) for both RH and T probes & \\
(up to 10 bar) & DTR502B \\
Solar radiation shield & HMT330MIK \\
Meteorological installation kit & 219916 \\
USB service port cable with PC software & 211339 \\
Connection cable for HM70 & 214829 \\
Wall-mounting plate (plastic) & 215109 \\
Pole installation kit with rain shield & 215094 \\
DIN rail installation set & HMT330WPA \\
Warmed probe accessory & DRW010281SP \\
PPS plastic grid filter with stainless steel net & DRW010276SP \\
PPS plastic grid filter & HM47280SP \\
Stainless steel sintered filter & HM47453SP \\
Stainless steel grid filter &
\end{tabular}




\section{HMT338 Humidity and Temperature Transmitter for Pressurized Pipelines}

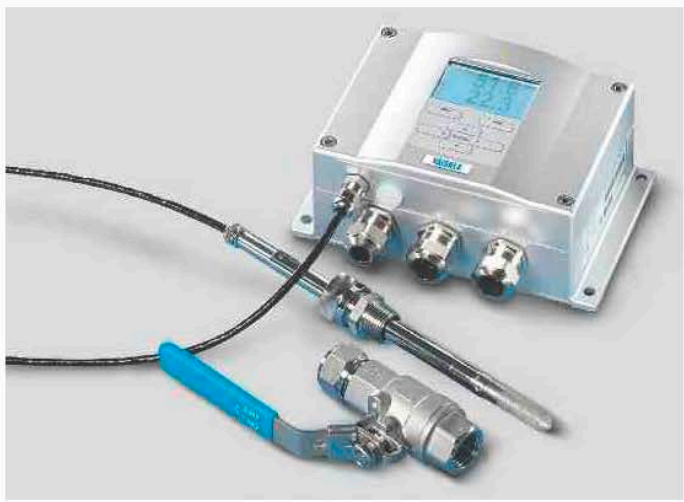

The HMT338 is ideal for installations in pressurized processes where the probe needs to be removed while the process is nuning.

The Vaisala HUMICAP ${ }^{\circledR}$ Humidity and Temperature Transmitter HMT338 is designed for pressurized processes.

Insert or Remove the Probe while the Process is Running

With "hot tapping", the probe is inserted directly into the process while it is running, without the need for venting or lowering the process pressure.

The probe is tightened to a ball-valve assembly fixed to the process pipe or wall. The adjustable hex nut is handtightened to temporarily hold the probe in place. The probe is then pushed down to the appropriate depth. The hex nut is then tightened with a wrench to lock the probe in place. Hot tapping is possible in pressures up to $10 \mathrm{bar}$.

\section{Typical Applications}

- process lines

- environmental chambers

- vacuum-drying processes

- compressed air lines with refrigerant dryers
Technical Data

Temperature measurement range $\quad-70 \ldots+180^{\circ} \mathrm{C}\left(-94 \ldots+356^{\circ} \mathrm{F}\right)$ Operating pressure $\quad 0 \ldots 4 \mathrm{MPa}(0 \ldots 40 \mathrm{bar})$ Accessories

\begin{tabular}{lr}
\hline Ball-valve set & BALLVALVE-1 \\
Pressure fitting ISO 1/2 to NPT 1/2 & 210662 \\
USB service port cable with PC software & 219916 \\
Connection cable for HM70 & 211339 \\
Wall-mounting plate (plastic) & 214829 \\
Pole installation kit with rain shield & 215109 \\
DIN rail installation set & 215094 \\
PPS plastic grid filter with stainless steel net & DRW010281SP \\
PPS plastic grid filter & DRW010276SP \\
Stainless steel sintered filter & HM47280SP \\
Stainless steel grid filter & HM47453SP \\
\hline
\end{tabular}




\section{Dimensions of the Probes for the HMT330 Series}

Dimensions in $\mathrm{mm}$ (inches)

HMT331 probe

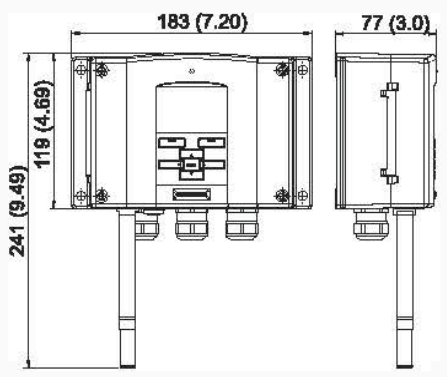

HMT335 probe

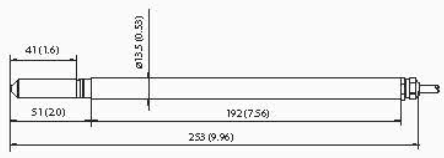

HMT337 RH probe

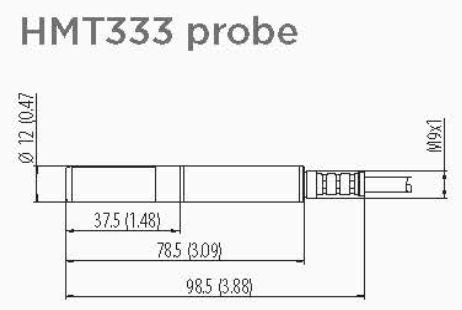

HMT334 probe

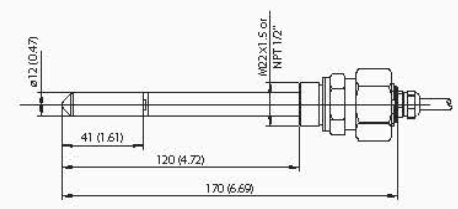

$100(6,69)$
HMT338 probe

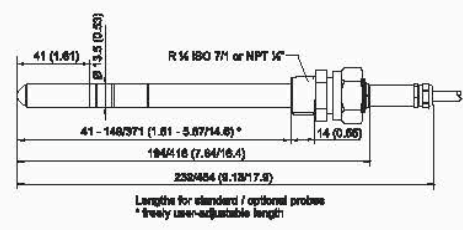

HMT337 T probe

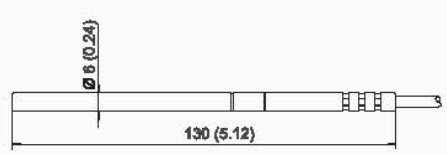

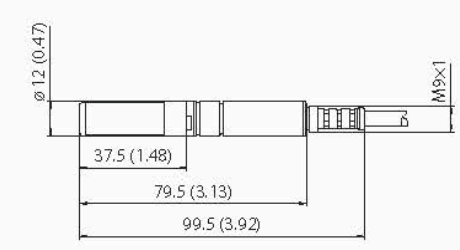

Installation flange

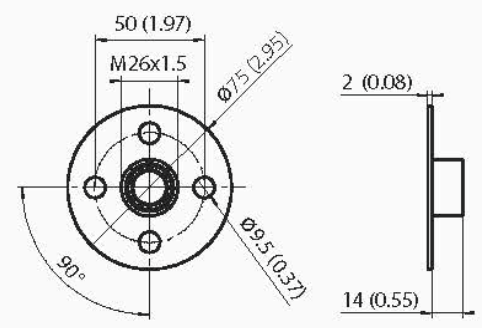




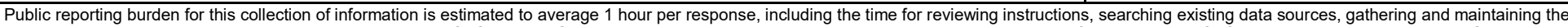

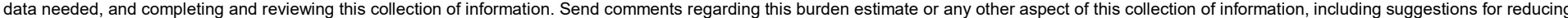

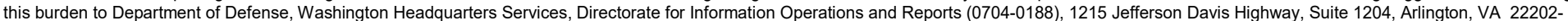

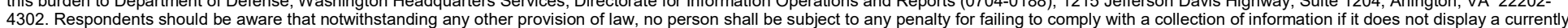
4302. Respondents should be aware that notwithstanding any other provision of law, no person shat
valid OMB control number. PLEASE DO NOT RETURN YOUR FORM TO THE ABOVE ADDRESS.

\begin{tabular}{l|l} 
valid OMB control number. PLEASE DO NOT RETURN YOUR FORM TO THE ABOVE ADDRESS. \\
\hline 1. REPORT DATE (DD-MM-YYYY) & $\mathbf{2 . ~ R E P O}$
\end{tabular}
2. REPORT TYPE
$08 / 08 / 2018$
Final

\section{TITLE AND SUBTITLE}

High Efficiency Dehumidification System

3. DATES COVERED (From - To)

\section{5a. CONTRACT NUMBER}

5b. GRANT NUMBER

\section{5c. PROGRAM ELEMENT}

\section{AUTHOR(S)}

Scot M. Duncan and Dahtzen Chu

\section{5d. PROJECT NUMBER}

ESTCP EW 201344

5e. TASK NUMBER

5f. WORK UNIT NUMBER

8. PERFORMING ORGANIZATION REPORT NUMBER

ERDC/CERL TR-18-19

U.S. Army Engineer Research and Development Center (ERDC)

Construction Engineering Research Laboratory (CERL)

PO Box 9005,

Champaign, IL 61826-9005

\section{SPONSORING / MONITORING AGENCY NAME(S) AND ADDRESS(ES)}

SERDP/ESTCP

480o Mark Center Drive, Suite 17Do8

Alexandria, VA 22350-3605

\section{NUMBER(S)}

\section{DISTRIBUTION / AVAILABILITY STATEMENT}

Approved for public release; distribution is unlimited.

\section{SUPPLEMENTARY NOTES}

\section{ABSTRACT}

The current "industry standard" method to control relative humidity $(\mathrm{RH})$ and biological growth involves sub-cooling air to condense moisture out of the air, then reheating the same air that was just sub-cooled to reduce the RH of the air before it enters the space. However, the heating, ventilating, and air-conditioning (HVAC) systems at many Federal Facilities are not equipped with (or do not use) the required reheat function, so high indoor RH and the growth of mold are often inevitable occurrences. The High Efficiency Dehumidification System (HEDS) is a patent-protected, proprietary energy recovery method designed to save more than $50 \%$ of the dehumidification-related cooling and heating plant energy in RH controlled environments. This work validated the performance of a new HVAC dehumidification technology and investigated performance claims, installation costs, and maintenance impacts through the installation of two test units at Tinker Air Force Base (AFB), OK and Fort Bragg, NC. Based on the results of the ESTCP tests from Fort Bragg, NC and Tinker AFB, OK, HEDS significantly exceeded the energy savings targets, providing HVAC system savings related to the cooling, dehumidification and reheat process of $50 \%$ to well over $70 \%$. HEDS appears to be a viable, low maintenance, effective alternative to current RH control technologies, and can be a significant contributor to meeting energy savings Policies, Mandates, and Executive Orders.

\section{SUBJECT TERMS}

Buildings, Molds (Fungi)-Control, Sick building syndrome, Dampness in buildings, Humidity--Control

\section{SECURITY CLASSIFICATION OF:}

\section{a. REPORT}

Unclassified

\section{b. ABSTRACT}

Unclassified

\section{c. THIS PAGE}

Unclassified

\section{LIMITATION OF ABSTRACT}

SAR
18. NUMBER OF PAGES

189 19a. NAME OF RESPONSIBLE PERSON

19b. TELEPHONE NUMBER (include area code) 